\title{
Capillary Electrophoresis Analysis of Metal/Metalloid Oxide Nanoparticles in Water: Method Development for the Enhancement of UV Detection Sensitivity
}

\author{
by \\ Samar Alsudir
}

A thesis submitted to the Faculty of Graduate and Postdoctoral Affairs in partial fulfillment of the requirements for the degree of

Doctor of Philosophy

in

Chemistry

Carleton University

Ottawa, Ontario

Canada

C 2017, Samar Alsudir 
Graphical Abstract

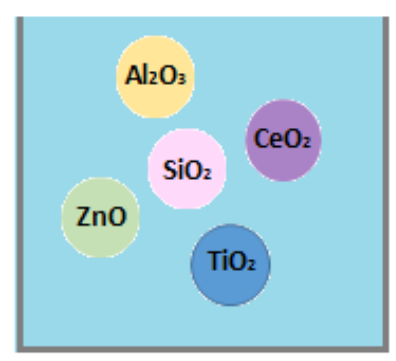

Tris

Sodium Phosphate

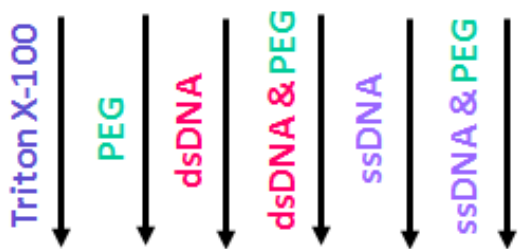

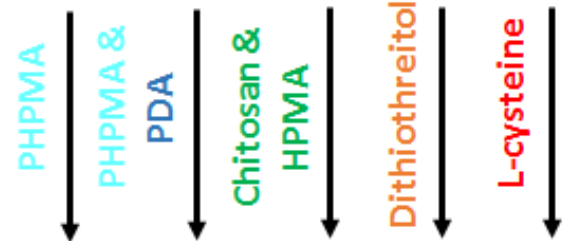

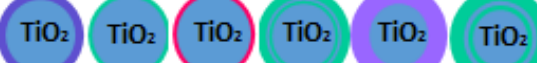

$\mathrm{SiO}_{2}$

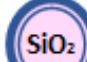

$\mathrm{SiO}_{2}$

Zno

Zno
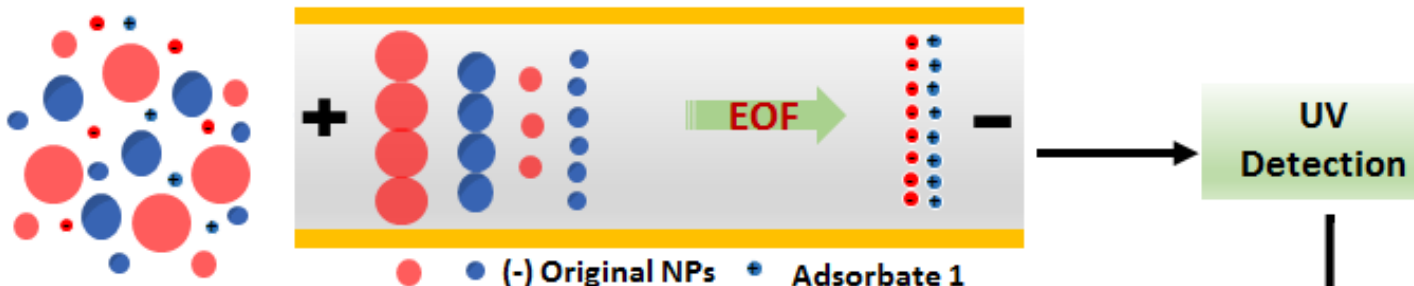

- (-) Original NPs - Adsorbate 1

(-) Modified NPs • Adsorbate 2

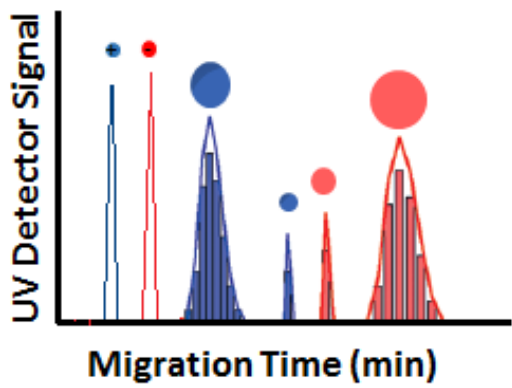




\begin{abstract}
Increasing production and applications of metal/metalloid oxide nanoparticles (NPs) have greatly raised the demand for new analytical techniques capable for trace quantification in water to assess their environmental impacts and health risks. A new analytical method was developed for the sensitive detection of silica $\left(\mathrm{SiO}_{2}\right)$, titania $\left(\mathrm{TiO}_{2}\right)$ and zinc oxide $(\mathrm{ZnO})$ as model metal/metalloid oxide NPs. This method was based on the formation of molecular layers and polymeric coatings on the NPs directly in water to selectively add chromophores to their surface for enhanced ultraviolet (UV) light absorption in capillary electrophoresis (CE) analysis. One unique advantage is the ability to identify nanoparticles by observing a stronger peak and/or a shifted migration time.
\end{abstract}

Controlled polymerization of 2-hydroxypropyl methacrylate (HPMA) on $\mathrm{SiO}_{2}$ NPs added a coating of poly-2-hydroxypropyl methacrylate (PHPMA) that increased their UV detection sensitivity by $6 \pm 1$ folds initially. A second coating with polydopamine produced a larger size of PHPMA-SiO 2 NPs, as confirmed by dynamic light scattering (DLS) and transmission electron microscopy, further enhancing their UV detection sensitivity by $12 \pm 2$ folds. Chitosan coating and HPMA binding on $\mathrm{SiO}_{2} \mathrm{NPs}$ produced a significant enhancement of UV detection sensitivity by $50 \pm 1$ folds. This method was selective for $\mathrm{SiO}_{2}$ in the presence of $\mathrm{TiO}_{2} \mathrm{NPs}$ in $10 \mathrm{mM} \mathrm{Na} \mathrm{HPO}_{4}$, a background electrolyte used for CE analysis.

Selective enhancement of UV detection sensitivity of $\mathrm{TiO}_{2}$ in the presence of alumina $\left(\mathrm{Al}_{2} \mathrm{O}_{3}\right), \mathrm{SiO}_{2}$, and $\mathrm{ZnO} \mathrm{NPs}$ in $100 \mathrm{mM}$ Tris was achieved using deoxyribonucleic acid (DNA) and polyethylene glycol (PEG). Single-stranded DNA (ssDNA) exhibited better performance than double-stranded DNA in enhancing the 
sensitivity of UV detection. PEG coating of ssDNA- $\mathrm{TiO}_{2} \mathrm{NPs}$ further enhanced the UV detection sensitivity in CE analysis, by providing electrosteric stabilization, up to $13 \pm 3$ folds for the determination of $\mathrm{TiO}_{2} \mathrm{NPs}$.

A monolayer adsorption of dithiothreitol (DTT) and cysteine (Cys) onto ZnO NPs in $10 \mathrm{mM} \mathrm{Na} 2 \mathrm{HPO}_{4}$ improved their detection sensitivity by $28 \pm 1$ and $25 \pm 1$ folds, respectively. The selectivity of DTT and Cys towards $\mathrm{ZnO}$ was validated in the presence of $\mathrm{Al}_{2} \mathrm{O}_{3}$, ceria $\left(\mathrm{CeO}_{2}\right), \mathrm{SiO}_{2}$ and $\mathrm{TiO}_{2} \mathrm{NPs}$ as no changes were observed in the CE-UV peak area of either adsorbates or the NPs. Similar evidence was provided using DLS by determining the hydrodynamic diameters of NPs in the presence of adsorbates. Cys improved the colloidal stability of $\mathrm{ZnO}$ NPs by breaking down the aggregates, as evidenced by a reduction of their hydrodynamic diameter.

The new approach provides a simple, rapid and efficient CE-based method towards the detection of $\mathrm{SiO}_{2}, \mathrm{TiO}_{2}$ and $\mathrm{ZnO}$ NPs selectively with enhanced sensitivity. The buffer composition was found to influence the selectivity of various molecular and polymeric coatings. Large enhancement factors have been obtained, improving the UV detection limits of NPs. This work demonstrates the feasibility of a new method for the direct detection of NPs in environmental waters. The lack of certified reference materials, particularly for the mass concentration of NPs, is hindering the validation of the developed method. The present UV detection limits are still not adequate for the quantitative determination of trace NPs in environmental waters. Further improvement will be required by coupling CE to laser-induced fluorescence and/or inductively coupled plasma- mass spectrometry. 


\section{Preface}

This preface provides full bibliographical details for each article included in this thesis, as well as whether the article is reproduced in whole or in part. Permissions were obtained from the publishers to include the articles in the thesis. When citing materials from this thesis, please cite both the thesis and the article relevant to the chapter, if the chapter is based on a publication.

Pursuant to the Integrated Thesis policy of Carleton University, the "supervisor" (Edward P.C. Lai) and the "student" (Samar Alsudir) confirm that the student was fully involved in setting up and conducting the research, obtaining data and analyzing results, as well as preparing and writing the materials presented in the co-authored article(s) integrated in this thesis. Additionally, the supervisor confirms the information provided by the student in this preface.

\section{Chapter 3}

Alsudir S, Lai EPC. Polymer Coatings for Sensitive Analysis of Colloidal Silica. Colloid Polym. Sci. 2014;292:1289-1296.

\section{Chapter 4}

Alsudir S, Lai EPC. Hydroxypropyl Methacrylate Interaction and Chitosan Coating for Enhanced UV Detection Sensitivity of Colloidal Nanoparticles in Capillary Electrophoresis Analysis. J. Anal. Bioanal. Tech. 2015;6:242-247.

\section{Chapter 5}

Alsudir S, Lai EPC. Electrosteric Stabilization of Colloidal $\mathrm{TiO}_{2}$ Nanoparticles with DNA and Polyethylene Glycol for Selective Enhancement of UV Detection Sensitivity in Capillary Electrophoresis Analysis. Anal Bioanal Chem. 2017;409:1857-1868.

\section{Chapter 6}

Alsudir S, Lai EPC. Selective detection of $\mathrm{ZnO}$ nanoparticles in aqueous suspension by capillary electrophoresis analysis using dithiothreitol and L-cysteine adsorbates. Talanta. 2017; 169:115-122.

These articles were wholly reproduced for formatting and clarity of presentation. The student performed all work presented in the articles. Writing was collaborative between the co-authors. 


\section{Acknowledgments}

\section{In the Name of God, the All-Merciful, the All-Compassionate}

"Almighty God, the uninterrupted flow of Thy graciousness has distracted me from thanking Thee. The flood of Thy bounty has rendered me incapable of counting Thy praises. The succession of Thy kind acts has diverted me from mentioning Thee in laudation. My God, my thanking is diminutive in front of Thy great boons, and my praise shrinks beside Thy generosity toward me. Your favors are many, and my understanding falls short of grasping them, not to speak of exhausting them. So how can I achieve thanksgiving! Praise belongs to God; praise whose bound has no utmost end, whose number has no reckoning, whose period cannot be cut off'- Imam Ali AlSajjad.

I would like to express my deepest sense of gratitude to my supervisor, Dr. Edward Lai, for his patient guidance, encouragement and valuable advices throughout my study. I would like to thank my colleagues for sharing experiences and knowledge as well for being always around whenever I needed them. I would like to extend my thanks to Chantelle Gravelle for her support and administrative assistance over the years. I am also thankful to Peter Mosher, Tanya and Susa in the science store for their help.

A huge thank you goes to my scholarship sponsor, the Saudi Ministry of Higher Education for financing my study.

I would like to express my profound gratitude to my beloved parents, children, sisters, brothers, and friends for their support, patience, prayers, and encouragement. Thank you from the bottom of my heart for believing in my abilities and having more faith in me than I ever had in myself. 
I am very much obliged to my husband, Fouzy Almisbaa, for being my greatest supporter, both in my personal and professional endeavors. His continuous help has allowed me to follow my aspirations, for which I am truly grateful. I can honestly say that I would not be where I am today without you.

Lastly, but most importantly, special thanks go to Imam Mahdi, peace be upon him, for his presence which is much more valuable than any other existence. You have been the motivation in each and every step I take forward and the simple phrase of "thank you" would pale and diminish in the sheer enormity of the gratitude I owe you. So, the least I can do is to dedicate this thesis to you. 


\section{Table of Contents}

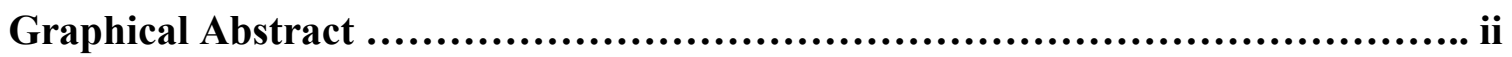

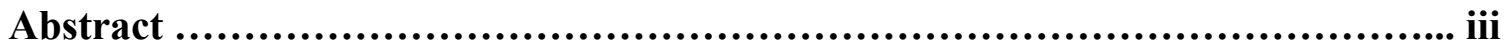

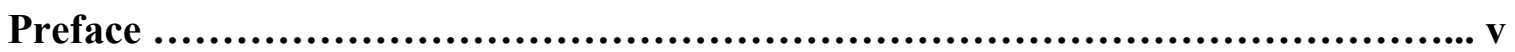

Acknowledgments ...................................................................... vi

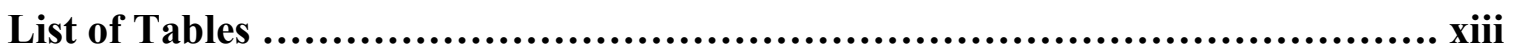

List of Figures .................................................................... xiv

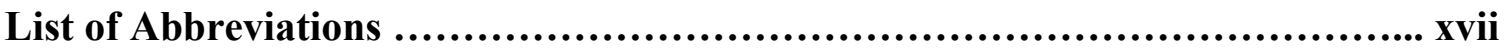

Chapter 1: Introduction ........................................................... 1

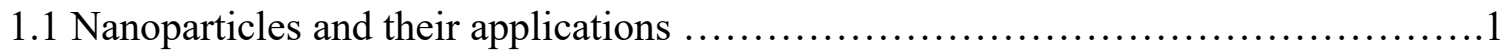

1.2 Environmental and health impacts of nanoparticles............................... 3

1.3 Environmental fate of metal/metalloid oxide nanoparticles ....................... 6

1.4 Influence of water chemistry on the behaviour of nanoparticles ................... 7

1.4.1 Van der Waals attraction ............................................ 7

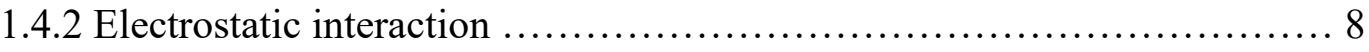

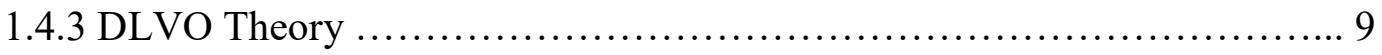

1.4.4 Stabilization mechanisms ........................................ 9

1.5 Analytical strategies for the quantification of metal/metalloid oxide nanoparticles ..11

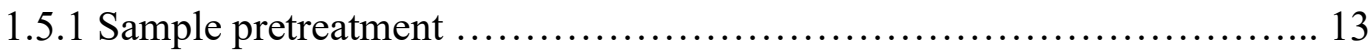

1.5.2 Separation, fractionation and preconcentration methods ................ 13

1.5.3 Screening methods for the detection of metal/metalloid oxide NPs ........ 16

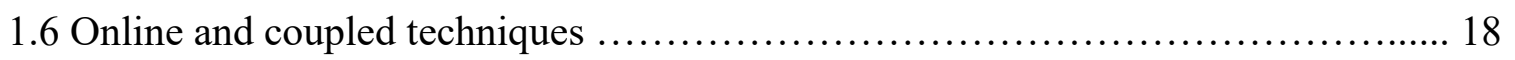

1.6.1 Hydrodynamic and size exclusion chromatography .................... 18

1.6.2 Field flow fractionation ........................................... 19

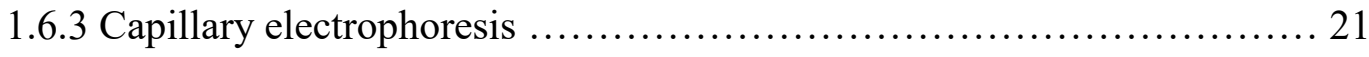

1.6.3.1 Principles of capillary electrophoresis ........................ 22

1.6.3.2 Physicochemical characterization of nanoparticles by capillary electrophoresis .................................................. 25 
1.6.3.3 Recent advances in the development of capillary electrophoresis.............................................. 27

1.7 Efforts towards method validation and reference materials ...................... 29

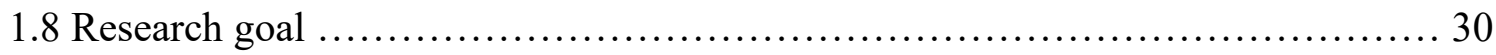

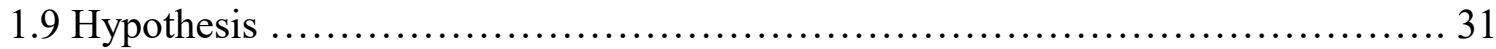

Chapter 2: Materials and Instrumentation ......................................... 33

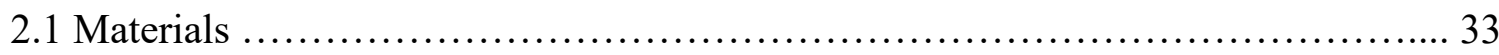

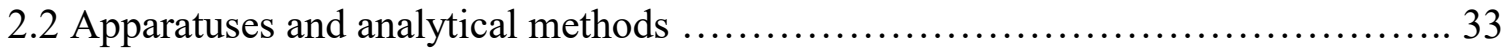

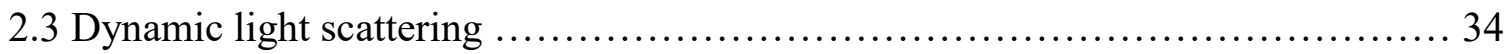

2.4 Transmission electron microscopy ..................................... 34

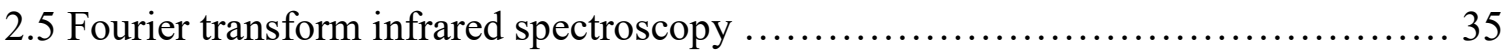

Chapter 3: Polymer Coatings for Sensitive Analysis of Colloidal Silica ............. 36

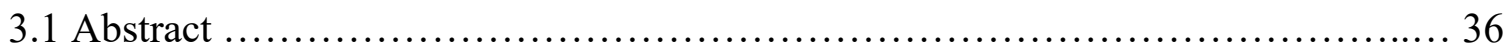

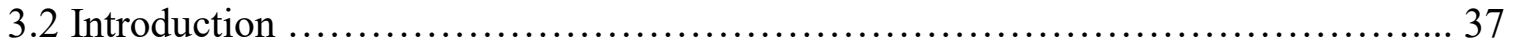

3.3 Methods ............................................................ 38

3.3.1 Polymerization of HPMA ....................................... 38

3.3.2 PHPMA growth on colloidal $\mathrm{SiO}_{2}$ nanoparticles $\ldots \ldots \ldots \ldots \ldots \ldots \ldots \ldots \ldots . \ldots . \ldots$

3.3.3 Effect of AIBN on PHPMA growth ................................ 38

3.3.4 Polymerization of HPMA with polyvinyl alcohol or bisphenol A ............. 39

3.3.5 Polydopamine growth on $\mathrm{SiO}_{2} @$ PHPMA ................................. 39

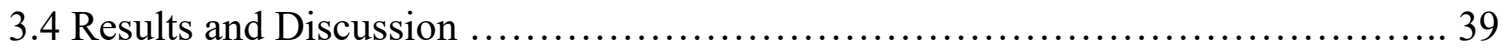

3.4.1 Silica nanoparticles ........................................... 39

3.4.2 CE-UV characterization of PHPMA particles ......................... 41

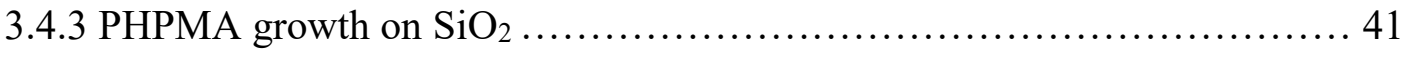

3.4.4 Effect of AIBN on PHPMA growth ................................. 44

3.4.5 Polymerization of HPMA with PVA or BPA $\ldots \ldots \ldots \ldots \ldots \ldots \ldots \ldots \ldots \ldots . \ldots . \ldots \ldots$ 
3.4.6 PDA growth on $\mathrm{SiO}_{2} @$ PHPMA particles in water 46

3.4.7 Dynamic light scattering ........................................ 49

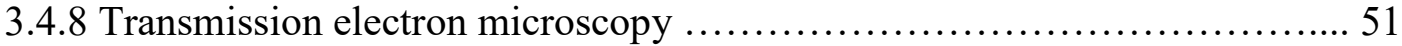

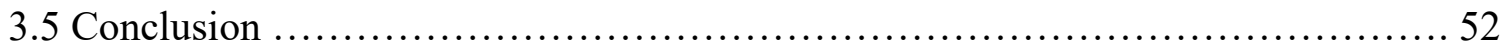

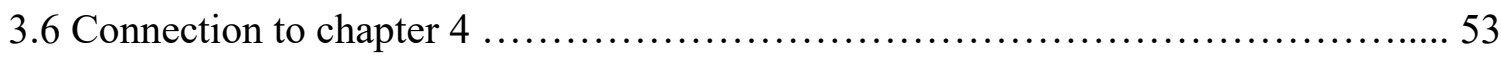

Chapter 4: Hydroxypropyl Methacrylate Interaction and Chitosan Coating for Enhanced UV Detection Sensitivity of Colloidal Nanoparticles in Capillary Electrophoresis Analysis ........................................................ 54

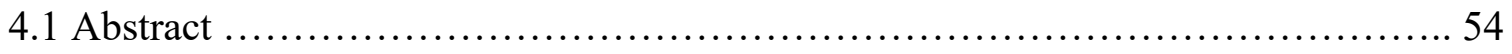

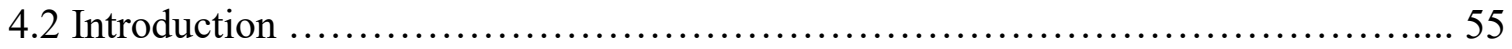

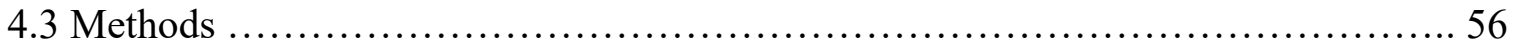

4.3.1 HPMA binding interaction with colloidal $\mathrm{SiO}_{2}$ or $\mathrm{TiO}_{2}$ nanoparticles ......... 56

4.3.2 HPMA binding interaction with polymeric nanoparticles ................... 56

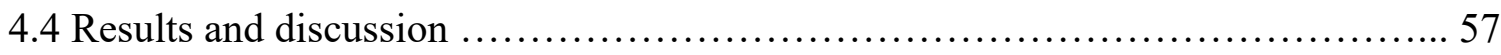

4.4.1 CE-UV characterization of silica and titania nanoparticles ................. 57

4.4.2. HPMA binding interaction with silica and titania nanoparticles ............. 59

4.4.3 Dynamic light scattering analysis of silica and titania nanoparticles ....... 60

4.4.4. Selectivity of HPMA binding with $\mathrm{SiO}_{2}$ and $\mathrm{TiO}_{2}$ nanoparticles ........... 61

4.4.5. Coating of silica and titania nanoparticles with chitosan .................... 62

4.4.6. HPMA binding with chitosan-coated $\mathrm{SiO}_{2}$ nanoparticles .................. 64

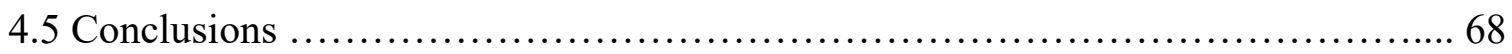

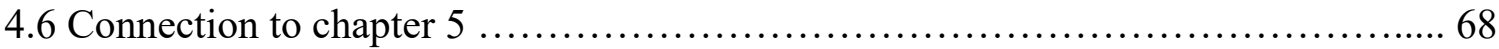

Chapter 5: Electrosteric Stabilization of Colloidal TiOz Nanoparticles with DNA and Polyethylene Glycol for Selective Enhancement of UV Detection Sensitivity in Capillary Electrophoresis Analysis............................................. 70

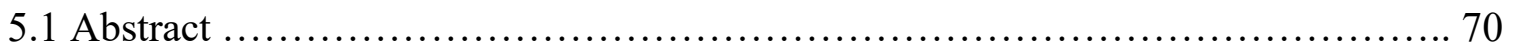

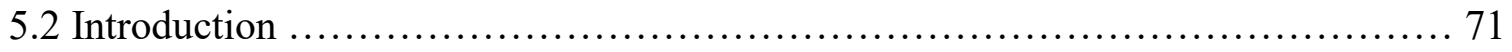

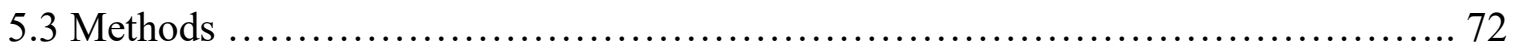


5.3.1 Triton X-100 adsorption onto $\mathrm{TiO}_{2}$ nanoparticles $\ldots \ldots \ldots \ldots \ldots \ldots \ldots \ldots \ldots . \ldots \ldots$

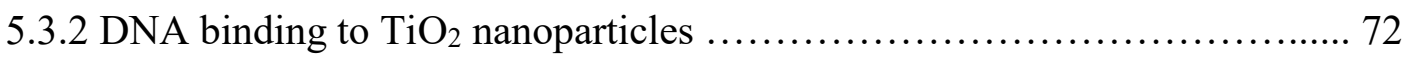

5.3.3 PEG coating on $\mathrm{TiO}_{2}$ and $\mathrm{DNA}-\mathrm{TiO}_{2}$ nanoparticles $\ldots \ldots \ldots \ldots \ldots \ldots \ldots . . \ldots 2$

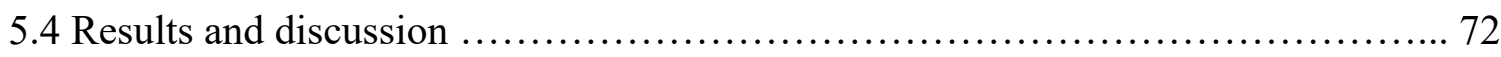

5.4.1 Triton $\mathrm{X}-100$ adsorption onto $\mathrm{TiO}_{2}$ nanoparticles ................... 72

5.4.2 Double-stranded DNA binding to $\mathrm{TiO}_{2}$ nanoparticles $\ldots \ldots \ldots \ldots \ldots \ldots \ldots . \ldots 7$

5.4.3 PEG coating of $\mathrm{TiO}_{2}$ and dsDNA- $\mathrm{TiO}_{2}$ nanoparticles $\ldots \ldots \ldots \ldots \ldots \ldots . \ldots 8$

5.4.4 Single-stranded DNA adsorption onto $\mathrm{TiO}_{2}$ nanoparticles .............. 84

5.4.5 PEG coating of ssDNA- $\mathrm{TiO}_{2}$ nanoparticles $\ldots \ldots \ldots \ldots \ldots \ldots \ldots \ldots \ldots \ldots$

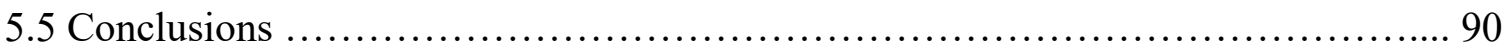

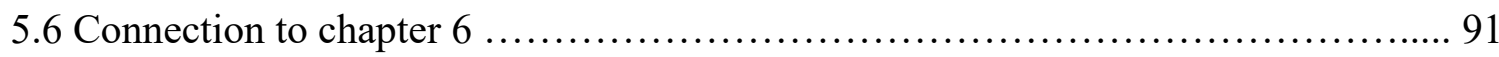

Chapter 6: Selective Enhancement of UV Detection Sensitivity for ZnO Nanoparticles in Capillary Electrophoresis Analysis using Dithiothreitol and LCysteine ............................................................................ 93

6.1 Abstract............................................................ 93

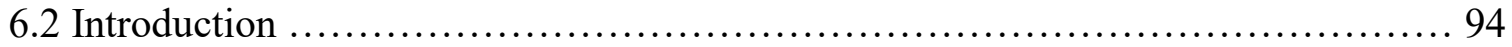

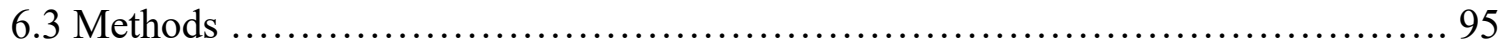

6.3.1 DDT and Cys adsorption onto $\mathrm{ZnO}$ nanoparticles ...................... 95

6.3.2 DDT and Cys adsorption onto $\mathrm{Al}_{2} \mathrm{O}_{3}, \mathrm{CeO}_{2}, \mathrm{SiO}_{2}$ and $\mathrm{TiO}_{2}$ nanoparticles .................................................. 96

6.4 Results and Discussion ............................................... 96

6.4.1 Stability of DTT and Cys solutions ............................... 96

6.4.2 DDT or Cys adsorption onto $\mathrm{ZnO}$ nanoparticles ....................... 97

6.4.3 Adsorption kinetics ......................................... 102

6.4.4 Adsorption isotherms ......................................... 107

6.4.5 Effect of $\mathrm{ZnO}$ dose on DTT and Cys adsorption ..................... 110

6.4.6 DDT and Cys adsorption onto $\mathrm{Al}_{2} \mathrm{O}_{3}, \mathrm{CeO}_{2}, \mathrm{SiO}_{2}$ and $\mathrm{TiO}_{2}$ nanoparticles . 111

6.4.7 Dynamic light scattering ...................................... 112 


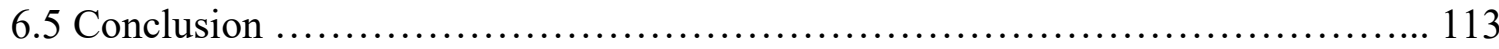

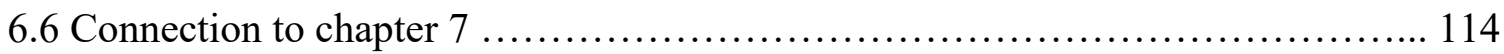

Chapter 7: Conclusions .............................................................. 115

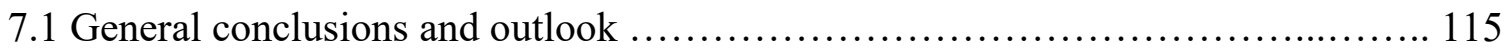

7.2 Contributions to knowledge ............................................ 119

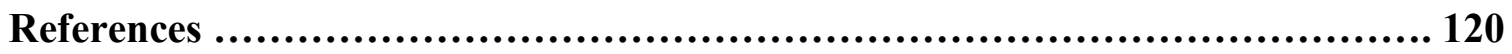

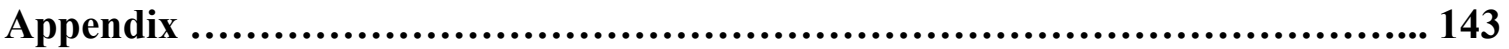




\section{List of Tables}

Table 3.1 CE-UV peak areas of HPMA, PHPMA and $\mathrm{SiO}_{2} @$ PHPMA under different conditions of HPMA polymerization. All peak areas are expressed in

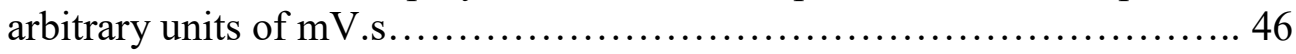

Table 3.2 DLS measurement of the hydrodynamic diameters of original and polymercoated $\mathrm{SiO}_{2}$ particles........................................... 50

Table 4.1 DLS analysis to determine the hydrodynamic diameters of different particles, followed by calculation of the HPMA thickness.......................... 64

Table 5.1 Enhancement factors obtained after addition of various organic/bioorganic compounds onto $\mathrm{TiO}_{2}, \mathrm{SiO}_{2}, \mathrm{Al}_{2} \mathrm{O}_{3}$ and $\mathrm{ZnO}$ nanoparticles as well as the LOD and LOQ for stabilized $\mathrm{TiO}_{2}$ nanoparticles...................... 89

Table 5.2 Hydrodynamic diameters of $\mathrm{TiO}_{2}, \mathrm{SiO}_{2}, \mathrm{Al}_{2} \mathrm{O}_{3}$ and $\mathrm{ZnO}$ nanoparticles measured by DLS before and after addition of various organic and bioorganic adsorbates....................................... 90

Table 6.1 Kinetic parameters for DTT adsorption onto $\mathrm{ZnO}$ nanoparticles............ 105

Table 6.2 Isotherm models parameters for the adsorption of DTT and Cys onto $\mathrm{ZnO}$ nanoparticles 109

Table 6.3 Hydrodynamic diameters of $\mathrm{Al}_{2} \mathrm{O}_{3}, \mathrm{CeO}_{2}, \mathrm{SiO}_{2}, \mathrm{TiO}_{2}$ and $\mathrm{ZnO}$ nanoparticles measured by DLS before and after addition of DTT or Cys............. 113 


\section{List of Figures}

Figure 3.1 CE-UV characterization of $\mathrm{SiO}_{2}$ nanoparticles (at $20 \mathrm{~g} / \mathrm{L}$ ) in LUDOX ${ }^{\circledR}$ AM colloid......................................................... 40

Figure 3.2 CE-UV characterization of (a) MO, (b) HPMA (and PHPMA) after $22 \mathrm{~h}$ of polymerization................................................. 41

Figure 3.3 Schematic representation of the polymerization process with/without

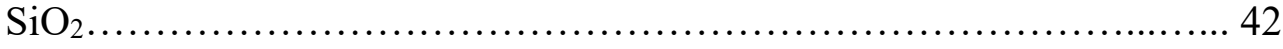

Figure 3.4 CE-UV analysis of PHPMA and $\mathrm{SiO}_{2} @$ PHPMA particles after $22 \mathrm{~h}$ of polymerization using AIBN at 3 wt. \%

Figure 3.5 $\mathrm{SiO}_{2} @$ PHPMA peak area obtained from different $\mathrm{SiO}_{2}$ concentrations $(\mathrm{g} / \mathrm{L})$.

Figure 3.6 CE-UV analysis of PHPMA and $\mathrm{SiO}_{2} @$ PHPMA particles after $22 \mathrm{~h}$ of polymerization using AIBN at 1 wt. \% 44

Figure 3.7 Schematic representation of PDA growth on PHPMA and $\mathrm{SiO}_{2} @$ PHPMA at room temperature (RT).

Figure 3.8 CE-UV analysis of DA, HPMA, PHPMA@PDA, SiO $2 @$ PHPMA@PDA and $\mathrm{SiO}_{2} @$ PDA particles... 48

Figure 3.9 Dynamic light scattering measurementsof (a) lognormal distribution of $\mathrm{SiO}_{2}$ nanoparticles in LUDOX ${ }^{\circledR}$ AM colloid, (b) lognormal distribution of PHPMA in DDW after $22 \mathrm{~h}$ of polymerization at $60^{\circ} \mathrm{C}$. 49

Figure 3.10 Transmission electron micrographs of (a) $\mathrm{SiO}_{2} @$ PHPMA, and (b) $\mathrm{SiO}_{2} @$ PHPMA@PDA...................................................... 51

Figure 4.1 CE-UV characterization of (a) $\mathrm{SiO}_{2}(20 \mathrm{~g} / \mathrm{L})$ and (b) $\mathrm{TiO}_{2}(20 \mathrm{~g} / \mathrm{L})$ nanoparticles. SDS was present at a concentration of $2 \mathrm{mg} / \mathrm{mL} \ldots \ldots \ldots \ldots . .58$

Figure 4.2 CE-UV characterization of $\mathrm{SiO}_{2}(20 \mathrm{~g} / \mathrm{L})$ nanoparticles with $3.0 \mathrm{~mL}$ of HPMA. SDS was present at a concentration of $2 \mathrm{mg} / \mathrm{mL}$ 59

Figure 4.3 Dynamic light scattering measurements to determine the lognormal distribution of (a) $\mathrm{SiO}_{2}$ nanoparticles and (b) HPMA-bound $\mathrm{SiO}_{2}$ nanoparticles. 61

Figure 4.4 Schematic representation of chitosan coating on $\mathrm{SiO}_{2}$ in the presence of $\mathrm{TiO}_{2}$ 62 
Figure 4.5 CE-UV characterization of HPMA-bound chitosan-coated $\mathrm{SiO}_{2}$ particles.. 66

Figure 4.6 HPMA-bound chitosan-coated $\mathrm{SiO}_{2}$ peak areas obtained for different $\mathrm{SiO}_{2}$ concentrations 66

Figure 4.7 Schematic representation of selective binding of HPMA to chitosan-coated $\mathrm{SiO}_{2}$ in the presence of $\mathrm{TiO}_{2}$ 67

Figure 5.1 Enhancement of UV detection sensitivity in CE analysis at $280 \mathrm{~nm}$ after adding TX-100 to $\mathrm{TiO}_{2}$ nanoparticles suspended in $100 \mathrm{mM}$ Tris 74

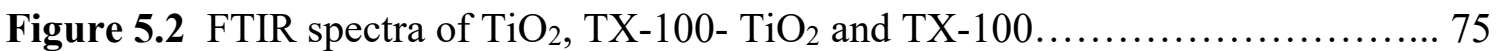

Figure 5.3 Enhancement of UV detection sensitivity in CE analysis after adding dsDNA to $\mathrm{TiO}_{2}$ nanoparticles suspended in $100 \mathrm{mM}$ Tris..................... 78

Figure 5.4 FTIR spectrum of $\mathrm{TiO}_{2}$ and dsDNA-TiO 2 nanoparticles................. 79

Figure 5.5 CE analysis, with UV detection at $260 \mathrm{~nm}$, of (a) $\mathrm{TiO}_{2}$ nanoparticles, (b) dsDNA (c) PEG@dsDNA and (d) $\mathrm{TiO}_{2}$ nanoparticles after dsDNA adsorption and PEG coating. 81

Figure 5.6 $\mathrm{CE}$ analysis, with UV detection at $325 \mathrm{~nm}$, of (a) $\mathrm{TiO}_{2}$ nanoparticles, (b) PEG@dsDNA, and (c) $\mathrm{TiO}_{2}$ nanoparticles after dsDNA adsorption and PEG coating. Only $\mathrm{TiO}_{2}$ can absorb the UV light; neither dsDNA nor PEG can............................................................... 82

Figure 5.7 FTIR spectra of $\mathrm{TiO}_{2}, \mathrm{PEG}, \mathrm{PEG} @ \mathrm{TiO}_{2}$ and PEG@dsDNA-TiO $2 \ldots \ldots . . .83$

Figure 5.8 CE analysis, with UV detection at $260 \mathrm{~nm}$, of (a) $\mathrm{TiO}_{2}$ nanoparticles, (b) ssDNA and (c) $\mathrm{TiO}_{2}$ nanoparticles after ssDNA adsorption.............. 84

Figure 5.9 Enhancement of UV detection sensitivity in CE analysis at $260 \mathrm{~nm}$ after adding ssDNA to $\mathrm{TiO}_{2}$ nanoparticles suspended in $100 \mathrm{mM}$ Tris 86

Figure 5.10 CE analysis, with UV detection at 260 nm, of (a) PEG@ssDNA and (b) $\mathrm{TiO}_{2}$ nanoparticles after ssDNA adsorption and PEG coating...

Figure 5.11 FTIR spectra of ssDNA, $\mathrm{TiO}_{2}$, ssDNA-TiO 2 , PEG and PEG@ssDNA-

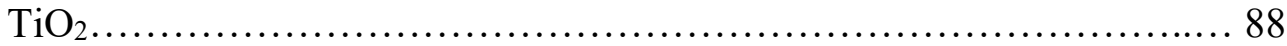

Figure 6.1 Stability of DTT and Cys in $10 \mathrm{mM} \mathrm{Na}_{2} \mathrm{HPO}_{4}$ and $100 \mathrm{mM}$ Tris by capillary electrophoresis with UV detection at $220 \mathrm{~nm}$ 97 
Figure 6.2 $\mathrm{CE}$ analysis, with UV detection at $220 \mathrm{~nm}$, of (a) $\mathrm{ZnO}$ nanoparticles, (b) $\mathrm{ZnO}$ nanoparticles after DTT adsorption and (c) $\mathrm{ZnO}$ nanoparticles after Cys adsorption.......................................................... 97

Figure 6.3 Enhancement of UV detection sensitivity in CE analysis after adding DTT or Cys to $\mathrm{ZnO}$ nanoparticles suspended in $10 \mathrm{mM} \mathrm{Na}_{2} \mathrm{HPO}_{4}$ 99

Figure 6.4 Schematic illustration of the possible different modes of DTT adsorption onto $\mathrm{ZnO}$ surface; (a) the cross-linking mode, (b) the horizontally aligned mode, and (c) the vertically aligned mode 99

Figure 6.5 FTIR spectra of $\mathrm{ZnO}, \mathrm{DTT}-\mathrm{ZnO}$ and DTT............................ 100

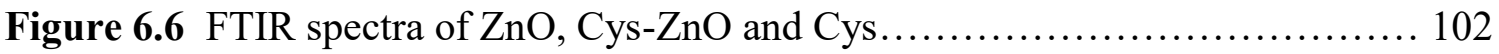

Figure 6.7 Effect of contact time on the kinetics of DTT adsorption at two different concentrations onto $\mathrm{ZnO}$ nanoparticles 103

Figure 6.8 Pseudo-first-order kinetic, pseudo-second-order kinetic and intraparticle diffusion models for DTT adsorption onto $\mathrm{ZnO}$ nanoparticles. 106

Figure 6.9 Langmuir, Freundlich and Temkin isotherm models for DTT adsorption onto $\mathrm{ZnO}$ nanoparticles. 110

Figure 6.10 Effect of $\mathrm{ZnO}$ dose on \% adsorption of DTT and Cys.... 111 


\section{List of Abbreviations}

\begin{tabular}{|c|c|}
\hline Alumina & $\mathrm{Al}_{2} \mathrm{O}_{3}$ \\
\hline 2,2'-azobis-2-isobutyronitrile & AIBN \\
\hline Background electrolyte & BGE \\
\hline Bisphenol A & BPA \\
\hline Capillary electrophoresis & $\mathrm{CE}$ \\
\hline Ceria & $\mathrm{CeO}_{2}$ \\
\hline Certified reference materials & CRMs \\
\hline Cysteine & Cys \\
\hline Deoxyribonucleic acid & DNA \\
\hline Dithiothreitol & DTT \\
\hline Dopamine & DA \\
\hline Double-stranded deoxyribonucleic acid & dsDNA \\
\hline Dynamic light scattering & DLS \\
\hline Electric double layer & EDL \\
\hline Electroosmotic flow & EOF \\
\hline Engineered nanoparticles & ENPs \\
\hline Fourier transform infrared & FTIR \\
\hline Graphene quantum dots & GQDs \\
\hline 2-hydroxypropyl methacrylate & HPMA \\
\hline Laser induced fluorescence & LIF \\
\hline Limit of detection & LOD \\
\hline Limit of quantification & LOQ \\
\hline Mesityl oxide & $\mathrm{MO}$ \\
\hline Natural organic matter & NOM \\
\hline Nanoparticles & NPs \\
\hline Polydopamine & PDA \\
\hline
\end{tabular}


Polyethylene glycol PEG

Poly-2-hydroxypropyl methacrylate

PHPMA

Polyvinyl alcohol

PVA

Silica

$\mathrm{SiO}_{2}$

Single-stranded deoxyribonucleic acid

ssDNA

Single particle inductively coupled plasma

SP-ICP-MS

mass spectrometry

Sodium dodecyl sulfate

SDS

Titania

$\mathrm{TiO}_{2}$

Transmission electron microscopy

TEM

Tris (hydroxymethyl) aminomethane

Tris

Triton X-100

TX-100

Ultraviolet

UV

Zinc oxide

$\mathrm{ZnO}$ 


\section{Chapter 1: Introduction}

\subsection{Nanoparticles and their applications}

Nanoparticles (NPs) are ultrafine objects having at least one dimension ranging from 1 to $100 \mathrm{~nm}$. [1] Generally, NPs can be of natural origin, accidentally produced or chemically engineered. [2] Due to their novel optical, electrical and chemical properties, engineered NPs (ENPs) have been commonly used in a wide array of applications covering a broad variety of fields in science and technology. [3] ENPs can be categorized as either carbon-based NPs or metal-containing NPs including zero-valent metals, metal/metalloid oxides, metal sulphides and semiconducting quantum dots. [4] Metal and metal oxide NPs can be synthesized by chemical or green methods [5] and have mainly found applications that take advantage of their sorptive, catalytic, or optical properties. [6] A promising new generation of photoresist materials uses metal oxide NPs to pattern 20-nm features for extreme ultraviolet lithography. [7] Polyethylene-metal oxide NP composites have recently emerged as an excellent material for the insulation of extruded high voltage direct current (HVDC) cables. [8] Flat-panel solar thermal collectors currently use metal oxide NPs in liquid-based nanofluids showing a thriving enhancement of the thermal absorption efficiency. [9] Transition metal oxide NPs have arisen as a potential nano-modifier to enhance the thermal decomposition of rocket propellants. [10] Mixed metal oxide NPs have attracted great interests for many energyrelated applications such as water splitting, fuel cells, and battery technology. [11]

The prevalent representative of metal oxide NPs is titania $\left(\mathrm{TiO}_{2}\right)$, which is

globally produced in different crystalline structures: rutile, anatase and brookite. [12] 
Due to its photocatalytic properties and UV light absorptivity, $\mathrm{TiO}_{2}$ finds numerous applications including utilization in consumer products such as sunscreens [13], cosmetics [14], plastics [15], electronics [16], sports equipment [17], clothing [18], household cleaning solutions [19], and paints. [20] Other fundamental applications [21] include agriculture, environmental remediation of pollutants in wastewater treatment, air purification, solar energy conversion, tunnel lighting, sound insulation, offset printing, medical imaging, and drug delivery. Zinc oxide $(\mathrm{ZnO})$ is widely used in the form of NPs, which exist in three crystal structures: hexagonal wurtzite, cubic zinc-blende, and a rarely-observed cubic rock-salt (NaCl-type) [22]. The unique properties of $\mathrm{ZnO}$ NPs have paved their way to diverse applications in photocatalysis, solar cells, sensors, piezoelectric and photodiode devices, sunscreen formulations, antireflection coatings, and biomedicines. [23-26] $\mathrm{ZnO}$ quantum dots have received a great deal of attention from the scientific community because of their utilization in various photodetector technologies $[27,28]$ and their controllable exciton energy by changing the confinement conditions. [29] Alumina $\left(\mathrm{Al}_{2} \mathrm{O}_{3}\right)$, with fifteen distinct crystallographic phases including alpha, delta, gamma and theta obtained as a function of annealing temperature [30], has been extensively used for high performance ceramics, cosmetic fillers, packing supplies, polishing materials, semiconductors, paints, resins, wearresistant supports, waterproof materials, catalysts, and catalyst carriers. [31] Ceria $\left(\mathrm{CeO}_{2}\right)$ is most commonly applied as a chemically stable catalyst for fuel oxidation and cracking of heavy petroleum residue to yield lighter fractions. [32,33] Silica $\left(\mathrm{SiO}_{2}\right)$ is the most prevailing metalloid oxide NPs. It has been widely used in various pharmaceutical products, cosmetics, printer toners, food products, paints, surgical tools, 
medical equipment, textiles, and as a potential vehicle for drug delivery. [34]

The 2020 production estimate of nanomaterials is 1 million to 6 million tons, ranging from metals and metal/metalloid oxides to carbon nanotubes and quantum dots. [35] Metal/metalloid oxide NPs have proportionally the greatest potential to enter the environment [36] via direct discharge into wastes/wastewater effluents [37] and accidental release to the aquatic environment. [38] The capture of NPs from water effluents through adhesion to clearing sludge varies in efficiency from $70 \%$ to $94 \%$. [39]

\subsection{Environmental and health impacts of nanoparticles}

Great concerns regarding the possible environmental and health risks have arisen with increasing production of metal/metalloid oxide NPs to meet the growing demands for numerous applications. Those NPs could find their way into the environment where their fate and behaviour are highly uncertain. The toxicity of NPs arises from a number of biophysicochemical factors, including their ability to penetrate the blood-brain barrier, tissues and cells. Their large surface area-to-volume ratio increases oxidative stress and results in undesirable interactions with biological macromolecules. [40,41] At a large environmental system, the small size of NPs enables them to translocate from their deposition site and enter to water sources. [42,43] Hence, there is a growing concern regarding the potential adverse effects of NPs on drinking water, juvenile fish, and terrestrial plants. [44-46] Industrial, commercial and agricultural applications of metal or metal/metalloid oxide NPs could result in their accumulation in soil, threatening higher terrestrial plants. Such NPs may have negative impacts on the growth and yield of food crops. [47] The physiological and biochemical responses of plants to stress imposed by 
metal/metalloid oxide NPs have been recently reviewed. [48] Various levels of toxicity have been observed based on bioluminescence activity, seed germination, and bacterial gene mutation in a wide range of organisms. [49] $\mathrm{TiO}_{2}$ NPs showed toxicity towards $R$. subcapitata $\left(\mathrm{EC}_{50}=6.8 \mathrm{mg} \mathrm{Ti} / \mathrm{L}\right)$ due to aggregation and entrapment of algal cells into $\mathrm{TiO}_{2}$ aggregates. [50] Exposures to high doses of $\mathrm{ZnO} \mathrm{NPs}\left(1000 \mathrm{mg} \mathrm{kg}^{-1}\right.$ feed) for 10 days resulted in $\mathrm{Zn}$ distribution to the liver of fish. [51] Biochemical disturbances associated with oxidative stress in the liver point to the ability of $\mathrm{ZnO}$ NPs to interfere with cytochrome $\mathrm{P} 450$ metabolic processes. Co-exposure to perfluorooctane sulfonate (widely distributed in the environment) and $\mathrm{ZnO}$ NPs can cause more serious thyroiddisrupting effects in zebrafish than exposure to the sulfonate alone. [52] $\mathrm{CeO}_{2}$ and $\mathrm{TiO}_{2}$ NPs have not shown cytotoxic effects in rats at concentrations $\leq 50 \mu \mathrm{g} / \mathrm{mL}$; however, they could cause subtle concentration-related changes in spontaneous and/or gammaaminobutyric acid (GABA) receptor-mediated neuronal activity in vitro at times when cytotoxicity is absent. [53] $\mathrm{ZnO} \mathrm{NPs,} \mathrm{for} \mathrm{instance,} \mathrm{induced} \mathrm{a} \mathrm{strong} \mathrm{decrease} \mathrm{in} \mathrm{the}$ mitochondrial activity, major perturbations in phagocytosis and an increased damage of the methylglyoxal-associated DNA in mice macrophages. [54,55] Moreover, they induced toxicity in RAW 264.7 cell line, leading to the generation of reactive oxygen species, excitation of inflammation, and cell death. [56] Moreover, $\mathrm{Al}_{2} \mathrm{O}_{3}, \mathrm{CeO}_{2}, \mathrm{TiO}_{2}$ and $\mathrm{ZnO}$ NPs induced changes to some specific hematological and biochemical blood parameters in mice. [57] The release of $\mathrm{Zn}^{2+}$ and $\mathrm{Ni}^{2+}$ from $\mathrm{ZnO}$ and $\mathrm{NiO}$ NPs motivated the allergic reaction to inhaled ovalbumin in mice. [58] A global upsurge in antibiotic resistance has led to research in metal oxide-based antimicrobial therapy. [59] Silver and $\mathrm{ZnO}$ NPs with antimicrobial action are present in consumer products. The bacterial 
toxicity of metal oxide NPs resulted from the action of the NPs themselves, the released ions, or a combination of both mechanisms depending on the composition of the NPs. [60] Anatase $\mathrm{TiO}_{2}$ NPs induced oxidative DNA damage, lipid peroxidation, and micronuclei formation in human bronchial epithelial cells, even in the absence of photoactivation. [61] Long-term exposure of lung alveolar epithelial cells to low levels of $\mathrm{TiO}_{2}$ NPs caused oxidative damage to DNA and intracellular accumulation. [62] $\mathrm{Al}_{2} \mathrm{O}_{3}$ NPs were capable of triggering up-regulation of genes related to cell death in a human A549 lung adenocarcinoma cell line. [63] CuO NPs $(5-15 \mu \mathrm{g} / \mathrm{mL})$ exerted cytotoxicity in A549 lung cells in a dose-dependent manner. [64] $\mathrm{Co}_{3} \mathrm{O}_{4}$ NPs decreased the cellular viability of human lymphocytes along with increasing cell membrane damage followed by $\mathrm{Fe}_{2} \mathrm{O}_{3}, \mathrm{SiO}_{2}$ and $\mathrm{Al}_{2} \mathrm{O}_{3}$ NPs after $24 \mathrm{~h}$ of exposure. [65]

The most common exposure routes for humans are via skin contact, inhalation, and oral uptake. [66-70] Sunscreen formulations are normally composed of $\mathrm{ZnO}(5 \%$ $\mathrm{w} / \mathrm{w})$ and $\mathrm{TiO}_{2}(25 \% \mathrm{w} / \mathrm{w})$. Topically applied $\mathrm{ZnO}$ could not penetrate into the viable epidermis; however, $\mathrm{Zn}^{2+}$ found in the blood and urine after topical application of $\mathrm{ZnO}$ probably arose from the acid catalyzed dissolution of $\mathrm{ZnO}$ on the skin surface and the permeation of released $\mathrm{Zn}^{2+}$ across the stratum corneum, into the viable epidermis, and then to the systemic circulation, from which they may be excreted in the urine. [71] $\mathrm{Fe}_{2} \mathrm{O}_{3}, \mathrm{Fe}_{3} \mathrm{O}_{4}, \mathrm{MnFe}_{2} \mathrm{O}_{4}$, and $\mathrm{CrOOH}$ NPs are representative of those found in the welder's lungs causing the development of peribronchiolar, perivascular and alveolar fibrosis. [72] NPs can potentially induce toxicity in the lung via activating the main mitogen-activated protein kinases (MAPKs) and the nuclear factor NFKB to release inflammatory cytokines. $[73,74]$ Inhaled $\mathrm{CdO}$ NPs translocated to other organs after 
accumulation in the lungs causing serious damage of cells and tissues. [75,76] The ubiquitous use of metal/metalloid oxide NPs in semiconductor fabrication raised alerts to protect the workers' health and safety. [77] A combination of filter-based air sampling and direct-reading instruments have been used to identify, characterize, and quantify the exposure potential to airborne $\mathrm{Al}_{2} \mathrm{O}_{3}$ and amorphous $\mathrm{SiO}_{2}$ NPs associated with the chemical-mechanical wafer polishing process. Oral uptake is probably the most prevalent route for metal/metalloid oxide NPs to enter the body from the high amounts of NPs present in food due to the large absorption area of the gastrointestinal tract. [78] These NPs can penetrate biological barriers at a high translocation rate and may distribute differently in the body according to their size and surface functionality. Humans are increasingly exposed through their diet to silver and $\mathrm{ZnO}$ NPs used in the food industry. Silver NPs were found to cause adverse effects on the gut microbiota at lower concentrations than that damaging the enterocytes; the opposite was found to be true for ZnO NPs. [79]

\subsection{Environmental fate of metal/metalloid oxide nanoparticles}

The environmental distribution of metal oxide NPs over air, water, soil and sediment was evaluated using the SimpleBox4nano model through which Monte Carlo simulations were performed on the environmental fate, concentrations and speciation of $\mathrm{CeO}_{2}, \mathrm{TiO}_{2}$ and $\mathrm{ZnO}$ NPs. The largest amount of metal oxide NPs was predicted to be dominant in the water compartment [80] followed by sedimentation via homo- or heteroagglomeration, which is highly affected by variations in concentration, ionic strength, $\mathrm{pH}$, temperature and natural colloids. [81] Additionally, surface properties of NPs may be altered by losing their surface coating or developing an additional coating of natural 
organic matter (NOM), which is an organic material present in environmental waters including both humic and non-humic fractions. [82] Moreover, metal/metalloid oxide NPs may undergo chemical transformations particularly oxidation, sulfidation, and dissolution due to their reactivity towards other contaminants in water. [83] Chemical transformation of metal/metalloid oxide NPs was exemplified by the complexation of $\mathrm{ZnO}$ NPs with carbonate or phosphate in solution, which can reduce $\mathrm{ZnO}$ dissolution due to the formation of insoluble carbonate and phosphate species on the NP surfaces. [84] The effects of various aquatic contaminants on the transformation, transport kinetics, and toxicity of metal/metalloid oxide NPs have been reviewed. [85] $\mathrm{TiO}_{2} \mathrm{NPs}$, for example, showed a high affinity for $\mathrm{Cd}^{2+}$ which significantly affected their environmental fate and transformation. [86]

\subsection{Influence of water chemistry on the behaviour of nanoparticles}

The stability, dissolution, and transformation of NPs in aquatic media determine their environmental fate, bioavailability, and toxicity. One fundamental aspect in colloid science is the stabilization mechanism of NPs in different media. Generally, NPs are unstable and tend to agglomerate/aggregate at short interparticle distances due to attraction via van der Waals or electrostatic forces, which can be counteracted by repulsive forces resulting in electrostatic, steric or electrosteric stabilization. [87]

\subsubsection{Van der Waals attraction}

Intermolecular forces are commonly explained by the Lennard-Jones potential that describes the potential energy of interaction $(w(D))$ between two molecules at a distance $r$ [88]:

$w(D)=\frac{B}{r^{12}}-\frac{C}{r^{6}}$ 
where $B$ is the Born repulsion constant and $C$ is the attractive van der Waals constant.

The van der Waals attraction energy $\left(w_{a}(D)\right)$ between two particles with radii $R_{1}$ and $R_{2}$ can be obtained by adding all forces between the particles yielding the following final equation for two spherical NPs:

$w_{a}(D)=-\frac{\pi^{2} \rho_{1} \rho_{2}}{6} C\left[\frac{2 R_{1} R_{2}}{c^{2}-\left(R_{1}+R_{2}\right)^{2}}+\frac{2 R_{1} R_{2}}{c^{2}-\left(R_{1}-R_{2}\right)^{2}}+\ln \left(\frac{c^{2}-\left(R_{1}+R_{2}\right)^{2}}{c^{2}-\left(R_{1}-R_{2}\right)^{2}}\right)\right]$

where $\rho$ is the number density of the particle, $c$ is the center to center distance between the two particles, and $D$ is the surface to surface distance between the particles $(D=c-$ $\left.\left(R_{1}+R_{2}\right)\right)$.

For two identical particles with $R=R_{1}=R_{2}$ and $D<<R$ (particles are in close proximity) the $w_{a}(D)$ becomes;

$w_{a}(D)=-\frac{\pi^{2} \rho_{1} \rho_{2} C R}{12 D}=-\frac{A R}{12 D}$

where $A$ is the Hamaker constant.

\subsubsection{Electrostatic interaction}

The van der Waals attractions discussed above could promote agglomeration/aggregation of suspended NPs. Stabilization of NPs requires forces opposing the van der Waals attractions. The particle surface charge could result in repulsive interparticle forces. In solution, solvated ions surround the NPs and shield their surface charge forming an electric double layer (EDL), which includes a Stern inner layer and a diffuse outer layer. The ions in the Stern layer are strongly bound whereas the ones in the diffuse layer are loosely bound. Within the diffuse layer a boundary, known as the slipping plane, exists. The potential at this boundary is called the zeta potential $(\zeta$ potential), which gives an indication of the colloid stability. NPs with $\zeta$-potential values greater than $+30 \mathrm{mV}$ or less than $-30 \mathrm{mV}$ are considered electrostatically stable. [89] The 
thickness of the EDL is called the Debye length $\lambda\left(\kappa^{-1}\right)$, which is the inverse of the Debye parameter $(\kappa)$. [90]

EDL repulsion forces $\left.\left(W_{\mathrm{r}} D\right)\right)$ can be described using the Derjaguin's equation [91] which assumes a constant surface potential $\left(\psi_{\delta}\right)$ and a particle radius much larger than the thickness of the EDL.

$w_{r}(D)=2 \pi \varepsilon_{0} \varepsilon R \psi_{\delta}^{2} e^{-\kappa D}$

where $\varepsilon_{0}$ is the permittivity of the vacuum and $\varepsilon$ is the dielectric constant of the solution.

\subsubsection{DLVO Theory}

The DLVO theory is named after Derjaguin, Landau, Verwey and Overbeek. $[91,92]$ It describes the total force between colloidal NPs by combining the attractive van der Waals and the repulsive EDL forces.

$w_{\text {total }}(D)=w_{a}(D)+w_{r}(D)=-\frac{A R}{12 D}+2 \pi \varepsilon_{0} \varepsilon R \psi_{\delta}^{2} e^{-\kappa D}$

Several factors affect the colloidal stability of NPs including the ionic strength (ion type and concentration), the surface potential and the particle size. The van der Waals attraction is relatively independent of ion concentration, but the repulsive EDL force strongly depends on the concentration of ions, which form the Stern and diffuse layers.

\subsubsection{Stabilization mechanisms}

Stability of colloidal NPs can be attained by various mechanisms [93];

1. Electrostatic stabilization is the mechanism in which the attractive van der Waals forces are counterbalanced by the repulsive EDL forces. When the repulsion is sufficiently high, it prevents the NPs from agglomeration/aggregation. Surfactants 
such as Tween 80 , Triton $\mathrm{X}-100$, sodium dodecyl sulfate (SDS) and sodium dodecylbenzenesulfonate are often used as electrostatic stabilizers.

2. Steric stabilization is promoted by the adsorption of large molecules (e.g. polymers) onto the surface of NPs, providing a protective layer surrounding each NP. It operates via three different modes. Firstly, the adsorbed layer causes steric hindrance that can prevent the NPs from getting close to each other and entering into the range of attractive forces. Secondly, when two NPs approach each other, their adsorbed layers overlap. The concentration of adsorbed molecules in the overlap region causes an increase in the osmotic pressure, which is relieved by the influx of water. This influx of water pushes the two NPs apart preventing their agglomeration/aggregation. Thirdly, the freedom of molecules in the overlap region is restricted producing a negative entropy change and thereby a positive change in the Gibbs free energy, which is unfavorable. Spontaneous entropic (steric) repulsion ensues to resist the negative change in entropy and thereby enabling colloidal stability of NPs.

3. Electrosteric stabilization is a combination of electrostatic and steric stabilization mechanisms. Therefore, both electrostatic repulsion and steric restriction prevent NPs from agglomeration/aggregation.

The stability of NPs is further influenced by the water chemistry. The aqueous $\mathrm{pH}$ determines surface potential and thereby the colloid status of NPs. Aggregation is triggered when the $\mathrm{pH}$ equals the point of zero charge of the NPs. $\mathrm{pH}$ also influences the dissolution of NPs. ZnO, for example, has limited dissolution between $\mathrm{pH} 8$ and 12, but increased with acidity and alkalinity. [94] The increase of ionic strength, especially in 
seawaters, enhanced the aggregation and sedimentation of NPs. [95] NOM adsorbed onto $\mathrm{CeO}_{2}, \mathrm{TiO}_{2}$ and $\mathrm{ZnO}$ NPs enhanced their stability in environmental waters. [96] High concentration of $\mathrm{Ca}^{2+}(>6 \mathrm{mM})$ could screen the charge on alginate, reducing the repulsion between alginate- $\mathrm{CuO}$ NPs to enhance their aggregation. [97] On the contrary, a high concentration of $\mathrm{SO}_{4}{ }^{2-}(>10 \mathrm{mg} / \mathrm{L})$ enhanced the stability of $\mathrm{ZnO}$ NPs. [98] Phosphate anions enhanced the stability of $\mathrm{CeO}_{2}$ NPs and suppressed their dissolution. [99] Zirconium phosphate improved the stability of $\mathrm{TiO}_{2} \mathrm{NPs}$ in water due to electrosteric stabilization. [100]

Although a number of instrumental techniques are available for the characterization and detection of metal/metalloid oxide NPs, their applications can be impractical when analyzing complex samples at environmentally relevant concentrations (ng/L). [101] Apparently, the chemical and physical processes synchronically affect the occurrence, fate and toxicity of metal/metalloid oxide NPs and greatly constrain the development of innovative approaches to detect, characterize and quantify them in environmental waters. [102-104]

\subsection{Analytical strategies for the quantification of metal/metalloid oxide nanoparticles}

Quantitative analysis of metal/metalloid oxide NPs is crucial to determine their path from the original source to various environmental compartments and their possible entry into living creatures. Quantification delivers a concentration based on mass, volume or particle number depending on the analysis method. Qualitative analysis of metal/metalloid oxide NPs uncovers their chemical composition to distinguish each type 
of NPs. Particle size determination is of high importance for data interpretation. Other parameters of high relevance include the particle shape, surface area, surface charge, surface functionality, and colloidal stability. A variety of complementary analytical techniques must be applied for the full analysis of metal/metalloid oxide NPs. These techniques can be sorted into five main categories:

1. Quantitative techniques to deliver mass- or particle number-based concentrations;

2. Qualitative techniques to identify the chemical composition;

3. Characterization techniques to measure the particle size;

4. Imaging techniques to determine the size and shape of individual NPs;

5. Surface characterization techniques to determine surface area, charge and coating. The general analytical procedure most often starts with sample pretreatment followed by separation, fractionation, pre-concentration, size determination and quantification of metal/metalloid oxide NPs. Each step will be reviewed in regard to its utilization in environmental water analysis. 


\subsubsection{Sample pretreatment}

The first challenging step in trace analysis is a proper sample pretreatment that avoids destabilization, aggregation/agglomeration, precipitation and contamination during sample transport and storage. Also, the vessels used for sample collection and storage should be carefully selected to eliminate the possibility of NPs adsorption on the vessel wall and prevent photo-induced electron transfer process. Obviously, different analytical techniques involve different sample pretreatment procedures. Therefore, it is essential to understand the influence of each sample treatment step such as temperature, dilution, $\mathrm{pH}$, or ionic strength on the stability of NPs. Freeze-drying and reconstitution of aqueous suspensions of $\mathrm{SiO}_{2}$ NPs have been verified to provide dispersed suspensions with reproducible sizes using trehalose during the freeze-drying process. Trehalose was capable of replacing water molecules due to hydrogen bonding between silanol groups and trehalose, forming a stable layer around the NPs preventing their aggregation. [105] Dilution [106], addition of stabilizing agents [107], or keeping samples at very low temperatures using liquid nitrogen [108] were successfully applied for the stabilization of metal/metalloid oxide NPs in environmental water samples. $\mathrm{TiO}_{2} \mathrm{NPs}$ in wastewater treatment plants effluents were isolated via filtration followed by rotary evaporation, dialysis, and lyophilization via freeze-drying for subsequent characterization and quantification. [109]

\subsubsection{Separation, fractionation and preconcentration methods}

Several separation methods have been used to eliminate matrix interferences and preconcentrate metal/metalloid oxide NPs. They include ultrafiltration, dialysis, ultracentrifugation, liquid extraction, solid phase extraction, and cloud point extraction. 
Ultrafiltration uses membranes to separate NPs based on their sizes, enabling fractionation as well as preconcentration, speciation (separation from corresponding ions), and purification of NPs. Regenerated cellulose membrane was effectively utilized to remove proteins and lysozyme from metal/metalloid oxide dispersions by selecting the proper membrane properties (molecular weight cut-off (MWCO), hydrophilicity, surface charge) and ultrafiltration conditions (pH, flux). [110] Ultrafiltration membranes with MWCO in the range of $1-100 \mathrm{kDa}$ (from ca. $1 \mathrm{~nm}$ ) are available. Hence, free ionic species can be isolated from NPs unless they form complexes or show affinity to the membrane surfaces, affecting their removal. [111] In general, ultrafiltration was identified as the best practice for the separation of dissolved species from NPs among various separation techniques. [112]

Dialysis works on the basis of diffusion across a membrane due to a concentration gradient and osmotic pressure. It has been extensively used to study the release of metal ions from metals and metal oxide NPs in model solutions. [113] Dialysis takes long times to reach equilibrium since it is based on diffusion. Therefore, ultrafiltration is preferred to speed up the separation process.

Ultracentrifugation separates NPs based on their mass density and allows fractionation by controlling the centrifugal force and time. However, the size distribution of NPs may be altered due to aggregation when applying a high centrifugal force. Dissolution of NPs could also occur at low concentrations as opposed to high ones. [114] Analytical ultracentrifugation with a multi-wavelength detector showed promise in determining the shape, size distribution and optical properties of NPs. However, high concentrations of NPs were required. [115] 
Liquid phase extraction has also been reported for the separation of metal/metalloid oxide NPs from environmental water samples. Surface modification of citrate-stabilized silver and $\mathrm{TiO}_{2}$ NPs with mercaptoundecanoic acid followed by interaction with octadecylamine, resulted in an efficient transfer of the coated NPs into cyclohexane. Extraction efficiencies of $78 \%$ and $73 \%$ were obtained for $1 \mathrm{mg} / \mathrm{L}$ of citrate-stabilized silver and $\mathrm{TiO}_{2}$ NPs, respectively. [116] Another method based on a microscopic oil-water interface trapping mechanism was reported for the separation of nanomaterials from contaminated waters. It worked with nearly $100 \%$ efficiency for separating 1D and 2D nanomaterials; however, it failed to separate spherical NPs. [117] Lauryl gallate (LG) showed strong adsorption on $\mathrm{Ag}$ and $\mathrm{MnO}_{2} \mathrm{NPs}$ facilitating their liquid extraction into the $n$-butanol phase. The adsorption mechanism involved the complexation of metal atoms on the surface of each NP with the phenolic OH groups of LG. [118]

Solid phase extraction, on the contrary, is based on different mechanisms such as covalent or non-covalent binding, complexation, and electrostatic interactions. It is mostly coupled with analytical instrumentations to enhance their detection performance. For example, an anion exchange resin was used to efficiently and selectively retain metal NPs after coating with mercaptosuccinic acid via a noncovalent reversible interaction. [119] Also, a strong metal binding resin (Chelex 100) was used to eliminate dissolved metal ions prior to size characterization and quantification of ZnO NPs by single particle inductively coupled plasma mass spectrometry (SP-ICP-MS). [120]

Cloud point extraction involves the formation of micellar aggregates in which NPs are incorporated for their subsequent separation from the aqueous phase by mild 
heating. Cloud point extraction coupled with ICP-MS was successfully applied for the analysis of $\mathrm{ZnO}$ NPs in water and wastewater samples. Extraction efficiency of $87 \%$ was obtained using Triton X-114 for $40 \mathrm{~nm} \mathrm{ZnO}$ NPs. [121] Pre-treatment of environmental water samples with $\mathrm{H}_{2} \mathrm{O}_{2}$ and a suitable complexing agent prior to cloud point extraction was required to improve the extraction efficiency of $\mathrm{CuO}$ NPs by eliminating the effect of NOM and the corresponding ionic species of NPs present in the water sample. Similar extraction efficiencies were observed for differently coated CuO NPs. [122] A mixture of Triton X-114 and Triton X-100 (30 wt.\%) further improved the extraction efficiency of $\mathrm{CuO}$ NPs.

Beside these methods, there are a number of electrophoretic and chromatographic separation techniques coupled online with various detection systems to enable the acquisition of additional information (discussed in section 1.6).

\subsubsection{Screening methods for the detection of metal/metalloid oxide NPs}

Several screening methods have been proposed for the detection of metal/metalloid oxide NPs. These methods are capable of recognizing the presence of particular metal/metalloid oxide NPs, providing preliminary or screening tests that are of critical value. They, however, could not serve to identify, quantify or characterize the NPs.

A protein-based biosensor was reported for the detection of negatively charged NPs in environmental waters. In particular, a green fluorescent protein (GFP) with a poly-lysine tag was engineered to facilitate its electrostatic interaction with gold, $\mathrm{Fe}_{2} \mathrm{O}_{3}$, $\mathrm{CeO}_{2}$, and $\mathrm{ZnO}$ NPs stabilized with a poly-acrylic acid (PAA) coating. The interaction between the positively charged GFP and the PAA coating on the negatively charged NPs 
resulted in visually observable turbidity changes that were quantified using a portable spectrometer. [123] This method, however; lacks selectivity, as it could not distinguish different types of NPs. Also, the protein biosensor could potentially interact with naturally occurring negatively charged colloids or substrates compromising the assay sensitivity. A simple method used epoxy silane to prepare fluorescent-labelled $\mathrm{SiO}_{2} \mathrm{NPs}$ directly in aqueous solutions. The amount of fluorescent label per particle remained constant regardless of the size of NPs, which facilitated the measurement of numberbased concentrations.[124]

A simple colorimetric assay was developed for the detection of NPs including gold, silver, $\mathrm{CeO}_{2}, \mathrm{SiO}_{2}$, and vanadium dioxide $\left(\mathrm{VO}_{2}\right)$ having multiple capping agents (tannic acid, polyvinylpyrrolidone, branched polyethylenimine, polyethylene glycol) in complex matrices. It is based on the catalytic electron transfer mechanism between an organic dye, methylene blue, and a reducing agent, sodium borohydride, in the presence of NPs serving as a catalyst. This method was sufficiently sensitive (ppb levels) to measure concentrations typically used in toxicological studies. [125] However, it was not selective for a specific type of NPs and could give false positive results in complex matrices. Other parameters, such as composition, size, concentration and redox potential, need to be considered to promote the development of dye-reducing agent pairs for use in the detection of NPs.

Raman spectroscopic analysis was used to assess the interactions between $\mathrm{TiO}_{2}$ NPs and flavonoids (i.e. apigenin, luteolin, fisetin, kaempferol, quercetin, myricetin, and baicalin) since $\mathrm{TiO}_{2} \mathrm{NPs}$ are commonly found in food additives and have been associated with potential adverse health effects. [126] Phenolic groups in flavonoids played a key 
role in their interaction with $\mathrm{TiO}_{2}$ NPs. Differences in the number and positions of phenolic groups contributed to distinctive spectral peaks for the different complexes.

Other contemporary NPs quantification methods such as laser induced break down detection [127], small angle neutron scattering [128], and fluorescent correlation spectroscopy [129] rely upon sophisticated instrumentation and a skilled analyst, making such approaches impractical for regular environmental monitoring.

\subsection{Online and coupled techniques}

\subsubsection{Hydrodynamic and size exclusion chromatography}

Hydrodynamic chromatography (HDC) is a solution-phase separation method that can be performed in an open tube (capillary) or in a column packed with nonporous microbeads. [130] Size exclusion chromatography (SEC) is another size fractionation technique that occurs via columns packed with a porous material. Elution order in HDC is the same as in SEC, larger particles being eluted ahead of smaller ones. However, the mechanisms of retention of these two techniques are different. In HDC, retention is due to preferential sampling of the flow streamlines, whereas in SEC it is based on particles

preference for certain pore volumes. Secondary interaction of NPs with the stationary phase could compromise the resolving power of the chromatographic separation. Therefore, surfactants may be needed to avoid the entrapment of NPs and the blockage of pores, at the expense of possible alteration of the hydrodynamic diameter of the NPs. [131]

HDC coupled with ICP-MS was evaluated for the analysis of NPs with different coatings and shapes using a commercially available HDC column. Retention behaviour 
was slightly affected by the type of the coating material and strongly influenced by the particle shape. However, particle composition had no influence on the retention behaviour. SP-ICP-MS was able to discriminate between spherical and non-spherical particles as long as the size distribution is large enough for profile analysis and the particles are similarly shaped. Complications due to NPs geometry may arise and need to be considered throughout the measurement of unknown NPs to minimize erroneous results. [132]

SEC-ICP-MS was demonstrated as a promising technique for speciation analysis of metal oxide $\mathrm{NPs}$ including $\mathrm{NiO}, \mathrm{CoO}, \mathrm{ZnO}, \mathrm{CuO}$ and $\mathrm{CeO}_{2}$ and their corresponding ions using a $1000 \AA$ pore size silica column. The composition of the mobile phase prevented the dissolution of NPs during the SEC separation. Addition of SDS into the mobile phase was crucial to prevent the adsorption of metal oxide NPs and the ions onto the silica column. The high recovery of ions from the SEC column ensured their accurate quantification by ICP-MS. Metal oxide NPs with sizes larger than the column pore size were completely filtered off by the column. Consequently, the quantification of metal oxide NPs was obtained by subtracting the ion content from the total metal content (which was determined with ICP-MS after digestion without SEC separation). The obtained detection limits were as low as $0.02-0.39 \mu \mathrm{g} / \mathrm{L}$ for both ions and metal oxide NPs. [133]

\subsubsection{Field flow fractionation}

Field flow fractionation (FFF) is a family of separation techniques that are classified according to the nature of the force field. For instance, in flow-FFF (F4), a perpendicular secondary flow is responsible for separating NPs according to their 
hydrodynamic diameter, whereas in sedimentation-FFF (SdFFF), NPs are separated as a function of volume and density by applying a centrifugal force. F4, in its two variants (symmetric and asymmetric (AF4)), is commonly used to separate natural and engineered NPs. AF4 and SdFFF are the only FFF techniques that have been coupled online to ICPMS. AF4 is highly efficient for small particles while SdFFF is best for particles larger than $50 \mathrm{~nm}$, which could readily sediment. [134]

AF4 coupled with ICP-MS technique was evaluated for the separation and detection of $\mathrm{CeO}_{2} \mathrm{NPs}$. Size characterization of $\mathrm{CeO}_{2} \mathrm{NPs}$ was challenging due to the scarcity of certified reference materials and the instability of $\mathrm{CeO}_{2}$ suspensions. The estimated size of $\mathrm{CeO}_{2} \mathrm{NPs}$ was in good agreement with those obtained with different techniques (TEM, XRD and DLS). Direct quantification of $\mathrm{CeO}_{2}$ NPs by ICP-MS using the corresponding ionic standard led to low recoveries $(<80 \%)$ with a detection limit of $0.9 \mu \mathrm{g} / \mathrm{L}$. [135] Characterization and quantification of $\mathrm{SiO}_{2} \mathrm{NPs}$ in aqueous suspensions using AF4-ICP-MS allowed for the separation of different sizes of $\mathrm{SiO}_{2} \mathrm{NPs}(20,40,60$, 80,100 and $150 \mathrm{~nm}$ ) and provided detection limits between 0.16 and $0.30 \mathrm{mg} / \mathrm{L}$ for smaller and larger particles, respectively. The pre-channel mass calibration approach with $\mathrm{SiO}_{2}$ NPs addressed the common quantification problem associated with losses of NPs during the separation process allowing the simultaneous characterization and quantification of $\mathrm{SiO}_{2}$ NPs. [136] The challenge of characterizing $\mathrm{SiO}_{2}$ NPs using SPICP-MS has been addressed to reduce or eliminate interfering signals generated due to abundant molecular interferences including dinitrogen ions. Conventional approaches using a helium collision gas or a reactive ammonia gas are sufficient for larger $\mathrm{SiO}_{2} \mathrm{NPs}$, but are limited by either the inherent random collisions or side reactions that reduce 
silicon ion sensitivity. A new approach using microsecond dwell times in SP-ICP-MS allowed for the detection and characterization of $\mathrm{SiO}_{2} \mathrm{NPs}$ without the need for these cell gases. When using shorter dwell times, the particle signal is greater than the constant dinitrogen signal. It was demonstrated that the accurate detection and characterization of $\mathrm{SiO}_{2}$ NPs using SP-ICP-MS is dependent on achieving a balance between reducing the contribution of the background interference and preserving the intensity of the particle signal. [137]

SdFFF coupled with ICP-MS/MS technique was evaluated for the potential separation and detection of $\mathrm{TiO}_{2}$ NPs in environmental waters. ICP-MS/MS technique (using the mass shift mode of $\mathrm{NH}_{3}$ ) allowed for the removal of different interferences that obscured the reliable detection and quantification of titanium. FL-70 was used as a stabilizer for colloidal $\mathrm{TiO}_{2}$ NPs. The ionic strength of the medium showed a strong impact on the analysis. Analysis of lake water, with a relatively low ionic strength, resulted in the detection of $\mathrm{TiO}_{2} \mathrm{NPs}$ in the size range between 75 and $400 \mathrm{~nm}$. However, seawater containing high salt concentrations resulted in a pronounced aggregation with the subsequent sedimentation of $\mathrm{TiO}_{2} \mathrm{NPs}$. The achieved detection limit in different matrix solutions were below $10 \mathrm{ng} / \mathrm{L}$. [138]

\subsubsection{Capillary electrophoresis}

Capillary electrophoresis (CE) research has come a long way since the technique was discovered in the 1980's. It has been applied to separate macromolecules as well as NPs using various separation modes to attain rapid analysis and high resolution of complex mixtures under a uniform electroosmotic flow (EOF). $[139,140]$ It has been used 
for the physicochemical characterization of NPs in terms of electrophoretic mobility, size, charge distribution, $\zeta$-potential and surface functionality. [141]

\subsubsection{Principles of capillary electrophoresis}

In $\mathrm{CE}$ analysis, different analytes migrate through the capillary at different speeds as they have different electrophoretic mobilities. CE provides unparalleled resolution in comparison to chromatography by using an open tubular column to eliminate multiple paths. There is no stationary phase in capillary electrophoresis, thereby eliminating the mass transfer term in the Van Deemter equation (1-6), which comes from the time needed for the analyte to equilibrate between the mobile and stationary phases. Longitudinal diffusion is the only source of peak broadening in CE analysis. Significantly, the plate height is reduced, the peak efficiency is increased, and the resolution between analytes is improved:

$H=A+\frac{B}{u}+\mathrm{Cu}$

where $\mathrm{H}$ is the plate height, $\mathrm{u}$ is the linear flow rate, and $\mathrm{A}, \mathrm{B}$ and $\mathrm{C}$ are constants for a given capillary.

When placing an analyte with charge $q$ (coulombs) in an electric field $E(\mathrm{~V} / \mathrm{m})$, the force on it is $q E$ (newton). The retarding frictional force $f v_{\text {ep }}$ also influences the movement of the analyte in the background electrolyte (BGE) solution. When the frictional force equals the accelerating force, the analyte rapidly attains a constant velocity $\left(f v_{\text {ep }}=q E\right)$.

Electrophoretic velocity: $\quad v_{e p}=\frac{q}{f} E=\mu_{e p} E$

where $\mu_{\mathrm{ep}}$ is the electrophoretic mobility, which is a proportionality constant between the 
ion velocity and the electric field strength. It is proportional to the charge of the ion and inversely proportional to the friction coefficient $(f)$ given by Stoke's law:

$$
f=6 \pi \eta r
$$

where $\eta$ is the viscosity of the solution, and $r$ is the hydrodynamic radius of analyte.

Above $\mathrm{pH}$ 2, the inside wall of a fused silica capillary is covered with silanol groups $(\mathrm{Si}-\mathrm{OH})$ that are negatively charged $\left(\mathrm{SiO}^{-}\right)$. The electric double layer at the wall of the capillary is composed of a fixed negative layer and excess cations nearby. The tightly adsorbed cations partially neutralize the negative charge on the wall. The mobile cations in the diffuse part of the double layer neutralize the remaining negative charges. When an electric field is applied, cations move toward the cathode and anions move toward the anode. A net momentum toward the cathode is produced by the excess cations in the diffuse part of the double layer. These cations drive a pumping action called electroosmosis and eventually create a uniform EOF of the entire BGE solution toward the cathode.

Electroosmotic mobility $\left(\mu_{\mathrm{eo}}\right)$ is the constant of proportionality between the $v_{\mathrm{eo}}$ and $E$ :

$$
v_{e o}=\mu_{e o} E
$$

Experimentally,

$v_{e o}=\frac{L_{d}}{t_{\text {neutral }}}$

where $L_{d}$ is the effective length of the capillary (to the detector) and $t_{\text {neutral }}$ is the migration time of a neutral marker.

$$
\mu_{e o}=\frac{v_{e o}}{E}=\frac{\left(\frac{L_{d}}{t_{\text {neutral }}}\right)}{\left(\frac{V}{L_{t}}\right)}
$$


where $\mathrm{L}_{\mathrm{t}}$ is the total length of the capillary and $\mathrm{V}$ is the applied voltage

Disturbance of the uniform EOF can cause peak broadening. Joule heating produced by the flow of ions in the capillary causes the solution viscosity to decrease and disturbs the uniform profile of the EOF. Therefore, the capillary inner diameter should be sufficiently small ranging from 20 to $50 \mu \mathrm{m}$ to rapidly dissipate the generated heat.

The apparent (observed) mobility, $\mu_{\mathrm{app}}$, of an analyte is the sum of the $\mu_{\mathrm{eo}}$ of the BGE solution and the $\mu_{\mathrm{ep}}$ of the analyte.

Apparent mobility: $\mu_{a p p}=\mu_{e o}+\mu_{e p}$

Positively charged analytes move along in the EOF direction. Therefore, $\mu_{\mathrm{eo}}$ and $\mu_{\text {ep }}$ have the same sign, contributing a greater value to $\mu_{\text {app }}$ than $\mu_{\mathrm{eo}}\left(\mu_{\mathrm{app}}=\mu_{\mathrm{eo}}+\mu_{\mathrm{ep}}\right)$. On the contrary, negatively charged analytes move in the opposite direction of the EOF. Thus, $\mu_{\mathrm{eo}}$ and $\mu_{\mathrm{ep}}$ have opposite signs, contributing a lesser value to $\mu_{\mathrm{app}}$ than $\mu_{\mathrm{eo}}\left(\mu_{\mathrm{app}}=\right.$ $\left.\mu_{\mathrm{eo}}-\mu_{\mathrm{ep}}\right)$. For a neutral analyte, its apparent mobility equals the electroosmotic mobility of the solution $\left(\mu_{\mathrm{app}}=\mu_{\mathrm{eo}}\right)$.

The apparent mobility of an analyte is the net velocity of the analyte, $v_{\text {net }}$, divided by the electric field, $E$.

$\mu_{\text {app }}=\frac{v_{n e t}}{E}=\frac{\left(\frac{L_{d}}{t}\right)}{\left(\frac{V}{L_{t}}\right)}$

where $t$ is the migration time of the analyte.

The amount of the sample (Q) introduced to the capillary during electrokinetic injection can be calculated from the $\mu_{\text {app }}$ as follows [142]:

$Q=\frac{\pi r^{2} V_{i} t_{i} C \mu_{a p p}}{L_{t}}$ 
where $\mathrm{C}$ is the sample concentration, $\mathrm{V}_{\mathrm{i}}$ is the injection voltage, and $\mathrm{t}_{\mathrm{i}}$ is the injection duration.

The electrophoretic mobility, $\mu_{\mathrm{ep}}$, is the difference between the $\mu_{\mathrm{app}}$ and the $\mu_{\mathrm{eo}}$. Variance from run to run should not have an effect on the electrophoretic mobility of NPs as it is measured in relation to a neutral marker, unless there are time-dependent or nonequilibrium interactions of NPs with the capillary wall. [143]

$$
\mu_{e p}=\left(\frac{L_{d} L_{t}}{V t}\right)-\left(\frac{L_{d} L_{t}}{V t_{\text {neutral }}}\right)
$$

\subsubsection{Physicochemical characterization of nanoparticles by capillary electrophoresis}

For spherical NPs, by assumption, $q$ is proportional to the surface area of NPs $\left(4 \pi r^{2}\right)$. Therefore, $\mu_{\mathrm{ep}}$ of a NP could be given by Equation (1-16), where $\mathrm{K}$ is a constant of proportionality that is related to the viscosity of the solution. [144,145]

$$
\mu_{e p}=\frac{q}{6 \pi \eta r} \propto \frac{4 \pi r^{2}}{6 \pi \eta r}=K r
$$

Equation (1-16) indicates that the $\mu_{\mathrm{ep}}$ is proportional to $r$. This relationship suggests that negatively charged particles with larger radii travel at a faster rate toward the anode (or capillary inlet). Since they move in the opposite direction to the EOF, $\mu_{\mathrm{eo}}$

and $\mu_{\mathrm{ep}}$ have opposite signs and thereby smaller values of $\mu_{\text {app }}$ would be obtained. The EOF travels at a much greater magnitude and thereby all particles are flushed toward the cathode at different rates depending on their sizes. Accordingly, CE can be used to determine the $\mu_{\mathrm{ep}}$ of NPs from their migration times.

The linear relationship between $\mu_{\mathrm{ep}}$ and $r$ allows the determination of the NP radius from a standard calibration curve. The obtained $r$ values were very similar to the 
ones determined by TEM. [146,145] A broad CE peak shape reflects the size distribution of NPs, which can be obtained by Gaussian fitting of the CE peak. [147] The composition and concentration of the BGE strongly influence the dispersion stability of NPs and thereby affecting their peak shape. [148,149]

The motion of particles inside the capillary is affected by four forces [150];

1. The driving force exerted by the external electric field;

2. Stokes viscous drag;

3. The electrophoretic retardation force resulting from the motion of counterions in the diffuse part of the electric double layer in a direction opposite to that of NPs;

4. Relaxation effect: the ionic atmosphere surrounding each NP lags behind it imposing an additional drag to its motion.

These forces are taken into consideration when calculating the electrical potential

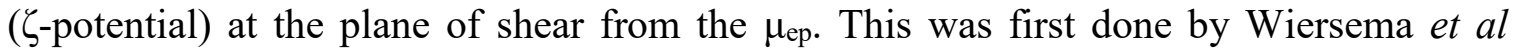
[151] and further extended to higher value of $\zeta$-potential by O'Brien and White. [152] Few years later, Oshimah presented the following approximate equation, which is valid for $1: 1$ electrolytes and $\zeta$-potential values $\leq 100 \mathrm{mV}[153]$;

$\mu=\frac{2 \varepsilon_{r} \varepsilon_{0} \zeta}{3 \eta}\left[f_{1}\left(\kappa R_{h}\right)-\left(\frac{z e \zeta}{k T}\right)^{2} f_{3}\left(\kappa R_{h}\right)-\frac{m_{+}+m_{-}}{2}\left(\frac{z e \zeta}{k T}\right)^{2} f_{4}\left(\kappa R_{h}\right)\right]$

where $\varepsilon_{\mathrm{r}}$ is the relative electric permittivity, $\varepsilon_{0}$ is the electric permittivity of vacuum,,$\kappa$ is the Debye-Hückel parameter, $\mathrm{R}_{h}$ is the hydrodynamic radius, $\mathrm{k}$ is Boltzmann constant, $e$ is the elementary electric charge, $\mathrm{T}$ is the absolute temperature, and $f_{1}, f_{3}$, and $f_{4}$ are a function of $\kappa R_{h}$ and are given by:

$$
f_{1}\left(\kappa R_{h}\right)=1+\frac{1}{2\left[1+\frac{2.5}{\left\{\kappa R_{h}\left(1+2 e^{-\kappa R_{h}}\right)\right\}}\right]^{3}}
$$




$$
\begin{gathered}
f_{3}\left(\kappa R_{h}\right)=\frac{\kappa R_{h}\left(\kappa R_{h}+1.3 e^{-0.18 \kappa R_{h}}+2.5\right)}{2\left(\kappa R_{h}+1.2 e^{-7.4 \kappa R_{h}}+4.8\right)^{3}} \\
f_{4}\left(\kappa R_{h}\right)=\frac{9 \kappa R_{h}\left(\kappa R_{h}+5.2 e^{-3.9 \kappa R_{h}}+5.6\right)}{8\left(\kappa R_{h}+1.55 e^{-0.32 \kappa R_{h}}+6.02\right)^{3}}
\end{gathered}
$$

The dimensionless ionic drag coefficients $\left(m_{+}\right.$and $\left.m_{-}\right)$are calculated from the limiting conductances, $\Lambda_{+}{ }^{0}$ for the cation and $\Lambda_{-}^{0}$ for the anion, of the background electrolyte solution:

$m_{ \pm}=\frac{2 \varepsilon_{r} \varepsilon_{0} k T N_{A}}{3 \eta z \Lambda_{ \pm}^{0}}$

where $\mathrm{N}_{\mathrm{A}}$ is the Avogadro number and $\mathrm{z}$ is the charge of electrolyte ions (symmetrical electrolyte).

When assuming a spherical geometry of NPs and a uniform distribution of charges on the sphere surface, the electric charge density, $\sigma$, at the plane of shear for a given $\zeta$-potential and $\mathrm{R}_{h}$ can be calculated as follows [154]:

$$
\sigma=\frac{Q}{4 \pi R_{h}^{2}}=\frac{\varepsilon_{r} \varepsilon_{0} k T}{e z} \kappa\left[2 \sinh \left(\frac{e \zeta}{2 k T}\right)+\frac{4}{\kappa R_{h}} \tanh \left(\frac{e \zeta}{4 k T}\right)\right]
$$

The effective charge number ( $\mathrm{Z}_{\mathrm{eff}}$ ) can be calculated from $\sigma$ and $\mathrm{R}_{\mathrm{h}}$ of NPs by:

$$
z_{e f f}=\frac{4 \pi \sigma R_{h}^{2}}{e}
$$

\subsubsection{Recent advances in the development of capillary electrophoresis}

Several strategies have been developed to improve the sensitivity of detection including metal-enhanced quantum dot fluorescence [155], different stacking strategies for on-line sample pre-concentration [156], online coupling to sensitive detection systems such as dark-field microscopy [157], evaporative light scattering [158], and ICP-MS. 
[149] Two CE modes (micellar electrokinetic chromatography (MEKC) [159] and capillary zone electrophoresis (CZE) [149], coupled to ICP-MS were utilized for the separation, identification, size characterization and speciation of different metal NPs (Au, $\mathrm{Ag}, \mathrm{Pt}$, and $\mathrm{Pd}$ ) in various matrices. The type and concentration of the surfactant introduced to the running buffer greatly influenced the resolution capability while the applied voltage and $\mathrm{pH}$ values of the buffer largely affected the migration times by varying the EOF. Also, the addition of complexing agents helped to maintain dissolved metal ions, particularly $\mathrm{Ag}^{+}$, in solution making elemental speciation possible. For environmental matrix effect, the NOM in a river water sample had no pronounced effect on the migration behavior of gold NPs. This behavior was explained by the strong adsorption of the surfactant onto the surface of gold NPs, which effectively reduced the influence of NOM. [145] CE-ICP-MS techniques seem promising not only for a reliable characterization of NPs but also for rapid screening of NPs in environmental matrices. A minor limitation is the need for calibrants having a similar surface chemistry to that of the NPs. This is generally not possible for environmental samples in which NPs could develop highly distinct coatings. [160]

CE was also coupled to Taylor dispersion analysis (TDA), which has been used to determine the average diffusion coefficient by analyzing peak shape after elution of an analyte from a broad capillary. CE-TDA seems to be a promising technique for the characterization of NPs in complex matrices since it combines the remarkable separation performance of CE to the size-based characterization of TDA. [161] 


\subsection{Efforts towards method validation and reference materials}

Despite the continuous development of various analytical techniques for the characterization and quantification of NPs, validation of such techniques is still challenging due to the lack of certified reference materials (CRMs). There are only four suspensions of NPs ( $\left.\mathrm{Au}, \mathrm{Ag}, \mathrm{Si}, \mathrm{SiO}_{2}\right)$ available as CRMs. The certified value is the size of the NPs while the concentration is only indicative. Also, all available CRMs - with the exception of Si NPs in toluene - are aqueous suspensions and no reference matrices are available to match CE running buffers. Stability of NPs in complex matrices cannot be assured owing to their physicochemical properties that promote their chemical transformation, dissolution, aggregation, and surface reactions. A new CRM for quality control of the size of NPs has been developed by the Institute for Reference Materials and Measurements of the European Commission's Joint Research Centre. The material, ERMFD102, consists of an aqueous suspension of a mixture of $\mathrm{SiO}_{2} \mathrm{NPs}$ of distinct particle sizes. [162] The characterization relied on an inter-laboratory comparison study in which a variety of techniques were used for particle size analysis including dynamic light scattering (DLS), centrifugal liquid sedimentation (CLS), scanning and transmission electron microscopy (SEM and TEM), atomic force microscopy (AFM), particle tracking analysis (PTA) and AF4. Final validation of new analytical methods and procedures requires real-world reference matrices, which are not yet available. For now, interlaboratory comparison tests of environmental samples and available CRMs are highly recommended but awaiting. 


\subsection{Research goal}

Analysis of metal/metalloid oxide NPs in environmental waters is currently a subject of intense research. Several analytical techniques have been proposed or applied for the quantitative determination of metal/metalloid oxide NPs in environmental waters despite their limitations. Several techniques require a long, tedious and time- consuming sample preparation that may disturb the original state of NPs in environmental waters. Also, highly trained personnel are required to operate such instruments and analyze the data. The objective of this research project is to develop a simple, rapid, cost effective and highly efficient method for the quantitative determination of metal/metalloid oxide NPs in environmental waters.

The main goal of the work focuses on the enhancement of the ultraviolet (UV) detection sensitivity for different types of metal/metalloid oxide NPs in CE analysis. The first objective is to develop a CE method, by choosing good background electrolytes and optimizing their concentrations, for the efficient detection and separation of metal/metalloid oxide NPs in water. The second objective is to demonstrate improved performance of the CE-UV technique for NPs analysis based on the following advantages:

I. UV detection at a fixed window position along the capillary, with different wavelengths available to optimize the measurement sensitivity and selectivity, reducing the requirements for sample pretreatment;

II. Electrokinetic preconcentration of NPs by simply injecting a sufficient volume of the sample suspension as required for low concentrations;

III. Partitioning provides the ability to use substrate-product combinations that cannot be used in conventional systems. 
CE has been employed for screening analysis of NPs due to its superior performance in the separation of differently sized/charged NPs over other separation techniques. [86] However, the major limitation is the relatively poor detection limits of CE-UV for the analysis of NPs. Hence, various molecular and polymeric coating strategies were developed to enhance the colloidal stability and the CE-UV detection sensitivity of metal/metalloid oxide NPs in aqueous suspensions. The binding/coating layer aimed to introduce chromophores to the surface of NPs, thus increasing their UV absorbance to enhance the CE-UV peak area for a significant improvement of their detection limit.

\subsection{Hypothesis}

The scientific question we had was: Could UV detection be made 10-fold more sensitive when chromophores are added on the surface of metal/metalloid oxide NPs in aqueous suspensions for direct CE analysis? Our hypothesis was that molecular layers and polymeric coatings could be selectively formed on different types of NPs to produce stronger peaks at shifted migration times for both improved detection limits and unmistaken identification. Two predictions that could be tested by experimenting were: (a) if we add molecular adsorbates or form polymeric coatings onto the NPs, then CE-UV analysis would produce standard calibration curves with steeper slopes to indicate enhancement of the analytical sensitivity hopefully by a factor of 10 or more; (b) if we study the scientific literature to find out what was already known on the topic, then the selectivity of molecular adsorbates and polymeric coatings would help identify the chemical composition of unknown NPs present in environmental waters. Even if insufficient information was available from previous publications, the scientific question 
could still be tackled through the general knowledge we had learned in chemistry and the experience we had gained from research on molecularly imprinted polymers. 


\section{Chapter 2: Materials and Instrumentation}

\subsection{Materials}

2,2'-azobis-2-isobutyronitrile (AIBN) was bought from Pfaltz \& Bauer (Waterbury, CT, USA). Alumina $\left(\mathrm{Al}_{2} \mathrm{O}_{3},<50 \mathrm{~nm}\right)$ nanopowder, bisphenol A (BPA), ceria $\left(\mathrm{CeO}_{2}\right)$ nanopowder, chitosan (medium molecular weight of 190,000-310,000, deacetylation degree of 75-85\%), dithiothreitol, dopamine hydrochloride (DA.HCl, $\geq 99.5 \%$ ), dsDNA sodium salt from salmon testes, 2-hydroxypropyl methacrylate (HPMA, $97 \%$ ), L-cysteine, mesityl oxide ( $\mathrm{MO}, \geq 90 \%$ ), polyethylene glycol (PEG ,average $\mathrm{M}_{\mathrm{n}}$ 6000), polyvinyl alcohol (PVA, with an average molecular weight of 10,000), sodium dodecyl sulfate (SDS, $\geq 99 \%$ ), ssDNA from salmon testes and LUDOX®colloidal silica $\left(\mathrm{SiO}_{2}, 30 \%\right.$ wt. suspension in $\mathrm{H}_{2} \mathrm{O}$, with a surface area of $198-250 \mathrm{~m}^{2} / \mathrm{g}$ ), titania nanopowder $\left(\mathrm{TiO}_{2}, 21 \mathrm{~nm}\right)$, triton $\mathrm{X}-100$, Tris (hydroxymethyl) aminomethane and zinc oxide $(\mathrm{ZnO},<50 \mathrm{~nm})$ nanopowder were all purchased from Sigma-Aldrich (Oakville, ON, Canada). Sodium phosphate dibasic was obtained from Fisher Scientific (Fair Lawn, NJ, USA).

\subsection{Apparatuses and analytical methods}

CE-UV analyses were performed on a modular system built in our laboratory, which includes a Spellman CZE1000R high-voltage power supply (Hauppauge, New York, USA). Fused-silica capillary (51 $\mu \mathrm{m}$ i.d., $356 \mu \mathrm{m}$ o.d.) was obtained from Polymicro Technologies (Phoenix, AZ, USA). The capillary total and effective lengths were $53.5 \mathrm{~cm}$ and $46.1 \mathrm{~cm}$, respectively. The background electrolyte (BGE) was composed of $10 \mathrm{mM} \mathrm{Na} \mathrm{HPO}_{4}$ or $100 \mathrm{mM}$ Tris in deionized distilled water (DDW) to attain $\mathrm{pH} 7.5 \pm 0.2$ or $\mathrm{pH} 9.5 \pm 0.5$, respectively. All $\mathrm{CE}$ analyses were run at an applied 
voltage of $20 \mathrm{kV}$, with the capillary inlet $2 \mathrm{~mm}$ away and below the electrode tip to improve both precision and baseline stability. A Bischoff Lambda 1010 (Leonberg, Germany) UV detector was set up at a wavelength of 190, 200, 220, 260 or $325 \mathrm{~nm}$ to monitor NPs, monomer(s), polymer(s) and the various adsorbates. Electrokinetic injection at $17 \mathrm{kV}$ for $12 \mathrm{~s}$ was employed to load the sample into the capillary for CE analysis. An independent run of $\mathrm{MO}$ as a neutral marker was carried out to determine the ionic charges of NPs, monomer, polymer and the various adsorbates. A PeakSimple chromatography data system (SRI model 203, Torrance, CA, USA) was used to acquire the detector output signal.

\subsection{Dynamic light scattering}

The average hydrodynamic diameters of NPs/surface-modified NPs were measured by dynamic light scattering (DLS) using a Brookhaven Instruments nanoDLS particle size analyzer (Holtsville, NY, USA), equipped with a 637-nm laser (variable laser power up to $35 \mathrm{~mW}$ ) and operating at an angle of $90^{\circ}$. Suspensions of NPs were prepared in $10 \mathrm{mM} \mathrm{KNO}_{3}$ solution and measured in ten replicates of $10 \mathrm{~s}$ each for higher accuracy.

\subsection{Transmission electron microscopy}

Dilute aqueous suspensions of $\mathrm{SiO}_{2}, \mathrm{SiO}_{2} @$ PHPMA, and $\mathrm{SiO}_{2} @$ PHPMA@PDA NPs were placed on a sample holder to dry for transmission electron microscopy (TEM) examination at an accelerating voltage of $120-200 \mathrm{kV}$ using an FEI Tecnai G2 transmission electron microscope (Hillsboro, OR, USA). The diameters of these NPs were compared to determine the thickness of different coatings. 


\subsection{Fourier transform infrared spectroscopy}

Infrared spectroscopy measurements were obtained using an ABB FTIR spectrometer (Bomem MB Series, Quebec, Canada). Disc samples were prepared by grinding $2 \mathrm{mg}$ of NPs/surface-modified NPs with $200 \mathrm{mg}$ of spectrophotometric-grade $\mathrm{KBr}$. 


\section{Chapter 3: Polymer Coatings for Sensitive Analysis of Colloidal Silica}

Modified from original manuscript, published as:

Alsudir S, Lai EPC. " "Polymer Coatings for Sensitive Analysis of Colloidal Silica", Colloid Polym Sci, 2014, 292,1289-1296.

*Department of Chemistry, Carleton University, Ottawa, ON, K1S 5B6, Canada

\subsection{Abstract}

A new analytical approach has been developed for the sensitive detection of trace NPs in water using silica $\left(\mathrm{SiO}_{2}\right)$ as model inorganic NPs. Our approach is based on coating the NPs with a polymer to make them larger in size for better UV light absorption. These polymer-coated NPs can be separated from the monomer and polymer by $\mathrm{CE}$ due to differences in their ionic charge, size, and surface functionality. Controlled polymerization of 2-hydroxypropyl methacrylate (HPMA) on $\mathrm{SiO}_{2} \mathrm{NPs}$ increased their UV detection sensitivity by $6 \pm 1$ fold. A second coating with polydopamine produced an extra 2-fold increase of the UV detection sensitivity. With both polyhydroxypropyl methacrylate and polydopamine coatings, a significant total enhancement of $12 \pm 2$ fold in detection sensitivity was attained. Alternatively, addition of bisphenol A or polyvinyl alcohol to the PHPMA-SiO 2 NPs resulted in $8 \pm 1$ fold increase of detection sensitivity due to additional absorption of the UV detector light. 


\subsection{Introduction}

Colloidal $\mathrm{SiO}_{2}$ NPs are more and more often used in various biomedical applications [163-165], and they are found in fresh water resources over a large range of concentrations. [166] Therefore, analytical techniques with high sensitivity are much sought after for the detection and quantification of $\mathrm{SiO}_{2}$ NPs. Measurement of the magnitude, frequency and duration of exposure to NPs is a critical first step in risk assessment. Unfortunately, it is difficult to build risk assessment scenarios for NPs due to the limited availability of sensitive methods for their detection and quantification.

Efforts have been focused in our lab to develop polymer growth on NPs as a new method for their trace analysis in water. The coating material was chosen on the basis of several experimental considerations including simplicity of polymerization in aqueous solution, ability to interact with specific NPs, uniform dispersion of the coated NPs in water, strong UV absorptivity, and good electrophoretic mobility for separation by CE with UV detection. Characterization of NPs by CE had been successfully developed in our research lab. [167] Their UV detection limits remained inadequate for general applications in environmental science and engineering studies.

In this chapter, aqueous polymerization of 2-hydroxypropyl methacrylate (HPMA) was investigated on $\mathrm{SiO}_{2}$ for better detection sensitivity in CE-UV analysis. Attempts were made to decrease the rate of HPMA polymerization by adding polyvinyl alcohol (PVA) [168], thus increasing the PHPMA coating thickness on $\mathrm{SiO}_{2}$ NPs. Also, bisphenol A (BPA) was added to increase the UV absorbance of $\mathrm{SiO}_{2} @$ PHPMA for extra detection sensitivity. Finally, an adhesive coating of polydopamine (PDA) was put on top of $\mathrm{SiO}_{2} @$ PHPMA to further enhance the detection sensitivity. 


\subsection{Methods}

\subsubsection{Polymerization of HPMA}

Poly (2-hydroxypropyl methacrylate) (PHPMA) was prepared following a procedure developed by Ali et al. [169] with some modification. In a glass vial, for free radical polymerization, HPMA (0.007 mol) was first dissolved in DDW $(25 \mathrm{~mL})$. SDS (10 wt. \% of HPMA) and AIBN ( 3 wt. \% of HPMA) were then added, followed by pure nitrogen gas bubbling for $5 \mathrm{~min}$ to remove dissolved oxygen molecules that could destroy the free radicals generated by the thermal decomposition of AIBN. Finally the vial was sealed and placed in a $60^{\circ} \mathrm{C}$ thermostatted water bath for $22 \mathrm{~h}$ without further mixing or shaking. The polymerization mixture turned cloudy, yielding PHPMA submicron particles with a white color.

\subsubsection{PHPMA growth on colloidal $\mathrm{SiO}_{2}$ nanoparticles}

HPMA (0.007 mol) was first dissolved in DDW (25 mL) containing colloidal $\mathrm{SiO}_{2}$ NPs $(5-20 \mathrm{~g} / \mathrm{L})$. Sonication for 30 min was allowed to facilitate their hydrogen bonding interaction. Next, SDS (10 wt. \% of HPMA) and AIBN (3 wt. \% of HPMA)

were added, followed by deoxygenation. Finally, the vial was placed in a $60^{\circ} \mathrm{C}$ thermostatted water bath for $22 \mathrm{~h}$ to produce PHPMA and PHPMA-coated $\mathrm{SiO}_{2}$ NPs ( $\mathrm{SiO}_{2} @$ PHPMA).

\subsubsection{Effect of AIBN on PHPMA growth}

The amount of AIBN on PHPMA growth on $\mathrm{SiO}_{2}$ NPs was investigated by using 1,2 and 3 wt. \%. The \% conversion to PHPMA was determined by CE analysis for any residual HPMA. 


\subsubsection{Polymerization of HPMA with polyvinyl alcohol or bisphenol A}

PVA (0.1 g) or BPA (0.005 g) was added to the HPMA-polymerization mixture to investigate any enhancement of $\mathrm{SiO}_{2}$ detection sensitivity.

\subsubsection{Polydopamine growth on $\mathrm{SiO}_{2} @$ PHPMA}

Aqueous solution of DA $(200 \mu \mathrm{L}$ of $25 \mathrm{~g} / \mathrm{L})$ was added into $\mathrm{SiO}_{2} @$ PHPMA aqueous suspension. The mixture was left alone at ambient temperature $\left(23 \pm 2^{\circ} \mathrm{C}\right)$ to allow for PDA growth on the particles, as monitored by CE-UV analysis daily for one week.

\subsection{Results and Discussion}

\subsubsection{Silica nanoparticles}

LUDOX ${ }^{\circledR}$ AM colloidal $\mathrm{SiO}_{2}$ NPs [170] were diluted by the BGE consisting of $10 \mathrm{mM} \mathrm{Na}_{2} \mathrm{HPO}_{4}$ for CE-UV analysis using electrokinetic injection. As shown in Fig. 3.1, $20 \mathrm{~g} / \mathrm{L}$ of $\mathrm{SiO}_{2} \mathrm{NPs}$ exhibited low UV absorbance at the UV detection wavelength of 190 $\mathrm{nm}$, producing a small peak at the migration time of $7.3 \pm 0.2 \mathrm{~min}$. 


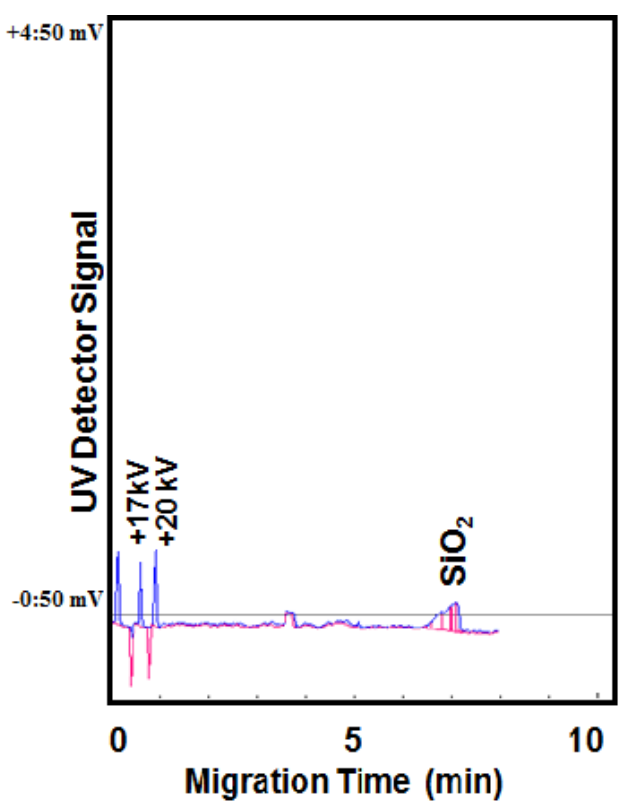

Figure 3.1 CE-UV characterization of $\mathrm{SiO}_{2}$ nanoparticles (at $20 \mathrm{~g} / \mathrm{L}$ ) in LUDOX ${ }^{\circledR}$ AM colloid.

The $\mathrm{SiO}_{2}$ NPs appeared after the neutral marker, mesityl oxide (MO), indicating their negative ionic charges in the $\mathrm{BGE}$ due to the adsorption of $\mathrm{HPO}_{4}{ }^{2-}$ anions onto their surface, yielding a negative electrophoretic mobility value. The standard calibration curve exhibited a linear coefficient of determination $\left(\mathrm{R}^{2}=0.98\right)$ between their CE-UV peak area and concentration in the working range up to $20 \mathrm{~g} / \mathrm{L}$. The limit of detection (LOD at $3 \sigma$ ) and the limit of quantification (LOQ at $10 \sigma$ ) were determined to be $3 \mathrm{~g} / \mathrm{L}$ and $9 \mathrm{~g} / \mathrm{L}$, which are inadequate for many environmental studies. 


\subsubsection{CE-UV characterization of PHPMA particles}

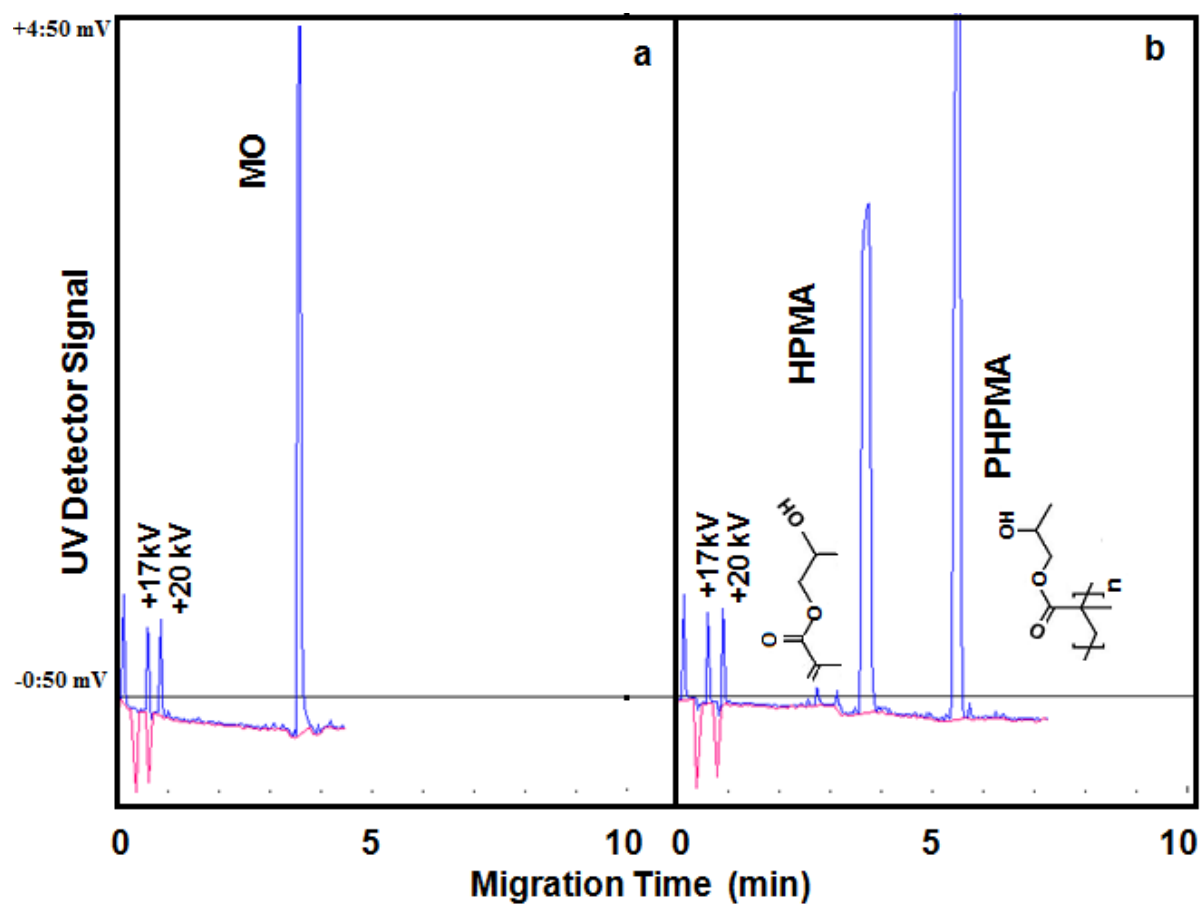

Figure 3.2 CE-UV characterization of (a) MO, (b) HPMA (and PHPMA) after $22 \mathrm{~h}$ of polymerization.

CE-UV analysis was next performed on the HPMA polymerization mixture after $22 \mathrm{~h}$ at $60^{\circ} \mathrm{C}$. As the neutral compound (MO), illustrated in Fig. 3.2a, the residual HPMA migrated at nearly the electroosmotic flow velocity to appear at a time close to $3.7 \pm 0.1$ min for the neutral marker as shown in Fig. 3.2b. The late migration time of 5.6 $\pm 0.1 \mathrm{~min}$ for PHPMA indicated its negative ionic charge in the BGE, possibly due to the adsorption of SDS anions on the hydrophobic polymer surface.

\subsubsection{PHPMA growth on $\mathrm{SiO}_{2}$}

HPMA polymerization can be done in aqueous solutions, enabling its utilization to encapsulate NPs in water samples to improve their CE-UV detection. Polymerization of $\mathrm{HPMA}$ at $60^{\circ} \mathrm{C}$ was conducted for 22 hours in the presence of $\mathrm{SiO}_{2} \mathrm{NPs}$ over a range 
of concentrations from 5-20 g/L. A schematic of the polymerization process is shown in Fig. 3.3.

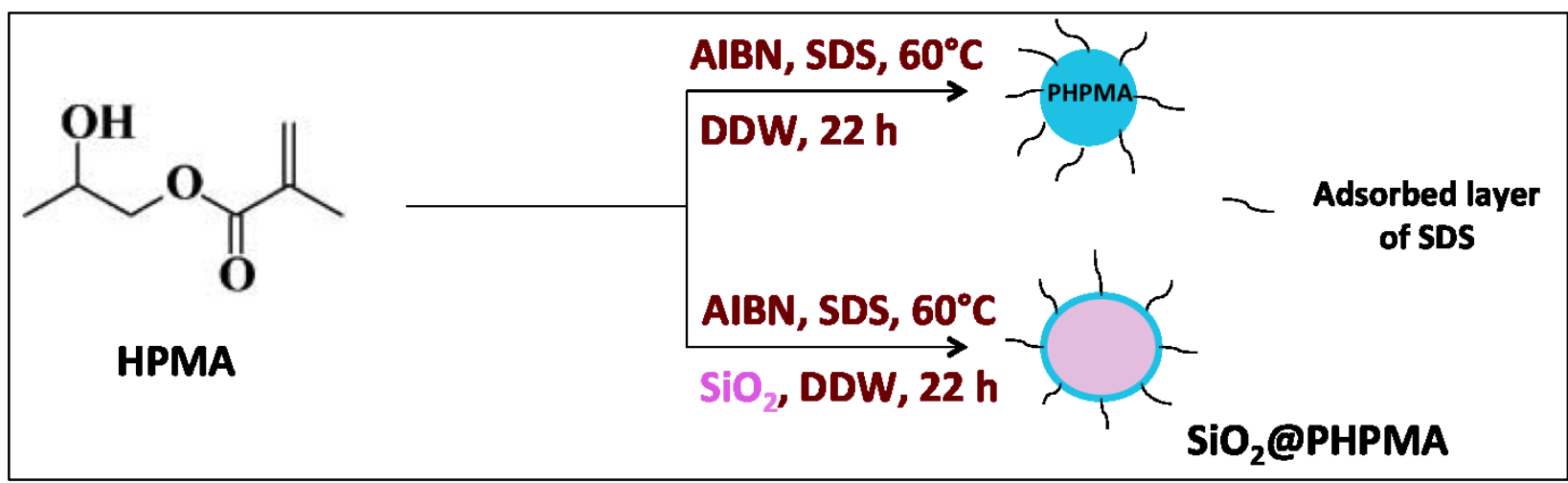

Figure 3.3 Schematic representation of the polymerization process with/without $\mathrm{SiO}_{2}$.

The resultant $\mathrm{SiO}_{2} @$ PHPMA particles were analyzed by CE-UV to determine their detection sensitivity.

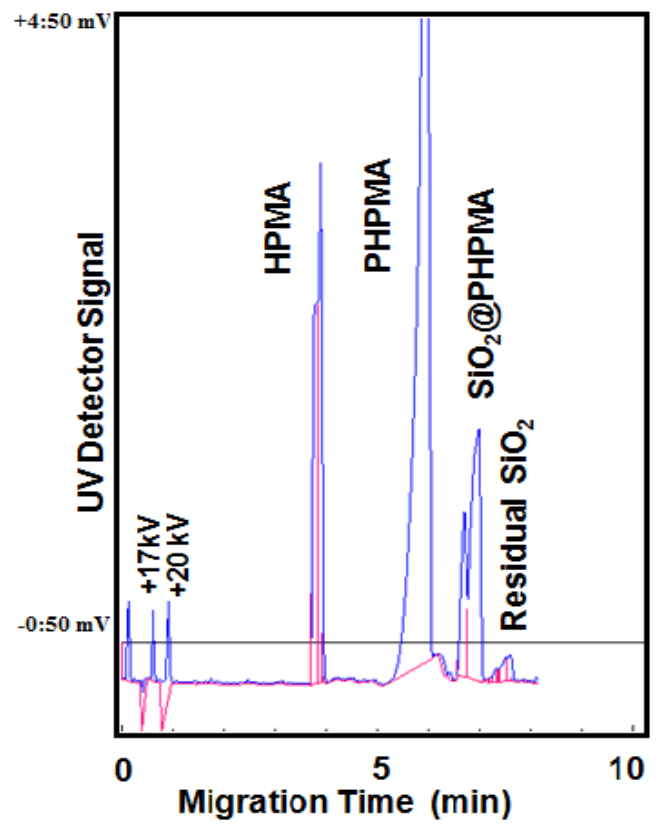

Figure 3.4 CE-UV analysis of PHPMA and $\mathrm{SiO}_{2} @$ PHPMA particles after $22 \mathrm{~h}$ of polymerization using AIBN at 3 wt. \%. 
As shown in Fig. 3.4, a new peak for $\mathrm{SiO}_{2} @$ PHPMA particles was detected at a migration time of $6.8 \pm 0.1 \mathrm{~min}$. These particles exhibited larger peak height and peak area than the original $\mathrm{SiO}_{2} \mathrm{NPs}$ (see Fig. 3.1). Apparently, $\mathrm{SiO}_{2} \mathrm{NPs}$ were coated by PHPMA to have their $\mathrm{Si}^{-} \mathrm{O}^{-}$groups buried under the surface, resulting in a faster migration than $\mathrm{SiO}_{2} \mathrm{NPs}$ (at 7.3 $\pm 0.2 \mathrm{~min}$ ) and good separation from PHPMA (at 5.6 $\pm 0.1 \mathrm{~min}$ ). Upon varying the concentration of $\mathrm{SiO}_{2} \mathrm{NPs}$ in the pre-polymerization mixture, the resultant $\mathrm{SiO}_{2} @$ PHPMA peak area changed accordingly as shown in Fig. 3.5, which provides very convincing proof of the $\mathrm{SiO}_{2} @$ PHPMA formation.

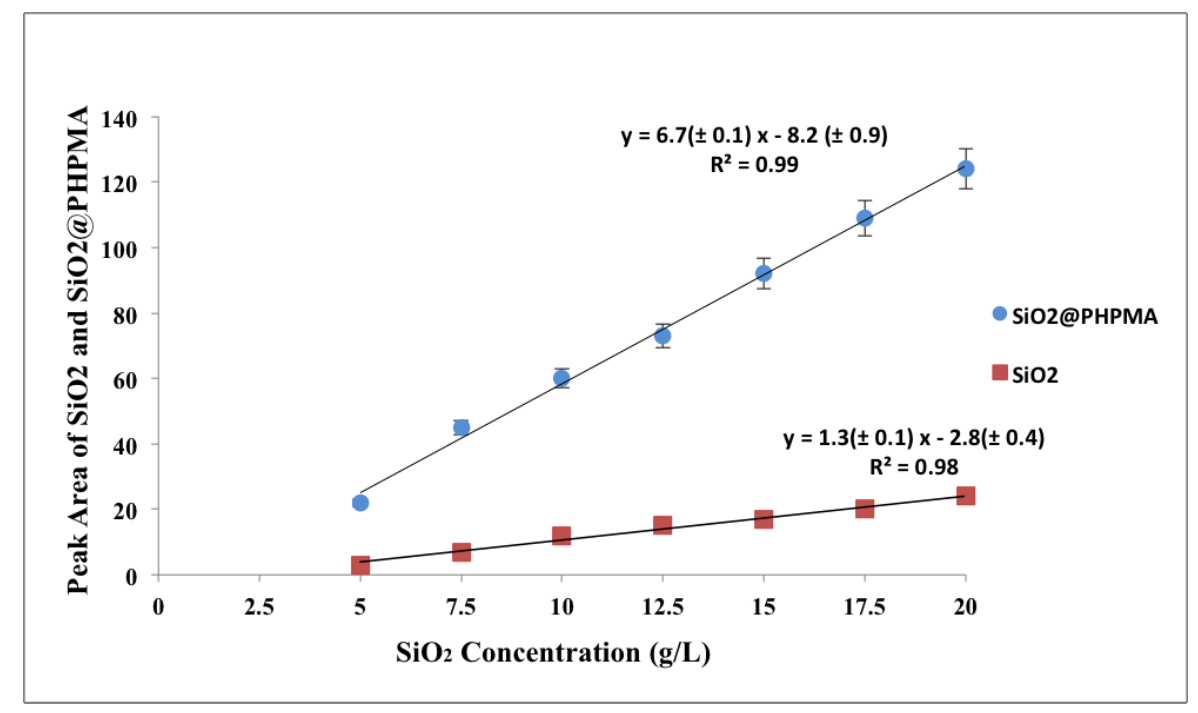

Figure 3.5 $\mathrm{SiO}_{2}$ and $\mathrm{SiO}_{2} @$ PHPMA peak areas obtained at different $\mathrm{SiO}_{2}$ concentrations $(\mathrm{g} / \mathrm{L})$.

The LOD and LOQ for $\mathrm{SiO}_{2} @$ PHPMA particles were determined to be $0.6 \mathrm{~g} / \mathrm{L}$ and $1.8 \mathrm{~g} / \mathrm{L}$. Consequently a 5-fold better CE-UV detection sensitivity was attained for $\mathrm{SiO}_{2}$ NPs after PHPMA coating. Hence, the approach seemed promising towards their sensitive detection in water. 


\subsubsection{Effect of AIBN on PHPMA growth}

Polymerization of HPMA to form a layer of PHPMA on $\mathrm{SiO}_{2}$ NPs was slightly increased from $94 \%$ to $96 \%$ when the mount of AIBN (the initiator) was reduced from 3 to 1 wt. $\%$. At 3 wt. \%, a larger concentration of reactive radicals would be generated leading to early termination of the polymerization process and production of a polymer of low molecular weight. [171,172] On the contrary, at $1 \mathrm{wt} \%$, a chain carrier will be produced from the reaction of a free radical with a monomer unit and propagation will occur continuously with other monomer units present, resulting in a higher conversion of HPMA to PHPMA. Thereby, larger $\mathrm{SiO}_{2} @$ PHPMA particles were produced. $33 \%$ increase in $\mathrm{SiO}_{2} @$ PHPMA peak area was attained and the amount of residual $\mathrm{SiO}_{2} \mathrm{NPs}$ was slightly reduced as shown in Fig. 3.6. Thus, PHPMA growth using AIBN at 1 wt. \% resulted in $6 \pm 1$ fold enhancement of $\mathrm{SiO}_{2}$ detection sensitivity.

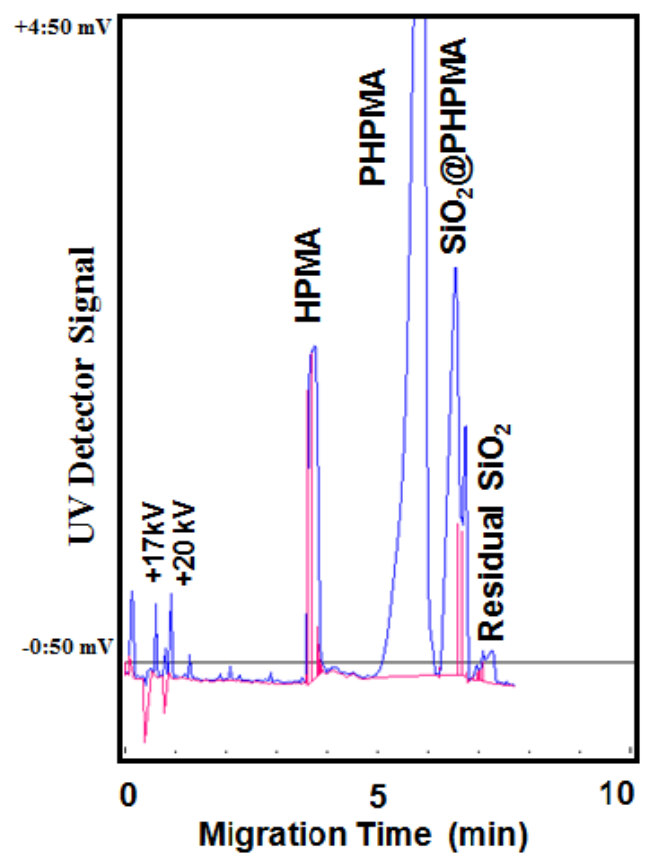

Figure 3.6 CE-UV analysis of PHPMA and $\mathrm{SiO}_{2} @$ PHPMA particles after $22 \mathrm{~h}$ of polymerization using AIBN at 1 wt. \%. 


\subsubsection{Polymerization of HPMA with PVA or BPA}

As shown in Table 3.1, the PHPMA peak areas attained in the presence of $\mathrm{SiO}_{2}$ NPs under different conditions of polymerization were significantly larger than those obtained in the absence of $\mathrm{SiO}_{2}$. The difference in PHPMA peak areas between the presence and absence of $\mathrm{SiO}_{2}$ NPs was also significantly larger than the peak area of $\mathrm{SiO}_{2} @$ PHPMA. One speculation for this significant difference is the catalytic effect of $\mathrm{SiO}_{2}$ NPs that could facilitate the HPMA polymerization and thus produce more PHPMA particles. Another speculation is the formation of a thick coating of PHPMA to cover up all the negative charges present on the $\mathrm{SiO}_{2}$ surface, thus producing $\mathrm{SiO}_{2} @$ PHPMA particles with effectively the same migration time as PHPMA particles. Nonetheless, the $\mathrm{SiO}_{2} @$ PHPMA peak area and height were significantly larger than that of the original $\mathrm{SiO}_{2}$ NPs. These $\mathrm{SiO}_{2} @$ PHPMA particles might have only a monolayer of PHPMA that could not cover up all the negative charges on $\mathrm{SiO}_{2}$ and thus they migrated after the PHPMA peak. Chu et al had previously used PVA to decrease the rate of HPMA polymerization, thereby producing larger particles. [173] In our study, PVA increased the PHPMA peak area, which indicates the formation of larger PHPMA particles as confirmed by DLS analysis below. Addition of BPA also resulted in the formation of larger PHPMA particles. Consequently, PVA or BPA addition to the HPMApolymerization mixture containing $\mathrm{SiO}_{2}$ NPs resulted in $8 \pm 1$ fold increase of $\mathrm{SiO}_{2}$ detection sensitivity probably due to additional absorption of the UV detector light. 
Table 3.1 CE-UV peak areas of HPMA, PHPMA and $\mathrm{SiO}_{2} @$ PHPMA under different conditions of HPMA polymerization. All peak areas are expressed in arbitrary units of mV.s.

\begin{tabular}{|c|c|c|c|c|}
\hline $\begin{array}{c}\text { Condition of } \\
\text { HPMA } \\
\text { polymerization }\end{array}$ & $\begin{array}{l}\text { Peak area of } \\
\text { residual } \\
\text { HPMA }\end{array}$ & $\begin{array}{c}\text { Peak } \\
\text { area of } \\
\text { PHPMA }\end{array}$ & $\begin{array}{c}\text { Peak area of } \\
\mathrm{SiO}_{2} @ \text { PHPMA }\end{array}$ & $\begin{array}{c}\% \\
\text { Polymerization } \\
\text { of HPMA to } \\
\text { form PHPMA }\end{array}$ \\
\hline $\begin{array}{c}\text { Without } \mathrm{SiO}_{2} \\
\text { (AIBN at } 3 \text { wt. \%) }\end{array}$ & $32 \pm 1$ & $57 \pm 1$ & -------- & $\sim 94 \%$ \\
\hline $\begin{array}{c}\text { With } \mathrm{SiO}_{2}(\mathrm{AIBN} \\
\text { at } 3 \text { wt. } \%)\end{array}$ & $31 \pm 3$ & $156 \pm 1$ & $27 \pm 1$ & $\sim 94 \%$ \\
\hline $\begin{array}{c}\text { Without } \mathrm{SiO}_{2} \\
\text { (AIBN at } 1 \text { wt. \%) }\end{array}$ & $29 \pm 1$ & $86 \pm 1$ & -------- & $\sim 95 \%$ \\
\hline $\begin{array}{c}\text { With } \mathrm{SiO}_{2}(\mathrm{AIBN} \\
\text { at } 1 \text { wt. } \%)\end{array}$ & $25 \pm 1$ & $221 \pm 10$ & $40 \pm 3$ & $\sim 96 \%$ \\
\hline $\begin{array}{c}\text { Without } \mathrm{SiO}_{2} \\
\text { PVA }\end{array}$ & $55 \pm 1$ & $153 \pm 1$ & -------- & $\sim 90 \%$ \\
\hline With $\mathrm{SiO}_{2}+$ PVA & $48 \pm 1$ & $261 \pm 4$ & $42 \pm 2$ & $\sim 91 \%$ \\
\hline $\begin{array}{c}\text { Without } \mathrm{SiO}_{2}+ \\
\text { BPA }\end{array}$ & $98 \pm 1$ & $102 \pm 2$ & -------- & $\sim 82 \%$ \\
\hline With $\mathrm{SiO}_{2}+\mathrm{BPA}$ & $185 \pm 1$ & $258 \pm 6$ & $47 \pm 1$ & $\sim 66 \%$ \\
\hline
\end{tabular}

\subsubsection{PDA growth on $\mathrm{SiO}_{2} @ P H P M A$ particles in water}

DA, as derived from the catecholamine and phenethylamine families, is a strong absorber of UV light. DA undergoes oxidation followed by intramolecular cyclization via Michael addition prior to polymerization. It can easily self-oxidize to PDA in basic aqueous solutions without the need for oxidants other than dissolved oxygen in water. Therefore, PDA growth on $\mathrm{SiO}_{2} @$ PHPMA particles in aqueous suspension over one 
week was investigated for further enhancement of detection sensitivity. A schematic representation of PDA growth on PHPMA and $\mathrm{SiO}_{2} @$ PHPMA is shown in Fig. 3.7.

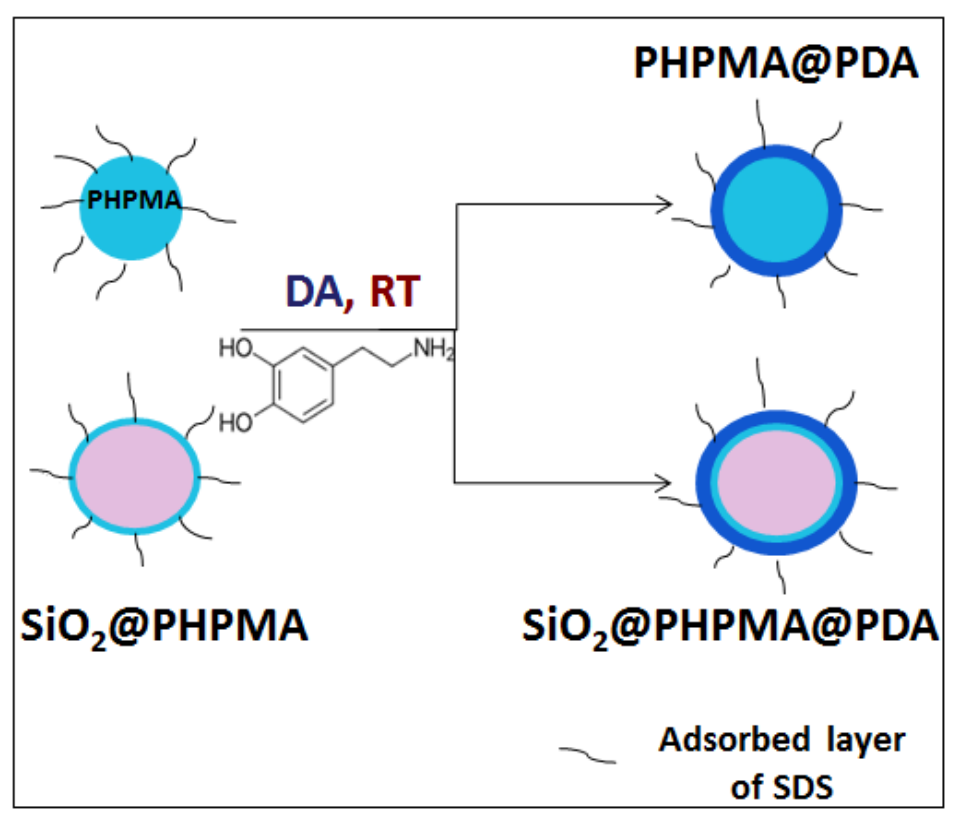

Figure 3.7 Schematic representation of PDA growth on PHPMA and $\mathrm{SiO}_{2} @$ PHPMA at room temperature (RT).

The resultant $\mathrm{SiO}_{2} @$ PHPMA@PDA particles were analyzed by CE-UV daily.

Fig. 3.8 shows the CE-UV electropherogram of DA, HPMA, PHPMA@PDA, $\mathrm{SiO}_{2} @$ PHPMA@PDA and $\mathrm{SiO}_{2} @ \mathrm{PDA}$ particles. DA (at 3.2 $\pm 0.1 \mathrm{~min}$ ) is positively charged in the BGE as it migrated before the neutral marker. Hence, electrostatic attraction between DA and PHPMA, $\mathrm{SiO}_{2} @$ PHPMA or residual $\mathrm{SiO}_{2}$ particles were expected. Due to the adsorption of SDS anions on the hydrophobic polymer surface, PDA acquired a slight negative charge and migrated behind the neutral marker (as observed in a separate CE-UV analysis). After seven days of polymerization, the suspension turned black as a result of PDA formation. Both the PHPMA@PDA peak at

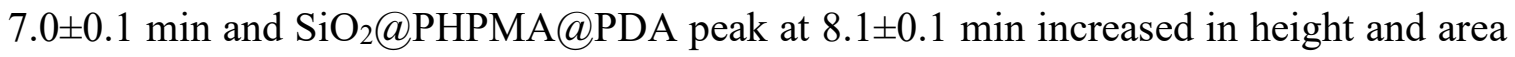
upon PDA growth. Apparently, PHPMA and $\mathrm{SiO}_{2} @$ PHPMA particles were coated with a 
thin layer of PDA to be acquiring extra negative charges on their surfaces, rendering them slower in migration. This thin layer of PDA coating produced an extra 2-fold enhancement of the CE-UV detection sensitivity for $\mathrm{SiO}_{2} @$ PHPMA NPs. Thus, with both PHPMA and PDA coatings, a total of $12 \pm 2$ fold enhancement in detection sensitivity was attained for $\mathrm{SiO}_{2} \mathrm{NPs}$ in the original sample.

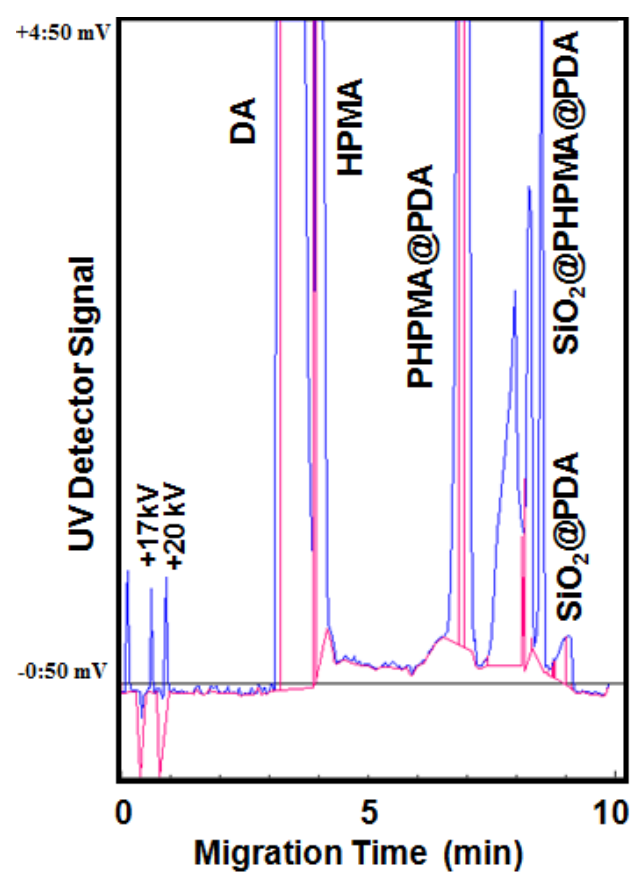

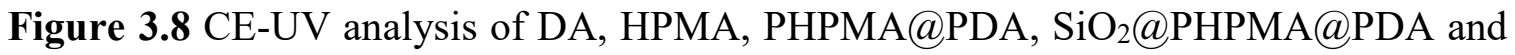
$\mathrm{SiO}_{2} @$ PDA particles. 


\subsubsection{Dynamic light scattering}

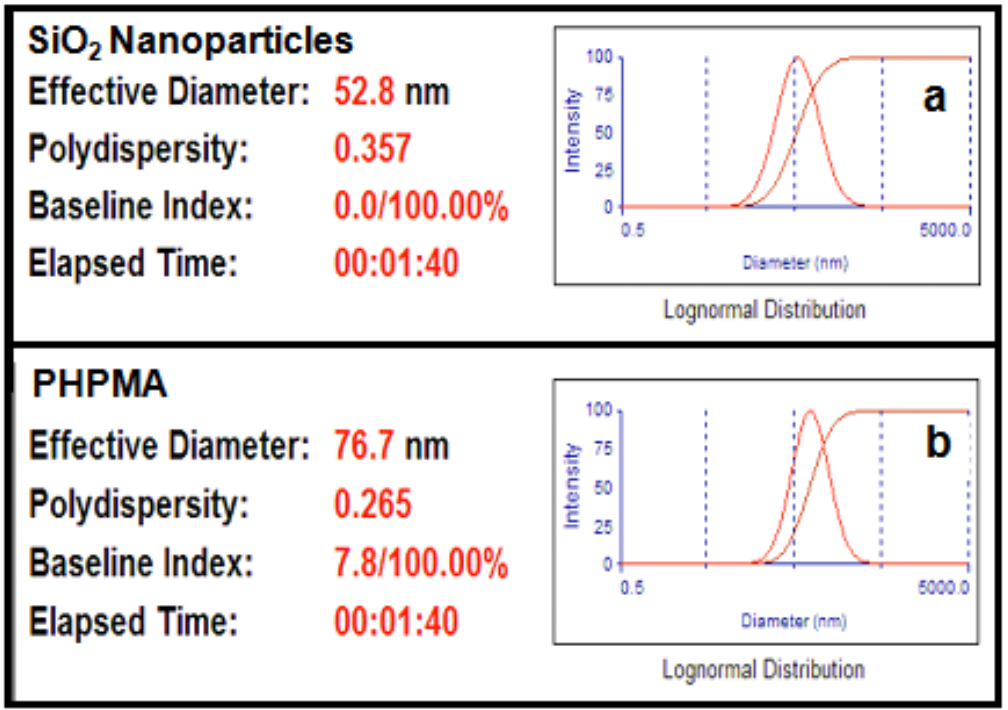

Figure 3.9 Dynamic light scattering measurements of (a) lognormal distribution of $\mathrm{SiO}_{2}$ nanoparticles in LUDOX ${ }^{\circledR}$ AM colloid, (b) lognormal distribution of PHPMA in DDW after $22 \mathrm{~h}$ of polymerization at $60^{\circ} \mathrm{C}$

Aqueous suspensions of original and polymer-coated $\mathrm{SiO}_{2}$ particles were analyzed by DLS to determine their hydrodynamic diameters to gain some insight of their growth. The hydrodynamic diameter is the diameter of a sphere (made of material with the same density) that diffuses at the same velocity as the particle being measured. It represents the actual particle diameter plus the layer of hydrated polymers surrounding the particle as it moves under the influence of Brownian motion. Velocity of the Brownian motion is defined by the translational diffusion coefficient (D), which can be converted into a particle size using the Stokes-Einstein equation;

$d_{h}=\frac{\kappa T}{6 \pi \eta D}$

where $d_{h}$ is the hydrodynamic diameter, $\kappa$ is the Boltzmann's constant, $\mathrm{T}$ is the temperature, $\eta$ is the medium's viscosity, and $\mathrm{D}$ is the diffusion coefficient. 
As shown in Fig. 3.9a and 3.9b, mean diameters of $53 \pm 3 \mathrm{~nm}$ and $77 \pm 5 \mathrm{~nm}$ were obtained for $\mathrm{SiO}_{2}$ NPs and PHPMA particles, respectively. Larger particle diameters were exhibited by $\mathrm{SiO}_{2} @$ PHPMA, $\mathrm{SiO}_{2} @$ PHPMA@PDA, and $\mathrm{SiO}_{2} @$ PHPMA formed in the presence of BPA and PVA as summarized in Table 3.2. These results provide strong evidence that $\mathrm{SiO}_{2}$ NPs in water can be made larger in size by polymer growth under simple experimental conditions to offer more sensitive detection by CE-UV analysis, with the option of electrophoretic separation from organic compounds possibly found in water.

Table 3.2 DLS measurement of the hydrodynamic diameters of original and polymercoated $\mathrm{SiO}_{2}$ particles.

\begin{tabular}{|c|c|}
\hline Particles & Hydrodynamic diameter (nm) \\
\hline $\mathrm{SiO}_{2}$ & $53 \pm 3$ \\
\hline PHPMA (AIBN at 3 wt. \%) & $64 \pm 3$ \\
\hline PHPMA (AIBN at 1 wt. \%) & $77 \pm 5$ \\
\hline BPA-PHPMA & $78 \pm 3$ \\
\hline $\mathrm{SiO}_{2} @$ PHPMA (AIBN at 3 wt. \%) & $89 \pm 2$ \\
\hline PVA-PHPMA & $91 \pm 3$ \\
\hline $\mathrm{SiO}_{2} @ \mathrm{PHPMA} \mathrm{(AIBN} \mathrm{at} \mathrm{1} \mathrm{wt.} \mathrm{\% )}$ & $101 \pm 1$ \\
\hline $\mathrm{SiO}_{2} @$ BPA-PHPMA & $114 \pm 2$ \\
\hline $\mathrm{SiO}_{2} @$ PVA-PHPMA & $129 \pm 4$ \\
\hline $\mathrm{SiO}_{2} @$ PHPMA@PDA & $140 \pm 4$ \\
\hline
\end{tabular}

Polymer growth on NPs formed larger particles with an increased signal response relative to original NP sizes. Treating a particle as a circle helps to understand this size dependent increase in peak intensity [174]; a particle with a larger diameter, and therefore 
larger area, scatters/absorbs more light than a particle with a smaller diameter, as confirmed in the present work. Following this line of thought, and taking into account Beer's Law, which states that the absorbance of a sample is proportional to its concentration, the apparent concentration of particles in a given volume of a sample is dependent on the number of particles as well as the diameter (and thereby the area) of those particles. Hence, the apparent concentration, $C_{\text {app, }}$, is the product of the crosssectional area of a particle ( $\left.A_{\text {circle }}\right)$ and its concentration, $C$, according to:

$C_{\text {app }}\left(\frac{n m^{2}}{m L}\right)=A_{\text {circle }}\left(\frac{n m^{2}}{\text { particles }}\right) \times C\left(\frac{\text { particles }}{m L}\right)$

\subsubsection{Transmission electron microscopy}

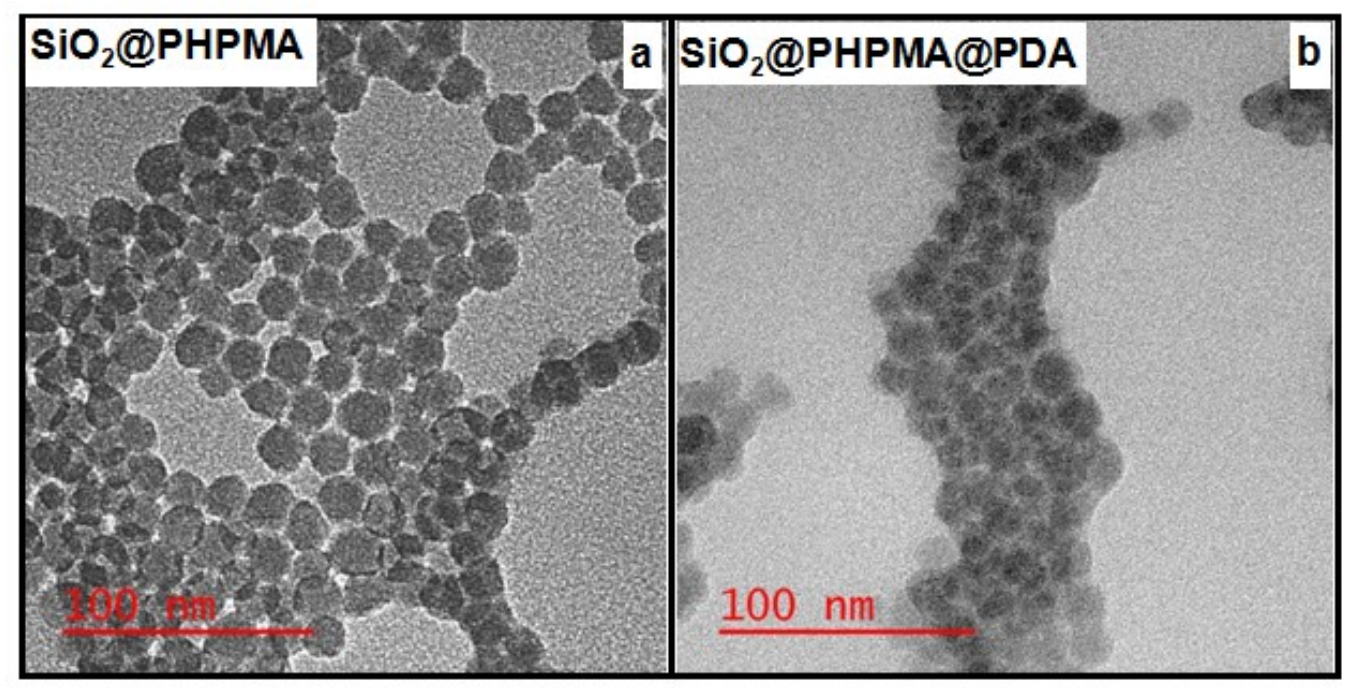

Figure 3.10 Transmission electron micrographs of (a) $\mathrm{SiO}_{2} @$ PHPMA, and (b) $\mathrm{SiO}_{2} @$ PHPMA@PDA.

A mean diameter of $14.6 \pm 2.9 \mathrm{~nm}$ was found for $\mathrm{SiO}_{2} \mathrm{NPs}$. As shown in Fig. $3.10 \mathrm{a}$ and $3.10 \mathrm{~b}$, mean diameters of $18.6 \pm 2.2 \mathrm{~nm}$ and $20.1 \pm 1.6 \mathrm{~nm}$ were obtained for SiO $@$ PHPMA and $\mathrm{SiO}_{2} @$ PHPMA@PDA, respectively. The thickness of PHPMA coating on the surface of $\mathrm{SiO}_{2} \mathrm{NPs}$ was approximately $2.0 \pm 0.4 \mathrm{~nm}$ whereas PDA coating 
on top of PHPMA was about $0.8 \pm 0.3 \mathrm{~nm}$. The diameters of these dry particles, as determined by TEM, seem to be much smaller than the corresponding hydrodynamic diameters obtained by DLS measurement for particles in aqueous suspensions. Particles in liquid media develop a hydration layer around their surfaces, which impacts on their movement under the influence of Brownian motion. As this hydration layer is not present in TEM analysis, smaller diameters were obtained.

\subsection{Conclusion}

This work has demonstrated a new analytical approach to enhance the sensitivity for CE-UV detection of colloidal $\mathrm{SiO}_{2}$ NPs in water by coating with PHPMA alone or with the assistance of BPA, PVA or PDA. The problem of inadequate sensitivity was broken down into smaller attempts toward technically simple and operationally cost effective solutions. Experimental results have demonstrated the feasibility of this approach that can potentially be applied for the determination of other NPs in water analysis. Controlled growth of thicker polymer coatings is underway in our lab to attain higher sensitivity needed for the detection of lower concentrations of NPs. Our ultimate objective is the implementation of this new approach in toxicology research regarding NPs in water, to gain better understanding of their long-term impact on environmental sustainability and public health. 


\subsection{Connection to chapter 4}

The current study brought up some new challenges including the partial coating of $\mathrm{SiO}_{2} \mathrm{NPs}$, the modest enhancement factors, and the long polymerization time. These challenges are tackled in Chapter 4 by studying $\mathrm{SiO}_{2}$ interaction with HPMA and developing a coating of chitosan on the NPs to obtain a greater enhancement of UV detection sensitivity. In addition, the selectivity towards $\mathrm{SiO}_{2}$ is investigated in the presence of $\mathrm{TiO}_{2} \mathrm{NPs}$. 


\section{Chapter 4: Hydroxypropyl Methacrylate Interaction and Chitosan Coating for Enhanced UV Detection Sensitivity of Colloidal Nanoparticles in Capillary Electrophoresis Analysis}

Modified from original manuscript, published as:

Alsudir S, Lai EPC." "Hydroxypropyl Methacrylate Interaction and Chitosan Coating for Enhanced UV Detection Sensitivity of Colloidal Nanoparticles in Capillary Electrophoresis Analysis", J Anal Bioanal Tech. 2015, 6,242-247.

*Department of Chemistry, Carleton University, Ottawa, ON, K1S 5B6, Canada

\subsection{Abstract}

The binding interactions between $\mathrm{SiO}_{2}, \mathrm{TiO}_{2}$ and polymeric NPs (e.g. chitosan) with HPMA were investigated for enhancing the UV detection sensitivity of these NPs in $\mathrm{CE}$ analysis. HPMA interacted with colloidal $\mathrm{SiO}_{2} \mathrm{NPs}$, producing a larger CE-UV peak at a slightly shorter migration time. An increase in particle size with HPMA binding was validated using dynamic light scattering. The interaction was selective as HPMA did not interact with $\mathrm{TiO}_{2}$ NPs in an aqueous suspension. Chitosan coating was also selective for $\mathrm{SiO}_{2}$ NPs producing a significantly larger hydrodynamic diameter to further enhance the sensitivity of their UV detection after HPMA binding. The analytical technique, which involves coating $\mathrm{SiO}_{2}$ NPs with chitosan first and binding with HPMA next, has allowed us to achieve a significant enhancement of $50 \pm 1$ fold in detection sensitivity. 


\subsection{Introduction}

Different chemistry-based encapsulation processes of NPs have been developed and showed promising results. [175] The growth of NPs in solution is complicated by several factors including changes in $\mathrm{pH}$ as well as interactions with ions and surfactants. [176] Either covalent attachment of end-functionalized polymers to the surface or in situ polymerization of monomers using immobilized initiator seems to be versatile. [177-178] Our approach is based on the controlled coating of NPs with a thick layer of polymer to grow them into a larger size for strong UV light absorption. The polymer coating also helps with the stabilization of NPs in aqueous suspension. These grown NPs can be separated by $\mathrm{CE}$ due to differences in electrophoretic mobility, depending on their electronic charge, size, and surface functionality. A first coating of $\mathrm{SiO}_{2} \mathrm{NPs}$ with PHPMA was successfully developed in our laboratory to enhance the UV detection sensitivity by $6 \pm 1$ fold during CE analysis. [179] A second coating with PDA produced an extra 2-fold increase of the UV detection sensitivity to attain a total enhancement of $12 \pm 2$ fold.

The goal of this chapter was to explore other coating materials that could further improve the CE-UV detection sensitivity for metal/metalloid oxide $\mathrm{NPs}\left(\mathrm{TiO}_{2}\right.$ and $\left.\mathrm{SiO}_{2}\right)$ in aqueous suspensions. Investigation started with the binding interaction between these NPs and HPMA, followed by coating with chitosan to produce larger diameters for enhanced UV detection sensitivities. Their hydrodynamic diameters were measured by DLS and their ionic charges were determined by CE. 


\subsection{Methods}

\subsubsection{HPMA binding interaction with colloidal $\mathrm{SiO}_{2}$ or $\mathrm{TiO}_{2}$ nanoparticles}

To investigate the binding interaction between HPMA and colloidal $\mathrm{SiO}_{2}$ or $\mathrm{TiO}_{2}$ NPs, HPMA (3 mL) was first dissolved in DDW $(25 \mathrm{~mL})$ containing colloidal $\mathrm{SiO}_{2}$ or $\mathrm{TiO}_{2}$ NPs $(20 \mathrm{mg} / \mathrm{mL})$. Next, SDS (1.7 wt. \% of HPMA) was added and then the mixture was sonicated for 5 min to ensure homogeneity. Finally, the vial was placed in a $60^{\circ} \mathrm{C}$ thermostatted water bath for $22 \mathrm{~h}$ to facilitate the binding interaction between HPMA and colloidal NPs. Percent binding of HPMA to $\mathrm{SiO}_{2}$ or $\mathrm{TiO}_{2}$ NPs was calculated as [180]:

$$
\% \text { binding of HPMA }=\left[\frac{(\text { HPMA peak area before binding }- \text { HPMA peak area after binding })}{\text { HPMA peak area before binding }}\right] \times 100
$$

\subsubsection{HPMA binding interaction with polymeric nanoparticles}

A suspension of chitosan (1 wt. \%) in 1\% acetic acid was prepared following a procedure reported by Shuai et al. [181] The mixture was stirred magnetically for $3 \mathrm{~h}$ to obtain a homogeneous suspension. Then, the chitosan suspension $(1 \mathrm{~mL})$ was added to $10 \mathrm{mM} \mathrm{Na} \mathrm{HPO}_{4}$ BGE $(30 \mathrm{~mL})$ containing colloidal $\mathrm{SiO}_{2}$ or $\mathrm{TiO}_{2} \mathrm{NPs}$ at varying concentrations $(0-20 \mathrm{~g} / \mathrm{L})$, followed by magnetic stirring for $22 \mathrm{~h}$. Addition of SDS (0.06 g) helped disperse the chitosan-coated particles to prevent precipitation. After addition of HPMA $(0.03 \%, 0.05 \%$ or $0.1 \% \mathrm{v} / \mathrm{v})$ to the chitosan-coated particles, the vial was placed in a $60^{\circ} \mathrm{C}$ thermostatted water bath for $22 \mathrm{~h}$ under continuous magnetic stirring. 


\subsection{Results and discussion}

\subsubsection{CE-UV characterization of silica and titania nanoparticles}

Growing interest in the development of nanocomposites consisting of $\mathrm{TiO}_{2}$ and $\mathrm{SiO}_{2}$ NPs has led to the release of these NPs in significant amounts to the water cycle, threating both humans and aquatic ecosystems. Cytotoxicity arises from the oxidative damage of these NPs owing to the production of reactive oxygen species. Moreover, $\mathrm{TiO}_{2}$ NPs can further damage cells due to photocatalysis-enhanced oxidation upon exposure to light or UV radiation. Wastewater treatment plants and filters are often poorly suited to efficiently remove these NPs. [182] In our work, an aliquot of LUDOX ${ }^{\circledR}$ AM colloidal $\mathrm{SiO}_{2}$ NPs was spiked into the BGE consisting of $10 \mathrm{mM} \mathrm{Na}_{2} \mathrm{HPO}_{4}$ that was loaded into the capillary by electrokinetic injection for CE-UV analysis. As shown in Fig. 4.1a, 20 $\mathrm{g} / \mathrm{L}$ of $\mathrm{SiO}_{2}$ NPs exhibited low UV absorbance at the detection wavelength of $190 \mathrm{~nm}$, producing a small peak at the migration time of $8.7 \pm 0.1 \mathrm{~min} . \mathrm{SiO}_{2} \mathrm{NPs}$ appeared after the neutral marker, indicating their negative ionic charges in the BGE. 

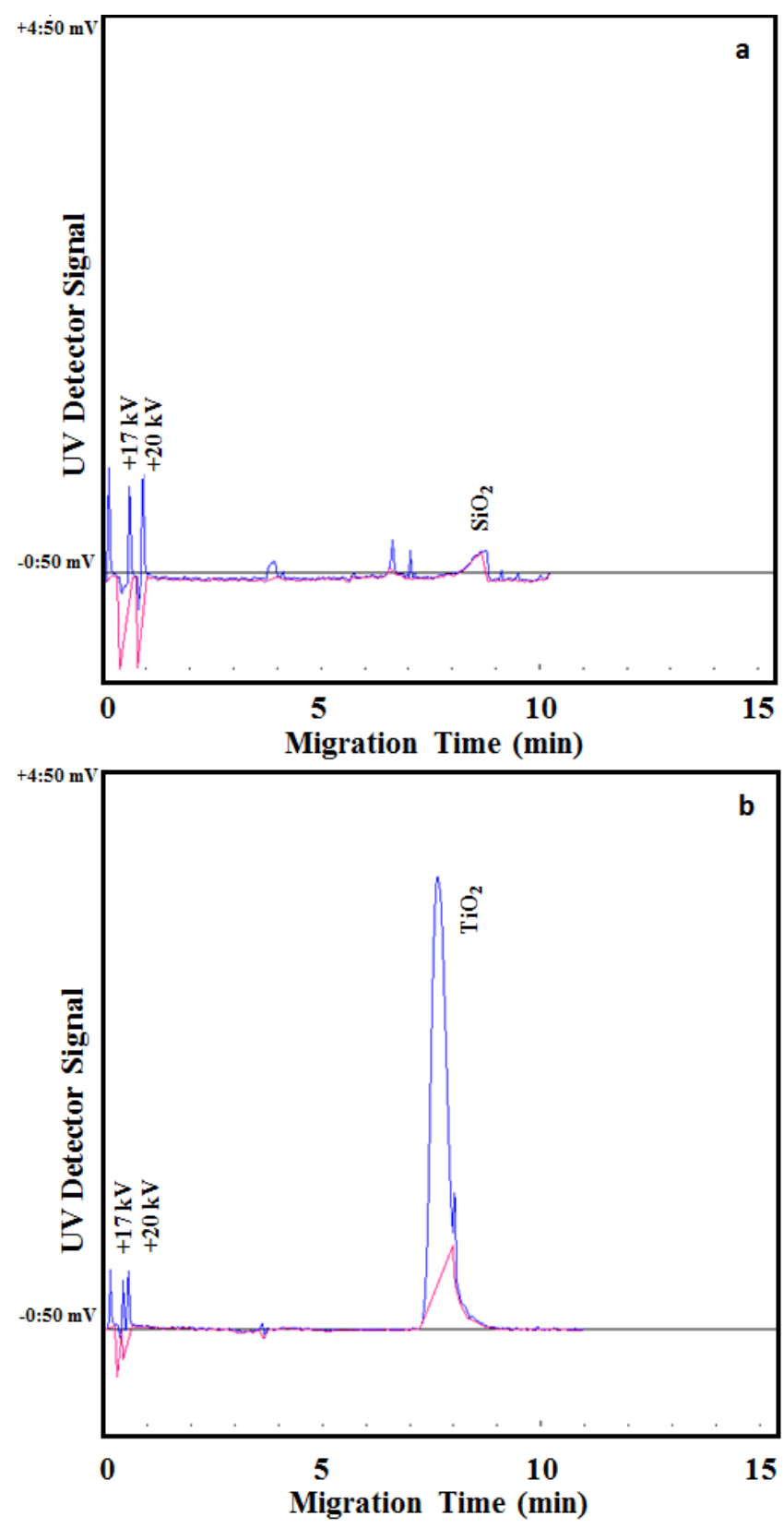

Figure 4.1 CE-UV characterization of (a) $\mathrm{SiO}_{2}(20 \mathrm{~g} / \mathrm{L})$ and (b) $\mathrm{TiO}_{2}(20 \mathrm{~g} / \mathrm{L})$ nanoparticles. SDS was present at a concentration of $2 \mathrm{mg} / \mathrm{mL}$.

On the contrary, $20 \mathrm{~g} / \mathrm{L}$ of $\mathrm{TiO}_{2}$ NPs showed high UV absorbance at $190 \mathrm{~nm}$, producing a large peak at the migration time of $8.4 \pm 0.1 \mathrm{~min}$, as shown in Fig. 4.1b. Similar to $\mathrm{SiO}_{2}, \mathrm{TiO}_{2}$ NPs migrated after the neutral marker, which indicates their negative ionic charges in the BGE. 


\subsubsection{HPMA binding interaction with silica and titania nanoparticles}

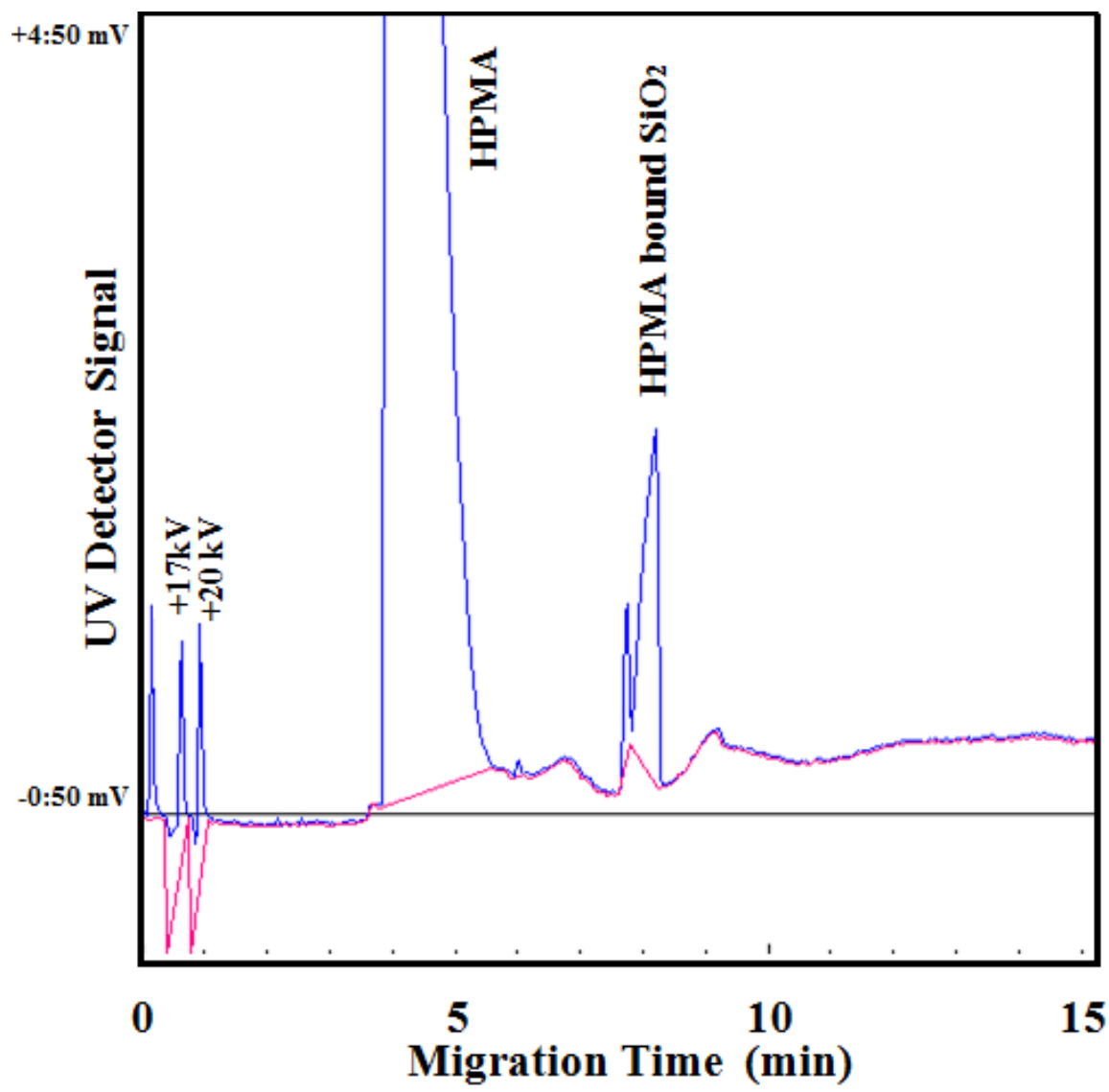

Figure 4.2 CE-UV characterization of $\mathrm{SiO}_{2}(20 \mathrm{~g} / \mathrm{L})$ nanoparticles with $3.0 \mathrm{~mL}$ of HPMA. SDS was present at a concentration of $2 \mathrm{mg} / \mathrm{mL}$.

Binding interaction of HPMA with $\mathrm{SiO}_{2} \mathrm{NPs}$ was conducted at $60^{\circ} \mathrm{C}$ for 22 hours and the resultant $\mathrm{SiO}_{2}$-HPMA particles were analyzed by CE-UV. As shown in Fig .4.2, a new peak for HPMA-bound $\mathrm{SiO}_{2}$ particles was detected at a migration time of $8.2 \pm 0.1$ min. These particles exhibited larger peak height and peak area than the original $\mathrm{SiO}_{2}$ NPs (see Fig. 4.1a). Apparently, the $\mathrm{SiO}_{2} \mathrm{NPs}$ bound to HPMA to have their $\mathrm{Si}^{-} \mathrm{O}^{-}$groups buried under the surface, resulting in a faster migration than $\mathrm{SiO}_{2} \mathrm{NPs}$ (at $8.7 \pm 0.1 \mathrm{~min}$ ) with good separation from HPMA (at $4.0 \pm 0.1 \mathrm{~min}$ ). HPMA binding to $\mathrm{SiO}_{2} \mathrm{NPs}$ was determined to be $19 \pm 3 \%$. Binding interaction of HPMA with $\mathrm{TiO}_{2}$ NPs was next 
conducted at $60^{\circ} \mathrm{C}$ for 22 hours. CE-UV analysis of the mixture showed no sign of interaction between HPMA and $\mathrm{TiO}_{2} \mathrm{NPs}$ as no significant changes were observed for HPMA peak area or the $\mathrm{TiO}_{2}$ peak area and migration time. Correspondingly, HPMA binding to $\mathrm{TiO}_{2}$ NPs was determined to be $0 \pm 5 \%$.

\subsubsection{Dynamic light scattering analysis of silica and titania nanoparticles}

$\mathrm{SiO}_{2}$ and $\mathrm{TiO}_{2}$ NPs in aqueous suspension, as well as their mixtures with HPMA, were analyzed by DLS to determine their hydrodynamic diameters. In DLS analysis, multiple scattering (where light scattered from one particle is scattered from a second particle before reaching the detector) occurs to give the size distribution as particles undergo Brownian motion caused by thermally induced collisions between the suspended particles and solvent molecules. As shown in Fig. 4.3a and 4.3b, the mean diameters of $53 \pm 3 \mathrm{~nm}$ and $83 \pm 13 \mathrm{~nm}$ were obtained for $\mathrm{SiO}_{2}$ NPs and HPMA-bound $\mathrm{SiO}_{2}$ particles,

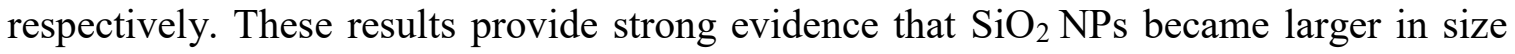
after interaction with HPMA under very simple experimental conditions. The interaction offers more sensitive detection of $\mathrm{SiO}_{2} \mathrm{NPs}$ (now in the form of HPMA-bound $\mathrm{SiO}_{2}$ particles) by CE-UV. Mean diameters of $155 \pm 6 \mathrm{~nm}$ and $154 \pm 5 \mathrm{~nm}$ were obtained for $\mathrm{TiO}_{2}$ NPs and their mixture with HPMA, respectively. DLS analysis confirmed that no interaction between $\mathrm{TiO}_{2}$ NPs and HPMA took place as no significant change in the hydrodynamic diameter was observed. 


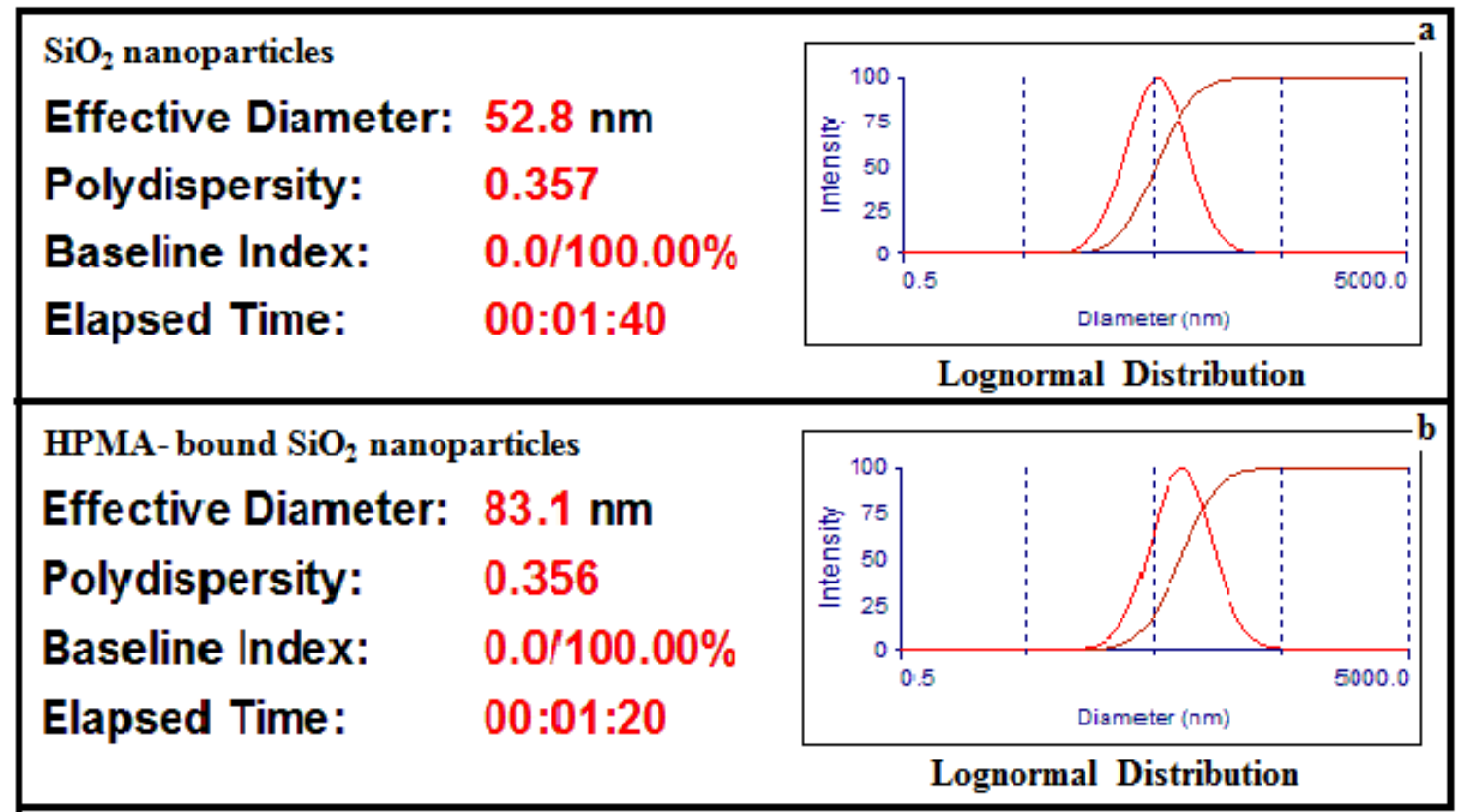

Figure 4.3 Dynamic light scattering measurements to determine the lognormal distribution of (a) $\mathrm{SiO}_{2}$ nanoparticles and (b) HPMA-bound $\mathrm{SiO}_{2}$ nanoparticles.

\subsubsection{Selectivity of HPMA binding with $\mathrm{SiO}_{2}$ and $\mathrm{TiO}_{2}$ nanoparticles}

HPMA selectively interacted with colloidal $\mathrm{SiO}_{2}$ NPs to produce a larger CE-UV peak at a slightly shorter migration time. It did not interact with $\mathrm{TiO}_{2} \mathrm{NPs}$ in aqueous suspension, resulting in no change of the CE-UV peak area or migration time. This chemical method could allow us to analyze an aqueous sample containing the two kinds of NPs, simply by adding HPMA and repeating the CE-UV analysis to observe any peak changes. A sample injection time of $3 \mathrm{~s}$ was used to maximize the resolution between different kinds of NPs. Initially, $\mathrm{SiO}_{2} \mathrm{NPs}(20 \mathrm{~g} / \mathrm{L})$ produced a small peak (at $\left.9.4 \pm 0.1 \mathrm{~min}\right)$ with substantial overlap with the $\mathrm{TiO}_{2} \mathrm{NPs}(1 \mathrm{~g} / \mathrm{L})$ peak (at $\left.8.6 \pm 0.1 \mathrm{~min}\right)$. After $3 \mathrm{~mL}$ of HPMA were added, the HPMA-bound $\mathrm{SiO}_{2}$ NPs moved ahead to appear as a sharp peak (at $8.4 \pm 0.1 \mathrm{~min}$ ) that could be readily quantified on top of the $\mathrm{TiO}_{2}$ NPs peak (still at $8.6 \pm 0.1 \mathrm{~min})$. Thus the chemical method was proven to be capable of identifying $\mathrm{SiO}_{2}$ 
NPs and quantifying them with enhanced sensitivity.

\subsubsection{Coating of silica and titania nanoparticles with chitosan}

Chitosan is a natural polysaccharide consisting of repeated glucosamine and Nacetyl-glucosamine units. It is multi-functional having hydroxyl, amino, and acetylamino groups. Although the main chain is hydrophilic, chitosan shows a slight degree of hydrophobic behavior due to the presence of $\mathrm{N}$-acetyl groups. The intra and intermolecular hydrogen bonds (due to the presence of $\mathrm{OH}$ and $\mathrm{NH}_{2}$ groups along the chitosan backbone) and hydrophobic interactions contribute to chitosan self-assembly into nanoaggregates. There are two types of chitosan self-assembly; the first one happening in aqueous solution wherein chitosan can self-assemble into nano-aggregates easily by direct dissolution with slight stirring. The other type occurs at the liquid/solid interface, wherein templates are involved to trigger the self-assembly of chitosan. Coating of $\mathrm{SiO}_{2}$ NPs with chitosan, as represented in the schematic shown in Fig. 4.4, was next investigated.

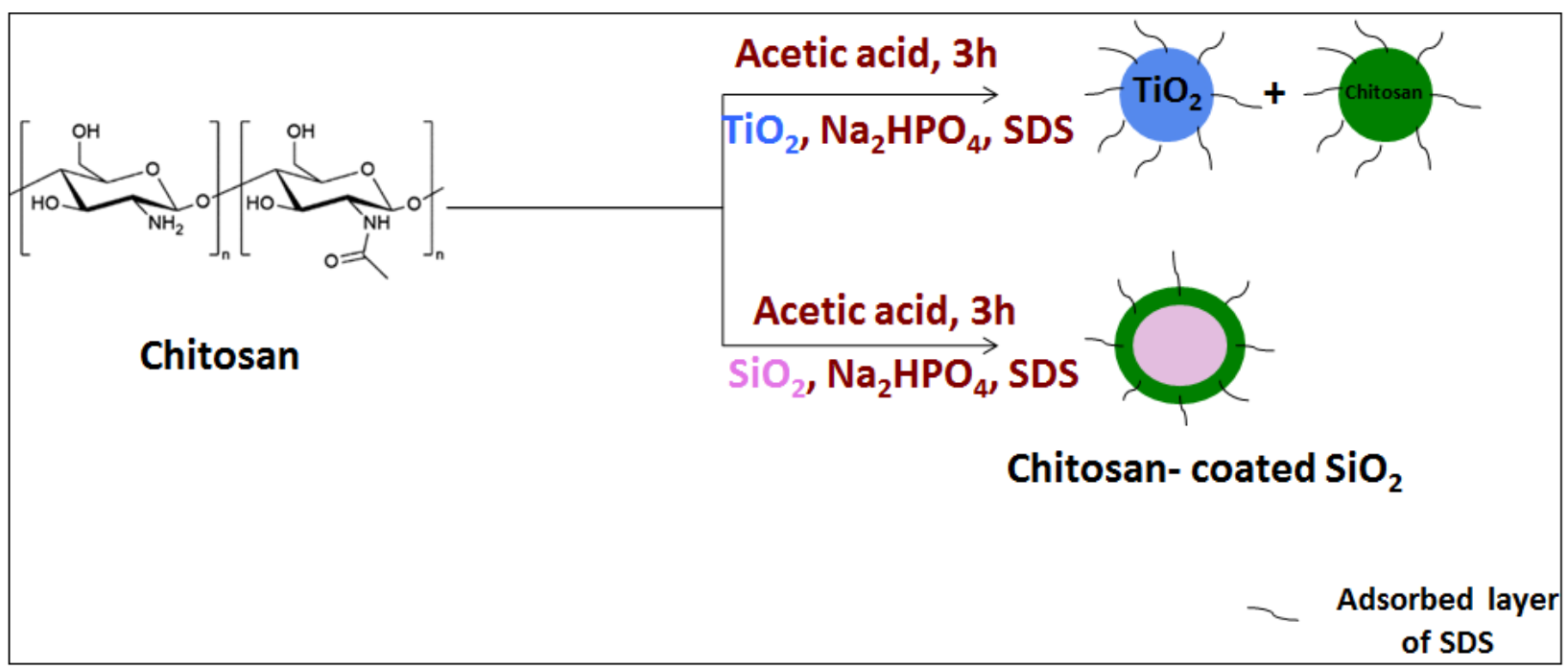

Figure 4.4 Schematic representation of chitosan coating on $\mathrm{SiO}_{2}$ in the presence of $\mathrm{TiO} 2$. 
A significant increase in hydrodynamic diameter, from $53 \pm 3 \mathrm{~nm}$ for $\mathrm{SiO}_{2}$ particles to $513 \pm 30 \mathrm{~nm}$ for chitosan-coated $\mathrm{SiO}_{2}$ particles (at $20 \mathrm{~g} / \mathrm{L}$ ) was observed, as shown in Table 4.1. The hydrodynamic diameter of chitosan-coated $\mathrm{SiO}_{2}$ particles was also larger than that of chitosan $(470 \pm 9 \mathrm{~nm})$. Electrostatic and hydrogen bonding interactions between chitosan amino groups and silanol groups enabled the encapsulation process. [183] On the contrary, DLS measurement of the hydrodynamic diameter of chitosan in the presence and absence of $\mathrm{TiO}_{2}$ NPs showed no significant difference, indicating no possible coating of $\mathrm{TiO}_{2} \mathrm{NPs}$ occurred.

Analysis of chitosan-coated $\mathrm{SiO}_{2}$ particles by $\mathrm{CE}-\mathrm{UV}$ failed badly because chitosan interacted with the capillary inner wall via electrostatic attraction, reducing the electroosmotic flow (EOF) significantly. 
Table 4.1 DLS analysis to determine the hydrodynamic diameters of different particles, followed by calculation of the HPMA thickness.

\begin{tabular}{|c|c|c|c|c|}
\hline Particles & $\begin{array}{l}\text { Hydrodynamic } \\
\text { Diameter }(\mathrm{nm})\end{array}$ & $\begin{array}{c}\text { HPMA } \\
\text { Thickness } \\
\text { (nm) }\end{array}$ & $\begin{array}{c}\text { Coating } \\
\text { Thickness } \\
\text { (nm) }\end{array}$ & $\begin{array}{l}\text { Polydispersity } \\
\text { Index } \\
\text { (PDI) }\end{array}$ \\
\hline $\mathrm{SiO}_{2}$ & $53 \pm 3$ & --- & --- & 0.357 \\
\hline $\begin{array}{c}\text { HPMA-bound } \\
\mathrm{SiO}_{2}\end{array}$ & $83 \pm 13$ & 15 & --- & 0.356 \\
\hline $\mathrm{TiO}_{2}$ & $155 \pm 6$ & --- & --- & 0.319 \\
\hline $\begin{array}{l}\mathrm{HPMA}-\mathrm{TiO}_{2} \\
\text { mixture }\end{array}$ & $154 \pm 5$ & 0 & --- & 0.323 \\
\hline Chitosan & $470 \pm 9$ & --- & --- & 0.322 \\
\hline $\begin{array}{c}\text { HPMA-bound } \\
\text { chitosan } \\
\text { (HPMA at } 0.05 \% \\
\text { to } 0.1 \% \mathrm{v} / \mathrm{v})\end{array}$ & $\begin{array}{l}411 \pm 10 \text { to } \\
509 \pm 12\end{array}$ & -30 to +20 & --- & $0.132-0.280$ \\
\hline $\begin{array}{l}\text { Chitosan-coated } \\
\mathrm{SiO}_{2}\end{array}$ & $513 \pm 30$ & --- & 230 & 0.343 \\
\hline $\begin{array}{c}\text { HPMA-bound } \\
\text { chitosan-coated } \\
\mathrm{SiO}_{2} \\
\text { (HPMA at } 0.05 \% \\
\text { to } 0.1 \% \mathrm{v} / \mathrm{v} \text { ) }\end{array}$ & $\begin{array}{c}417 \pm 17 \text { to } \\
440 \pm 12\end{array}$ & -48 to -37 & --- & $0.322-0.338$ \\
\hline $\begin{array}{l}\text { Chitosan- } \mathrm{TiO}_{2} \\
\text { mixture }\end{array}$ & $477 \pm 11$ & --- & --- & 0.300 \\
\hline $\begin{array}{c}\text { HPMA-bound } \\
\text { chitosan- } \mathrm{TiO}_{2} \\
\text { mixture } \\
\text { (HPMA at } 0.05 \% \\
\text { to } 0.1 \% \mathrm{v} / \mathrm{v} \text { ) }\end{array}$ & $\begin{array}{c}416 \pm 11 \text { to } \\
514 \pm 8\end{array}$ & -31 to +19 & --- & $0.122-0.288$ \\
\hline
\end{tabular}

\subsubsection{HPMA binding with chitosan-coated silica nanoparticles}

Afterwards, the interaction of HPMA with chitosan-coated $\mathrm{SiO}_{2}$ particles was investigated in the hope of covering up chitosan surface to prevent its interaction with the capillary inner wall. Initially the hydrodynamic diameter of the chitosan-coated $\mathrm{SiO}_{2}$ particles decreased to $417 \pm 17 \mathrm{~nm}$. One plausible reason for the reduction in the hydrodynamic diameter of chitosan-coated $\mathrm{SiO}_{2}$ particles upon HPMA binding is that 
HPMA disturbed the natural agglomeration tendency of chitosan. [184]. Further addition of HPMA, however, changed the hydrodynamic diameter to $440 \pm 12 \mathrm{~nm}$. Similarly, HPMA (at $0.05 \% \mathrm{v} / \mathrm{v}$ ) interacted with chitosan NPs decreasing their hydrodynamic diameter from $470 \pm 9 \mathrm{~nm}$ to $411 \pm 10 \mathrm{~nm}$. However, further addition of HPMA (at $0.1 \%$ $\mathrm{v} / \mathrm{v}$ ) increased their hydrodynamic diameter to $509 \pm 12 \mathrm{~nm}$.

A significant increase in peak area was observed after HPMA $(0.03 \% \mathrm{v} / \mathrm{v})$ bound to chitosan-coated $\mathrm{SiO}_{2}$ particles. More importantly, after HPMA binding, CE-UV analysis could be performed with no disturbance of the EOF. Fig. 4.5 shows the improved detection of HPMA-bound chitosan-coated $\mathrm{SiO}_{2}$ particles. Upon varying the $\mathrm{SiO}_{2}$ concentration in chitosan suspension, the resultant HPMA-bound chitosan-coated $\mathrm{SiO}_{2}$ peak area changed accordingly as shown in Fig. 4.6. A significant total enhancement of $50 \pm 1$ fold in detection sensitivity was attained by coating $\mathrm{SiO}_{2} \mathrm{NPs}$ with chitosan followed by HPMA binding. This high enhancement factor could be attributed to the significant increase in $\mathrm{SiO}_{2}$ size as a result of the template triggered self-assembly of chitosan. This result is better than the enhancement of $12 \pm 2$ fold previously attained by using both PHPMA and PDA coatings. In addition, no chemical initiator is needed for this technique, which does not involve in-situ polymerization. 


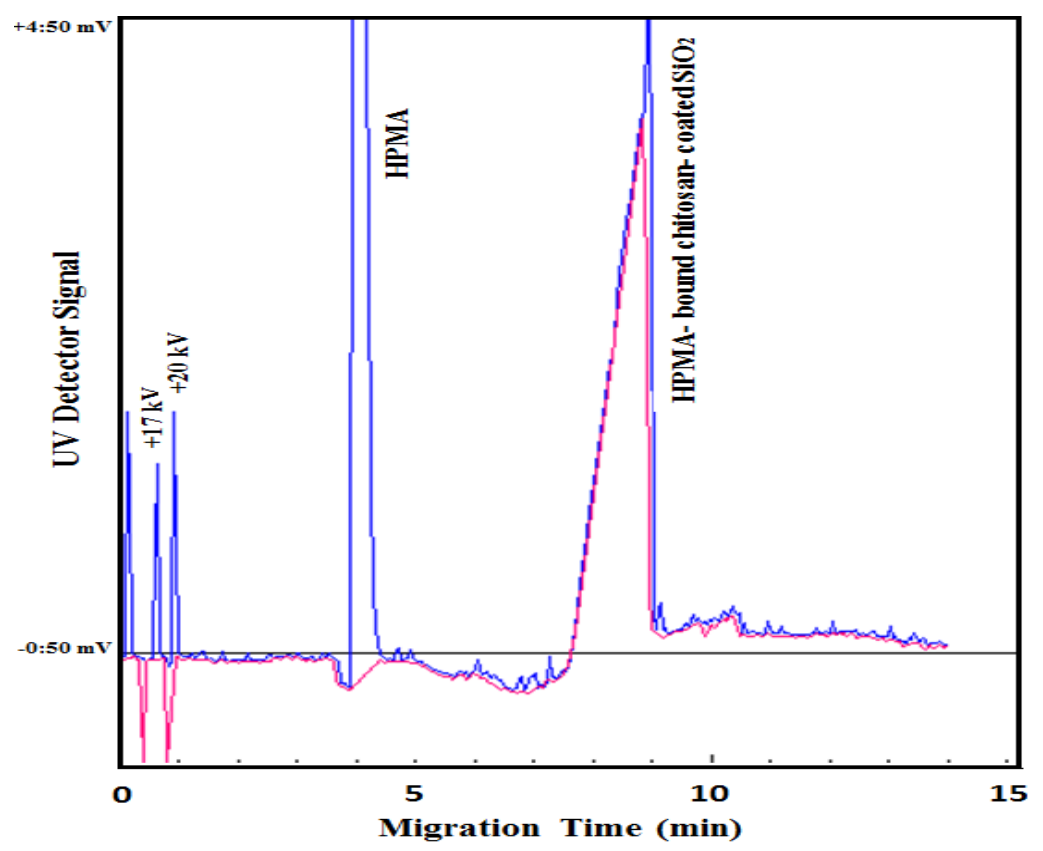

Figure 4.5 CE-UV characterization of HPMA-bound chitosan-coated $\mathrm{SiO}_{2}$ particles.

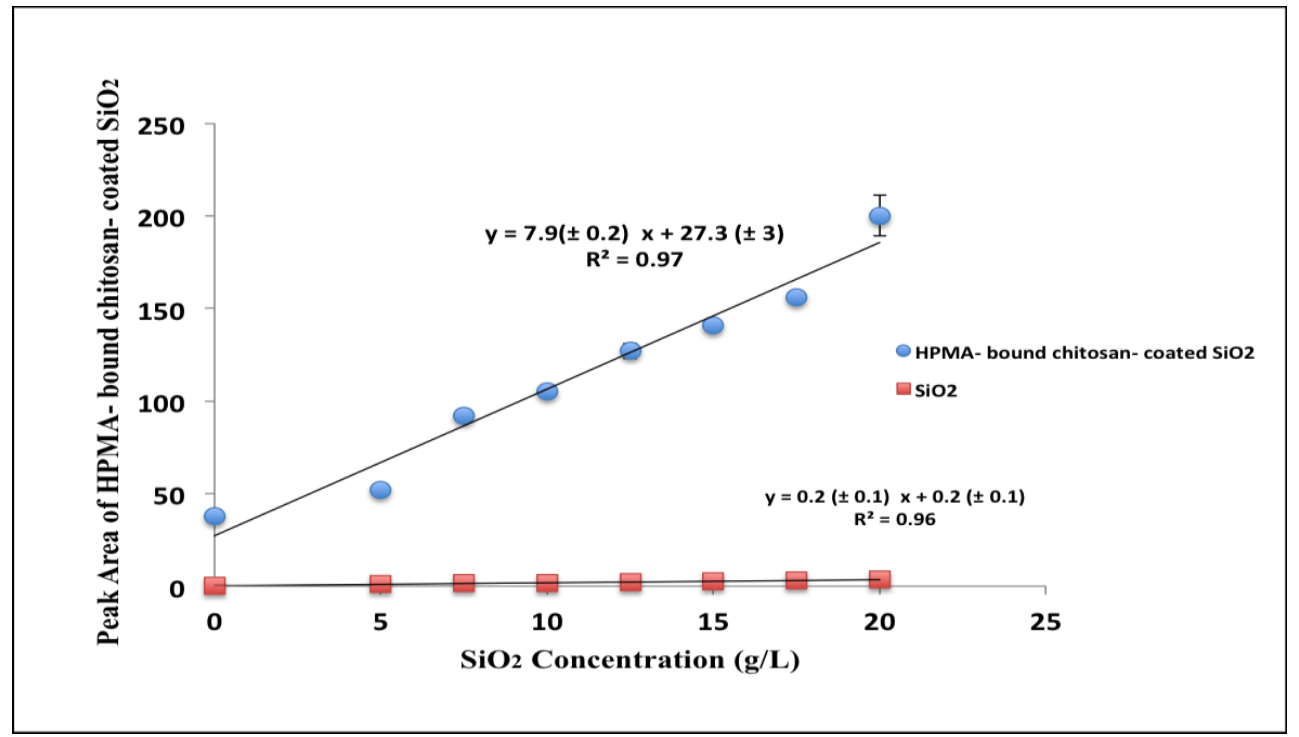

Figure 4.6 HPMA-bound chitosan-coated $\mathrm{SiO}_{2}$ peak areas obtained for different $\mathrm{SiO}_{2}$ concentrations.

However, CE-UV analysis of HPMA-bound chitosan in the presence of $\mathrm{TiO}_{2} \mathrm{NPs}$ showed no sign of interaction, as no change in their peak areas was observed. $\mathrm{TiO}_{2} \mathrm{NPs}$ strongly adsorb phosphate anions [185] present in the $10 \mathrm{mM} \mathrm{Na} \mathrm{HPO}_{4}$ medium, possibly forming a layer surrounding the NPs that prevented their interaction with 
HPMA-bound chitosan. These results confirmed the obtained DLS data and demonstrated the selectivity of the method towards $\mathrm{SiO}_{2}$ in the presence of $\mathrm{TiO}_{2}$ as illustrated in Fig. 4.7.

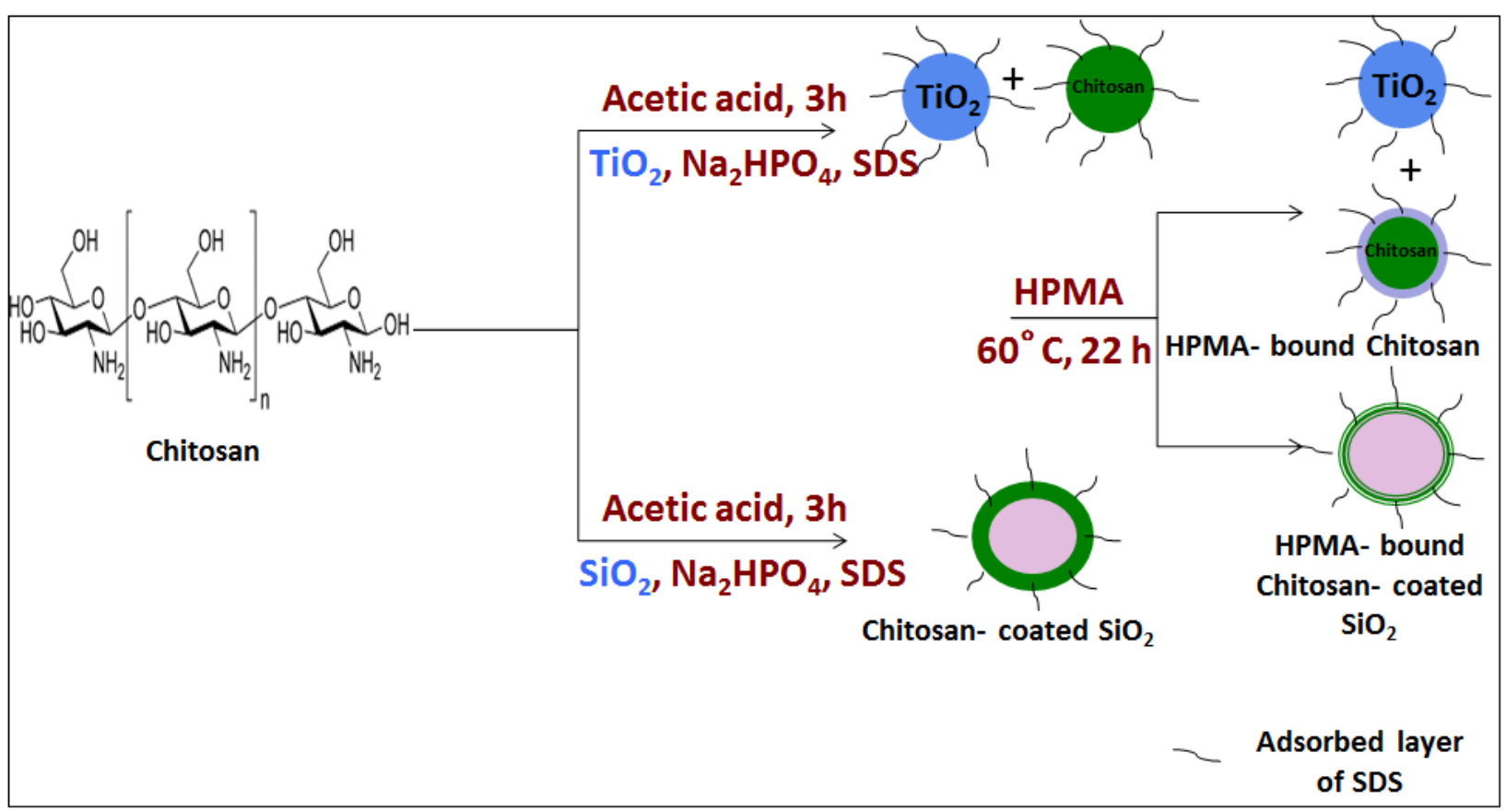

Figure 4.7 Schematic representation of selective binding of HPMA to chitosan-coated $\mathrm{SiO}_{2}$ in the presence of $\mathrm{TiO}_{2}$.

Apparently, $\mathrm{SiO}_{2}$ NPs can be made larger in size by interaction with HPMA alone and even larger after coating with chitosan under very simple experimental conditions offering more sensitive detection of $\mathrm{SiO}_{2} \mathrm{NPs}$ in water by $\mathrm{CE}-\mathrm{UV}$ analysis. 


\subsection{Conclusions}

A simple and inexpensive method for the detection of NPs, which are a burden in aquatic ecosystem, has been successfully developed. HPMA and chitosan interacted with colloidal $\mathrm{SiO}_{2}$ NPs to produce larger sizes for more sensitive detection by CE-UV. They, however, did not interact with $\mathrm{TiO}_{2} \mathrm{NPs}$ in $10 \mathrm{mM} \mathrm{Na}_{2} \mathrm{HPO}_{4}$, resulting in no change of the CE-UV detection sensitivity of $\mathrm{TiO}_{2}$ NPs. This chemical technique allows the analysis of an aqueous sample containing $\mathrm{SiO}_{2}$ and $\mathrm{TiO}_{2} \mathrm{NPs}$, both qualitatively and quantitatively, simply by adding chitosan and HPMA to observe any CE-UV peak enhancement. HPMA interaction is time-saving as less than 22 hours can be used to reach a binding equilibrium with the NPs. Chitosan coating on $\mathrm{SiO}_{2} \mathrm{NPs}$ produced a significant increase in their hydrodynamic diameter to $513 \pm 30 \mathrm{~nm}$. Subsequent HPMA binding facilitated the CE-UV analysis without causing disturbance of the EOF. A total enhancement of $50 \pm 1$ fold in detection sensitivity was attained by coating $\mathrm{SiO}_{2}$ NPs with chitosan followed by HPMA binding. The new detection limit is estimated at $0.06 \mathrm{~g} / \mathrm{L}$ for $\mathrm{SiO}_{2}$. Only NPs, but not organic compounds, would change in area and migration time after binding to HPMA or coating with chitosan. No chemical initiator is required, unlike what we reported previously using the in-situ polymerization to attain coating with PHPMA.

\subsection{Connection to chapter 5}

A promising enhancement of $50 \pm 1$ fold in UV detection sensitivity along with the complete coating of $\mathrm{SiO}_{2}$ NPs using chitosan and HPMA overcame the encountered challenges. The method applied in this chapter was selective towards $\mathrm{SiO}_{2}$ in the presence of $\mathrm{TiO}_{2}$. Nonetheless, the LOD is not quite satisfactory for environmental water analysis 
of NPs. Hence, deoxyribonucleic acid binding followed by polyethylene glycol coating of $\mathrm{Al}_{2} \mathrm{O}_{3}, \mathrm{SiO}_{2}, \mathrm{TiO}_{2}$, and $\mathrm{ZnO}$ NPs are ensued in Chapter 5 to optimize the LOD of NPs in CE-UV analysis. 


\section{Chapter 5: Electrosteric Stabilization of Colloidal TiOz Nanoparticles with DNA and Polyethylene Glycol for Selective Enhancement of UV Detection Sensitivity in Capillary Electrophoresis Analysis}

Modified from original manuscript, published as:

Alsudir S, Lai EPC.* "Electrosteric Stabilization of Colloidal $\mathrm{TiO}_{2}$ Nanoparticles with DNA and Polyethylene Glycol for Selective Enhancement of UV Detection Sensitivity in Capillary Electrophoresis Analysis", Anal Bioanal Chem. 2017,409,1857-1868.

*Department of Chemistry, Carleton University, Ottawa, ON, K1S 5B6, Canada

\subsection{Abstract}

A new approach to selectively enhance the UV detection sensitivity of $\mathrm{TiO}_{2}$, albeit in the presence of $\mathrm{SiO}_{2}, \mathrm{Al}_{2} \mathrm{O}_{3}$ and $\mathrm{ZnO}$, NPs in $\mathrm{CE}$ analysis was developed. Interactions of Triton X-100 (TX-100), polyethylene glycol (PEG), deoxyribonucleic acid (DNA) with $\mathrm{TiO}_{2}$ NPs produced larger CE-UV peaks at various enhancement factors. Single-stranded DNA (ssDNA) was a more effective adsorbate than double-stranded DNA (dsDNA) due to its flexible molecular structure that participated in a stronger interaction with $\mathrm{TiO}_{2}$ NPs via its sugar-phosphate backbone. Disaggregation of $\mathrm{TiO}_{2} \mathrm{NPs}$ upon DNA binding due to electrosteric stabilization was validated using dynamic light scattering. PEG coating of DNA- $\mathrm{TiO}_{2} \mathrm{NPs}$ further enhanced the UV detection sensitivity in $\mathrm{CE}$ analysis by providing extra electrosteric stabilization. This analytical technique, which involves binding of $\mathrm{TiO}_{2}$ NPs with DNA followed by coating with PEG, has allowed us to achieve progressively an enhancement factor up to $13 \pm 3$ fold in analytical sensitivity for the accurate determination of $\mathrm{TiO}_{2} \mathrm{NPs}$. 


\subsection{Introduction}

Strong interactions between human DNA and $\mathrm{TiO}_{2}$ NPs were evidenced by both a hyperchromic effect in UV-visible spectroscopy and a marked decrease in fluorescence spectral characteristics. [186] A direct chemical interaction between $\mathrm{TiO}_{2}$ NPs and DNA through the phosphate group has been reported. [187,188]

In this chapter, we investigated the binding interaction between $\mathrm{TiO}_{2} \mathrm{NPs}$ and DNA for potential enhancement of their UV detection sensitivity in CE analysis. Additional enhancement was explored by further interaction with PEG. Previous investigations had found that the molecular size of PEG could affect the thermal stability of DNA triplex and duplexes of varying nucleotide lengths. [189,190] Another study had demonstrated that the hydrocarbon chains of PEG promoted hydrophobic interactions with DNA nucleobases to enhance the formation of nanosized DNA. [191] Our work attempted to disaggregate $\mathrm{TiO}_{2}$ NPs for quantitative UV detection at a specific migration time in a qualitative $\mathrm{CE}$ analysis. Their selective interaction with DNA, followed by coating with PEG, attains one order-of-magnitude enhancement in the analytical sensitivity of CE-UV determination. Disaggregation via electrosteric stabilization also ensures higher accuracy in the determination of $\mathrm{TiO}_{2}$ as individual NPs, rather than aggregates or agglomerates. 


\subsection{Methods}

\subsubsection{Triton $\mathrm{X}-100$ adsorption onto $\mathrm{TiO}_{2}$ nanoparticles}

Triton X-100 (2\% v/v) was added to $\mathrm{TiO}_{2}$ NPs suspended in $100 \mathrm{mM}$ Tris at different concentrations $(0.05-2.5 \mathrm{mg} / \mathrm{mL})$. The mixtures were sonicated for $30 \mathrm{~min}$ before analysis by CE with UV detection at $280 \mathrm{~nm}$. Triton X-100 adsorption onto $\mathrm{SiO}_{2}$, $\mathrm{Al}_{2} \mathrm{O}_{3}$ and $\mathrm{ZnO}$ NPs was also examined.

\subsubsection{DNA binding to $\mathrm{TiO}_{2}$ nanoparticles}

Double- or single-stranded DNA from salmon testes was used. The concentrated ssDNA solution was boiled for 10 minutes and then cooled on ice for at least 5 minutes prior to use in order to reduce the chances of reannealing. $\mathrm{TiO}_{2} \mathrm{NPs}$ were added to a DNA solution $(0.5 \mathrm{mg} / \mathrm{mL})$ in $100 \mathrm{mM}$ Tris with increasing concentrations $(0.05-12.5$ $\mathrm{mg} / \mathrm{mL}$ ). Each mixture was sonicated for $30 \mathrm{~min}$ before analysis by CE with UV detection at $260 \mathrm{~nm}$. Further examination of DNA binding to $\mathrm{SiO}_{2}, \mathrm{Al}_{2} \mathrm{O}_{3}$ and $\mathrm{ZnO}$ NPs was also investigated.

\subsubsection{PEG coating on $\mathrm{TiO}_{2}$ and $\mathrm{DNA}-\mathrm{TiO}_{2}$ nanoparticles}

PEG was added to $\mathrm{TiO}_{2}, \mathrm{SiO}_{2}, \mathrm{Al}_{2} \mathrm{O}_{3}$ and $\mathrm{ZnO}$ as well as $\mathrm{DNA}-\mathrm{TiO}_{2}$ suspensions (at 2:1 w/w ratio). Each mixture was stirred for 2 hours before analysis by CE with UV detection at $260 \mathrm{~nm}$.

\subsection{Results and discussion}

\subsubsection{Triton $\mathrm{X}-100$ adsorption onto $\mathrm{TiO}_{2}$ nanoparticles}

Triton X-100 (TX-100) is a non-ionic surfactant consisting of a hydrophilic polyethylene oxide chain and a hydrophobic phenyl group. It is well established in bioanalytical chemistry that TX-100 adsorption onto NPs often results in enhanced 
colloid stability. [192] As the phenyl group strongly absorbs UV light at $280 \mathrm{~nm}$, this surfactant was selected to investigate whether it could enhance the UV detection sensitivity of $\mathrm{TiO}_{2}$ in $\mathrm{CE}$ analysis. TX-100 in $100 \mathrm{mM}$ Tris gave a sharp peak at a migration time of 2.8 min, just after the neutral marker $\mathrm{MO}$, indicating its slightly negative charge in the $\mathrm{BGE}$. $\mathrm{TiO}_{2}$ NPs in $100 \mathrm{mM}$ Tris were separated into two or three peaks appearing around the migration time of $4.2 \mathrm{~min}$. Multiple peaks of $\mathrm{TiO}_{2} \mathrm{NPs}$ could be attributed to the effect of the co- and counter-ion in the buffer solution, influencing the peak shape of $\mathrm{TiO}_{2}$. Another doable explanation is that $\mathrm{TiO}_{2}$ sample contains a population of NPs of various sizes as confirmed by the multimodal size distribution of $\mathrm{TiO}_{2}$ obtained by DLS measurement. CE can separate $\mathrm{TiO}_{2} \mathrm{NPs}$ to several peaks based on their different sizes. Hence, those peak areas were added together to construct a plot of total peak area versus concentration of $\mathrm{TiO}_{2}$ NPs. As shown in Fig. 5.1, a linear calibration curve was obtained using $280 \mathrm{~nm}$ for UV detection. The limit of detection (LOD) and the limit of quantification (LOQ) of $\mathrm{TiO}_{2} \mathrm{NPs}$ were determined to be $0.06 \mathrm{mg} / \mathrm{mL}$ and $0.18 \mathrm{mg} / \mathrm{mL}$, respectively. CE-UV analysis of the $\mathrm{TX}-100-\mathrm{TiO}_{2}$ NPs showed an increase in the total peak area after TX-100 adsorption. 


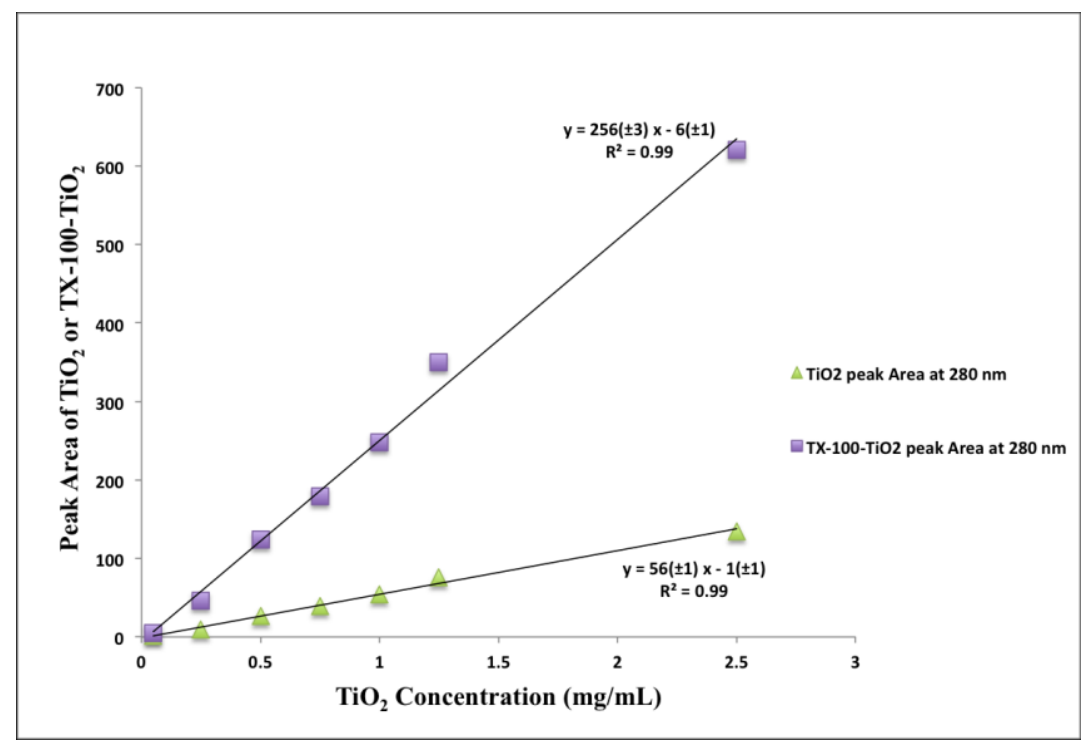

Figure 5.1 Enhancement of UV detection sensitivity in CE analysis at $280 \mathrm{~nm}$ after adding TX-100 to $\mathrm{TiO}_{2}$ nanoparticles suspended in $100 \mathrm{mM}$ Tris.

Triton X-100 had traditionally been used to fully disperse $\mathrm{TiO}_{2} \mathrm{NPs}$ due to its strong adsorption, which is independent of the ionic strength. [193,194] With a steeper slope of $\sim 256$, the enhancement factor was approximately $4.6 \pm 0.1$ fold using $280 \mathrm{~nm}$ for UV detection of TX-100- $\mathrm{TiO}_{2}$ NPs. 


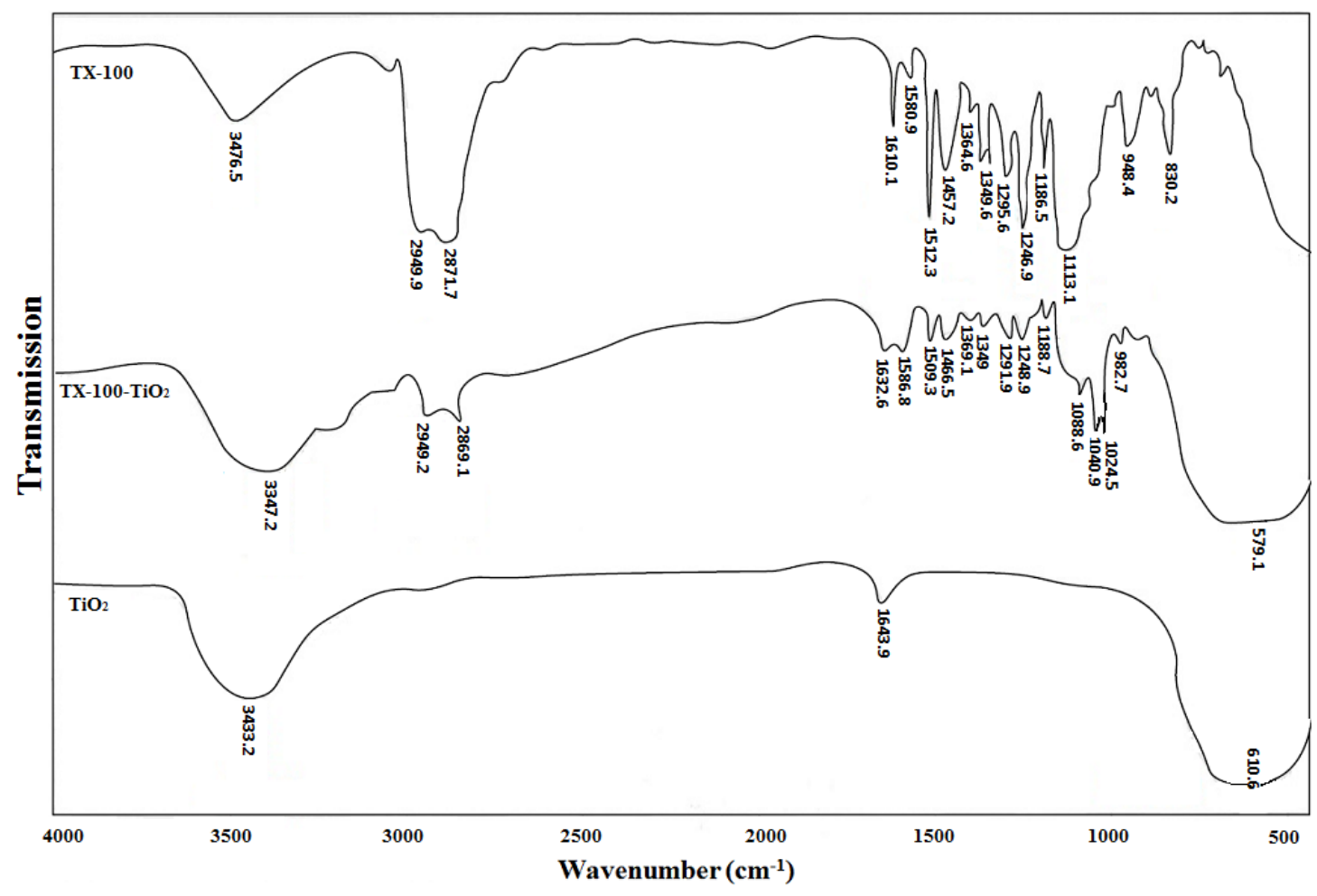

Figure 5.2 FTIR spectra of $\mathrm{TiO}_{2}, \mathrm{TX}-100-\mathrm{TiO}_{2}$ and $\mathrm{TX}-100$.

Strong adsorption of TX-100 onto $\mathrm{TiO}_{2}$ NPs was confirmed by the FTIR spectra shown in Fig. 5.2. Many TX-100 peaks from between 948 and $1580 \mathrm{~cm}^{-1}$ appear in the TX-100- $\mathrm{TiO}_{2}$ spectrum. Notably, the $\mathrm{v}(\mathrm{C}-\mathrm{O})$ stretching vibration of TX-100 at $1113 \mathrm{~cm}^{-1}$ shifted to a lower wavenumber upon adsorption onto a $\mathrm{TiO}_{2}$ surface. In addition, the TX$100-\mathrm{TiO}_{2}$ spectrum showed bands at 2869-2949 and 1349-1466 $\mathrm{cm}^{-1}$ corresponding to the symmetric/asymmetric stretching and bending vibrations, respectively, of the $-\mathrm{CH}_{2}$ groups in TX-100.

The average hydrodynamic diameters of $\mathrm{TiO}_{2}, \mathrm{SiO}_{2}, \mathrm{Al}_{2} \mathrm{O}_{3}$ and $\mathrm{ZnO} \mathrm{NPs}$, as determined by DLS, were $447 \pm 22,76 \pm 3,591 \pm 27$ and $558 \pm 21 \mathrm{~nm}$, respectively. The diameters of these dry NPs, as determined by TEM, seem to be much smaller than the corresponding hydrodynamic diameters obtained by DLS measurement for NPs in 
aqueous suspensions. This is not totally surprising due to different principles behind each technique used. DLS measures Brownian motion of particles and calculate the size distribution to yield the mean hydrodynamic diameter that includes the diameter of the particle plus the hydration layers surrounding it, providing sizes greater than that observed for dry particles under vacuum in a TEM analysis. Also, variations in sample preparation may in principle introduce some incongruity when comparing results obtained from various techniques. [195] A wide range of primary particle sizes of $\mathrm{TiO}_{2}$ measured by TEM $(5,16,50$, and $100 \mathrm{~nm})$ had previously been evaluated by DLS. All particles tested were highly aggregated in aqueous solutions giving sizes above $1500 \mathrm{~nm}$. [196] Several factors highly contribute to the aggregation of NPs including composition, concentration, size, surface coating, zeta potential, sonication time, temperature, dispersant $\mathrm{pH}$, presence of serum, salt and/or surfactant. [197] All these parameters may provide a reasonable explanation for the discrepancy between the average size (and the size distribution) of NPs given by TEM versus DLS.

The average hydrodynamic diameters of $\mathrm{TiO}_{2}, \mathrm{SiO}_{2}, \mathrm{Al}_{2} \mathrm{O}_{3}$ and $\mathrm{ZnO}$ NPs after TX-100 addition were $330 \pm 16,79 \pm 4,595 \pm 28$ and $552 \pm 22 \mathrm{~nm}$, respectively. Apparently, TX-100 helped to electrostatically stabilize the colloidal $\mathrm{TiO}_{2}$ NPs by increasing the number of surface charges. [198] This strengthens the repulsion forces between the NPs and hampers their aggregation (to form dimers, trimers, tetramers and pentamers), thus resulting in a decrease of the average hydrodynamic diameter for the TX-100- $\mathrm{TiO}_{2} \mathrm{NPs}$.

In comparison, TX-100 did not seem to adsorb onto $\mathrm{SiO}_{2} \mathrm{NPs}$ as no change in $\mathrm{SiO}_{2}$ peak area or height was observed by CE-UV analysis. Also, no significant change 
was observed in the peak areas for $\mathrm{Al}_{2} \mathrm{O}_{3}$ or $\mathrm{ZnO}$ NPs and only a slight increase in their peak heights was noticeable. DLS measurements validated the CE-UV results, showing no significant changes in the hydrodynamic diameters of $\mathrm{SiO}_{2}, \mathrm{Al}_{2} \mathrm{O}_{3}$ and $\mathrm{ZnO} \mathrm{NPs}$ after TX-100 addition. This indicated that TX-100 adsorption could not take place.

The present work demonstrated, for the first time to our knowledge, a new benefit of sensitivity enhancement by $4.6 \pm 0.1$ fold using the $\lambda_{\max }$ of $280 \mathrm{~nm}$ for TX-100 detection to determine TX-100- $\mathrm{TiO}_{2}$ NPs. This enhanced sensitivity could be used as a reference point for us to pursue further enhancement via the binding interaction of $\mathrm{TiO}_{2}$ NPs with DNA and PEG.

\subsubsection{Double-stranded DNA binding to $\mathrm{TiO}_{2}$ nanoparticles}

DNA is a long double-stranded biopolymer with each strand comprising a unique combination of four nucleotides to carry genetic information. Each nucleotide consists of a purine or pyrimidine base (adenine, guanine, thymine, or cytosine) associated with a deoxyribose sugar molecule and a phosphate group. Sperm cells from salmon testes are a good source for non-mammalian DNA. Salmon sperm DNA can be used to study the physicochemical interactions of DNA with various binding agents, intercalation agents, modification agents, detection agents and compaction agents, biomolecules as well as NPs. An adsorption test of dsDNA $(0.5 \mathrm{mg} / \mathrm{mL})$ was performed with increasing concentrations of $\mathrm{TiO}_{2}$ NPs $(0.05-12.5 \mathrm{mg} / \mathrm{mL})$ in $100 \mathrm{mM}$ Tris. CE-UV analysis using $260 \mathrm{~nm}$ for UV detection showed two or three peaks for $\mathrm{TiO}_{2}$ NPs around 4.2 min and one sharp peak for dsDNA at 6.2 min indicating their negative ionic charge in the BGE. The LOD and the LOQ of $\mathrm{TiO}_{2}$ NPs using $260 \mathrm{~nm}$ for UV detection were determined to be $0.01 \mathrm{mg} / \mathrm{mL}$ and 
$0.03 \mathrm{mg} / \mathrm{mL}$, respectively. Adsorption of dsDNA produced increases in the peak area and height of $\mathrm{TiO}_{2} \mathrm{NPs}$ as well as the migration time from $4.2 \mathrm{~min}$ to $4.6 \mathrm{~min}$. As shown in Fig. 5.3, the peak areas were enhanced for all the concentrations of $\mathrm{TiO}_{2} \mathrm{NPs}$ studied up to $12.5 \mathrm{mg} / \mathrm{mL}$. As a result of dsDNA adsorption, the sensitivity was enhanced by $1.6 \pm 0.1$ fold using the $\lambda_{\max }$ of $260 \mathrm{~nm}$ for dsDNA detection and dsDNA- $\mathrm{TiO}_{2}$ NPs determination. Thus, dsDNA was proven to be a good adsorbate for sensitivity enhancement in the determination of $\mathrm{TiO}_{2}$ NPs by the CE-UV method. UV detection of $\mathrm{TiO}_{2} \mathrm{NPs}$ was attempted at two other wavelengths (325 and $190 \mathrm{~nm}$ ) but the slopes were actually gentler. In comparison, dsDNA did not seem to adsorb onto $\mathrm{SiO}_{2} \mathrm{NPs}$ as no change in $\mathrm{SiO}_{2}$ peak area or height was observed by CE-UV analysis. A change in $\mathrm{Al}_{2} \mathrm{O}_{3}$ peak shape was seen, after dsDNA addition, from a sharp peak to a very small one probably due to the change in the surrounding environment. Upon addition of dsDNA to $\mathrm{ZnO}$ suspension and with continuous sonication for about $30 \mathrm{~min}, \mathrm{ZnO}$ NPs clustered together and some precipitated down the vial and the sample was no longer suitable for CE-UV analysis.

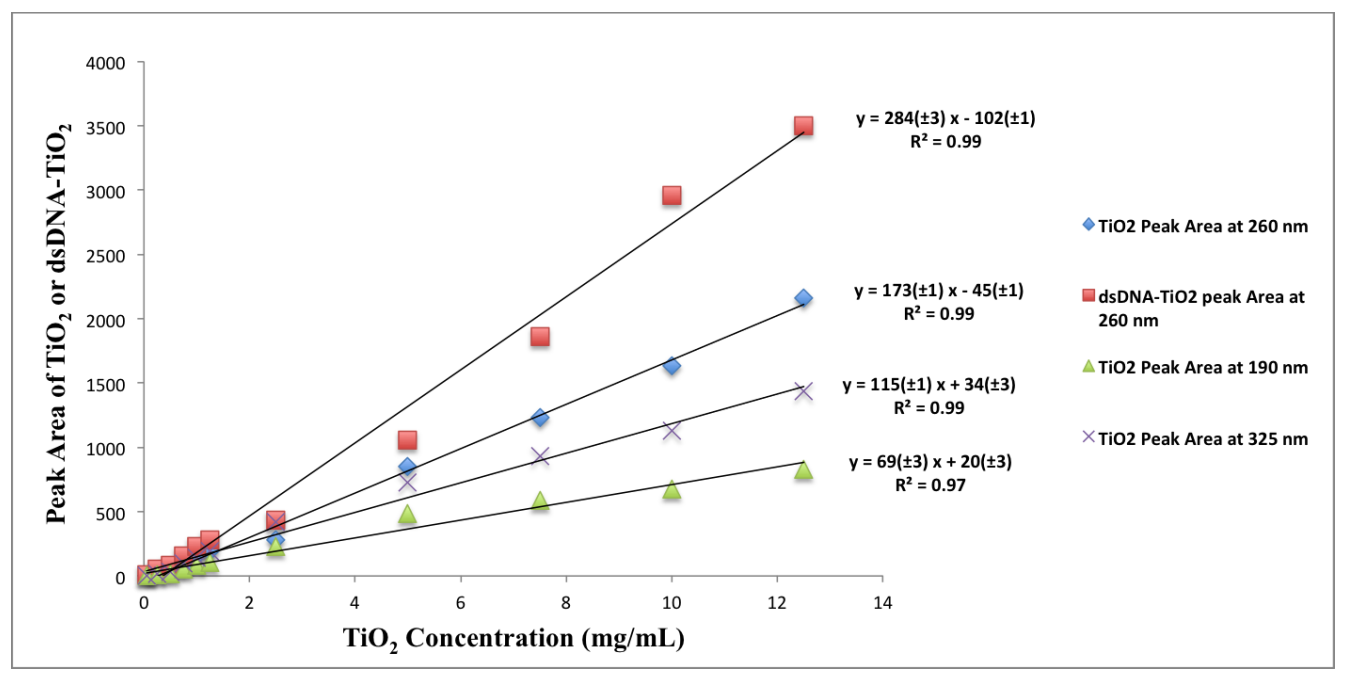

Figure 5.3 Enhancement of UV detection sensitivity in CE analysis after adding dsDNA to $\mathrm{TiO}_{2}$ nanoparticles suspended in $100 \mathrm{mM}$ Tris. 
Apparently, dsDNA helped to electrosterically stabilize the colloidal $\mathrm{TiO}_{2} \mathrm{NPs}$, reducing their hydrodynamic diameter down to $365 \pm 9 \mathrm{~nm}$. In comparison, dsDNA addition showed no significant change in the hydrodynamic diameters of $\mathrm{SiO}_{2}$ and $\mathrm{Al}_{2} \mathrm{O}_{3}$ NPs. However, dsDNA addition to $\mathrm{ZnO}$ NPs resulted in an increase in their hydrodynamic diameter to $1185 \pm 193 \mathrm{~nm}$, indicating the formation of clusters of larger aggregates. Binding of dsDNA onto $\mathrm{TiO}_{2} \mathrm{NPs}$ was confirmed by the FTIR spectra shown in Fig. 5.4

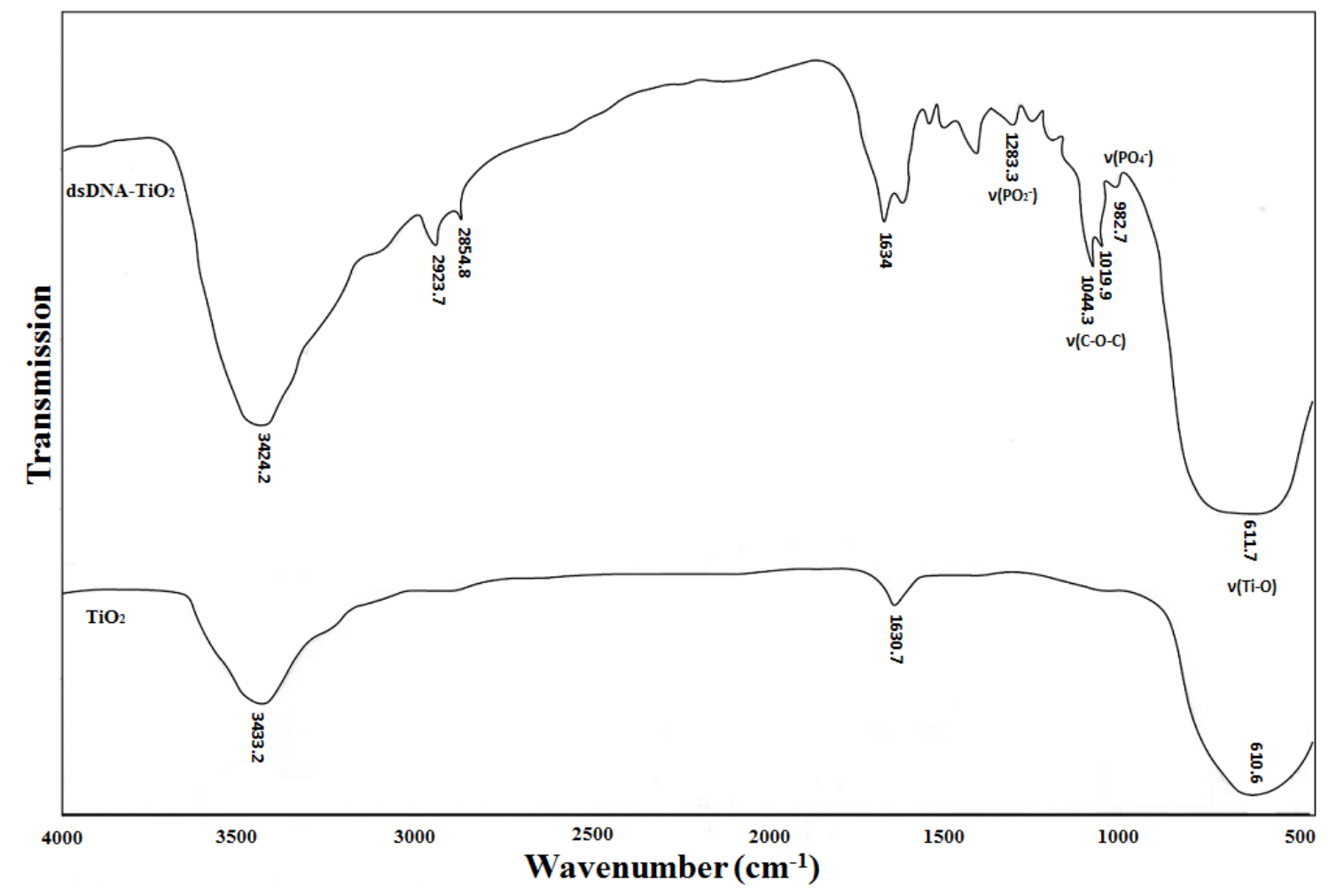

Figure 5.4 FTIR spectrum of $\mathrm{TiO}_{2}$ and dsDNA- $\mathrm{TiO}_{2}$ nanoparticles

Binding interaction took place via the phosphate backbone of dsDNA as indicated by a shift of the phosphate peaks from 967 to $982 \mathrm{~cm}^{-1}$ and from 1234 to $1283 \mathrm{~cm}^{-1}$. In addition, the dsDNA- $\mathrm{TiO}_{2}$ spectrum showed bands at $2854-2923$ and $1400-1500 \mathrm{~cm}^{-1}$ corresponding to the symmetric/asymmetric stretching and bending vibrations of the $-\mathrm{CH}_{2}$ 
groups, respectively. The peak at $1044 \mathrm{~cm}^{-1}$ corresponded to the C-O-C bond of deoxyribose [199], and $1019 \mathrm{~cm}^{-1}$ was assigned as a C-O-C stretching band from the carbohydrate component of dsDNA. [200]

\subsubsection{PEG coating of $\mathrm{TiO}_{2}$ and dsDNA-TiO 2 nanoparticles}

PEG is a coiled polymer of repeating ethylene ether units. It has been reported that PEG improves the stability of $\mathrm{TiO}_{2}$ in aqueous suspensions by increasing the steric distance along with improving the NPs hydrophilicity via hydrogen bonding formation between the ether repeating units and water molecules. [201,202] The polymer slightly absorbs UV light, exhibiting low detection sensitivity at wavelengths longer than $200 \mathrm{~nm}$. [203] In the present work PEG coating resulted in a significant increase of the $\mathrm{TiO}_{2}$ peak area and height while no change in the $\mathrm{TiO}_{2}$ migration time was observed, which suggests that only a thin coating of PEG was formed. An enhancement factor of $3.0 \pm 1.0$ was determined by comparing the $\mathrm{TiO}_{2}$ peak areas before and after PEG coating. One plausible reason is that PEG coating improved the stability of $\mathrm{TiO}_{2} \mathrm{NPs}$, preventing their aggregation (as confirmed by DLS analysis showing a hydrodynamic diameter of $255 \pm 7$ $\mathrm{nm}$ ) and thereby maximizing the absorption of UV light. In comparison, PEG addition to $\mathrm{SiO}_{2}, \mathrm{Al}_{2} \mathrm{O}_{3}$ and $\mathrm{ZnO}$ suspensions showed no change in the peak area or height of the NPs in CE-UV analyses as well as no significant changes to their hydrodynamic diameters, indicating that PEG coating could not take place.

PEG addition to the dsDNA- $\mathrm{TiO}_{2}$ suspensions resulted in a total of $5.5 \pm 1.5$ fold enhancement of CE-UV detection sensitivity of $\mathrm{TiO}_{2}$ as shown in Fig. 5.5d. 


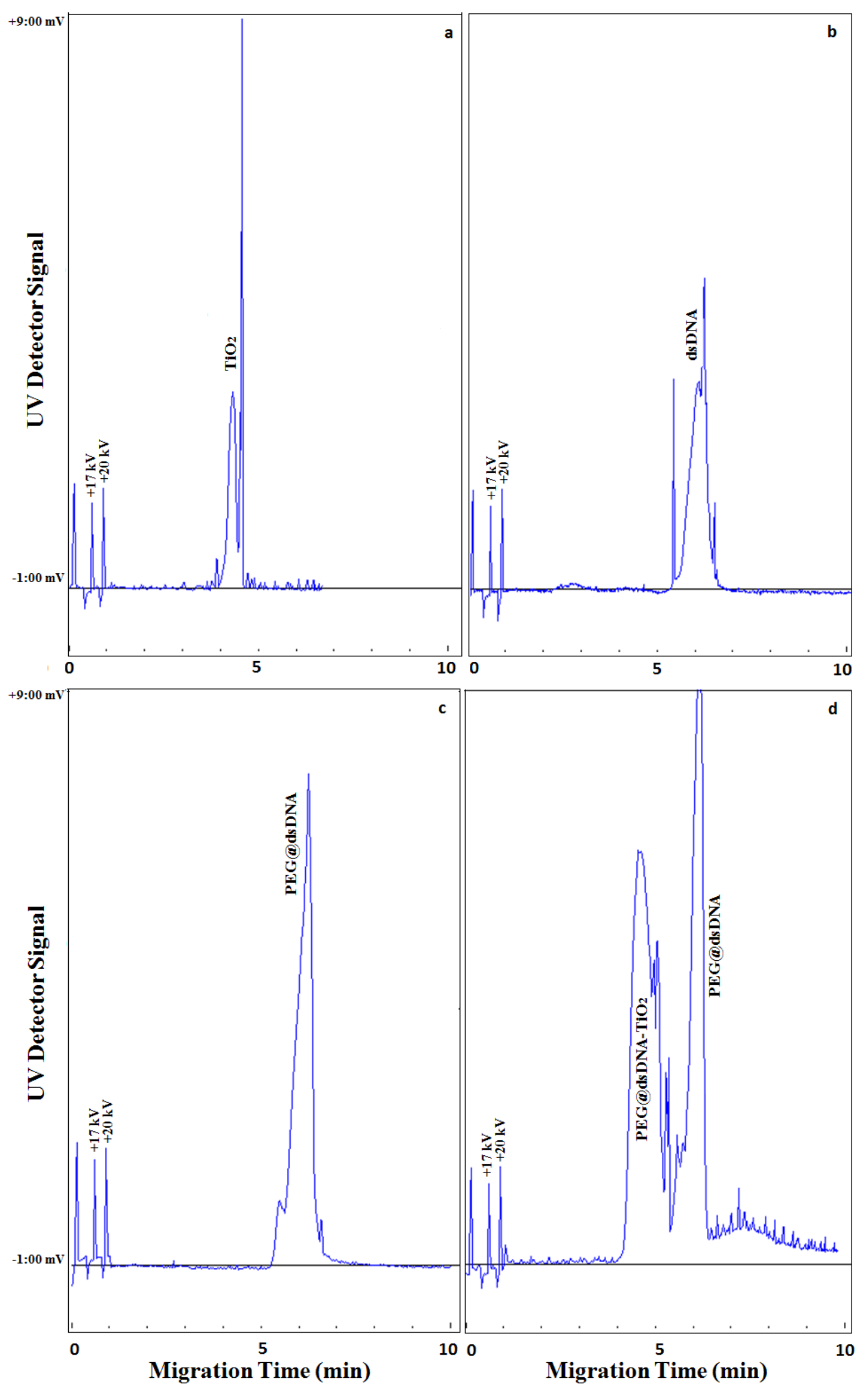

Figure 5.5 $\mathrm{CE}$ analysis, with UV detection at $260 \mathrm{~nm}$, of (a) $\mathrm{TiO}_{2}$ nanoparticles, (b) dsDNA (c) PEG@dsDNA and (d) $\mathrm{TiO}_{2}$ nanoparticles after dsDNA adsorption and PEG coating. 
CE-UV analyses of PEG@dsDNA and PEG@dsDNA-TiO 2 were also attempted at $325 \mathrm{~nm}$. At this wavelength, no peak can be seen for PEG@dsDNA, however; the PEG@dsDNA-TiO 2 peak can be detected as evidenced in Fig. 5.6.

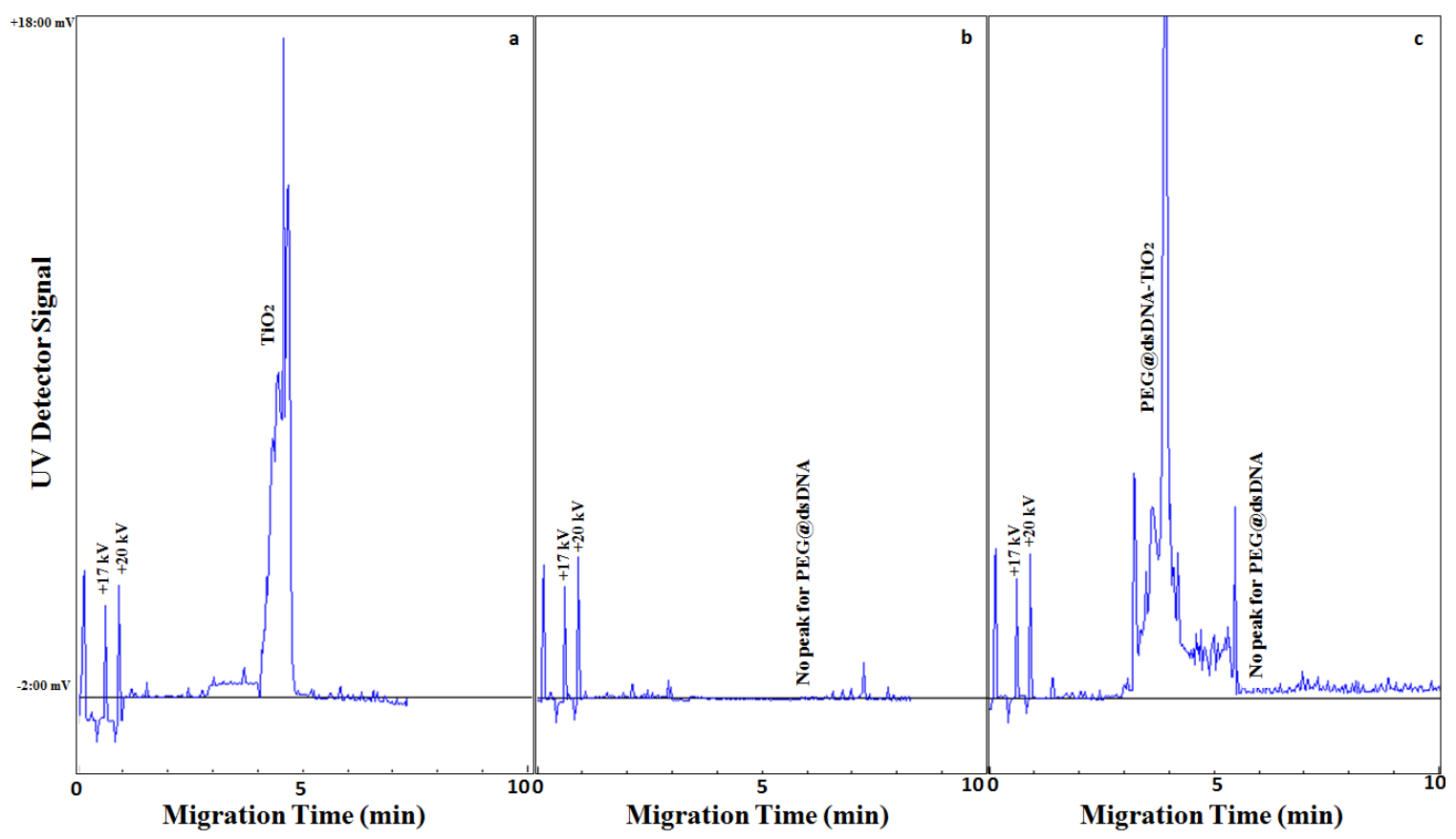

Figure 5.6 $\mathrm{CE}$ analysis, with $\mathrm{UV}$ detection at $325 \mathrm{~nm}$, of (a) $\mathrm{TiO}_{2}$ nanoparticles, (b) PEG@dsDNA, and (c) $\mathrm{TiO}_{2}$ nanoparticles after dsDNA adsorption and PEG coating. Only $\mathrm{TiO}_{2}$ can absorb the UV light; neither dsDNA nor PEG can.

This proves that the peak at 4.6 min assigned for PEG@dsDNA-TiO 2 actually contains $\mathrm{TiO}_{2}$ NPs. 


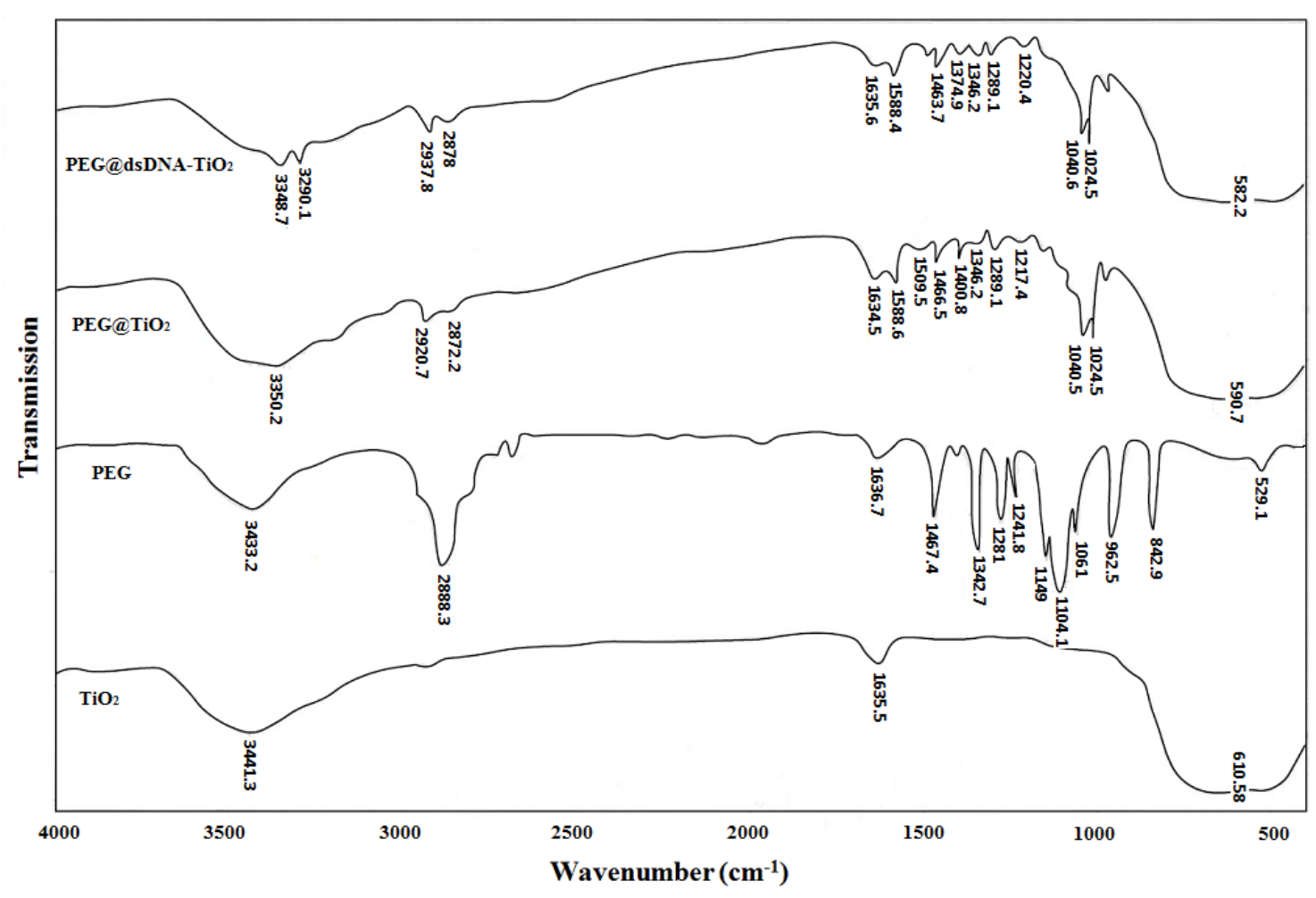

Figure 5.7 FTIR spectra of $\mathrm{TiO}_{2}, \mathrm{PEG}, \mathrm{PEG} @ \mathrm{TiO}_{2}$ and PEG@dsDNA-TiO .

FTIR spectroscopy confirmed the formation of a thin PEG coating on the dsDNA$\mathrm{TiO}_{2}$ NPs. As evidenced in Fig. 5.7, the C-O stretching vibrations shifted to lower wavenumbers (at 1024 and $1040 \mathrm{~cm}^{-1}$ ) relative to PEG. The symmetric/asymmetric stretching and bending vibrations of the $-\mathrm{CH}_{2}$ groups indicated that PEG coating was successfully formed.

Adsorption of PEG and dsDNA resulted in a decrease in the average hydrodynamic diameter of $\mathrm{TiO}_{2} \mathrm{NPs}$, as presented in Table 5.2, due to an improved colloidal stability of $\mathrm{TiO}_{2}$ by electrosteric stabilization using the two anionic polyelectrolytes as a dispersant. [204-206] These findings are in agreement with the results obtained by Pacia et al. who reported a decrease in the hydrodynamic diameters of $\mathrm{TiO}_{2}$ after chemisorption of various organic ligands. [207] 


\subsubsection{Single-stranded DNA adsorption onto $\mathrm{TiO}_{2}$ nanoparticles}

Adsorption of ssDNA onto $\mathrm{TiO}_{2}$ NPs was next investigated for comparison with dsDNA. An adsorption test of ssDNA $(0.5 \mathrm{mg} / \mathrm{mL})$ was performed with increasing concentrations of $\mathrm{TiO}_{2}$ NPs $(0.05-5.0 \mathrm{mg} / \mathrm{mL})$ in $100 \mathrm{mM}$ Tris. Fig. $5.8 \mathrm{~b}$ showed ssDNA as a sharp peak at 7.3 min due to its more negative ionic charge in the BGE than dsDNA. Adsorption of ssDNA produced increases in the peak area and height of $\mathrm{TiO}_{2}$ NPs as well as the migration time from $4.6 \mathrm{~min}$ to $5.6 \mathrm{~min}$. $\mathrm{TiO}_{2}$ and ssDNA peaks were actually separated as they had different migration times. Thereby, no possibility of overlapping between these peaks could occur.

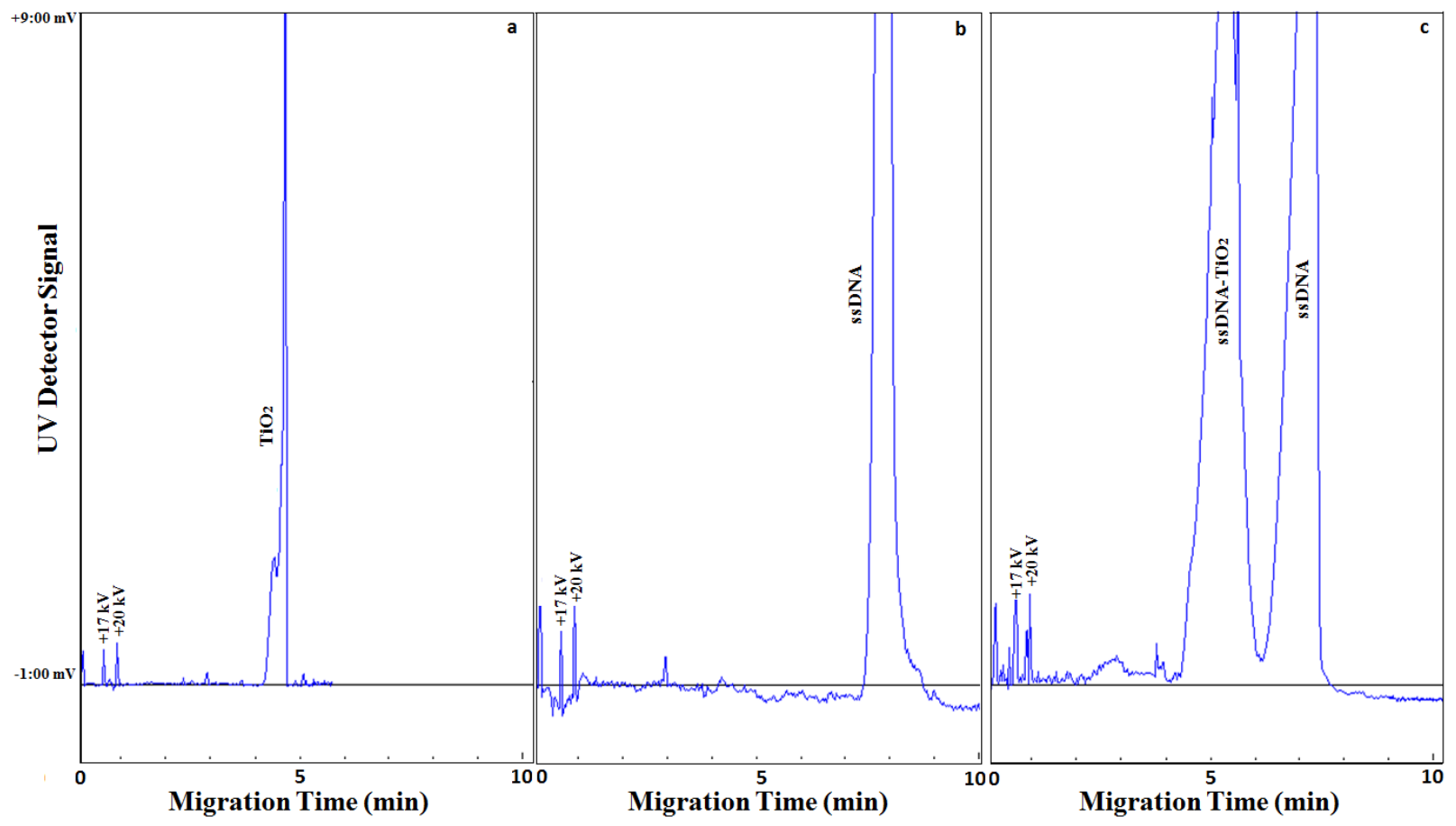

Figure 5.8 $\mathrm{CE}$ analysis, with UV detection at $260 \mathrm{~nm}$, of (a) $\mathrm{TiO}_{2}$ nanoparticles, (b) ssDNA and (c) $\mathrm{TiO}_{2}$ nanoparticles after ssDNA adsorption.

As shown in Fig. 5.9, the peak areas were enhanced for all the concentrations of

$\mathrm{TiO}_{2} \mathrm{NPs}$ studied up to $5 \mathrm{mg} / \mathrm{mL}$. Higher concentrations caused the ssDNA peak to 
broaden and overlap with the $\mathrm{TiO}_{2}$ peaks. As a result of DNA adsorption, the UV detection sensitivity was enhanced by $7.0 \pm 0.2$ fold using the $\lambda_{\max }$ of $260 \mathrm{~nm}$. Apparently ssDNA exhibited more adsorption onto $\mathrm{TiO}_{2}$ NPs than dsDNA. This might be explained by the fact that ssDNA is much more flexible to wrap around the NPs in large numbers. Also, the sugar-phosphate backbone of ssDNA could participate in stronger interaction with $\mathrm{TiO}_{2} \mathrm{NPs}$, thus maximizing the binding affinity. On the contrary dsDNA is rigid, difficult to bend and has to break hydrogen bonds with base partners to get free bases, hampering the strong adsorption onto the NPs. [208-210] Hence, ssDNA was proven to be a better adsorbate than dsDNA for sensitivity enhancement in the determination of $\mathrm{TiO}_{2}$ NPs by the CE-UV method. Similar to dsDNA, ssDNA did not seem to adsorb onto $\mathrm{SiO}_{2} \mathrm{NPs}$ as no change in $\mathrm{SiO}_{2}$ peak area or height was observed by CE-UV analysis. A change in $\mathrm{Al}_{2} \mathrm{O}_{3}$ peak shape was seen after ssDNA addition, comparable to the effect of dsDNA. No significant change was observed in the peak area or height for ZnO NPs after ssDNA addition. DLS measurements validated the CE-UV results, showing no significant changes to the hydrodynamic diameters of $\mathrm{SiO}_{2}, \mathrm{Al}_{2} \mathrm{O}_{3}$ and $\mathrm{ZnO}$ NPs after ssDNA addition, as summarized in Table 5.2. 


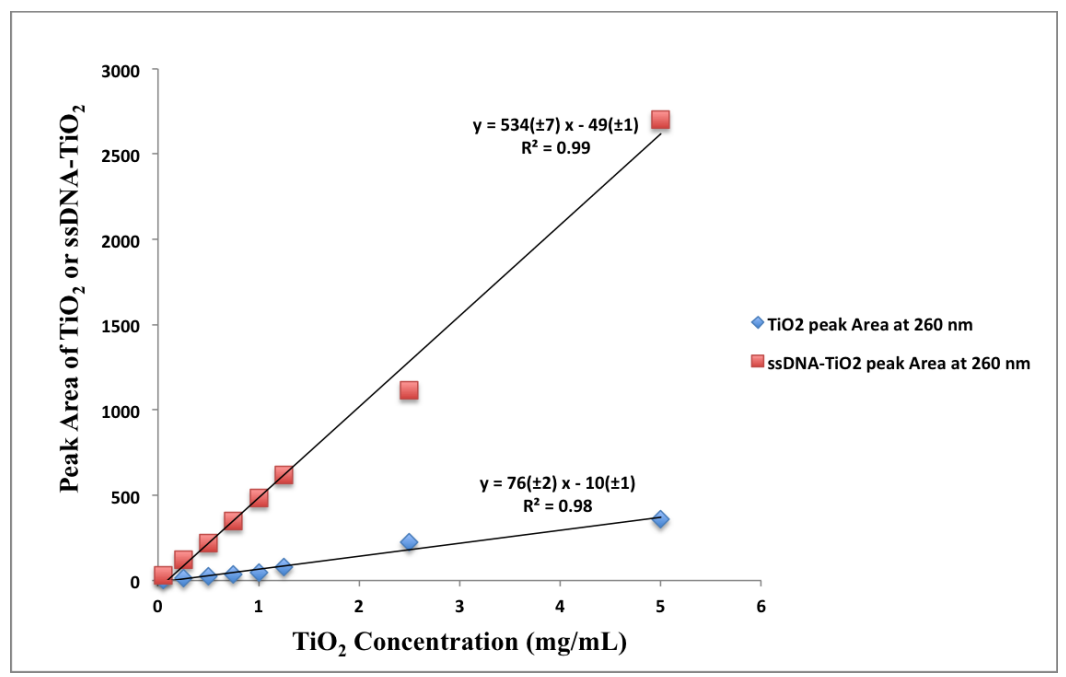

Figure 5.9 Enhancement of UV detection sensitivity in CE analysis at $260 \mathrm{~nm}$ after adding ssDNA to $\mathrm{TiO}_{2}$ nanoparticles suspended in $100 \mathrm{mM}$ Tris.

\subsubsection{PEG coating of ssDNA-TiO2 nanoparticles}

Last, PEG was added to ssDNA-TiO 2 NPs at a $\mathrm{PEG}: \mathrm{TiO}_{2}$ ratio of 2:1. Coating of the ssDNA- $\mathrm{TiO}_{2}$ NPs with PEG resulted in a total of $13 \pm 3$ fold enhancement of the CEUV detection sensitivity of $\mathrm{TiO}_{2}$ NPs as shown in Fig. 5.10b. PEG has no UV absorbance at $260 \mathrm{~nm}$ and did not show any peak during its CE-UV analysis. This eliminated any interference that could arise due to overlapping of consecutive $\mathrm{TiO}_{2}$ and ssDNA peaks. 


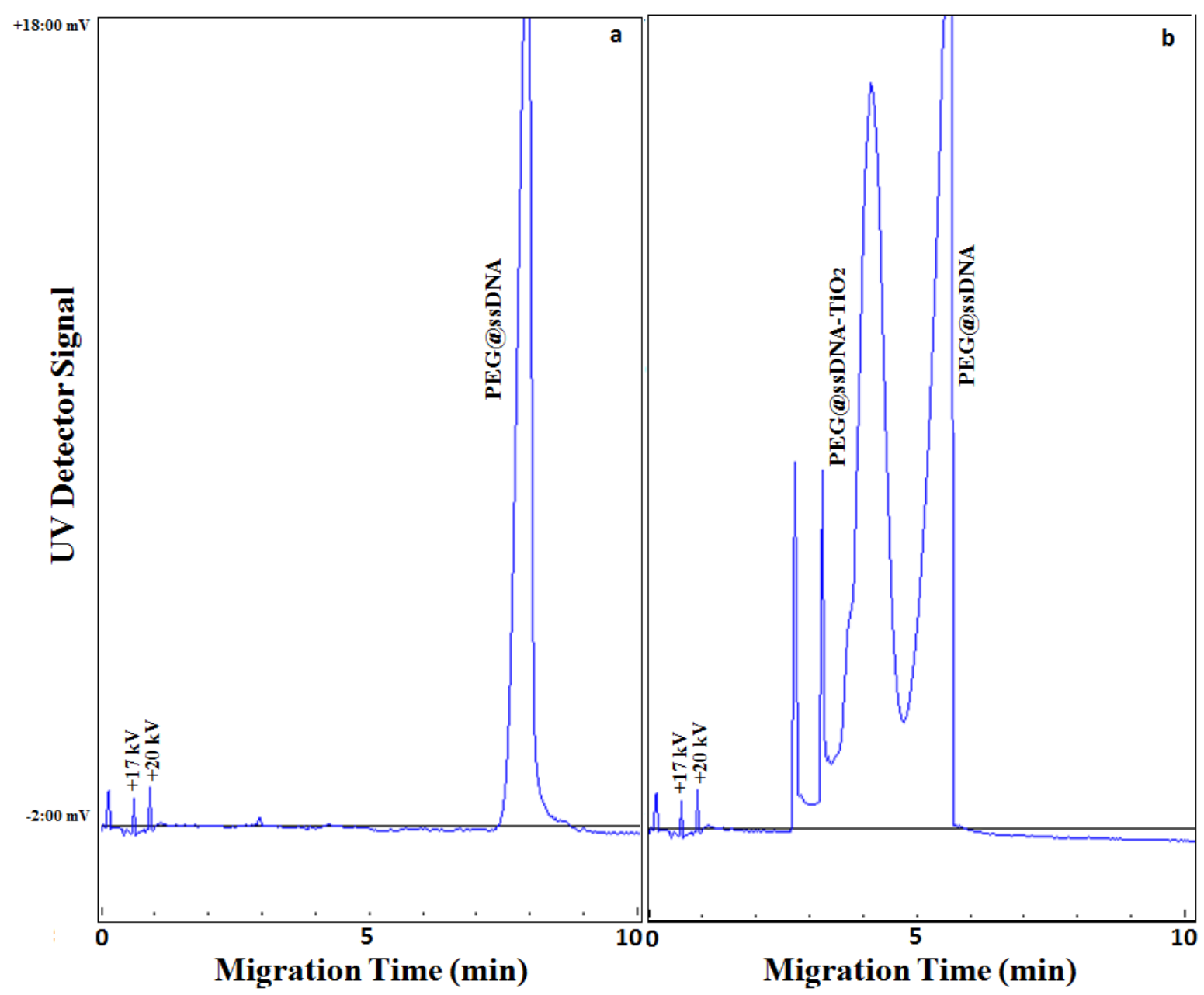

Figure 5.10 CE analysis, with UV detection at 260 nm, of (a) PEG@ssDNA and (b) $\mathrm{TiO}_{2}$ nanoparticles after ssDNA adsorption and PEG coating.

FTIR spectra shown in Fig. 5.11, exhibited a shift to lower wavenumbers of the C-O stretching vibrations (at 1024 and $1041 \mathrm{~cm}^{-1}$ ) relative to PEG. The symmetric/asymmetric stretching and bending vibrations of $-\mathrm{CH}_{2}$ groups also verified the successful coating of ssDNA- $\mathrm{TiO}_{2}$ NPs with PEG. 


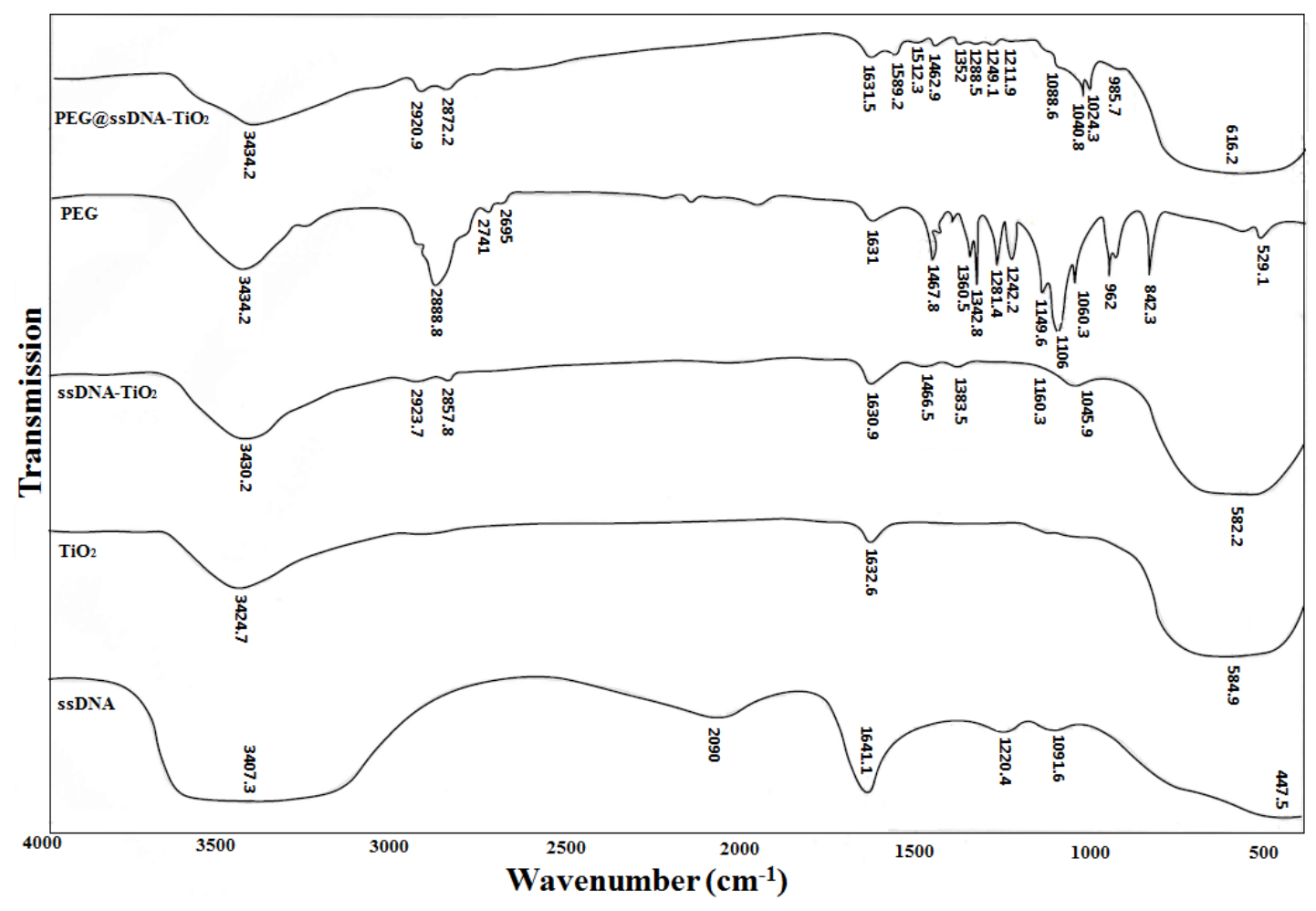

Figure 5.11 FTIR spectra of ssDNA, TiO 2 , ssDNA-TiO 2 , PEG and PEG@ssDNA-TiO

All the enhancement factors obtained from adsorption of various organic and bioorganic compounds onto $\mathrm{TiO}_{2}, \mathrm{SiO}_{2}, \mathrm{Al}_{2} \mathrm{O}_{3}$ and $\mathrm{ZnO}$ NPs are summarized in Table 5.1. It becomes apparent that a simple method has been successfully developed for the detection of $\mathrm{TiO}_{2}$ NPs. It involves binding $\mathrm{TiO}_{2}$ NPs with DNA followed by coating with PEG to attain a total enhancement of $13 \pm 3$ fold in detection sensitivity in CE-UV analysis. We propose that the progressive enhancement factors, specifically $7.0 \pm 0.2$ for ssDNA and $13 \pm 3$ for ssDNA+PEG, are reporting on the total surface area of disaggregated NPs as well as the chemical functionality of the nanoparticle surfaces. The new analytical method is rapid, as only 3 hours are needed to reach a binding and coating equilibrium with the NPs. No chemical initiator or elevated temperature is required. It is 
worth noting that the method is selective and does not work for colloidal $\mathrm{SiO}_{2}, \mathrm{Al}_{2} \mathrm{O}_{3}$ or ZnO NPs.

Table 5.1 Enhancement factors obtained after addition of various organic/bioorganic compounds onto $\mathrm{TiO}_{2}, \mathrm{SiO}_{2}, \mathrm{Al}_{2} \mathrm{O}_{3}$ and $\mathrm{ZnO}$ nanoparticles as well as the $\mathrm{LOD}$ and $\mathrm{LOQ}$ for stabilized $\mathrm{TiO}_{2}$ nanoparticles.

\begin{tabular}{|c|c|c|c|c|c|}
\hline $\begin{array}{l}\text { Organic/Bioorganic } \\
\text { Compound }\end{array}$ & $\begin{array}{c}\text { UV } \\
\text { Detection } \\
\text { Wavelength } \\
(\mathbf{n m})\end{array}$ & $\begin{array}{c}\text { Enhancement } \\
{\text { Factor for } \mathrm{TiO}_{2}}_{2} \\
\text { Nanoparticles }\end{array}$ & $\begin{array}{c}\text { LOD for } \\
\mathrm{TiO}_{2} \\
(\mathrm{mg} / \mathrm{mL})\end{array}$ & $\begin{array}{c}\text { LOQ for } \\
\mathrm{TiO}_{2} \\
(\mathrm{mg} / \mathrm{mL})\end{array}$ & $\begin{array}{c}\text { Enhancement } \\
\text { Factor for } \\
\mathrm{SiO}_{2}, \mathrm{Al}_{2} \mathrm{O}_{3} \text { and } \\
\mathrm{ZnO}^{\text {Nanoparticles }}\end{array}$ \\
\hline TX-100 & 280 & $4.6 \pm 0.1$ & 0.013 & 0.039 & $0.00 \pm 0.1$ \\
\hline dsDNA & 260 & $1.6 \pm 0.1$ & 0.006 & 0.018 & $0.00 \pm 0.1$ \\
\hline PEG & 260 & $3.0 \pm 1.0$ & 0.003 & 0.009 & $0.00 \pm 0.1$ \\
\hline dsDNA + PEG & 260 & $5.5 \pm 1.5$ & 0.002 & 0.006 & $0.00 \pm 0.1$ \\
\hline ssDNA & 260 & $7.0 \pm 0.2$ & 0.001 & 0.003 & $0.00 \pm 0.1$ \\
\hline ssDNA + PEG & 260 & $13 \pm 3$ & 0.0008 & 0.0024 & $0.00 \pm 0.1$ \\
\hline
\end{tabular}

Binding of $\mathrm{TiO}_{2}$ NPs with ssDNA produced a decrease in hydrodynamic diameter to $339 \pm 8 \mathrm{~nm}$, as measured by DLS. Electronegative charges of DNA could play an important role on the size of $\mathrm{TiO}_{2} \mathrm{NPs}$. With more electronegative charges on its surface than dsDNA (as verified by CE-UV analysis), ssDNA proved to be a more effective adsorbate in controlling the aggregation of $\mathrm{TiO}_{2} \mathrm{NPs}$ to give a smaller hydrodynamic diameter. These findings are in agreement with the results obtained by Dharanivasan et al. who found that ssDNA has superior capability to control gold NPs aggregation than dsDNA. [211] Further reduction of hydrodynamic diameter down to $323 \pm 6$ was observed after PEG coating due to extra steric stabilization. These results, as summarized in Table 5.2, supported the observed enhancement of UV detection sensitivity of $\mathrm{TiO}_{2} \mathrm{NPs}$ in $\mathrm{CE}$ 
analysis.

Table 5.2 Hydrodynamic diameters of $\mathrm{TiO}_{2}, \mathrm{SiO}_{2}, \mathrm{Al}_{2} \mathrm{O}_{3}$ and $\mathrm{ZnO}$ nanoparticles measured by DLS before and after addition of various organic and bioorganic adsorbates.

\begin{tabular}{|c|c|c|c|c|}
\hline & \multicolumn{4}{|c|}{ Hydrodynamic Diameter (nm) } \\
\hline $\begin{array}{c}\text { Organic/ } \\
\text { bioorganic } \\
\text { Adsorbate }\end{array}$ & $\mathbf{T i O}_{2}$ & $\mathbf{S i O}_{2}$ & $\mathbf{A l}_{2} \mathbf{O}_{3}$ & $\mathbf{Z n O}$ \\
\hline----- & $447 \pm 22$ & $76 \pm 3$ & $591 \pm 27$ & $558 \pm 21$ \\
\hline TX-100 & $330 \pm 16$ & $79 \pm 4$ & $595 \pm 28$ & $552 \pm 22$ \\
\hline PEG & $255 \pm 7$ & $74 \pm 2$ & $586 \pm 25$ & $555 \pm 40$ \\
\hline dsDNA & $365 \pm 9$ & $77 \pm 3$ & $588 \pm 35$ & $1185 \pm 193$ \\
\hline PEG@dsDNA & $351 \pm 6$ & ------ & ------ & ----- \\
\hline ssDNA & $339 \pm 8$ & $78 \pm 4$ & $588 \pm 38$ & $558 \pm 27$ \\
\hline PEG@ssDNA & $323 \pm 6$ & ------ & ------ & ----- \\
\hline
\end{tabular}

\subsection{Conclusions}

The total concentration of $\mathrm{TiO}_{2}$ NPs in aqueous suspensions is conventionally measured by inductively coupled plasma-mass spectrometry after acidification and microwave-assisted digestion. [212] However, no distinction between soluble and insoluble fractions of engineered NPs can be attained. To the best of our knowledge, this is the first work that attempts to determine $\mathrm{TiO}_{2}$ as disaggregated NPs by UV detection at a specific migration time in CE analysis. Their selective interaction with DNA, followed by coating with PEG, attains an enhancement of many fold in the analytical sensitivity of CE-UV determination. The reaction medium seemed to be the most influencing factors controlling the selectivity of various adsorbates towards $\mathrm{TiO}_{2} \mathrm{NPs}$. Tris was chosen as 
the BGE instead of phosphate since the latter could strongly adsorb onto $\mathrm{TiO}_{2}$ surface $[213,214]$ preventing any further interaction with another adsorbate. On the other hand, $\mathrm{SiO}_{2}$ adsorbed Tris molecules that provided a dense coverage of hydroxyl groups surrounding it. [215] Additionally, $\mathrm{ZnO}$ strongly adsorbed Tris molecules that inhibited its growth. [216] Moreover, $\mathrm{Al}_{2} \mathrm{O}_{3}$ could strongly adsorb Tris, forming Al-O-C bonds [217] and disabling any further adsorption onto its surface. Therefore, $\mathrm{SiO}_{2}, \mathrm{ZnO}$ and $\mathrm{Al}_{2} \mathrm{O}_{3}$ were apparently inert to ssDNA and PEG due to their strong adsorption of Tris. We propose that the progressive enhancement factors, specifically $7.0 \pm 0.2$ for ssDNA and $13 \pm 3$ for ssDNA $+\mathrm{PEG}$, are reporting on the total surface area of disaggregated NPs, as well as the chemical functionality of the NP surfaces. Now that the feasibility is demonstrated for this approach, further exploration with various biochemical probes (including dyes for laser induced fluorescence detection of DNA-stabilized $\mathrm{TiO}_{2} \mathrm{NPs}$ ) to further enhance sensitivity should be exciting. [218] Analytical separation from other NPs, if needed for complex environmental water samples, can be further improved by adding a gel matrix inside the capillary for electrophoresis under the size filtration mechanism. [219] Interferences occurring in the presence of dissolved organic matter (DOM) can be overcome by pretreatment of environmental water samples with hydrogen peroxide $\left(\mathrm{H}_{2} \mathrm{O}_{2}\right)$, in which inorganic oxide NPs are chemically inert. [86]

\subsection{Connection to chapter 6}

In an effort to improve the LOD of $\mathrm{SiO}_{2}$ NPs utilizing DNA and PEG, a new route to enhance the CE-UV detection sensitivity of $\mathrm{TiO}_{2}$ NPs was revealed. ssDNA + PEG resulted in a progressive enhancement factor of $13 \pm 3$ fold showing a superior performance over dsDNA+PEG in improving the UV detection sensitivity of 
$\mathrm{TiO}_{2}$. Accordingly, in Chapter 6, the search is directed towards investigating the adsorption of dithiothreitol and L-cysteine onto $\mathrm{Al}_{2} \mathrm{O}_{3}, \mathrm{CeO}_{2}, \mathrm{SiO}_{2}, \mathrm{TiO}_{2}$ and $\mathrm{ZnO} \mathrm{NPs}$ for selective enhancement of their UV detection sensitivity. 


\section{Chapter 6: Selective detection of $\mathrm{ZnO}$ nanoparticles in aqueous suspension by capillary electrophoresis analysis using dithiothreitol and L-cysteine adsorbates}

Modified from original manuscript, published as:

Alsudir S, Lai EPC." "Selective detection of $\mathrm{ZnO}$ nanoparticles in aqueous suspension by capillary electrophoresis analysis using dithiothreitol and L-cysteine adsorbates", Talanta . 2017, 169,115-122.

*Department of Chemistry, Carleton University, Ottawa, ON, K1S 5B6, Canada

\subsection{Abstract}

The UV detection sensitivity of ZnO NPs in CE analysis was selectively enhanced, by $28 \pm 1$ or $25 \pm 1$ fold, after adsorption of dithiothreitol (DTT) or cysteine (Cys) in 10 $\mathrm{mM}$ sodium phosphate buffer. Adsorption equilibrium was reached within $90 \mathrm{~min}$ for DTT but only 10 min for Cys. The adsorption process was best modeled by the Langmuir isotherm, indicating the formation of a monolayer of DTT or Cys onto the surface of $\mathrm{ZnO}$ NPs. The selectivity of DTT and Cys towards $\mathrm{ZnO}$ NPs was tested using $\mathrm{Al}_{2} \mathrm{O}_{3}, \mathrm{CeO}_{2}$, $\mathrm{SiO}_{2}$ and $\mathrm{TiO}_{2}$ NPs. No changes in the CE-UV peak area of either adsorbates or NPs were observed, indicating a lack of adsorption. Dynamic light scattering (DLS) provided similar evidence of the selectivity of both adsorbates towards $\mathrm{ZnO}$. Cys also improved the colloidal stability of ZnO NPs by breaking down the aggregates, as evidenced by a reduction of their average hydrodynamic diameter. This new analytical approach provides a simple and rapid methodology to detect ZnO NPs selectively by CE-UV analysis with enhanced sensitivity. 


\subsection{Introduction}

The innovation of nanotechnologies, in a truly scientific revolution, has deeply transformed many aspects of our lives. Engineered NPs are commonly used in groundbreaking applications. The global market value of nano-enabled products is expected to rise to $\$ 4.4$ trillion by 2018 as declared by the National Science Foundation. [220] As per global annual production, $\mathrm{ZnO}$ NPs are ranked the third with 550 tons, after $\mathrm{SiO}_{2}$ with 5550 tons and $\mathrm{TiO}_{2}$ with 3000 tons. [221] Massive production of ZnO NPs poses a high risk to environmental ecology and human health.

Comprehensive understanding of environmental nanotoxicity is still a major challenge due to the limitations of analytical methods. SP-ICPMS is one of the very few existing techniques that can characterize and detect $\mathrm{ZnO}$ NPs. However, significant dissolution of $\mathrm{ZnO}$ largely increases the background levels of dissolved $\mathrm{Zn}^{2+}$ to the point where measurement of NPs at very low concentrations is not likely possible. [222] Online combination of UV-visible, fluorescence and ICP-MS detectors to hydrodynamic chromatography has been utilized for the detection of $\mathrm{ZnO}$ NPs. However this approach is not quantitative since larger particles or agglomerates have to be removed before analysis. [223]

In this chapter, we investigated the binding interaction between ZnO NPs and dithiothreitol (DTT) or L-cysteine (Cys) for potential enhancement of their UV detection sensitivity in CE analysis. DTT is a strong reducing agent often used to reduce protein disulfides. It has been used to probe dissolved oxygen in the presence of carbon NPs. [224] As a strong chelator of zinc [225], DTT was expected to adsorb onto ZnO NPs to 
form a monolayer via its dithiol functionality. Cys is an amino acid having carboxylic, amino, and thiol functional groups. Therefore, it can potentially interact via the different functional groups with $\mathrm{ZnO}$ NPs. Sandmann et al. reported that Cys acted as a source for sulfur resulting in the formation of a $\mathrm{ZnS}$ shell around the $\mathrm{ZnO}$ core and helped to stabilize the core-shell NPs. [226] Our goal was to use DTT and Cys to both improve the dispersion of $\mathrm{ZnO}$ NPs in aqueous suspensions and enhance their CE-UV detection sensitivity.

\subsection{Methods}

\subsubsection{DTT and Cys adsorption onto ZnO nanoparticles}

Adsorption experiments were carried out to optimize various parameters including the interaction medium, contact time and $\mathrm{ZnO}$ dose. The wavelength of maximum light absorption of each adsorbate (DTT or Cys) was determined by UV-visible spectroscopy. The adsorbate concentration before and after adsorption onto $\mathrm{ZnO}$ NPs was determined using CE-UV at a wavelength of $220 \mathrm{~nm}$. The \% adsorption of each adsorbate was calculated as: $\%$ Adsorption $=\frac{\left(C_{0}-C_{e}\right)}{C_{0}} \times 100$

where $\mathrm{C}_{0}$ is the initial adsorbate concentration $\left(\mathrm{mg} \mathrm{L}^{-1}\right)$ and $\mathrm{C}_{\mathrm{e}}$ is the equilibrium adsorbate concentration $\left(\mathrm{mg} \mathrm{L}^{-1}\right)$. The adsorption capacity, $\mathrm{q}_{\mathrm{e}}\left(\mathrm{mg} \mathrm{g}^{-1}\right)$, was calculated as: $q_{e}=\frac{\left(C_{0}-C_{e}\right) V}{m}$

where $\mathrm{V}$ is the volume of adsorbate solution (L) and $\mathrm{m}$ is the mass of $\mathrm{ZnO}$ NPs (g).

The stability of adsorbate solution $\left(0.45 \mathrm{mg} \mathrm{mL}^{-1}\right.$ DTT or Cys $)$ in $100 \mathrm{mM}$ Tris at pH $9.5 \pm 0.5$ and $10 \mathrm{mM} \mathrm{Na} 2 \mathrm{HPO}_{4}$ at $\mathrm{pH} 7.5 \pm 0.2$ over time was investigated. Kinetic studies were performed by adding ZnO NPs $\left(0.05 \mathrm{mg} \mathrm{mL}^{-1}\right)$ into adsorbate solutions (0.15-0.45 mg mL $\left.\mathrm{mL}^{-1}\right)$ in $10 \mathrm{mM} \mathrm{Na}_{2} \mathrm{HPO}_{4}$ and analyzing the mixtures by CE-UV at 
different time intervals (15-120 min). Adsorption isotherms were studied by mixing $\mathrm{ZnO}$ NPs $\left(0.05 \mathrm{mg} \mathrm{mL}^{-1}\right)$ with various concentrations of adsorbate solution $(0.15-0.45 \mathrm{mg}$ $\mathrm{mL}^{-1}$ ) in $10 \mathrm{mM} \mathrm{Na}_{2} \mathrm{HPO}_{4}$ and analyzing the mixtures by CE-UV at the optimal contact time. The effect of $\mathrm{ZnO}$ dose $\left(0.02-0.2 \mathrm{mg} \mathrm{mL}^{-1}\right)$ on adsorption was investigated using standard adsorbate solutions $\left(0.45 \mathrm{mg} \mathrm{mL}^{-1}\right)$.

\subsubsection{DTT and Cys adsorption onto $\mathrm{Al}_{2} \mathrm{O}_{3}, \mathrm{CeO}_{2}, \mathrm{SiO}_{2}$ and $\mathrm{TiO}_{2}$ nanoparticles}

DTT or Cys $\left(0.45 \mathrm{mg} \mathrm{mL}^{-1}\right)$ was added to $\mathrm{Al}_{2} \mathrm{O}_{3}, \mathrm{CeO}_{2}, \mathrm{SiO}_{2}$ and $\mathrm{TiO}_{2}$ suspensions ( $1 \mathrm{mg} \mathrm{mL}^{-1}$ ) in $10 \mathrm{mM} \mathrm{Na}_{2} \mathrm{HPO}_{4}$ to test its selectivity towards $\mathrm{ZnO}$ NPs. Suspensions containing DTT were stirred for 2 hours and those containing Cys were stirred for $10 \mathrm{~min}$ before analysis by CE-UV at $220 \mathrm{~nm}$ to determine DTT, Cys, and the NPs.

\subsection{Results and Discussion}

\subsubsection{Stability of DTT and Cys solutions}

CE-UV analysis of DTT solution in $100 \mathrm{mM}$ Tris (at $\mathrm{pH} 9.5 \pm 0.5$ ) showed a peak at a migration time of $4.2 \mathrm{~min}$ (after $\mathrm{MO}$, the neutral marker), indicating its negative charge. As time progressed, a decrease in DTT peak area was noticeable as shown in Fig. 6.1. A new peak was also seen at 3.6 min with increasing peak area over time due to the oxidation of DTT by deprotonation of the two thiol groups $(\mathrm{pKa}=9.2$ and 10.1) to form a disulfide bond, which may not facilitate the adsorption of DTT onto the NPs. Hence, DTT in $100 \mathrm{mM}$ Tris lacked chemical stability required for quantitative analysis of the NPs. On the contrary, DTT in $10 \mathrm{mM} \mathrm{Na} \mathrm{HPO}_{4}$ (at $\mathrm{pH} 7.5 \pm 0.2$ ) exhibited a migration time of 3.7 min (slightly after MO), indicating its low negative charge. No change in the DTT peak area was noticeable over time. Similarly Cys exhibited a migration time of 4.2 min indicating its higher negative charge than DTT. It was also stable over time as no 
change in its peak area was observed. Therefore, $10 \mathrm{mM} \mathrm{Na}_{2} \mathrm{HPO}_{4}$ was chosen as the BGE for all subsequent experiments.

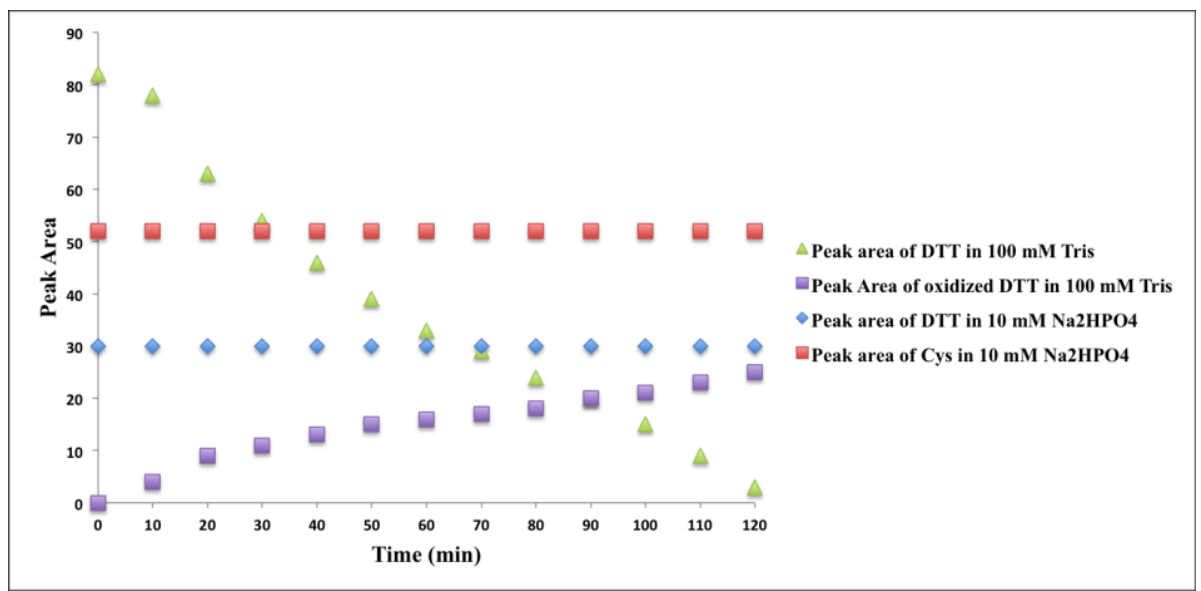

Figure 6.1 Stability of DTT and Cys in $10 \mathrm{mM} \mathrm{Na}_{2} \mathrm{HPO}_{4}$ and $100 \mathrm{mM}$ Tris by capillary electrophoresis with UV detection at $220 \mathrm{~nm}$.

\subsubsection{DTT or Cys adsorption onto ZnO nanoparticles}

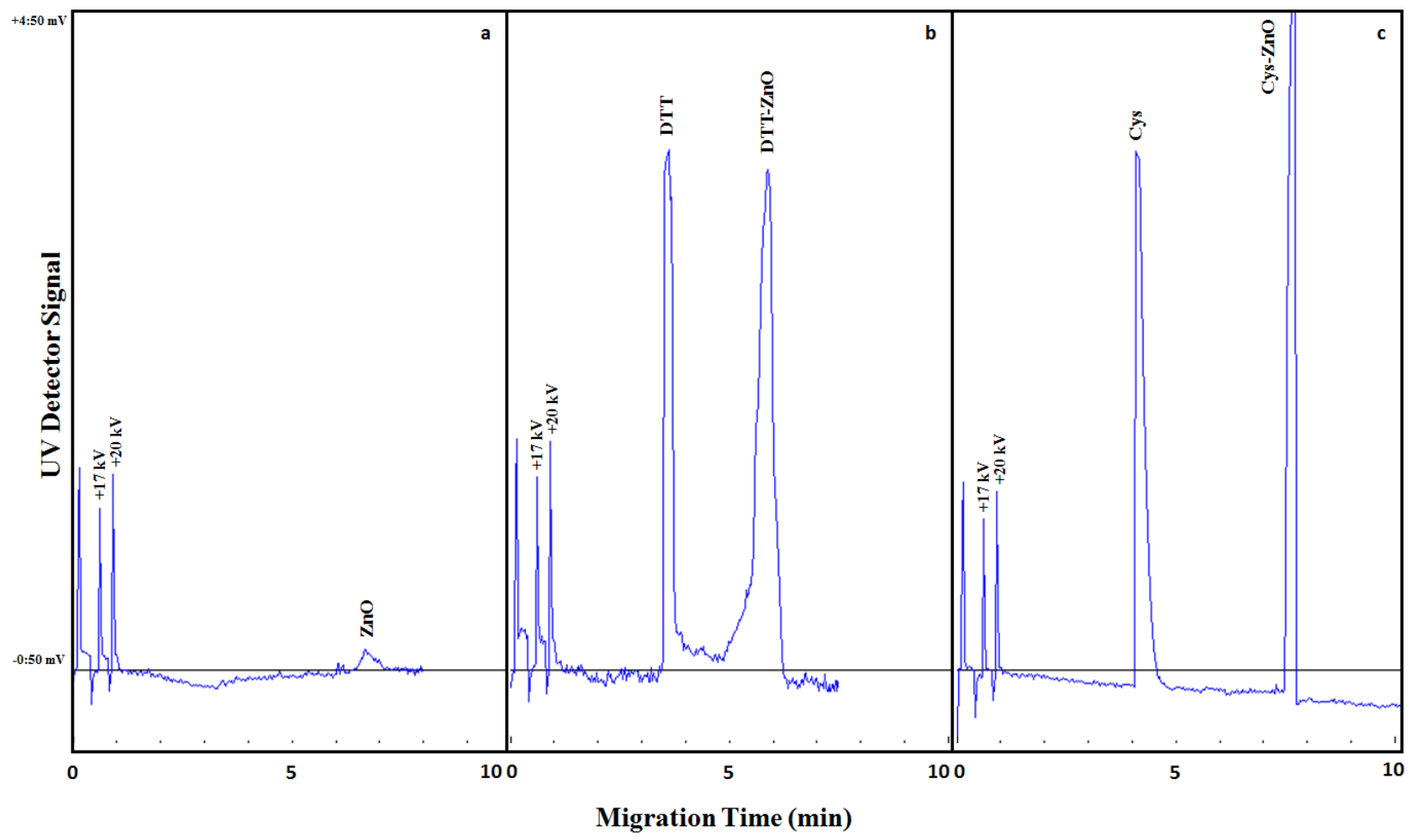

Figure 6.2 CE analysis, with UV detection at $220 \mathrm{~nm}$, of (a) $\mathrm{ZnO}$ nanoparticles, (b) $\mathrm{ZnO}$ nanoparticles after DTT adsorption and (c) ZnO nanoparticles after Cys adsorption. 
CE-UV analysis of $\mathrm{ZnO}$ suspension in $10 \mathrm{mM} \mathrm{Na}_{2} \mathrm{HPO}_{4}(\mathrm{pH} 7.5 \pm 0.1)$ showed a small peak at a migration time of 6.6 min (after MO), as shown in Fig. 6.2a, indicating their strong negative charge in this $\mathrm{BGE}$ due to the adsorption of $\mathrm{HPO}_{4}{ }^{2-}$ anions onto their surface. A linear calibration curve was obtained using $220 \mathrm{~nm}$ for $\mathrm{UV}$ detection of $\mathrm{ZnO}$ NPs as shown in Fig. 6.3 (at bottom). The limit of detection (LOD) and the limit of quantification (LOQ) were determined to be $0.005 \mathrm{mg} \mathrm{mL}^{-1}$ and $0.015 \mathrm{mg} \mathrm{mL}^{-1}$ respectively. DTT (0.45 $\left.\mathrm{mg} \mathrm{mL}^{-1}\right)$ adsorption onto ZnO NPs $\left(0.02-0.14 \mathrm{mg} \mathrm{mL}^{-1}\right)$ in 10 $\mathrm{mM} \mathrm{Na} \mathrm{HPO}_{4}$ was next investigated for enhancing their UV absorptivity. As shown in Fig. 6.2b, DTT adsorption increased the peak height and area of $\mathrm{ZnO} \mathrm{NPs}$; their migration time also decreased down to $5.7 \mathrm{~min}$. Peak areas were enhanced for all the concentrations of $\mathrm{ZnO}$ suspension studied as a result of DTT adsorption as shown in Fig. 6.3 (at top). The sensitivity was enhanced by $28 \pm 1$ fold, calculated as the ratio of the two trend line slopes, using $220 \mathrm{~nm}$ for the determination of DTT-ZnO NPs too. Thus, DTT was proven to be an excellent adsorbate for sensitivity enhancement in the determination of ZnO NPs by the CE-UV method. The new LOD and LOQ were determined to be 0.2 $\mu \mathrm{g} \mathrm{mL} L^{-1}$ and $0.6 \mu \mathrm{gLL}^{-1}$, respectively. 


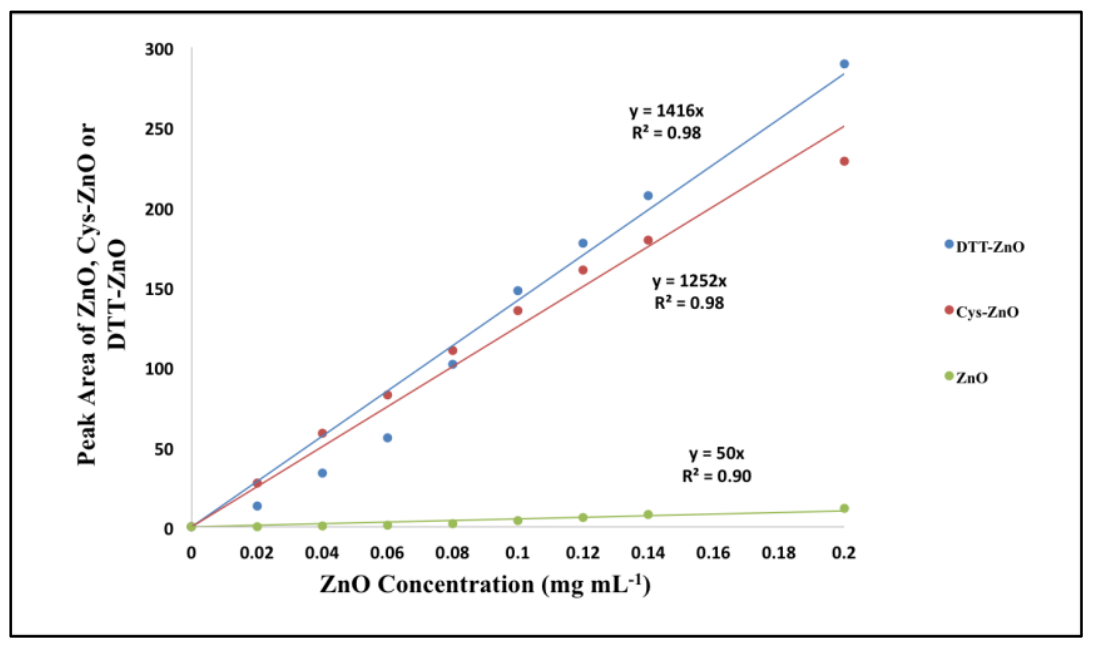

Figure 6.3 Enhancement of UV detection sensitivity in CE analysis after adding DTT or Cys $\left(0.45 \mathrm{mg} \mathrm{mL}^{-1}\right)$ to $\mathrm{ZnO}$ nanoparticles suspended in $10 \mathrm{mM} \mathrm{Na}_{2} \mathrm{HPO}_{4}$.

DTT, with its two thiol functional groups, could adsorb on the surface of $\mathrm{ZnO}$ NPs with high affinity. Three possible mechanisms of adsorption are speculated: (a) the cross-linking mode that bridges two ZnO NPs by forming Zn-S bonds, (b) the horizontally aligned mode that permits the formation of a dithiolate- $\mathrm{Zn}$ bond, and (c) the vertically aligned mode that forms a single $\mathrm{Zn}-\mathrm{S}$ bond per DTT molecule as shown in Fig.

\section{4 .}

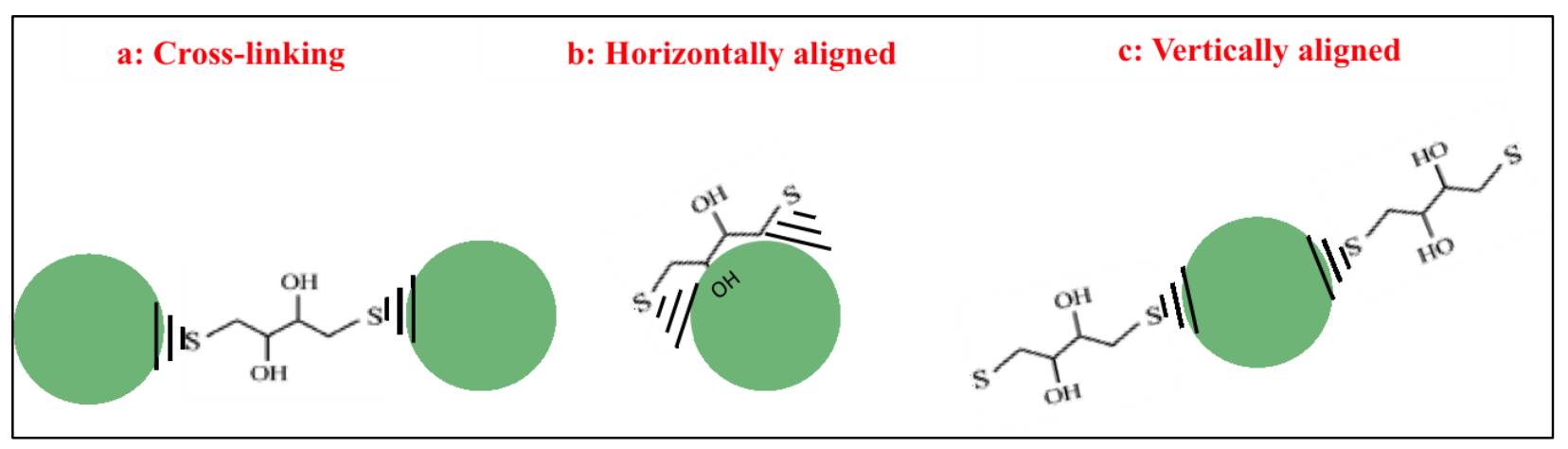

Figure 6.4 Schematic illustration of the possible different modes of DTT adsorption onto $\mathrm{ZnO}$ surface; (a) the cross-linking mode, (b) the horizontally aligned mode, and (c) the vertically aligned mode. 


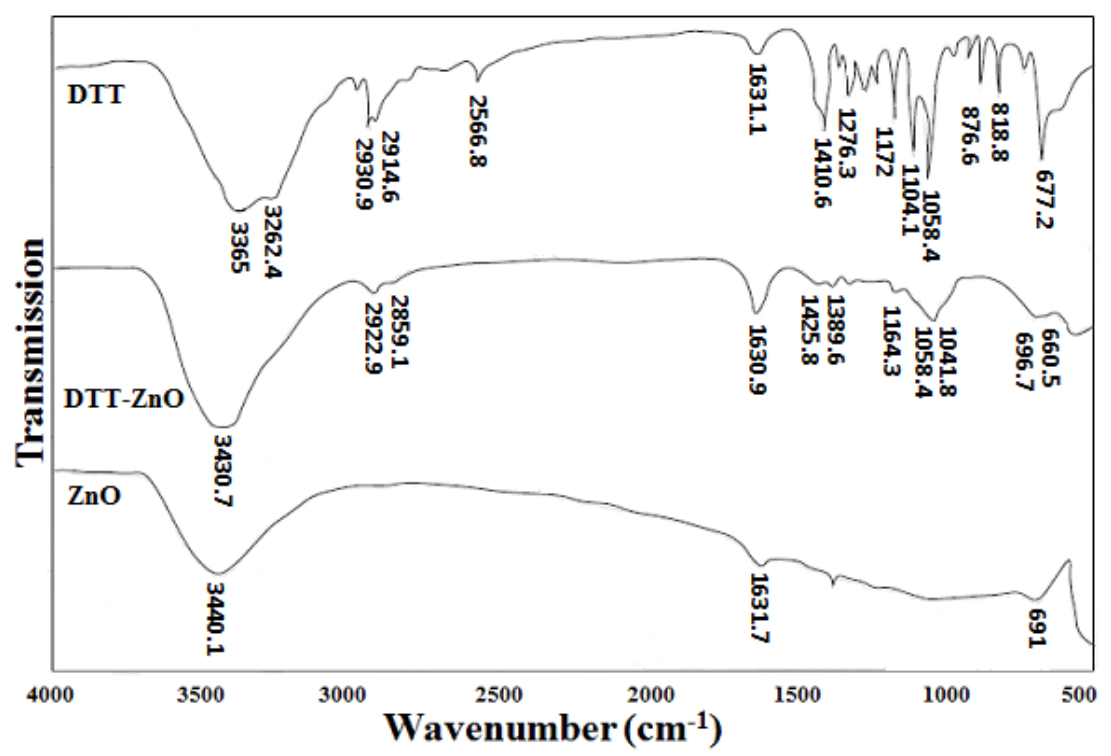

Figure 6.5 FTIR spectra of $\mathrm{ZnO}$, DTT-ZnO and DTT.

FTIR spectroscopy was performed to investigate the adsorption of DTT onto ZnO NPs. As shown in Fig. 6.5, the characteristic absorption peak of $-\mathrm{SH}$ at $2567 \mathrm{~cm}^{-1}$ disappeared in the FTIR spectrum of DTT-ZnO, indicating that DTT had been successfully adsorbed onto the surface of $\mathrm{ZnO}$ via the thiolate group. Moreover, the $\mathrm{C}-\mathrm{O}$ stretching vibration at $1058 \mathrm{~cm}^{-1}$, as well as the symmetric/asymmetric stretching and bending vibrations of the $-\mathrm{CH}_{2}$ groups at $2859-2923$ and $1390-1426 \mathrm{~cm}^{-1}$ respectively, appeared in the FTIR spectrum of DTT-ZnO.

Cys (0.45 mg mL $\left.\mathrm{m}^{-1}\right)$ adsorption onto ZnO NPs $\left(0.02-0.14 \mathrm{mg} \mathrm{mL}^{-1}\right)$ in $10 \mathrm{mM}$ $\mathrm{Na}_{2} \mathrm{HPO}_{4}$ was next investigated using $220 \mathrm{~nm}$ for the determination of Cys-ZnO NPs. As shown in Fig. 6.2c, Cys adsorption increased the peak height and area of ZnO NPs as well as their migration time (from $6.6 \mathrm{~min}$ ) to $7.6 \mathrm{~min}$ indicating their very strong negative charge in this BGE. The difference in the peak shapes between DTT-ZnO and Cys- $\mathrm{ZnO}$ could be attributed to the variation in the size distribution of $\mathrm{ZnO}$ NPs by deagglomeration after DTT and Cys adsorption. As shown in Fig. 6.3 (at middle), the 
peak areas of all concentrations of $\mathrm{ZnO}$ suspension were enhanced as a result of Cys adsorption and the enhancement factor was calculated to be $25 \pm 1$ fold. Thus, Cys was proven to be a very good adsorbate for sensitivity enhancement in the determination of ZnO NPs by the CE-UV method. The LOD and LOQ were determined to be $0.3 \mu \mathrm{g} \mathrm{mL}^{-}$ ${ }^{1}$ and $0.9 \mu \mathrm{g} \mathrm{mL}^{-1}$, respectively.

The white suspension of ZnO NPs became transparent after Cys addition. One proposed mechanism of interaction is that cysteine is dissociatively adsorbed onto $\mathrm{ZnO}$ NPs converting the $\mathrm{ZnO}$ surface to $\mathrm{ZnS}$ with the release of oxygen. The excess Cys molecules are adsorbed onto the ZnS surface stabilizing the NPs. [226] Apparently, Cys improved the dispersion of $\mathrm{ZnO} \mathrm{NPs}$ in the aqueous suspension (breaking down aggregation by repulsion of negative charges) and enhanced their CE-UV detection sensitivity.

FTIR spectroscopic analysis confirmed the adsorption of Cys onto ZnO NPs. As shown in Fig. 6.6, the $-\mathrm{SH}$ vibration peak at $2551 \mathrm{~cm}^{-1}$ disappeared in the FTIR spectrum of Cys- $\mathrm{ZnO}$, indicating that Cys had been successfully adsorbed onto the surface of $\mathrm{ZnO}$. Moreover, the $\mathrm{C}-\mathrm{O}$ and $\mathrm{C}-\mathrm{N}$ stretching vibration at $1051-1092 \mathrm{~cm}^{-1},-\mathrm{COO}^{-}$stretching vibration at $1409 \mathrm{~cm}^{-1}$ as well as the symmetric/asymmetric stretching vibrations of $-\mathrm{CH}$ at $2861-2924 \mathrm{~cm}^{-1}$ appeared in the FTIR spectrum of Cys- $\mathrm{ZnO}$. 


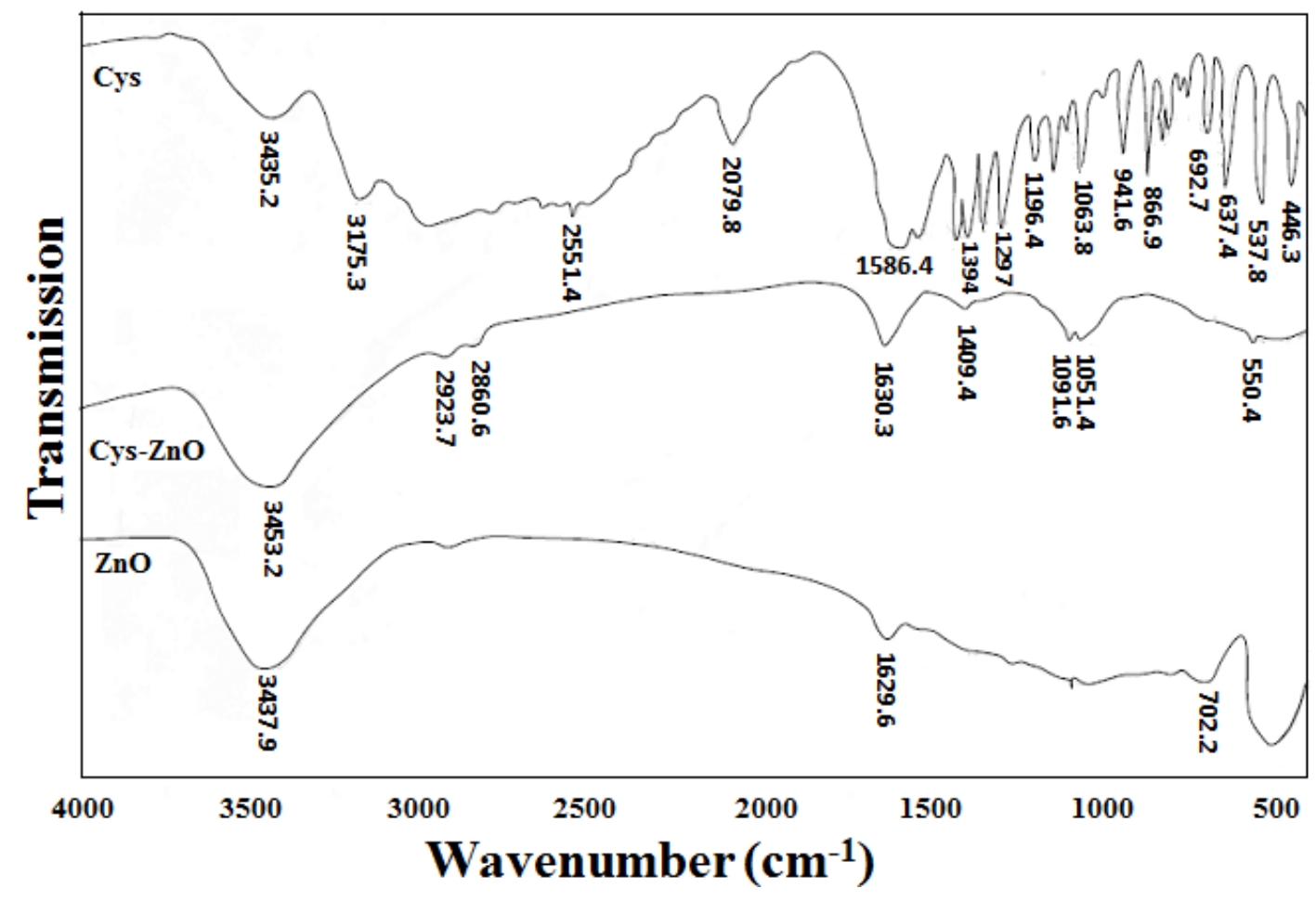

Figure 6.6 FTIR spectra of $\mathrm{ZnO}$, Cys- $\mathrm{ZnO}$ and Cys.

\subsubsection{Adsorption kinetics}

To study the adsorption kinetics, $\mathrm{ZnO}\left(0.05 \mathrm{mg} \mathrm{mL}^{-1}\right)$ was added into DTT solutions $\left(0.15\right.$ and $\left.0.35 \mathrm{mg} \mathrm{mL}^{-1}\right)$ in $10 \mathrm{mM} \mathrm{Na}_{2} \mathrm{HPO}_{4}$ and the mixtures were analyzed by CE-UV at regular time intervals up to $120 \mathrm{~min}$. As shown in Fig. 6.7, \% DTT adsorption exhibited a fast initial increase followed by a leveling off as time proceeded. The adsorption equilibrium was reached within 90 min for the two DTT concentrations studied. 


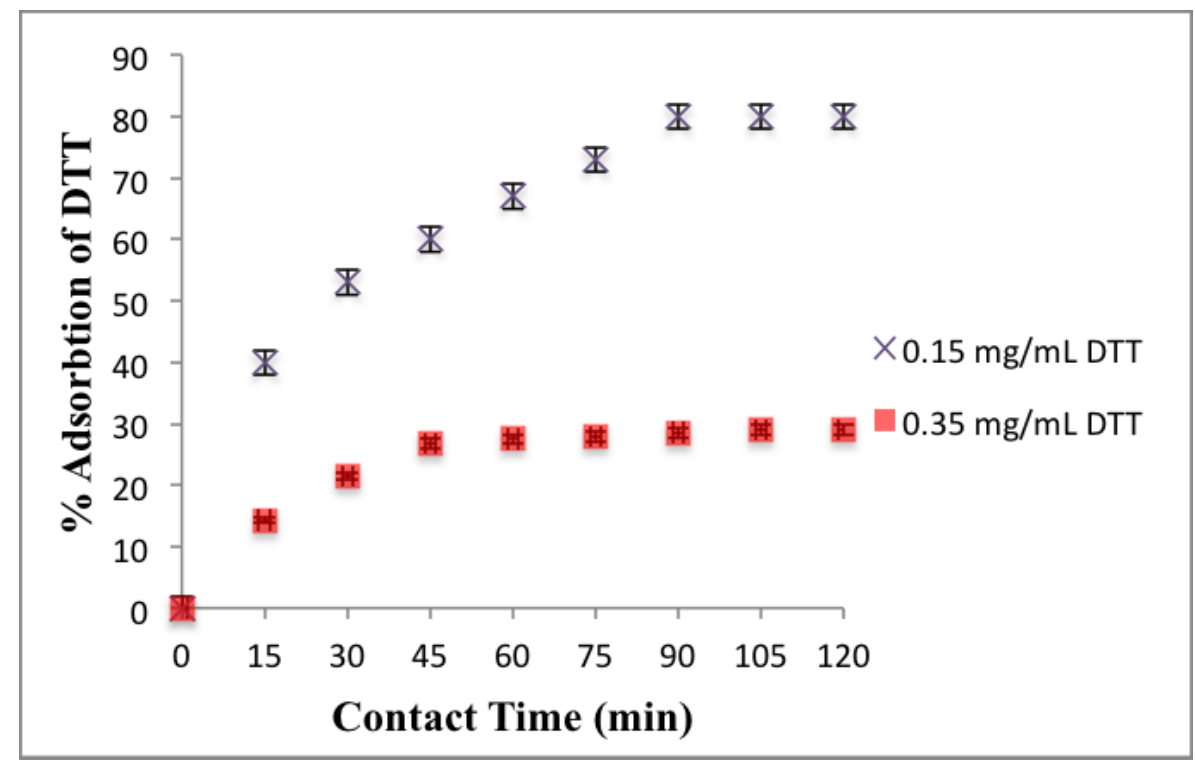

Figure 6.7 Effect of contact time on the kinetics of DTT adsorption at two different concentrations onto $\mathrm{ZnO}$ nanoparticles.

Pseudo-first-order, pseudo-second-order and intraparticle diffusion models were applied for characterizing the kinetics for DTT adsorption to provide valuable insights into the mechanism of reaction. The Lagergren's pseudo-first order rate equation had previously been used to describe liquid-solid adsorption systems. [227] Its linear form is expressed as:

$\log \left(q_{e}-q_{t}\right)=\log q_{e}-\left(\frac{k_{1}}{2.303}\right) t$

where $q_{e}$ and $q_{t}\left(\mathrm{mg} \mathrm{g}^{-1}\right)$ are the adsorption capacities at equilibrium and at time $\mathrm{t}$, respectively. $k_{1}\left(\mathrm{~min}^{-1}\right)$ is the pseudo-first order rate constant; their values are presented in Table 6.1. The coefficient of determination $\left(\mathrm{R}^{2}\right)$ values for the pseudo-first-order rate equation were the same and equal to 0.81 . The calculated values of $q_{e}$ (obtained by the pseudo-first-order model) were much larger than the experimental value.

The kinetics data were next analyzed by the pseudo-second order kinetic model. The linear form of this model is generally expressed, as proposed by Ho and McKay [228] as: $\frac{\boldsymbol{t}}{\boldsymbol{q}_{t}}=\left(\frac{1}{\boldsymbol{k}_{2} \boldsymbol{q}_{e}^{2}}\right)+\frac{\boldsymbol{t}}{\boldsymbol{q}_{e}}$ 
where $k_{2}\left(\mathrm{~g} \mathrm{mg}^{-1} \mathrm{~min}^{-1}\right)$ is the pseudo-second-order rate constant.

The values of $q_{e}$ and $k_{2}$ were calculated from the slope and intercept of the plot shown in Fig. 6.8 and are summarized in Table 6.1. The $\mathrm{R}^{2}$ values for the pseudo-second-order rate equation were the same and equal to 0.99 . The calculated values of $q_{e}$ obtained by the pseudo-second-order model were 2000 and $3333 \mathrm{mg} \mathrm{g}^{-1}$.

The kinetics data were last analyzed by Weber-Morris intraparticle diffusion model [229]:

$$
q_{t}=k_{i d} t^{0.5}+C
$$

where $C$ is the intercept, $k_{i d}$ is the intraparticle diffusion rate constant $\left(\mathrm{mg} \mathrm{g}^{-1} \min ^{0.5}\right)$, which is the slope of the linear plot of $q_{t}$ versus $t^{0.5}$.In this model, the equilibrium changes as a function of $\left(\mathrm{Dt} / \mathrm{r}^{2}\right)^{0.5}$, where $\mathrm{D}$ is the diffusion coefficient $\left(\mathrm{nm}^{2} \mathrm{~s}^{-1}\right)$ and $\mathrm{r}$ is the particle radius $(\mathrm{nm})$.

The $\mathrm{R}^{2}$ values for the intraparticle diffusion equation were 0.97 and 0.78 . The calculated values of $q_{e}$ obtained were 1852 and $2707 \mathrm{mg} \mathrm{g}^{-1}$. In accordance with the Weber-Morris model, the intercept $C$ should cross the origin if the diffusion mechanism is controlled by intraparticle diffusion. However both intercepts did not cross the origin; therefore intraparticle diffusion was not the rate-limiting step. 
Table 6.1 Kinetic parameters for DTT adsorption onto ZnO nanoparticles

\begin{tabular}{|c|c|c|c|c|}
\hline $\begin{array}{l}\text { Kinetics } \\
\text { model }\end{array}$ & Linear Equation & Parameters & $\begin{array}{c}\text { Values } \\
\text { at } 0.15 \\
\text { mg mL }{ }^{-1} \\
\text { DTT }\end{array}$ & $\begin{array}{l}\text { Values } \\
\text { at } 0.35 \\
\text { mg mL }^{-1} \\
\text { DTT }\end{array}$ \\
\hline \multirow{3}{*}{$\begin{array}{l}\text { Pseudo-first } \\
\text { order }\end{array}$} & \multirow{3}{*}{$\log \left(q_{e}-q_{t}\right)=\log q_{e}-\left(\frac{k_{1}}{2.303}\right) t$} & $k_{1}\left(\min ^{-1}\right)$ & 0.079 & 0.191 \\
\hline & & $q_{e}\left(\mathrm{mg} \mathrm{g}^{-1}\right)$ & 10000 & 165959 \\
\hline & & $\mathrm{R}^{2}$ & 0.81 & 0.81 \\
\hline \multirow{3}{*}{$\begin{array}{c}\text { Pseudo- } \\
\text { second order }\end{array}$} & \multirow{3}{*}{$\frac{t}{q_{t}}=\left(\frac{1}{k_{2} q_{e}^{2}}\right)+\frac{t}{q_{e}}$} & $k_{2}\left(\mathrm{~g} \mathrm{mg}^{-1} \mathrm{~min}^{-1}\right)$ & 0.00001 & 0.00003 \\
\hline & & $q_{e}\left(\mathrm{mg} \mathrm{g}^{-1}\right)$ & 3333 & 2000 \\
\hline & & $\mathrm{R}^{2}$ & 0.99 & 0.99 \\
\hline \multirow[t]{3}{*}{$\begin{array}{l}\text { Intraparticle } \\
\text { diffusion }\end{array}$} & \multirow[t]{3}{*}{$q_{t}=k_{i d} t^{0.5}+C$} & $k_{i d}\left(\begin{array}{c}\mathrm{mg} \mathrm{g}^{-1} \mathrm{~min}^{-} \\
0.5\end{array}\right)$ & 189.25 & 110 \\
\hline & & $q_{e}\left(\mathrm{mg} \mathrm{g}^{-1}\right)$ & 2707 & 1852 \\
\hline & & $\mathrm{R}^{2}$ & 0.97 & 0.78 \\
\hline
\end{tabular}

The $\mathrm{R}^{2}$ values of different kinetic models in Table 6.1 were compared to select the best model. When the $\mathrm{R}^{2}$ value is close to 1 , it means that the experimental data and the model-predicted values are in agreement. It is quite clear from the results reported that the $\mathrm{R}^{2}$ value for pseudo-second-order kinetics (0.99) is the highest obtained. Thus, it can be concluded that the pseudo-second-order model is best fitted to the experimental kinetic data. The adsorption kinetics is governed by the rate of surface adsorption, which is the transition of adsorbate molecules from the free state in solution to the adsorbed state on the NP surfaces. 


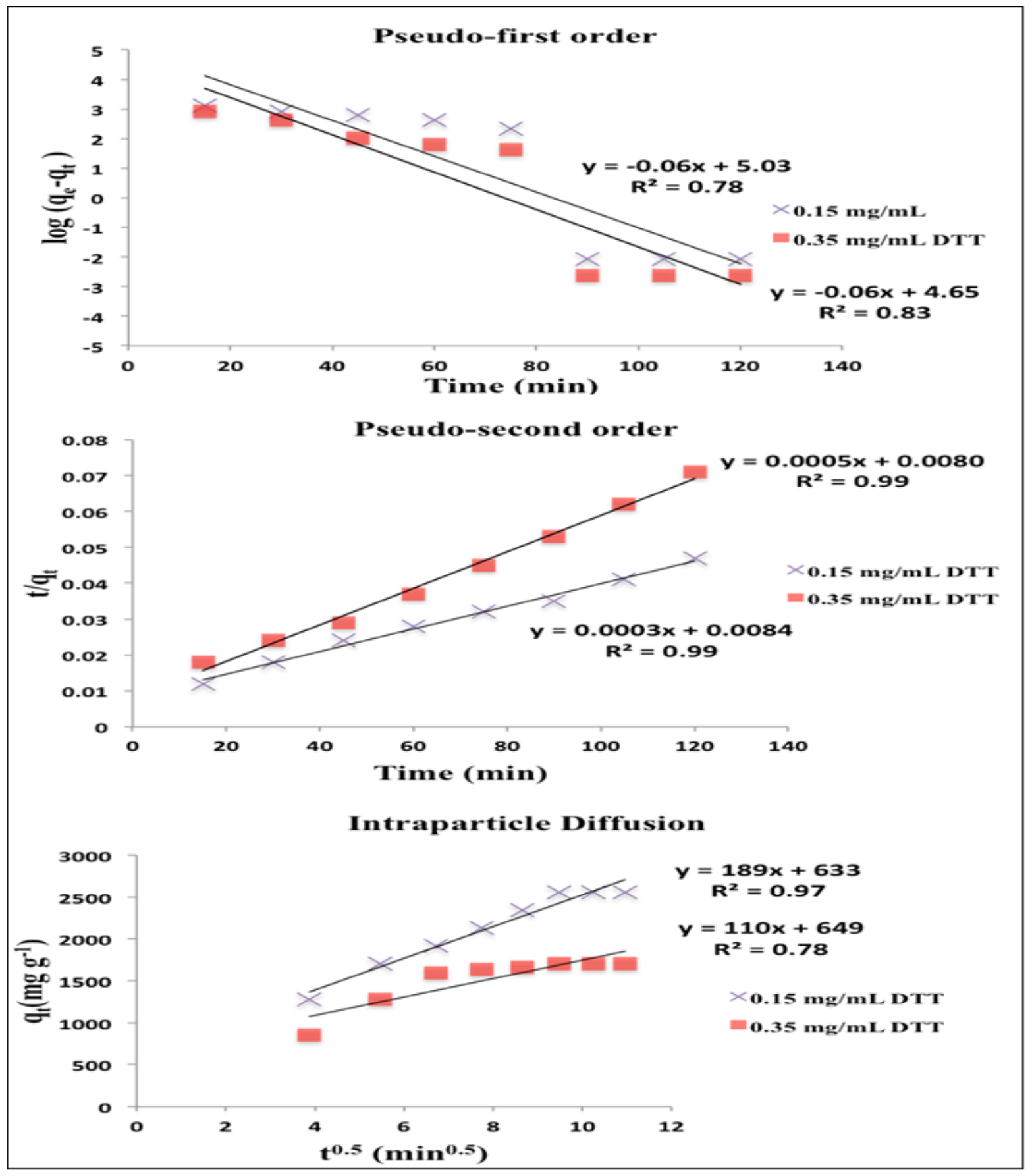

Figure 6.8 Pseudo-first-order kinetic, pseudo-second-order kinetic and intraparticle diffusion models for DTT adsorption onto $\mathrm{ZnO}$ nanoparticles.

Cys adsorption onto ZnO NPs was very rapid as the equilibrium was reached within $10 \mathrm{~min}$ and therefore kinetic study was not performed. 


\subsubsection{Adsorption isotherms}

Adsorption isotherms help to elucidate the adsorption behavior in liquid-solid systems and are represented as the amount of adsorbate molecules per unit adsorbent mass as a function of equilibrium concentration at a constant temperature. The fitting of equilibrium data to different isotherm models (including Langmuir, Freundlich and Temkin) were applied to study the adsorption behavior of DTT and Cys onto ZnO NPs. A previous investigation had found that $\mathrm{ZnO}$ NPs adsorbed cationic Victoria blue B dye from aqueous solution by the Langmuir and Temkin isotherm models. [230] The Langmuir model describes the saturated monolayer adsorption on homogenous adsorption sites [231,232], as represented by:

$$
\frac{C_{e}}{q_{e}}=\left(\frac{1}{q_{\max } b}\right)+\frac{C_{e}}{q_{\max }}
$$

where $C_{e}$ is the equilibrium concentration of the adsorbate in solution $\left(\mathrm{mg} \mathrm{L}^{-1}\right), q_{e}$ is the amount adsorbed per unit mass of adsorbent $\left(\mathrm{mg} \mathrm{g}^{-1}\right), q_{\max }$ is the maximum adsorption capacity $\left(\mathrm{mg} \mathrm{g}^{-1}\right)$, and $b\left(\mathrm{~L} \mathrm{mg}^{-1}\right)$ is the Langmuir isotherm constant which relates to the energy of adsorption. All Langmuir parameters and correlation coefficient are presented in Table 6.2. The characteristics of the Langmuir isotherm can be explained by the dimensionless constant, which is called the separation factor $\left(R_{L}\right)$ expressed as [233]:

$$
R_{L}=\frac{1}{1+b C_{0}}
$$

The value of $R_{L}$ indicates if the isotherm is either favorable $\left(0<R_{L}<1\right)$ or unfavorable $\left(R_{L}>1\right)$

The adsorption data were next analyzed by the Freundlich isotherm model, which assumes a multilayer adsorption on heterogeneous adsorption sites. The linear form of the Freundlich equation is expressed as [234]: 
$\log q_{e}=\log k_{f}+\frac{1}{n} \log C_{e}$

where $k_{f}\left(\mathrm{mg} \mathrm{g}^{-1}\right)$ is the adsorption capacity and $\frac{1}{n}$ is the adsorption intensity. The value of $\frac{1}{n}$ indicates if the isotherm is favorable $\left(0<\frac{1}{n}<1\right)$, unfavorable $\left(\frac{1}{n}>1\right)$ or irreversible $\left(\frac{1}{n}=0\right)$. The values of $\frac{1}{n}$ and $k_{f}$ obtained from the slope and intercept of the plot of $\log q_{e}$ vs $\log C_{e}$ are presented in Table 6.2

The adsorption data were last analyzed by the Temkin isotherm model, which assumes a monolayer adsorption on heterogeneous adsorption sites, expressed as [235]:

$$
q_{e}=\mathrm{B} \ln k_{t}+\mathrm{B} \ln C_{e}
$$

where $\mathrm{B}$ and $k_{t}$ are the Temkin isotherm constant $\left(\mathrm{J} \mathrm{mol}^{-1}\right)$ and equilibrium binding constant $\left(\mathrm{L} \mathrm{mg}^{-1}\right)$, respectively. The parameters of Temkin isotherm obtained from the linear plot of $q_{e} \mathrm{vs} \ln C_{e}$ are presented in Table 6.2.

The $\mathrm{R}^{2}$ values suggest that the experimental data are best represented by the Langmuir isotherm model, indicating the formation of a monolayer of DTT or Cys onto the surface of each $\mathrm{ZnO} \mathrm{NP}$. The value of $\mathrm{q}_{\max }$ calculated from the Langmuir isotherm is higher for Cys that that of DTT. This might be affected by the orientation of each adsorbate on the $\mathrm{ZnO}$ NP surface. Cys has only one probable adsorption mode on the $\mathrm{ZnO}$ surface, which is the vertically aligned mode. This would intuitively allow more Cys molecules to be adsorbed. On the other hand, DTT adsorption is more likely to have a mixed conformation (i.e., a combination of the three possible modes of adsorption; vertically aligned, horizontally aligned and cross-linking modes)[236] on the $\mathrm{ZnO}$ surface. 
Table 6.2 Isotherm models parameters for the adsorption of DTT and Cys onto $\mathrm{ZnO}$ nanoparticles

\begin{tabular}{|c|c|c|c|c|c|c|c|c|c|c|}
\hline Adsorbate & \multicolumn{3}{|c|}{ Langmuir } & \multicolumn{3}{c|}{ Freundlich } & \multicolumn{3}{c|}{ Temkin } \\
\hline & $\begin{array}{c}q_{\text {max }} \\
\left(\mathrm{mg} \mathrm{g}^{-1}\right)\end{array}$ & $\begin{array}{c}b \\
\left(\mathrm{~L} \mathrm{mg}^{-1}\right)\end{array}$ & $R_{L}$ & $\mathrm{R}^{2}$ & $\begin{array}{c}k_{f} \\
\left(\mathrm{mg} \mathrm{g}^{-1}\right)\end{array}$ & $\frac{1}{n}$ & $\mathrm{R}^{2}$ & $k_{t}$ & $\mathrm{~B}$ & $\mathrm{R}^{2}$ \\
$\left(\mathrm{~L} \mathrm{mg}^{-1}\right)$ & $\left(\mathrm{J} \mathrm{mol}^{-1}\right)$ & \\
\hline DTT & 2500 & 0.19 & 0.03 & 0.99 & 1938 & 0.06 & 0.68 & 620983 & 139.7 & 0.67 \\
\hline Cys & 3333 & 0.14 & 0.05 & 0.99 & 2139 & 0.08 & 0.98 & 2590 & 253.6 & 0.98 \\
\hline
\end{tabular}




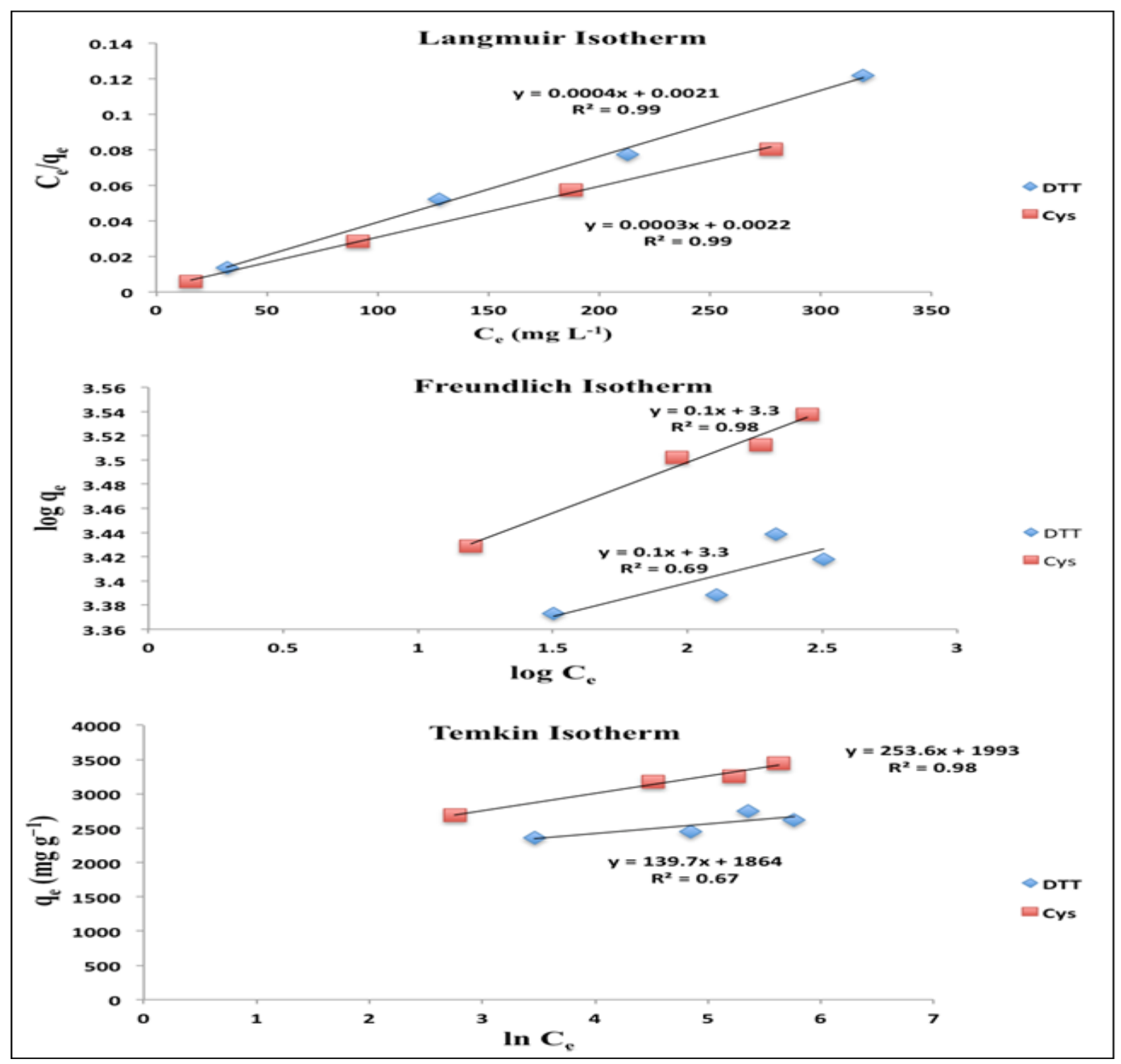

Figure 6.9 Langmuir, Freundlich and Temkin isotherm models for DTT adsorption onto $\mathrm{ZnO}$ nanoparticles.

\subsubsection{Effect of ZnO dose on DTT and Cys adsorption}

The effect of $\mathrm{ZnO}$ dose $\left(0.02-0.2 \mathrm{mg} \mathrm{mL}^{-1}\right)$ on the adsorption of DTT and Cys $\left(0.45 \mathrm{mg} \mathrm{mL}^{-1}\right)$ was next investigated. As shown in Fig. 6.10, a linear increase of \% adsorption of DTT and Cys was achieved with increasing ZnO dose. DTT adsorption was completed using $0.14 \mathrm{mg} \mathrm{mL}^{-1}$ of ZnO NPs with $99 \%$ of $2.9 \mathrm{mM}$ DTT adsorption while 3.7 mM Cys adsorption reached 98\% using $0.20 \mathrm{mg} \mathrm{mL}^{-1}$ of $\mathrm{ZnO}$ NPs. 


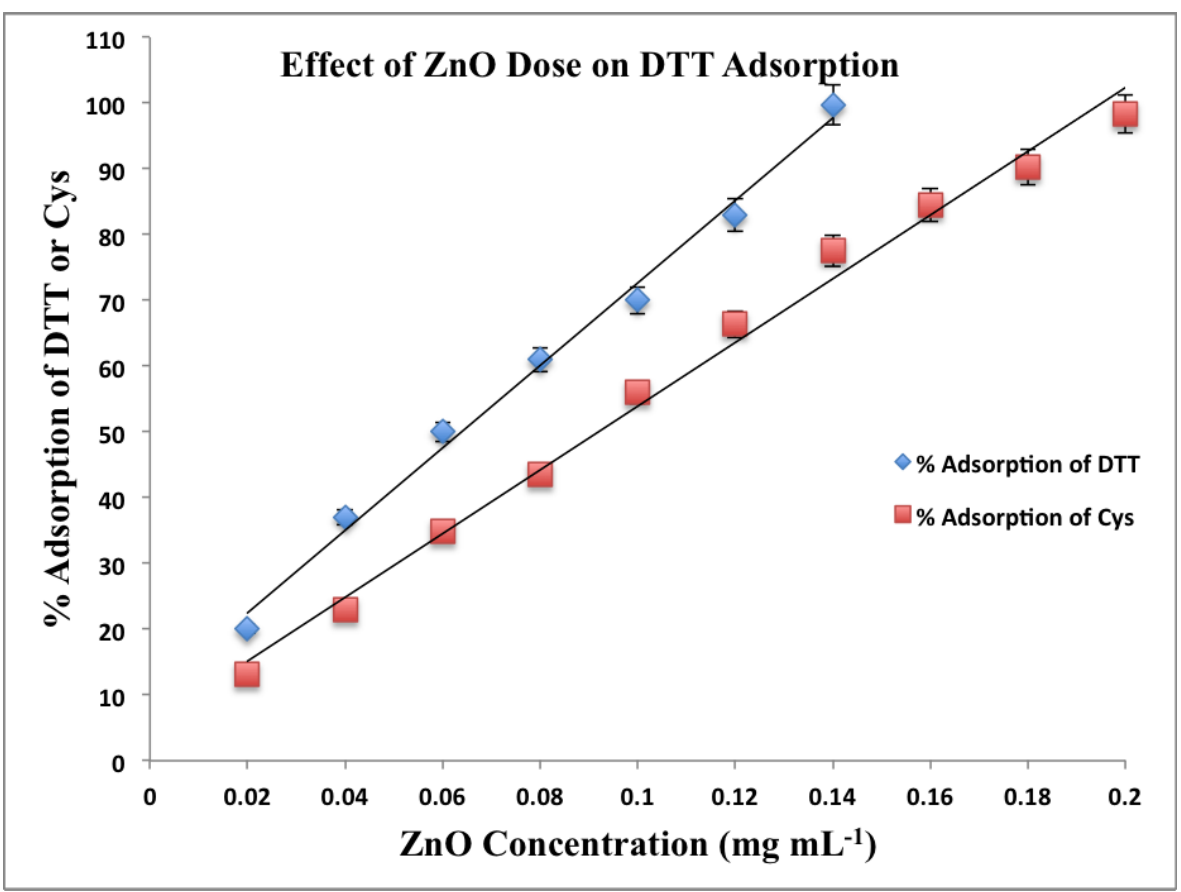

Figure 6.10 Effect of $\mathrm{ZnO}$ dose on \% adsorption of DTT and Cys.

\subsubsection{DTT and Cys adsorption onto $\mathrm{Al}_{2} \mathrm{O}_{3}, \mathrm{CeO}_{2}, \mathrm{SiO}_{2}$ and $\mathrm{TiO}_{2}$ nanoparticles}

DTT or Cys $\left(0.45 \mathrm{mg} \mathrm{mL} \mathrm{m}^{-1}\right)$ was added into other types of NPs, namely $\mathrm{Al}_{2} \mathrm{O}_{3}$, $\mathrm{CeO}_{2}, \mathrm{SiO}_{2}$ and $\mathrm{TiO}_{2},\left(1 \mathrm{mg} \mathrm{mL}{ }^{-1}\right)$, suspended in $10 \mathrm{mM} \mathrm{Na}_{2} \mathrm{HPO}_{4}$ for comparison. The CE-UV analysis results showed no changes in the peak area of either adsorbates or NPs, indicating no occurrence of adsorption. These results confirm the selectivity of DTT and Cys towards $\mathrm{ZnO}$, without any potential interference by the presence of $\mathrm{Al}_{2} \mathrm{O}_{3}, \mathrm{CeO}_{2}$, $\mathrm{SiO}_{2}$ and $\mathrm{TiO}_{2} \mathrm{NPs}$, in aqueous suspension. A plausible explanation of the selectivity of DTT and Cys towards $\mathrm{ZnO}$ is the strong affinity of thiols to zinc [237] compared with aluminum, cerium, silicon and titanium. In contrast to $\mathrm{TiO}_{2}, \mathrm{ZnO}$ exhibited a stronger adsorption for thiol-functionalized dyes than carboxylic acid-functionalized dyes via the formation of $\mathrm{Zn}-\mathrm{S}$ bonds. [238] Also, $\mathrm{Al}_{2} \mathrm{O}_{3}$ and $\mathrm{TiO}_{2}$ strongly adsorbed phosphate anions [239,240] present in the $10 \mathrm{mM} \mathrm{Na}_{2} \mathrm{HPO}_{4}$ medium, possibly forming a layer 
surrounding the NPs that prevented their interaction with DTT and Cys. The redox property of $\mathrm{CeO}_{2}$ was blocked by phosphate anions that occupied the oxygen vacancies at the surface forming $\mathrm{CePO}_{4}$ due to the strong association between cerium and phosphate. Blocking surface sites with phosphate had previously been reported to avert the $\mathrm{CeO}_{2}$ toxicity. [241] This high affinity for phosphate most likely prevented DTT and Cys from adsorbing onto the $\mathrm{CeO}_{2} \mathrm{NP}$ surfaces. Moreover, $\mathrm{SiO}_{2}$ showed no affinity for thiols [242,243], hence facilitating neither DTT nor Cys adsorption onto the NP surfaces.

\subsubsection{Dynamic light scattering}

Aqueous suspensions of the original and DTT-adsorbed ZnO NPs were analyzed by DLS to determine their hydrodynamic diameters with the hope of gaining more insight regarding their size increase after DTT addition. The hydrodynamic diameter represents the actual particle diameter plus the surrounding layer of hydrated adsorbates when the particle undergoes Brownian motion. As shown in Table 6.3, mean diameters of $355 \pm 17$ $\mathrm{nm}$ and $404 \pm 22 \mathrm{~nm}$ were obtained for ZnO and DTT-ZnO NPs, respectively. Apparently DTT formed a layer (hydrodynamically $25 \mathrm{~nm}$ thick) surrounding each agglomerate of $\mathrm{ZnO}$ NPs. These results provide strong evidence that ZnO NPs in water can adsorb DTT to develop a strongly light-absorbing layer surrounding the NPs under very simple experimental conditions to offer more sensitive detection by CE-UV. On the other hand, Cys adsorption onto $\mathrm{ZnO}$ NPs reduced their average hydrodynamic diameter down to $198 \pm 6 \mathrm{~nm}$. Cys adsorption onto $\mathrm{ZnO}$ increased its migration time to $7.6 \mathrm{~min}$ due to more negative charges on its surface. The higher negative charges improved the colloidal stability of the resultant Cys-ZnO nanoparticles. DLS analysis showed no significant change in the hydrodynamic diameters of $\mathrm{Al}_{2} \mathrm{O}_{3}, \mathrm{CeO}_{2}, \mathrm{SiO}_{2}$ and $\mathrm{TiO}_{2} \mathrm{NPs}$ after DTT or 
Cys addition, as summarized in Table 6.3. This confirms the above CE-UV analysis results (in Section 6.4.6) that indicated no DTT or Cys adsorption onto these NPs.

Table 6.3 Hydrodynamic diameters of $\mathrm{Al}_{2} \mathrm{O}_{3}, \mathrm{CeO}_{2}, \mathrm{SiO}_{2}, \mathrm{TiO}_{2}$ and $\mathrm{ZnO}$ nanoparticles measured by DLS before and after addition of DTT or Cys.

\begin{tabular}{|c|c|c|c|}
\hline & $\begin{array}{c}\text { Hydrodynamic } \\
\text { Diameter of Original } \\
\text { Nanoparticles (nm) }\end{array}$ & $\begin{array}{c}\text { Hydrodynamic } \\
\text { Diameter of } \\
\text { Nanoparticles After } \\
\text { DTT Addition (nm) }\end{array}$ & $\begin{array}{c}\text { Hydrodynamic } \\
\text { Diameter of } \\
\text { Nanoparticles } \\
\text { After Cys } \\
\text { Addition (nm) }\end{array}$ \\
\hline $\mathrm{Al}_{2} \mathrm{O}_{3}$ & $425 \pm 18$ & $430 \pm 17$ & $421 \pm 15$ \\
\hline $\mathrm{CeO}_{2}$ & $264 \pm 7$ & $262 \pm 12$ & $260 \pm 4$ \\
\hline $\mathrm{SiO}_{2}$ & $95 \pm 2$ & $91 \pm 4$ & $96 \pm 10$ \\
\hline $\mathrm{TiO}_{2}$ & $450 \pm 24$ & $448 \pm 22$ & $440 \pm 30$ \\
\hline $\mathrm{ZnO}$ & $355 \pm 17$ & $404 \pm 22$ & $198 \pm 6$ \\
\hline
\end{tabular}

\subsection{Conclusion}

A simple and rapid method has been developed for the detection of $\mathrm{ZnO}$ NPs in aqueous suspensions by CE-UV analysis. Modeling by the Langmuir isotherm confirmed the adsorption in a monolayer of DTT or Cys molecules around the NPs to enhance their colloidal stability and UV light absorptivity. Adsorption equilibrium was reached within 90 min for DTT but only 10 min for Cys. Cys adsorption onto ZnO NPs prevented their aggregation. After centrifugation of the transparent Cys- $\mathrm{ZnO}$ suspension, no precipitation of NPs occurred. This greatly helped to separate Cys-ZnO NPs from any precipitated $\mathrm{Al}_{2} \mathrm{O}_{3}, \mathrm{CeO}_{2}$ and $\mathrm{TiO}_{2}$ NPs. DTT and Cys adsorption onto $\mathrm{ZnO}$ NPs enhanced the UV detection sensitivity of ZnO NPs by $28 \pm 1$ and $25 \pm 1$ fold, respectively. Importantly, any 
observed changes in CE migration time and UV peak area could identify the analyte to be NPs but not solute species. More significantly, the developed method is selective towards $\mathrm{ZnO}$ NPs even in the presence of $\mathrm{Al}_{2} \mathrm{O}_{3}, \mathrm{CeO}_{2}, \mathrm{SiO}_{2}$ and $\mathrm{TiO}_{2} \mathrm{NPs}$ in the water sample. Potential matrix interference can be minimized by sample dialysis to remove UV-absorbing solutes prior to the addition of DTT or Cys for CE-UV analysis.

\subsection{Connection to chapter 7}

DTT and Cys showed a rapid and selective adsorption onto $\mathrm{ZnO}$ in the presence of $\mathrm{Al}_{2} \mathrm{O}_{3}, \mathrm{CeO}_{2}, \mathrm{SiO}_{2}$ and $\mathrm{TiO}_{2}$ NPs enhancing its $\mathrm{UV}$ detection sensitivity by $28 \pm 1$ and $25 \pm 1$ fold, respectively. Reaching this milestone, the ongoing research is concluded with accomplishments summarized in Chapter 7. 


\section{Chapter 7: Conclusions}

\subsection{General conclusions and outlook}

The projects described in this thesis all concern the quantitative determination of metal/metalloid oxide NPs in aqueous solutions using CE-UV analysis. CE has recently emerged as a well-suited technique for the analysis of environmental samples due to its separation capability. [86] During NPs analysis, it is of critical importance to consider their stability and tendency to aggregate in solution as a consequence of their intrinsic characteristics such as size and surface chemistry in combination with the complex aqueous matrices found in realistic environmental conditions.

A rapid, simple, cost- effective and highly efficient CE-based method for the analysis of NPs was developed. Herein, various polymeric and molecular coatings were investigated to assess their feasibility of enhancing the UV detection of different metal/metalloid oxide NPs including $\mathrm{SiO}_{2}, \mathrm{TiO}_{2}$ and $\mathrm{ZnO}$, optimizing parameters such as the compositions and concentration of the BGE, the injection time, the applied voltage and the use of surfactants. This method allowed for the separation of various components in the analysis mixture including the monomer and polymer as well as bare and coated NPs. Also, UV detection at different wavelengths enabled optimizing the measurement sensitivity and selectivity. Moreover, changes observed in CE migration time and UV peak area could identify the analyte to be NPs but not solute species. The obtained results suggest the viability of the method for the direct detection of NPs in environmental waters in hopes to assess their potential risks for humans and the environment. However, the obtained detection limits are still not adequate for the quantitative determination of NPs in environmental waters, despite the many folds enhancements in UV detection. 
Also, the lack of CRMs, particularly for the mass concentration of NPs, hindered the validation of the developed method.

The work presented in chapter 3 concerned the CE-UV characterization and detection of colloidal $\mathrm{SiO}_{2} \mathrm{NPs}$ in water. The challenge of inadequate sensitivity was tackled using technically simple and operationally cost effective solutions. PHPMA and PDA coatings resulted in a moderate enhancement of the UV detection sensitivity of $\mathrm{SiO}_{2}$ NPs of about $12 \pm 2$ fold, demonstrating the feasibility of the method towards the quantitative determination of NPs in water. However, the partial coating of $\mathrm{SiO}_{2} \mathrm{NPs}$, the modest enhancement factors and the long polymerization time suggested the need for thicker polymer coatings to attain higher sensitivity preferably in shorter times.

These challenges were tackled in chapter 4 by studying $\mathrm{SiO}_{2}$ interaction with HPMA and chitosan, each of which were able to produce larger sizes of $\mathrm{SiO}_{2}$ for more sensitive detection by CE-UV. On the contrary, no interactions with $\mathrm{TiO}_{2} \mathrm{NPs}$ in $10 \mathrm{mM}$ $\mathrm{Na}_{2} \mathrm{HPO}_{4}$ could take place, resulting in no change of their CE-UV detection sensitivity. Chitosan coating was more efficient producing a significant increase in $\mathrm{SiO}_{2}$ hydrodynamic diameter. However, CE-UV analysis of chitosan or chitosan- coated $\mathrm{SiO}_{2}$ failed due to the adsorption of chitosan onto the capillary wall affecting the EOF. Subsequent HPMA binding facilitated the CE-UV analysis without any disturbance. A total enhancement of $50 \pm 1$ fold in $\mathrm{SiO}_{2}$ detection sensitivity was gained after chitosan coating and HPMA binding. The applied method is simple, rapid and most importantly selective for $\mathrm{SiO}_{2}$ in the presence of $\mathrm{TiO}_{2} \mathrm{NPs}$ in $10 \mathrm{mM} \mathrm{Na}_{2} \mathrm{HPO}_{4}$. Also, it is more environmentally friendly as no chemical initiator was required, unlike the in-situ polymerization of HPMA. Nonetheless, the promising enhancement of $50 \pm 1$ fold in 
detection sensitivity is still not sufficient for the quantitative determination of NPs at environmentally relevant concentrations.

Further investigation of the binding interaction of other polymers including DNA and PEG as well as the UV absorbing surfactant, TX-100, onto $\mathrm{Al}_{2} \mathrm{O}_{3}, \mathrm{SiO}_{2}, \mathrm{TiO}_{2}$ and $\mathrm{ZnO}$ NPs was ensued in chapter 5. The equilibrium was reached within 3 hours, improving the speed of analysis. All adsorbates were selective for $\mathrm{TiO}_{2} \mathrm{NPs}$ in $100 \mathrm{mM}$ Tris, enabling the enhancement of many folds in UV detection sensitivity in CE analysis. The reaction medium was the most influencing factor controlling the selectivity of various adsorbates towards $\mathrm{TiO}_{2}$ NPs. ssDNA exhibited more adsorption onto $\mathrm{TiO}_{2} \mathrm{NPs}$ among the other adsorbates. ssDNA+PEG produced a progressive enhancement of $13 \pm 3$ fold in UV detection sensitivity of $\mathrm{TiO}_{2}$ NPs, reporting on the total surface area of disaggregated NPs, as well as their chemical functionality.

Thiol molecular coatings including DTT and Cys, investigated in chapter 6, were found to be selective for $\mathrm{ZnO}$ in the presence of $\mathrm{Al}_{2} \mathrm{O}_{3}, \mathrm{CeO}_{2}, \mathrm{SiO}_{2}$ and $\mathrm{TiO}_{2} \mathrm{NPs}$ in 10 $\mathrm{mM} \mathrm{Na} 2 \mathrm{HPO}_{4}$. Adsorption equilibrium was reached within 90 min for DTT but only 10 min for Cys, further improving the speed of analysis. A monolayer of DTT or Cys molecules around $\mathrm{ZnO}$ NPs enhanced their colloidal stability and UV light absorptivity. Cys adsorption onto ZnO NPs enabled their long-term colloidal stability. Centrifugation of the transparent Cys-ZnO suspension showed no precipitation of the NPs, allowing their separation from any precipitated $\mathrm{Al}_{2} \mathrm{O}_{3}, \mathrm{CeO}_{2}$ and $\mathrm{TiO}_{2}$ NPs. Promising enhancement factors of $28 \pm 1$ and $25 \pm 1$ fold were attained after DTT and Cys adsorption onto $\mathrm{ZnO} \mathrm{NPs}$, respectively. 
In-capillary stacking can greatly help to concentrate water samples providing more than 10 fold improvement in detector response. It is based on a sudden change in the analyte electrophoretic velocity that can be brought about by different magnitudes of the electric field in the water sample versus the BGE. Environmental water samples can be treated prior to $\mathrm{CE}$ analysis by dialysis to reduce their conductivity for in-capillary stacking. Concentric dialysis tubes of ultra-high MWCOs can be used to fractionate NPs on the basis of size and to remove unwanted microparticles. Now that the feasibility is demonstrated for this approach, exploring various fluorescent probes to further enhance the sensitivity should be exciting. Introducing a fluorescent label to $\mathrm{SiO}_{2} \mathrm{NPs}$ directly in aqueous solutions by employing a cationic inorganic dye, tris $\left(2,2^{\prime}-\right.$ bipyridyl)dichlororuthenium(II) hexahydrate, $\mathrm{Ru}(\mathrm{bpy})_{3}$, for laser induced fluorescence (LIF) detection in CE analysis can be explored.

DAPI (4',6-diamidino-2-phenylindole), a DNA-specific probe, could form a fluorescent complex by attaching in the minor groove of A-T rich sequences of DNA, enabling its visualization and quantitation. DAPI can be investigated for the detection of DNA-stabilized $\mathrm{TiO}_{2}$ NPs using CE-LIF.

Graphene quantum dots (GQDs), the zero-dimensional form of graphene with diameters below $100 \mathrm{~nm}$, offer a promising potential in divers applications due to their tunable electronic and optoelectronic properties directly associated with quantum confinement and chemical functionalization. GQDs can be easily prepared in aqueous solutions using citric acid via hydrothermal process at a high temperature. GQDs can be simultaneously functionalized with Cys in a basic environment through an amidation reaction. ${ }^{244]}$ Cys-GQDs can be explored as a fluorescent probe for the sensitive 
detection of $\mathrm{ZnO}$ NPs in water using CE-LIF.

With the successful application of these proposed strategies in improving the detection sensitivity of NPs, the method must be validated using CRMs to assure its applicability for the quantitative determination of NPs in real-world water samples.

\subsection{Contributions to knowledge}

The main goal of this research was to investigate whether UV detection can be made more sensitive for the quantitative determination of metal/metalloid oxide NPs in aqueous suspensions for direct $\mathrm{CE}$ analysis. Molecular layers and polymeric coatings could selectively form on different types of NPs to produce stronger peaks at shifted migration times for enhanced colloidal stability and detection limits as well as unmistaken identification. While this research provides a number of important insights, it devoted significant efforts on optimizing the CE-UV analysis of NPs. The developed method is exciting because it bridges the well-known advantages of CE analysis and the achievable improvement of UV detection in a simple, rapid and cost effective technique. UV detection sensitivities can in principle be further enhanced by multiple molecular layers and polymeric coatings, being limited only by the onset of NPs precipitation. The selectivity and identity knowledge can promote the direct detection of NPs in environmental waters to gain prominent understanding of their behavior, fate and toxicity. 


\section{References}

[1] Policy Statement on Health Canada's Working Definition for Nanomaterial. Health Canada. 2011, http://www.hc-sc.gc.ca/sr-sr/pubs/nano/faq-eng.php, accessed 21092016.

[2] Bottero JY. Environmental Risks of Nanotechnology: A New Challenge? Nanosci Nanotechnol. Springer International Publishing, Switzerland. 2016;287-311.

[3] Stark WJ, Stoessel PR, Wohlleben W, Hafner A. Industrial applications of nanoparticles. Chem Soc Rev. 2015;44:5793-5805.

[4] Teske SS, Detweiler CS. The Biomechanisms of Metal and Metal-Oxide Nanoparticles' Interactions with Cells. Int J Environ Res Public Health. 2015; 12:1112-1134.

[5] Rajakumar G, Abdul Rahuman A. Phytosynthesis of metal and metal-oxide nanoparticles - technological concepts and their biomedical applications. Springer International Publishing, Switzerland. 2016;8:51-80.

[6] Bendicho C, Bendicho-Lavilla C, Lavilla I. Nanoparticle-assisted chemical speciation of trace elements. Trends Anal Chem. 2016;77:109-121.

[7] Siauw M, Du K, Valade D, Trefonas P, Thackeray JW, Whittaker A, Blakey I. Systematic investigation of the synthesis, characterization and switching mechanism of metal oxide nanoparticle resists. Proc SPIE. 2016;9779: 1-12.

[8] Liu D, Pourrahimi AM, Pallon LKH, Sánchez CC, Olsson RT, Hedenqvist MS, Fogelström L, Malmström E, Gedde UW. Interactions between a phenolic antioxidant, moisture, peroxide and crosslinking by-products with metal oxide nanoparticles in branched polyethylene. Polym Degrad Stab. 2016;125: 21-32.

[9] Milanese M, Colangelo G, Cretì A, Lomascolo M, Iacobazzi F, de Risi A. Optical absorption measurements of oxide nanoparticles for application as nanofluid in direct absorption solar power systems - part I: water-based nanofluids behavior. Sol Energy Mater Sol Cells. 2016;147: 315-320.

[10] Dave PN, Ram PN, Chaturvedi S. Transition metal oxide nanoparticles: Potential nano-modifier for rocket propellants. Part Sci Technol. 2016; 34:676-680.

[11] Gliech M, Bergmann A, Spöri C, Strasser P. Synthesis-structure correlations of manganese-cobalt mixed metal oxide nanoparticles. J Energ Chem. 2016; 25:278-281.

[12] Wiechers JW, Musee N. Engineered Inorganic Nanoparticles and Cosmetics: Facts, Issues, Knowledge Gaps and Challenges. J Biomed Nanotechnol. 2010;6:408-431. 
[13] Weir A, Westerhoff P, Fabricius L, Hristovski K, Goetz N. Titanium dioxide nanoparticles in food and personal care products. Environ Sci Technol. 2012;46: 22422250 .

[14] Nagelreiter C, Valenta C. Size analysis of nanoparticles in commercial O/W sunscreens. Int J Pharm. 2013;456: 517-519.

[15] Spinazzè A, Cattaneo A, Limonta M, Bollati V, Bertazzi PA, Cavallo DM. Titanium dioxide nanoparticles: occupational exposure assessment in the photocatalytic paving production. J Nanopart Res. 2016;18:151-163.

[16] Lee SJ, Cho IH, Kim H, Hong SJ. Microstructure characterization of $\mathrm{TiO}_{2}$ photoelectrodes for dye-sensitized solar cell using statistical design of experiments. Trans Electr Electron Mater. 2009;10:177-181.

[17] Gong ZG. Nanotechnology application in sports. Adv Mat Res. 2013;662:186- 189.

[18] Abramova A, Gedanken A, Popov V, Ooi EH, Mason TJ, Joyce EM, Beddow J, Bayazitov V. A sonochemical technology for coating of textiles with antibacterial nanoparticles and equipment for its implementation. Mater Lett. 2013;96: 121-124

[19] Khan MJ, Maskat MY. Interaction of titanium dioxide nanoparticles with human serum albumin: a spectroscopic approach. Int J Pharm Pharm Sci. 2014;6:43-46.

[20] Galletti A, Seo S, Joo SH, Su C, Blackwelder P. Effects of titanium dioxide nanoparticles derived from consumer products on the marine diatom Thalassiosira pseudonana. Environ Sci Pollut Res. 2016;23:21113-21122.

[21] Nakataa K, Fujishima A. TiO2 photocatalysis: Design and applications. J Photochem Photobiol C: Photochem Rev. 2012;13:169- 189.

[22] Sirelkhatim A, Mahmud S, Seeni A, Haida N, Kaus M, Ann LC, Bakhori SKM, Hasan H, Mohamad D. Review on Zinc Oxide Nanoparticles: Antibacterial Activity and Toxicity Mechanism. NanoMicro Lett. 2015;7: 219-242.

[23] Bajpai SK, Jadaun M, Tiwari S. Synthesis, characterization and antimicrobial applications of zinc oxide nanoparticles loaded gum acacia/poly(SA) hydrogels. Carbohydr Polym. 2016;153: 60-65.

[24] Tomino M, Nagano K, Hayashi T, Kuroki K, Kawai T. Antimicrobial efficacy of gutta-percha supplemented with cetylpyridinium chloride. J Oral Sci. 2016;58:277-282. 
[25] Morimoto Y, Izumi H, Yoshiura Y, Tomonaga T, Oyabu T, Myojo T, Kawai K, Yatera K, Shimada M, Kubo M, Yamamoto K, Kitajima S, Kuroda E, Kawaguchi K, Sasaki T. Evaluation of pulmonary toxicity of zinc oxide nanoparticles following inhalation and intratracheal instillation. Int J Mol Sci. 2016;17:1241-1257.

[26] Abdelaal EA, Rashad MM, ElShazly EN, Ibrahim IA, ElShahat MF. Hydrometallurgical treatment of non-sulfide zince ore for precipitation of zinc oxide nanoparticles. Physicochem Probl Miner Process. 2016;52:729-737.

[27] Wahab R, Khan F, Yang YB, Hwang IH, Shin HS, Ahmad J, Dwivedi S, Khan ST, Siddiqui MA, Saquib Q, Musarrat J, AlKhedhairy AA, Mishrai YK, Alibj BA. Zinc oxide quantum dots: multifunctional candidates for arresting $\mathrm{C} 2 \mathrm{C} 12$ cancer cells and their role towards caspase 3 and 7 genes. RSC Adv. 2016;6: 26111-26120.

[28] Boruah BD, Misra A. Conjugated assembly of colloidal zinc oxide quantum dots and multiwalled carbon nanotubes for an excellent photosensitive ultraviolet photodetector Nanotechnol. 2016; 27:355204- 355212.

[29] Repp S, Erdem E. Controlling the exciton energy of zinc oxide quantum dots by changing the confinement conditions. Spectrochim Acta Mol Biomol Spectrosc. 2016;152:637-644.

[30] Bharthasaradhi R, Nehru LC. Structural and phase transition of $\alpha$-Al2O3 powders obtained by co-precipitation method. Phase Transitions. 2016;89:77-83.

[31] Mui J, Ngo J, Kim B. Aggregation and Colloidal Stability of Commercially Available A12O3 Nanoparticles in Aqueous Environments. Nanomaterials. 2016;6: 90-115.

[32] Taylor NS, Merrifield R, Williams TD, Chipman JK, Lead JR,Viant MR. Molecular toxicity of cerium oxide nanoparticles to the freshwater alga Chlamydomonas reinhardtii is associated with supra-environmental exposure concentrations. Nanotoxicology. 2016; 10: 32-41.

[33] Golmohammadi M, Ahmadi SJ, Towfighi J. Catalytic cracking of heavy petroleum residue in supercritical water: study on the effect of different metal oxide nanoparticles. $J$ Supercrit Fluids. 2016;113:136-143.

[34] Wang Y, Kalinina A, Sun T, Nowack B. Probabilistic modeling of the flows and environmental risks of nano-silica. Sci Total Environ. 2016;545-546;67-76.

[35] Nanoportal-Nanomaterial Uses. Comparison with Findings from other Commercial Data

Gathering

Activities. 
2015.http://nanoportal.gc.ca/default.asp?lang=En\&n=57FB12B0-1\&offset=2\&toc=hide, accessed date 5-12-2016.

[36] Heithmar EM. Screening Methods for Metal-Containing Nanoparticles in Water. U.S. Environmental Protection Agency (EPA). 2011, accessed date 5-12-2016.

[37] Gagnon C, Pilote M, Turcotte P, André C, Gagné F. Effects of exposure to zinc oxide nanoparticles in freshwater mussels in the presence of municipal effluents. ISJ. 2016;13:140-152.

[38] Liu HH, Cohen Y. Multimedia environmental distribution of engineered nanomaterials. Environ Sci Technol. 2014;48:3281-3292.

[39] Giovanni M, Tay CY, Setyawati MI, Xie J, Ong CN, Far R, Yue J, Zhang L, Leong DT. Toxicity profiling of water contextual zinc oxide, silver, and titanium dioxide nanoparticles in human oral and gastrointestinal cell systems. Environ Toxicol. 2015;30:1459-1469.

[40] Chang YN, Zhang M, Xia L, Zhang J, Xing G. The toxic effects and mechanisms of $\mathrm{CuO}$ and $\mathrm{ZnO}$ nanoparticles. Materials. 2012;5:2850-2871.

[41] Wehling J, Volkmann E, Grieb T, Rosenauer A, Maas M. A critical study: assessment of the effect of silica particles from 15 to $500 \mathrm{~nm}$ on bacterial viability. Environ Pollut. 2013;176:292-299.

[42] Hazeem LJ, Bououdina M, Rashdan S, Brunet L, Slomianny C, Boukherroub R. Cumulative effect of zinc oxide and titanium oxide nanoparticles on growth and chlorophyll a content of Picochlorum sp. Environ Sci Pollut Res. 2016;23:2821-2830.

[43] Tiede K, Hanssen SF, Westerhoff P, Fern GJ, Hankin SM, Aitken RJ, Chaudhry Q, Boxall ABA. How important is drinking water exposure for the risks of engineered nanoparticles to consumers?. Nanotoxicology. 2016;10:102-110.

[44] Wang B, He X, Zhang Z, Zhao Y, Feng W. Metabolism of nanomaterials in vivo: blood circulation and organ clearance. Acc Chem Res. 2013;46:761-769.

[45] Miranda RR, Silveira ALRD, de Jesus IP, Grötzner SR, Voigt CL, Campos SX, Garcia JRE, Randi MAF, Ribeiro CAO, Neto FF. Effects of realistic concentrations of $\mathrm{TiO}_{2}$ and $\mathrm{ZnO}$ nanoparticles in Prochilodus lineatus juvenile fish. Environ Sci Pollut Res. 2016;23:5179-5188. 
[46] Andersen CP, King G, Plocher M, Storm M, Pokhrel LR, Johnson MG, Rygiewicz PT. Germination and early plant development of ten plant species exposed to titanium dioxide and cerium oxide nanoparticles. Environ Toxicol Chem. 2016;35: 2223-2229.

[47] Rizwan M, Ali S, Qayyum MF, Ok YS, Adrees M, Ibrahim M, ZiaurRehman M, Farid $\mathrm{M}$, Abbas F. Effect of metal and metal oxide nanoparticles on growth and physiology of globally important food crops: a critical review. J Hazard Mater A. 2017; 322:2-16.

[48] Du W, Tan W, Peralta-Videab JR, Gardea-Torresdey JL, Jia R, Yin Y, Guo H. Interaction of metal oxide nanoparticles with higher terrestrial plants: physiological and biochemical aspects. Plant Physiol Biochem. 2017,110:210-225.

[49] Ko K, Kong IC. Toxic effects of nanoparticles on bioluminescence activity, seed germination, and gene mutation. Appl Microbiol Biotechnol. 2014;98: 3295-3303.

[50] Bondarenko OM, Heinlaan M, Sihtmäe M, Ivask A, Kurvet I, Joonas E, Jemec A, Mannerström M, Heinonen T, Rekulapelly R. Singh S, Zou J, Pyykköf I, Drobne D, Kahru A. Multilaboratory evaluation of 15 bioassays for (eco)toxicity screening and hazard ranking of engineered nanomaterials: FP7 project NANOVALID. Nanotoxicology. 2016;28:1-14

[51] Connolly M, Fernández M, Conde E, Torrent F, Navas JM, Fernández-Cruz ML. Tissue distribution of zinc and subtle oxidative stress effects after dietary administration of ZnO nanoparticles to rainbow trout. Sci Total Environ. 2016;551:334-343.

[52] Du J, Wang S, You H, Liu Z. Effects of $\mathrm{ZnO}$ nanoparticles on perfluorooctane sulfonate induced thyroid-disrupting on zebrafish larvae. J Environ Sci. 2016;47:153164.

[53] Strickland JD, Lefew WR, Crooks J, Hall D, Ortenzio JNR, Dreher K, Shafer TJ. In vitro screening of metal oxide nanoparticles for effects on neural function using cortical networks on microelectrode arrays. Nanotoxicology. 2016;10:619-628.

[54] Aude-Garcia C, Dalzon B, Ravanat JL, Collin-Faure V, Diemer H, Strub JM, Cianferani S, Dorsselaer AV, Carrière M, Rabilloud T. A combined proteomic and targeted analysis unravels new toxic mechanisms for zinc oxide nanoparticles in macrophages. J Proteomics. 2016;134: 174-185.

[55] Tyagia N, Srivastavaa SK, Aroraa S, Omara Y, Ijaza ZM, ALGhadhbana A, Deshmukha SK, Carterd JE, Singha AP, Singh S. Comparative analysis of the relative potential of silver, Zinc-oxide and titanium-dioxide nanoparticles against UVB-induced DNA damage for the prevention of skin carcinogenesis. Cancer Lett. 2016;383:53-61. 
[56] Xia T, Kovochich M, Liong M, Mädler L, Gilbert B, Shi H, Yeh JI, Zink JI, Nel AE. Comparison of the mechanism of toxicity of zinc oxide and cerium oxide nanoparticles based on dissolution and oxidative stress properties. ACS Nano. 2008; 2:2121-2134.

[57] Zeinalov OA, Kombarova SP, Bagrov DV, Petrosyan MA, Tolibova GH, Feofanov $\mathrm{AV}$, Shaitan KV. About the influence of metal oxide nanoparticles on living organisms physiology. Rev Clin Pharmacol Drug Ther. 2016; DOI: http://dx.doi.org/10.17816/RCF14324-33

[58] Horie M, Stowe M, Tabei M, Kuroda E. Metal ion release of manufactured metal oxide nanoparticles is involved in the allergic response to inhaled ovalbumin in mice. ODEM. 2016;4:17-26.

[59] Mishra RK, Shalom Y, Kumar VB, Luong JHT, Gedanken A, Banin E. Surfactant-free synthesis of a water-soluble PEGylated nanographene oxide/metal-oxide nanocomposite as engineered antimicrobial weaponry. J Mater Chem B. 2016;4:6706-6715.

[60] Wang D, Lin Z, Wang T, Yao Z, Qin M, Zheng S, Lu W. Where does the toxicity of metal oxide nanoparticles come from: The nanoparticles, the ions, or a combination of both?. J Hazard Mater. 2016;308:328-334.

[61] Gurra JR, Wang ASS, Chen CH, Jan KY. Ultrafine titanium dioxide particles in the absence of photoactivation can induce oxidative damage to human bronchial epithelial cells. Toxicology. 2005;213:66-73.

[62] Armand L, Tarantini A, Beal D, Biola-Clier M, Bobyk L, Sorieul S, Gallay KP, Desvergne CM, Lynch I, Boime NH, Carriere M. Long-term exposure of A549 cells to titanium dioxide nanoparticles induces DNA damage and sensitizes cells towards genotoxic agents. Nanotoxicology. 2016;10:913-923.

[63] Li X, Zhang C, Bian Q, Gao N, Zhang X, Meng Q, Wu S, Wang S, Xi Y, Chen R. Integrative functional transcriptomic analyses implicate specific molecular pathways in pulmonary toxicity from exposure to aluminum oxide nanoparticles. Nanotoxicology. 2016;10:957-969.

[64] Akhtar MJ, Kumar S, Alhadlaq HA, Alrokayan SA, AbuSalah KM, Ahamed M. Dosedependent genotoxicity of copper oxide nanoparticles stimulated by reactive oxygen species in human lung epithelial cells. Toxicol Ind Health. 2016;32:809-821.

[65] Rajiv S, Jerobin J, Saranya V, Nainawat M, Sharma A, Makwana P, Gayathri C, Bharath L, Singh M, Kumar M, Mukherjee A, Chandrasekaran N. Comparative cytotoxicity and genotoxicity of cobalt (II, III) oxide, iron (III) oxide, silicon dioxide, 
and aluminum oxide nanoparticles on human lymphocytes in vitro. Hum Exp Toxicol. 2016;35:170-183.

[66] Yolanda P. Challenges in the determination of engineered nanomaterials in foods. Trends Anal Chem. 2016;84:149-159.

[67] Brennner SA, Neu-Baker NM, Eastlake AC, Beaucham CC, Geraci CL. NIOSH field studies team assessment: worker exposure to aerosolized metal oxide nanoparticles in a semiconductor fabrication facility. J Occup Environ Hyg. 2016;12:1-31.

[68] Eastlake AC, Beaucham C, Martinez KF, Dahm MM, Sparks C, Hodson LL, Geraci CL. Refinement of the nanoparticle emission assessment technique into the nanomaterial exposure assessment technique (NEAT 2.0). J Occup Environ Hyg. 2016;13:708-717.

[69] Ding Y, Kuhlbusch TAG, Tongeren MV, Jiménez AS, Tuinman I, Chen R, Alvarez IL, Mikolajczyk U, Nickel C, Meyer J, Kaminski H, Wohlleben W, Stahlmecke B, Clavaguera S, Riediker M. Airborne engineered nanomaterials in the workplace-a review of release and worker exposure during nanomaterial production and handling processes. J Hazard Mater. 2016;322:17-28.

[70] Filon FL, Bello D, Cherrie JW, Sleeuwenhoek A, Spaan S, Brouwer DH. Occupational dermal exposure to nanoparticles and nano-enabled products: Part I-Factors affecting skin absorption. Int. J Hyg Environ Health. 2016;219:536-544.

[71] Holmes AM, Song Z, Moghimi HR, Roberts MS. Relative Penetration of Zinc Oxide and Zinc Ions into Human Skin after Application of Different Zinc Oxide Formulations. ACS Nano. 2016; 10:1810-1819.

[72] Présumé M, Simon-Deckers A, Tomkiewicz-Raulet C, Grand BL, Nhieu JTV, Beaune G, Duruphty O, Doucet J, Coumoul X, Pairon JC, Boczkowski J, Lanone S, Andujar P. Exposure to metal oxide nanoparticles administered at occupationally relevant doses induces pulmonary effects in mice. Nanotoxicology. 2016;10:1535-1544.

[73] Sukwong P, Somkid K, Kongseng S, Pissuwan D, Yoovathaworn K. Respiratory tract toxicity of titanium dioxide nanoparticles and multi-walled carbon nanotubes on mice after intranasal exposure. IET Micro Nano Lett. 2016;11:183-187.

[74] Simón-Vázquez R, Lozano-Fernández T, Dávila-Grana A, González-Fernández A. Analysis of the activation routes induced by different metal oxide nanoparticles on human lung epithelial cells. Future Sci OA. 2016;2:1-13. 
[75] Rehberg M, Nekolla K, Sellner S, Praetner M, Mildner K, Zeuschner D, Krombach F. Intercellular transport of nanomaterials is mediated by membrane nanotubes in vivo. Small. 2016;12:1882-1890.

[76] Dumkova J, Vrlikova L, Vecera Z, Putnova B, Docekal B, Mikuska P, Fictum P, Hampl A, Buchtova M. Inhaled cadmium oxide nanoparticles: their in vivo fate and effect on target organs. Int J Mol Sci. 2016;17:874-894.

[77] Brenner SA, Neu-Baker NM, Eastlake AC, Beaucham CC, Geraci CL. NIOSH field studies team assessment: Worker exposure to aerosolized metal oxide nanoparticles in a semiconductor fabrication facility. J Occup Environ Hyg. 2016;13:871-880.

[78] Fröhlich E, Roblegg E. Oral uptake of nanoparticles: human relevance and the role of in vitro systems. Arch Toxicol. 2016;90:2297-2314.

[79] Fröhlich EE, Fröhlich E. Cytotoxicity of nanoparticles contained in food on intestinal cells and the gut microbiota. Int J Mol Sci. 2016;17:509-531.

[80] Meesters JAJ, Quik JTK, Koelmans AA, Hendriksa AJ, de Meent DV. Multimedia environmental fate and speciation of engineered nanoparticles: a probabilistic modeling approach. Environ Sci Nano. 2016;3:715-727.

[81] Schaumann GE, Philippe A, Bundschuh M, Metreveli G, Klitzke S, Rakcheev D, Grun A, Kumahor SK, Kuhn M, Baumann T, Lang F, Manz W, Schulz R, Vogel HJ. Understanding the fate and biological effects of Ag- and TiO2-nanoparticles in the environment: the quest for advanced analytics and interdisciplinary concepts. Sci Total Environ. 2015;535:3-19.

[82] Philippe A, Schaumann GE. Interactions of dissolved organic matter with natural and engineered inorganic colloids: a review. Environ Sci Technol. 2014;48:8946-8962.

[83] Xua H, Pan J, Zhang H,Yang L. Interactions of metal oxide nanoparticles with extracellular polymeric substances (EPS) of algal aggregates in an eutrophic ecosystem. Ecol Eng. 2016; 94:464-470.

[84] Kuech TR, Hamers RJ, Pedersen JA. Chemical transformation of metal, metal oxide, and metal chalcogenide nanoparticles in the environment. Eng Nanoparticles Environ: Biochem Proc Toxicity.2016. John Wiley \& Sons, Inc., Hoboken, NJ, USA. doi: 10.1002/9781119275855.ch14.

[85] Joo SH, Zhao D. Environmental dynamics of metal oxide nanoparticles in heterogeneous systems: a review. J Hazard Mater A. 2017;322:29-47. 
[86] Leopold K, Philippe A, Wörle K, Schaumann GE. Analytical strategies to the determination of metal-containing nanoparticles in environmental waters. Trends Anal Chem. 2016;84:107-120.

[87] Razzaque S, Hussain SZ, Hussain I, Tan B. Design and Utility of Metal/Metal Oxide Nanoparticles Mediated by Thioether End-Functionalized Polymeric Ligands. Polymers. 2016;8: 156-182.

[88] Polte J. Fundamental growth principles of colloidal metal nanoparticles - a new perspective. Cryst Eng Comm. 2015;17:6809-6830.

[89] Juganson K, Ivask A, Blinova I, Mortimer M, Kahru A. New and in-depth database concerning ecotoxicity of nanomaterials. Beilstein J Nanotechnol. 2015;6:1788-1804.

[90] Polte J. Fundamental growth principles of colloidal metal nanoparticles - a new perspective. Cryst Eng Comm. 2015;17:6809-6830.

[91] Derjaguin B, Landau LD. Theory of the stability of strongly charged lyophobic sols and of the adhesion of strongly charged particles in solutions of electrolytes. Acta Phys Chim. 1941;14: 633-662.

[92] Verwey EJW, Overbeek JTG. Theory of the stability of lyophobic colloids. 1948. Amsterdam, The Netherlands: Elsevier.

[93] Razzaque S, Hussain SZ, Hussain I, Tan B. Design and Utility of Metal/Metal Oxide Nanoparticles Mediated by Thioether End-Functionalized Polymeric Ligands. Polymers. 2016;8: 156-182.

[94] Odzak N, Kistler D, Behra R, Sigg L. Dissolution of metal and metal oxide nanoparticles in aqueous media. Environ Pollut. 2014;191:132-138.

[95] Peng YH, Tso CP, Tsai YC, Zhuang CM, Shih YH. The effect of electrolytes on the aggregation kinetics of three different $\mathrm{ZnO}$ nanoparticles in water. Sci Total Environ. 2015;530-531:183-190.

[96] Keller AA, Wang H, Zhou D, Lenihan HS, Cherr G, Cardinale BJ, Miller R, Ji Z..Stability and Aggregation of Metal Oxide Nanoparticles in Natural Aqueous Matrices. Environ Sci Technol. 2010;44:1962-1967.

[97] Miao L, Wang C, Hou J, Wang P, Li A, Lv B, Yang Y, You G. Effect of alginate on the aggregation kinetics of copper oxide nanoparticles (CuO NPs): bridging interaction and hetero-aggregation induced by Ca2+. Environ Sci Pollut Res. 2016;23:11611-11619. 
[98] Peng YH, Tsai YC, Hsiung CE, Lin YH, Shih YH. Influence of water chemistry on the environmental behaviors of commercial $\mathrm{ZnO}$ nanoparticles in various water and wastewater samples. J Hazard Mater. 2017;322:348-356.

[99] Dahle JT, Livi K, Arai Y. Effects of $\mathrm{pH}$ and phosphate on $\mathrm{CeO}_{2}$ nanoparticle dissolution. Chemosphere. 2015;119:1365-1371.

[100] Liu Z, Chen Y, Mo S, Cheng Z, Li H. Stability of TiO2 Nanoparticles in Deionized Water with ZrP Nanoplatelets. J Nanosci Nanotechnol. 2015;15:3271-3275.

[101] Kaegi R. Separation and analysis of nanoparticles in aqueous environmental samples. Engi Nanoparticles Environ: Biophysicochem Proc Toxicity. John Wiley \& Sons, Inc., Hoboken, NJ, USA. 2016;53-57

[102] Bouwmeester H, Lynch I, Marvin HJP, Dawson KA, Berges M, Braguer D, Byrne HJ, Casey A, Chambers G, Clift MJD, Elia G, Fernandes TF, Fjellsb LB, Hatto P, Juillerat L, Klein C, Kreyling WG, Nickel C, Riediker M, Stone V. Minimal analytical characterization of engineered nanomaterials needed for hazard assessment in biological matrices. Nanotoxicology. 2011;5:1-11.

[103] Markus AA, Parsons JR, Roex EWM, Kenter GCM, Laane RWPM. Predicting the contribution of nanoparticles ( $\mathrm{Zn}, \mathrm{Ti}, \mathrm{Ag}$ ) to the annual metal load in the Dutch reaches of the Rhine and Meuse. Sci Total Environ. 2013; 456-457:154-160.

[104] Andreani T, Kiill CP, de Souza ALR, Fangueiro JF, Doktorovova'S, Garcia ML, Gramia o MPD, Silva AM, Souto EB. Effect of cryoprotectants on the reconstitution of silica nanoparticles produced by sol-gel technology. $J$ Therm Anal Calorim. 2015;120:1001-1007.

[105] Schwertfeger DM, Velicogna JR, Jesmer AH, Scroggins RP, Princz JI. Single Particle-Inductively Coupled Plasma Mass Spectroscopy Analysis of Metallic Nanoparticles in Environmental Samples with Large Dissolved Analyte Fractions. Anal Chem. 2016;88: 9908-9914.

[106] Vidmar J, Milacic R, Golja V, Novakcd S, Scancar J. Optimization of the procedure for efficient dispersion of titanium dioxide nanoparticles in aqueous samples. Anal Methods. 2016;8: 1194-1201.

[107] Vila L, Rubio L, Annangi B, García-Rodríguez A, Marcos R, Hernández A. Frozen dispersions of nanomaterials are a useful operational procedure in nanotoxicology. Nanotoxicology. 2016; DOI: 10.1080/17435390.2016.1262918. 
[108] Westerhoff P, Song G, Hristovskib K, Kiser MA. Occurrence and removal of titanium at full scale wastewater treatment plants: implications for $\mathrm{TiO} 2$ nanomaterials. $J$ Environ Monit. 2011;13,1195-1203.

[109] Alele N, Ulbricht M. Membrane-based purification of proteins from nanoparticle dispersions:Influences of membrane type and ultrafiltration conditions. Sep Purif Technol. 2016;158:171-182.

[110] Ladner DA, Steele M, Weir A, Hristovski K, Westerhoff P. Functionalized nanoparticle interactions with polymeric membranes. JHazard Mater. 2012; 211212:288-295.

[111] Fabricius AL, Duester L, Meermann B, Ternes TA. ICP-MS-based characterization of inorganic nanoparticles - sample preparation and off-line fractionation strategies. Anal Bioanal Chem. 2014; 406:467-479.

[112] Merdzan, V.; Domingos, R. F.; Monteiro, C. E.; Hadioui, M.; Wilkinson, K. J. The effects of different coatings on zinc oxide nanoparticles and their influence on dissolution and bioaccumulation by the green alga, C. reinhardtii. Sci. Total Environ. 2014, 488, $316-324$.

[113] Walter J, Löhr K, Karabudak E, Reis W, Mikhael J, Peukert W, Wohlleben W, Cölfen H. Multidimensional Analysis of Nanoparticles with Highly Disperse Properties Using Multiwavelength Analytical Ultracentrifugation. ACS Nano. 2014; 8:8871-8886.

[114] Majedi SM, Kelly BC, Lee HK. Efficient hydrophobization and solvent microextraction for determination of trace nano-sized silver and titanium dioxide in natural waters. Anal Chim Acta. 2013;789:47-57.

[115] Tiwari B, Zhang D, Winslow D, Lee CH, Hao B, Yap YK. A simple and universal technique to extract one- and two-dimensional nanomaterials from contaminated water. ACS Appl Mater Interf. 2015;7:26108-26116.

[116] Wallar C, Zhang T, Shi K, Zhitomirsky I. Synthesis of metal and metal oxide nanoparticles, liquid-liquid extraction and application in supercapacitors. Colloids Surf A: Physicochem Eng Aspects. 2016;500:195-202.

[117] Li L, Leopold K, Schuster M. Effective and selective extraction of noble metal nanoparticles from environmental water through a noncovalent reversible reaction on an ionic exchange resin. Chem Commun. 2012; 48:9165-9167. 
[118] Hadioui M, Merdzan V, Wilkinson KJ. Detection and Characterization of $\mathrm{ZnO}$ Nanoparticles in Surface and Waste Waters Using Single Particle ICPMS. Environ Sci Technol. 2015;49:6141-6148.

[119] Majedi SM, Lee HK, Kelly BC. Chemometric analytical approach for the cloud point extraction and inductively coupled plasma mass spectrometric determination of zinc oxide nanoparticles in water samples. Anal Chem. 2012;84:6546-6552.

[120] Majedi SM, Kelly BC, Lee HK. Evaluation of a cloud point extraction approach for the preconcentration and quantification of trace $\mathrm{CuO}$ nanoparticles in environmental waters. Anal Chim Acta. 2014;814:39-48.

[121] Majedi SM, Kelly BC, Lee HK. Toward a robust analytical method for separating trace levels of nano-materials in natural waters: cloud point extraction of nano-copper (II) oxide. Environ Sci Pollut Res. 2014;21:11811-11822.

[122] Bhomkar P, Goss G, Wishart DS. A simple and sensitive biosensor for rapid detection of nanoparticles in water. J Nanopart Res. 2014;16:2253-2270.

[123] Corredor C, Borysiak MD, Wolfer J, Westerhoff P, Posner JD. Colorimetric Detection of Catalytic Reactivity of Nanoparticles in Complex Matrices. Environ Sci Technol. 2015;49: 3611-3618.

[124] Ojea-Jiménez I, Urbán P, Barahona F, Pedroni M, Capomaccio R, Ceccone G, Kinsner-Ovaskainen A, Rossi F, Gilliland D. Highly flexible platform for tuning surface properties of silica nanoparticles and monitoring their biological interaction. ACS Appl Mater Interfaces. 2016; 8:4838-4850.

[125] Cao X, Ma C, Gao Z, Zheng J, He L, McClements DJ, Xiao H. Characterization of the Interactions between Titanium Dioxide Nanoparticles and Polymethoxyflavones Using Surface-Enhanced Raman Spectroscopy. J Agric Food Chem. 2016;64:9436-9441.

[126] Bundschuh T, Yun JI, Knopp R. Determination of size, concentration and elemental composition of colloids with laser-induced breakdown detection/spectroscopy. J Anal Chem. 2001;371:1063-1069.

[127] Diallo MS, Glinka CJ, Goddard WA, Johnson JH. Characterization of nanoparticles and colloids in aquatic systems 1 . small angle neutron scattering investigations of Suwannee River fulvic acid aggregates in aqueous solutions. $J$ Nanopart Res. 2005;7:435-448.

[128] Kuyper CL, Fujimoto BS, Zhao Y, Schiro PG, Chiu DT. Accurate sizing of 
nanoparticles using confocal correlation spectroscopy. J Phys Chem B. 2006;110:2443324441.

[129] Malysheva A, Lombi E, Voelcker NH. Bridging the divide between human and environmental nanotoxicology. Nature Nanotechnol. 2015;10:835-844.

[130] Philippe A, Gangloff M, Rakcheev D, Schaumann GE. Evaluation of hydrodynamic chromatography coupled with inductively coupled plasma mass spectrometry detector for analysis of colloids in environmental media - effects of colloid composition, coating and shape Anal Methods. 2014;6:8722-8728.

[131] Zhou XX, Liu JF, Geng FL. Determination of metal oxide nanoparticles and their ionic counterparts in environmental waters by size exclusion chromatography coupled to ICP-MS. NanoImpact. 2016;1:13-20

[132] Meermann B. Field-flow fractionation coupled to ICP-MS: separation at the nanoscale, previous and recent application trends. Anal Bioanal Chem. 2015; 407:26652674.

[133] Sánchez-García L, Bolea E, Laborda F, Cubel C, Ferrer P, Gianolio D, da Silva I, Castillo JR. Size determination and quantification of engineered cerium oxide nanoparticles by flow field-flow fractionation coupled to inductively coupled plasma mass spectrometry. J Chromatogr A. 2016;1438:205-215.

[134] Barahona F, Geiss O, Urbań P,Ojea-Jimenez I, Gilliland D, Barrero-Moreno J. Simultaneous Determination of Size and Quantification of Silica Nanoparticles by Asymmetric Flow Field-Flow Fractionation Coupled to ICPMS Using Silica Nanoparticles Standards. Anal Chem. 2015; 87:3039-3047.

[135] Montaño MD, Majestic BJ, Jämting AK, Westerhoff P, Ranville JF. Methods for the Detection and Characterization of Silica Colloids by Microsecond spICP-MS. Anal Chem. 2016;88: 4733-4741.

[136] Soto-Alvaredo J, Dutschke F, Bettmer J, Montes-Bayon M, Pr”ofrock D, Prangeb A. Initial results on the coupling of sedimentation field-flow fractionation (SdFFF) to inductively coupled plasma-tandem mass spectrometry (ICPMS/ MS) for the detection and characterization of TiO2 nanoparticles. J Anal At Spectrom. 2016;31:1549-1555.

[137] Alsudir S, Iqbal Z, Lai EPC. Rapid CE-UV binding tests for selective recognition of bisphenol A by molecularly imprinted polymer particles. Electrophoresis. 2012;33:12551262.

[138] Shuai HH, Yang CY, Harn HIC, York RL, Liao TC, Chen WS, Yeh JA, Cheng CM. 
Using surfaces to modulate the morphology and structure of attached cells - a case of cancer cells on chitosan membranes. Chem Sci. 2013;4:3058-3067.

[139] Trapiella-Alfonso L, d'Orlyé F, Varenne A. Recent advances in the development of capillary electrophoresis methodologies for optimizing, controlling, and characterizing the synthesis, functionalization, and physicochemical, properties of nanoparticles. Anal Bioanal Chem. 2016; 408:2669-2675.

[140] Voracova I, Kleparnık K, Liskova M, Foret F. Determination of $\xi$-potential, charge, and number of organic ligands on the surface of water soluble quantum dots by capillary electrophoresis. Electrophoresis. 2015;36:867-874.

[142] Li YQ, Guan LY, Zhang HL, Chen J, Lin S, Ma ZY, Zhao YD. Distance-dependent metal-enhancement quantum dots fluorescence analysis in solution by capillary electrophoresis and its application to DNA detection. Anal Chem. 2011;83:4103-4109.

[142] RoseJr DJ, Jorgenson JW. Characterization and automation of sample introduction methods for capillary zone electrophoresis. Anal Chem. 1988;60: 642-648.

[143] Cacho C, Markova Z, Sevcik J, Zboril R, Petr J. Study of behavior of carboxylic magnetite core shell nanoparticles on a pH boundary. J Chromatogr A. 2014;1364:59-63.

[144] Qu H, Mudalige TK, Linder SW. Capillary Electrophoresis/Inductively-Coupled Plasma-Mass Spectrometry: Development and Optimization of a High Resolution Analytical Tool for the Size-Based Characterization of Nanomaterials in Dietary Supplements. Anal Chem. 2014;86: 11620-11627.

[145] Liu L, He B, Liu Q, Yun Z, Yan X, Long Y, Jiang G. Identification and accurate size characterization of nanoparticles in complex media. Angew Chem Int Ed. 2014;53:14476-14479.

[146] Liua FK, Linb YY, Wub CH. Highly efficient approach for characterizing nanometersized gold particles by capillary electrophoresis. Analytica Chimica Acta. 2005;528:249254.

[147] Oszwałdowski S, Gibuła KZ, Roberts KP. Capillary electrophoretic separation of nanoparticles. Anal Bioanal Chem. 2011;399:2831-2842

[148] Qu H, Mudalige TK, Linder SW.Capillary electrophoresis coupled with inductively coupled mass spectrometry as an alternative to cloud point extraction based methods for rapid quantification of silver ions and surface coated silver nanoparticles. J Chromatogr A. 2016;1429: 348-353.

[149] Rodriguez MA, Armstrong DW. Separation and analysis of colloidal/nano-particles 
including microorganisms by capillary electrophoresis: a fundamental review. $J$ Chromatogr B. 2004;800: 7-25.

[150] Wiersema PH, Loeb AL, Overbeek JThG. Calculation of the electrophoretic mobility of a spherical colloid particle. J Colloid Interface Sci. 1966; 22:78-99.

[151] O'Brien RW, White LR. Electrophoretic mobility of a spherical colloidal particle. $J$ Chem Soc Faraday Trans. 1978;77:1607-1626.

[152] Ohshima, H. Approximate analytic expression for the electrophoretic mobility of a spherical colloidal particle. J. Colloid Interface Sci. 2001; 239:587-590.

[153] Ibrahim A, Ohshima H, Allisonc SA, Cotteta H. Determination of effective charge of small ions, polyelectrolytes and nanoparticles by capillary electrophoresis. J Chromatogr A. 2012;1247: 154- 164 .

[154] Lin KH, Chu TC, Liu FK. On-line enhancement and separation of nanoparticles using capillary electrophoresis. J Chromatogr A. 2007;1161:314-21.

[155] Li L, Yu H, Liu D, You T. A novel dark-field microscopy technique coupled with capillary electrophoresis for visual analysis of single nanoparticles. Analyst. 2013;138:3705-3710.

[156] Adelantado C, Farinas NR, Doimeadios RCRM, Zougagh M, Ríos A. Analysis of silica nanoparticles by capillary electrophoresis coupled to an evaporative light scattering detector. Analytica Chimica Acta. 2016;923:82-88.

[157] Bouri M, Salghi R, Algarra M, Zougagh M, Ríos A. A novel approach to size separation of gold nanoparticles by capillary electrophoresis-evaporative light scattering detection. RSC Adv.2015;5:16672-16677.

[158] Qu H, Mudalige TK, Linder SW. Capillary electrophoresis/ inductively-coupled plasma-mass spectrometry: development and optimization of a high resolution analytical tool for the size-based characterization of nanomaterials in dietary supplements. Anal Chem. 2014;86:11620-11627.

[159] Franze B, Engelhard C. Fast separation, characterization, and separation of gold and silver nanoparticles and their ionic counterparts with micellar electrokinetic chromatography coupled to ICP-MS. Anal Chem. 2014;86:5713-5720.

[160] Qu H, Mudalige TK, Linder SW. Capillary electrophoresis coupled with inductively coupled mass spectrometry as an alternative to cloud point extraction based methods for rapid quantification of silver ions and surface coated silver nanoparticles. J Chromatogr A. 2016;1429: 348-353. 
[161] Qu H, Linder SW, Mudalige TK. Surface coating and matrix effect on the electrophoretic mobility of gold nanoparticles: a capillary electrophoresis-inductively coupled plasma mass spectrometry study. Anal Bioanal Chem. 2017.DOI $10.1007 / \mathrm{s} 00216-016-0012-0$.

[162] Oukacine F, Morel A, Desvignes I, Cottet H. Size-based characterization of nanoparticle mixtures by the inline coupling of capillary electrophoresis to Taylor dispersion analysis. J Chromatogr A. 2015;1426:220-225.

[163] Kestens V, Roebben G, Herrmann J, Jämting A, Coleman V, Minelli C, Clifford C, Temmerman PJD, Mast J, Junjie L, Babick F, Cölfen H, Emons H. Challenges in the size analysis of a silica nanoparticle mixture as candidate certified reference material. Nanopart Res. 2016;18:171-193.

[164] Achatz DE, Heiligtag FJ, Li X, Link M, Wolfbeis OS. Colloidal silica nanoparticles for use in click chemistry-based conjugations and fluorescent affinity assays. Sens Actuators B: Chem. 2010;150:211-219.

[165] Graf C, Gao Q, Schütz I, Noufele CN, Ruan W, Posselt U, Korotianskiy E, Nordmeyer D, Rancan F, Hadam S, Vogt A, Lademann J, Haucke V, Rühl E. Surface Functionalization of Silica Nanoparticles Supports Colloidal Stability in Physiological Media and Facilitates Internalization in Cells. Langmuir. 2012;28:7598-7613.

[166] Bonacchi S, Genovese D, Juris R, Montalti M, Prodi L, Rampazzo E, Zaccheroni N. Luminescent Silica Nanoparticles: Extending the Frontiers of Brightness. Angew Chem Int $E d .2011 ; 50: 4056-4066$.

[167] Egerton TA. The Influence of Surface Alumina and Silica on the Photocatalytic Degradation of Organic Pollutants. Catalysts. 2013; 3:338-362.

[168] DeMaleki Z, Lai E PC, Dabek-Zlotorzynska E. Capillary electrophoresis characterization of molecularly imprinted polymer particles in fast binding with $17 \mathrm{~b}$ estradiol. J Sep Sci. 2010;33: 2796-2803.

[169] Chu HH, Fu DC. Preparation of poly(hydroxyethy1 methacrylate) and poly(hydroxypropy1 methacrylate) lattices. Macromol Rapid Commun. 1998;19:107110.

[170] Ali AMI, Pareek P, Sewell L, Schmid A, Fujii S, Armes SP, Shirley IM. Synthesis of poly(2-hydroxypropyl methacrylate) latex particles via aqueous dispersion polymerization. Soft Matter. 2007;3:1003-1013.

[171] 420875 ALDRICH, LUDOX ${ }^{\circledR}$ AM colloidal silica, 30 wt. \% suspension in $\mathrm{H}_{2} \mathrm{O}$. http://www.sigmaaldrich.com/catalog/product/aldrich/420875?lang=en\&region=CA.

[172] Costa ROR, Vasconcelos WL. Organic/Inorganic Nanocomposite Star Polymers via 
Atom Transfer Radical Polymerization of Methyl Methacrylate Using Octafunctional Silsesquioxane Cores. Macromolecules. 2001; 34:5398-5407.

[173] Christian P, Giles, MR, Griffiths, RMT, Irvine DJ, Major RC, Howdle SM. Free Radical Polymerization of Methyl Methacrylate in Supercritical Carbon Dioxide Using a Pseudo-Graft Stabilizer: Effect of Monomer, Initiator, and Stabilizer Concentrations. Macromolecules. 2000; 33:9222-9227.

[174] Chu HH, Fu DC. Preparation of poly(hydroxyethyl methacrylate) and poly(hydroxypropy1 methacrylate) lattices. Macromol Rapid Commun. 1998;19:107110.

[175] Faure B, Salazar-Alvarez G, Ahniyaz A, Villaluenga I, Berriozabal G, Miguel YRD, Bergstrom L. Dispersion and surface functionalization of oxide nanoparticles for transparent photocatalytic and UV-protecting coatings and sunscreens. Sci Technol Adv Mater. 2013;14:1-23.

[176] Ladj R, Bitar A, Eissa MM, Fessi H, Mugnier Y, Dantec RL, Elaissari A. Polymer encapsulation of inorganic nanoparticles for biomedical applications. Int J Pharm. 2013;458:230-241.

[177] Yamada H, Urata C, Higashitamori S, Aoyama Y, Yamauchi Y, Kuroda K. Critical roles of cationic surfactants in the preparation of colloidal mesostructured silica nanoparticles: control of mesostructure, particle size, and dispersion. ACS Appl Mater Interfaces. 2014;6:3491-3500.

[178] Zou H, Wu S, Shen J. Polymer/silica nanocomposites: preparation, characterization, properties, and applications. Chem Rev. 2008;108:3893-3957.

[179] Moraes, J, Ohno K, Maschmeyerc T, Perrier S. Synthesis of silica-polymer core-shell nanoparticles by reversible addition-fragmentation chain transfer polymerization. Chem Commun. 2013;49:9077-9088.

[180] Alsudir S, Lai EPC. Polymer coatings for sensitive analysis of colloidal silica nanoparticles in Water. Colloid Polym Sci. 2014;292: 1289-1296.

[181] Alsudir S, Iqbal Z, Lai EPC. Rapid CE-UV binding tests for selective recognition of bisphenol A by molecularly imprinted polymer particles. Electrophoresis. 2012;33:12551262.

[182] Shuai HH, Yang CY, Harn HIC, York RL, Liao TC, Chen WS, Yeh JA, Cheng CM. Using surfaces to modulate the morphology and structure of attached cells - a case of cancer cells on chitosan membranes. Chem Sci. 2013;4:3058-3067. 
[183] Reijnders L.The release of $\mathrm{TiO}_{2}$ and $\mathrm{SiO}_{2}$ nanoparticles from nanocomposites. Polym Degrad Stab. 2009;94:873-876.

[184] AlSagheer F, Muslim S. Thermal and mechanical properties of chitosan $/ \mathrm{SiO}_{2}$ hybrid composites. J Nanomater. 2010;3:1-7.

[185] ElHefian EA, Nasef MM, Yahaya AH. Chitosan-based polymer blends: current status and applications. J Chem Soc Pak. 2014;36:11-27.

[186] Zhao D, Chen C, Wang Y, Ji H, Ma W, Zang L, Zhao J. Surface Modification of $\mathrm{TiO}_{2}$ by Phosphate: Effect on Photocatalytic Activity and Mechanism Implication. $J$ Phys Chem C. 2008;112:5993-6001.

[187] Patel S, Patel P, Undre SB, Pandy SR, Singh M, Bakshi S. DNA binding and dispersion activities of titanium dioxide nanoparticles with UV/vis spectrophotometry, fluorescence spectroscopy and physicochemical analysis at physiological temperature. $J$ Mol Liq. 2016;213:304-311.

[188] Zhu RR, Wang SL, Zhang R, Sun XY, Yao SD. A novel toxicological evaluation of $\mathrm{TiO}_{2}$ nanoparticles on DNA structure.Chin J Chem. 2007;25:958-961.

[189] Li S, Zhu H, Zhu R, Sun X, Yao S, Wang S. Impact and mechanism of $\mathrm{TiO}_{2}$ nanoparticles on DNA synthesis in vitro. Sci China Ser B Chem. 2008;51:367-372.

[190] Spink CH, Chaires JB. Selective Stabilization of Triplex DNA by Poly(ethylene glycols). J Am Chem Soc. 1995; 117:12887-12888.

[191] Nakano S, Karimata H, Ohmichi T, Kawakami J, Sugimoto N. The effect of molecular crowding with nucleotide length and cosolute structure on DNA duplex stability. J Am Chem Soc. 2004;126:14330-14331.

[192] Feng B, Frykholm K, Nordena B, Westerlund F. DNA strand exchange catalyzed by molecular crowding in PEG solutions. Chem Commun. 2010;46:8231-8233.

[193] Biplab KC, Paudel SN, Rayamajhi S, Karna D, Adhikari S, Shrestha BG, Bisht G. Enhanced preferential cytotoxicity through surface modification: synthesis, characterization and comparative in vitro evaluation of TritonX-100 modified and unmodified zinc oxide nanoparticles in human breast cancer cell. Chem Cent J. 2016;10:1-10.

[194] Lee SJ, Cho IH, Kim H, Hong SJ. Microstructure characterization of $\mathrm{TiO}_{2}$ photoelectrodes for dye-sensitized solar cell using statistical design of experiments. Trans Electr Electron Mater. 2009;10:177-181. 
[195] Sun P, Zhang K, Fang J, Lin D, Wang M, Han J. Transport of TiO2 nanoparticles in soil in the presence of surfactants. Sci Total Environ. 2015;15:527-528.

[196] Dhawan A, Sharma V. Toxicity assessment of nanomaterials: methods and challenge. Anal Bioanal Chem. 2010; 398:589-605.

[197] Murdock RC, Stolle LB, Schrand AM, Schlager JJ, Hussain SM. Characterization of Nanomaterial Dispersion in Solution Prior to In VitroExposure Using Dynamic Light Scattering Technique. Toxicol Sci.2008;101:239-253.

[198] Teeguarden J, Hinderliter P, Orr G, Thrall B, Pounds J. Particokinetics in vitro: dosimetry considerations for in vitro nanoparticles toxicity assessments. Toxicol Sci. 2007;95:300-312.

[199] Romero-Cano MS, Martın-Rodriguez A, de las Nieves FJ, Electrosteric Stabilization of Polymer Colloids with Different Functionality. Langmuir. 2001;17:3505-3511.

[200] Kunitsyn VG, Kuznetsov PA, Demchenko EN, Gimautdinova OI. Structural study of methylated and non-methylated duplexes by IR Fourier spectroscopy. Open J Phys Chem. 2015;5:87-92.

[201] Aksoy C, Severcan F. Role of vibrational spectroscopy in stem cell research. Spectrosc-Int J. 2012;27:167-184.

[202] Jokerst JV, Lobovkina T, Zare RN, Gambhir SS, Nanoparticle PEGylation for imaging and therapy. Nanomedicine (Lond). 2011;6:715-728.

[203] Du Y, Ren W, Li Y, Zhang Q, Zeng L, Chi C, Wu A, Tian J. The enhanced chemotherapeutic effects of doxorubicin loaded PEG coated $\mathrm{TiO}_{2}$ nanocarriers in an orthotopic breast tumor bearing mouse model. J Mater Chem B. 2015;3:1518-1528.

[204] Cheng TL, Chuang KH, Chen BM, Roffler SR. Analytical measurement of PEGylated molecules. Bioconjugate Chem. 2012;23:881-899.

[205] Fritz G, Schadler V, Willenbacher N,Wagner NJ. Electrosteric Stabilization of Colloidal Dispersions. Langmuir. 2002;18:6381-6390.

[206] Pettersson A, Marino G, Pursiheimo A, Rosenholm JB. Electrosteric stabilization of $\mathrm{Al} 2 \mathrm{O} 3, \mathrm{ZrO} 2$ and $3 \mathrm{Y}-\mathrm{ZrO} 2$ suspensions: effect of dissociation and type of polyelectrolyte. J Colloid Interface Sci. 2000;228:73-81.

[207] Hang J, Shi L, Feng X, Xiao L. Electrostatic and electrosteric stabilization of aqueous suspensions of barite nanoparticles. Powder Technol. 2009;192:166-170. 
[208] Pacia M, Warszyński P, Macyk W. UV and visible light active aqueous titanium dioxide colloids stabilized by surfactants. Dalton Trans. 2014;43:12480-12485.

[209] Zhang X, Wang F, Liu B, Kelly EY, Servos MR, Liu J. Adsorption of DNA oligonucleotides by titanium dioxide nanoparticles. Langmuir. 2014;30:839-845.

[210] Cleaves HJ, Crapster-Pregont E, Jonsson CM, Jonsson CL, Sverjensky DA, Hazen RA. The adsorption of short single-stranded DNA oligomers to mineral surfaces. Chemosphere.2011; 83:1560-1567.

[211] Shi B, Shin YK, Hassanali AA, Singer SJ. DNA Binding to the Silica Surface. J Phys Chem B. 2015;119:11030-11040.

[212] Dharanivasan G, Jesse DMI, Chandirasekar S, Rajendiran N, Kathiravan K. Label Free Fluorometric Characterization of DNA Interaction with Cholate Capped Gold Nanoparticles Using Ethidium Bromide as a Fluorescent Probe. $J$ Fluoresc. 2014;24:1397-1406.

[213] Laborda F, Bolea E, Lamana JJ. Single particle inductively coupled plasma mass spectrometry for the analysis of inorganic engineered nanoparticles in environmental samples. TrEAC. 2016;9:15-23

[214] Hofer R, Textor M, Spencer ND. Alkyl Phosphate Monolayers, Self-Assembled from Aqueous Solution onto Metal Oxide Surfaces. Langmuir. 2001;17:4014-4020.

[215] Zwahlen M, Tosatti S, Textor M, Hahner G. Orientation in Methyl- and HydroxylTerminated Self-Assembled Alkanephosphate Monolayers on Titanium Oxide Surfaces Investigated with Soft X-ray Absorption. Langmuir. 2002;18:3957-3962.

[216] Rapuano R, Carmona-Ribeiro AM. Physical Adsorption of Bilayer Membranes on Silica. J Colloid Interface Sci. 1997;193:104-111.

[217] Faure B, Salazar-Alvarez G, Ahniyaz A, Villaluenga I, Berriozabal G, Miguel YRD, Bergstrom L. Dispersion and surface functionalization of oxide nanoparticles for transparent photocatalytic and UV-protecting coatings and sunscreens. Sci. Technol. Adv Mater. 2013;14:1-23.

[218] Barrère F, Lebugle A, Blitterswijk CA, Groot K, Layrolle P. Calcium phosphate interactions with titanium oxide and alumina substrates: an XPS study. J Mater Sci Mater Med. 2003;14: 419-425.

[219] Chung YA, Chen YH, Chang PL. Strategies of fluorescence staining for trace total ribonucleic acid analysis by capillary electrophoresis with argon ion laser-induced fluorescence. Electrophoresis. 2015;36:1781-1784. 
[220] Mori Y. Size-selective separation techniques for nanoparticles in liquid. KONA Powder Part J. 2015;32:102-114.

[221] Update: Corporations Up Their Spending as Revenues for Nano-enabled Products $\begin{array}{llll}\text { Increase } & \text { National } & \text { Science } & \text { Foundation. }\end{array}$ https://www.nsf.gov/crssprgm/nano/reports/LUX14-

0214_Nanotechnology\%20StudyMarketResearch\%20Final\%2017p.pdf. Accessed on 2410-2016.

[222]Aravantinou AF, Tsarpali V, Dailianis S, Manariotis ID. Effect of cultivation media on the toxicity of $\mathrm{ZnO}$ nanoparticles to freshwater and marine microalgae. Ecotoxicol Environ Saf. 2015;114:109-116.

[223] Hadioui M, Merdzan V, Wilkinson KJ. Detection and Characterization of $\mathrm{ZnO}$ Nanoparticles in Surface and Waste Waters Using Single Particle ICPMS. Environ Sci Technol. 2015;49: 6141-6148.

[224] Philippe A, Schaumann GE. Evaluation of Hydrodynamic Chromatography Coupled with UV-Visible, Fluorescence and Inductively Coupled Plasma Mass Spectrometry Detectors for Sizing and Quantifying Colloids in Environmental Media. PLoS ONE. 2014; 9:90559-90568.

[225] Sauvain JJ, Rossi MJ. Quantitative aspects of the interfacial catalytic oxidation of dithiothreitol by dissolved oxygen in the presence of carbon nanoparticles. Environ Sci Technol. 2016;50: 996-1004.

[226] Ollig J, Kloubert V, Weßels I, Haase H, Rink L. Parameters influencing zinc in experimental systems in vivo and in vitro. Metals. 2016; 6:71-87.

[227] Sandmann A, Kompch A, Mackert V, Liebscher CH, Winterer M. Interaction of L-Cysteine with ZnO: Structure, Surface Chemistry, and Optical Properties. Langmuir. 2015;31:5701-5711.

[228] Shan YH. Citation review of Lagergren kinetic rate equation on adsorption reactions. Scientometrics. 2004;59:171-177.

[229] Ho Y, McKay G. Pseudo-second order model for sorption processes. Process Biochem. 1999;34: 451-465.

[230] Weber WJ, Morris J.C. Advances in water pollution research: removal of biologically resistant pollutant from waste water by adsorption. Int Conf Water Pollut Symp. 1962;2: 231-266.

[231] Kataria N, Garg VK, Jain M, Kadirvelu K. Preparation, characterization and potential 
use of flower shaped Zinc oxide nanoparticles (ZON) for the adsorption of Victoria Blue B dye from aqueous solution. Adv Powder Technol. 2016;27:1180-1188.

[232] Langmuir I. The adsorption of gases on plane surfaces of glass, mica and platinum. $J$ Am Chem Soc. 1918;40:1361-1403.

[233] Zhanga F, Chena X, Wua F, Ji Y. High adsorption capability and selectivity of ZnO nanoparticles for dye removal. Colloids Surf A: Physicochem Eng Aspects. 2016;509:474-483.

[234] Sharma S, Kumar V, Kaith BS, Jindal R. Synthesis of Hybrid Ion Exchanger for Rhodamine B Dye Removal: Equilibrium, Kinetic and Thermodynamic Studies. Ind Eng Chem Res. 2016;55: 10492-10499.

[235] Rahman N, Haseen U. Equilibrium Modeling, Kinetic, and Thermodynamic Studies on Adsorption of $\mathrm{Pb}(\mathrm{II})$ by a Hybrid Inorganic-Organic Material: Polyacrylamide Zirconium(IV) Iodate. Ind Eng Chem Res. 2014;53:8198-8207.

[236] Tsai DH, Cho TJ, DelRio FW, Gorham JM, Zheng J, Tan J, Zachariah MR, Hackley VA. Controlled Formation and Characterization of Dithiothreitol-Conjugated Gold Nanoparticle Clusters. Langmuir. 2014;30:3397-3405.

[237] Singh J, Im J, Whitten JE. Encapsulation of Zinc Oxide Nanorods and Nanoparticles. Langmuir. 2009;25:9947-9953.

[238] Singh J, Im J, Whitten JE, Soares JW, Steeves DM. Chemisorption of a thiolfunctionalized ruthenium dye on zinc oxide nanoparticles: Implications for dyesensitized solar cells. Chem Phys Lett. 2010;497:196-199.

[239] Zwahlen M, Tosatti S, Textor M, Hähner G. Orientation in Methyl- and HydroxylTerminated Self-Assembled Alkanephosphate Monolayers on Titanium Oxide Surfaces Investigated with Soft X-ray Absorption. Langmuir. 2002;18:3957-3962.

[240] Hofer R, Textor M, Spencer ND. Alkyl Phosphate Monolayers, Self-Assembled from Aqueous Solution onto Metal Oxide Surfaces. Langmuir. 2001;17:4014-4020.

[241] Reyes GP, Palomares IR, Das S, Sakthivel TS, Leganes F, Rosal R, Seal S, Piñas FF. Untangling the biological effects of cerium oxide nanoparticles: the role of surface valence states. Sci Rep. 2015;5:15613-15627.

[242] Osterloh F, Hiramatsu H, Porter R, Guo T. Alkanethiol-Induced Structural Rearrangements in Silica-Gold Core-Shell-type Nanoparticle Clusters: An Opportunity for Chemical Sensor Engineering. Langmuir. 2004;20:5553-5558.

[243] Zhang X, Wu T, Zhang Y, Ng DHL, Zhao H, Wang G. Adsorption of Hg by thiol 
functionalized hollow mesoporous silica microspheres with magnetic cores. RSC $A d v$. 2015;5: 51446-51453.

[244] Tam TV, Hong SH, Choi WM. Facile synthesis of cysteine functionalized graphene quantum dots for a fluorescence probe for mercury ions. RSC Adv. 2015;5:97598- 97603. 
Appendix- UV-vis Spectra

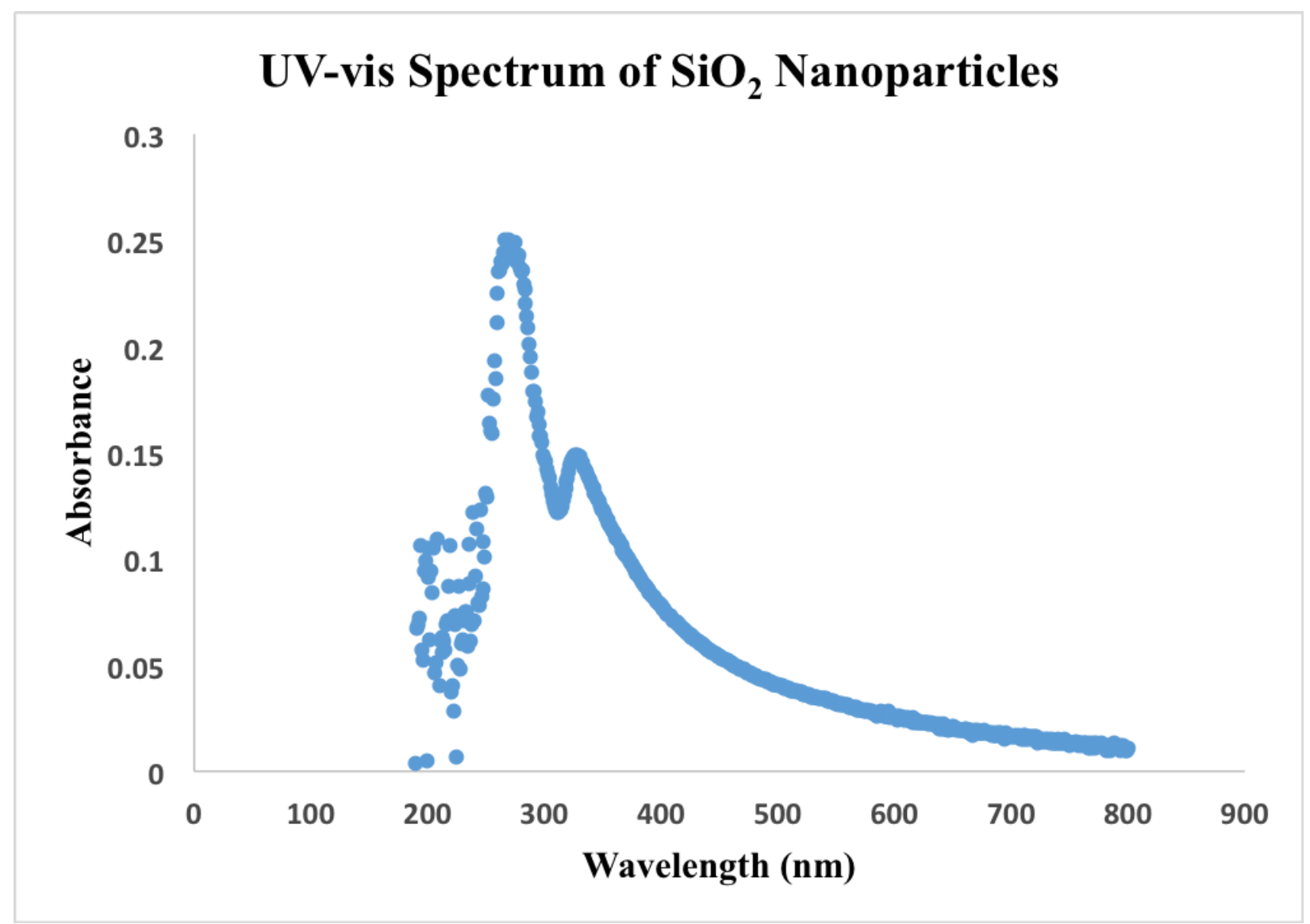

Figure A1: UV-vis spectrum of $\mathrm{SiO}_{2}$. 


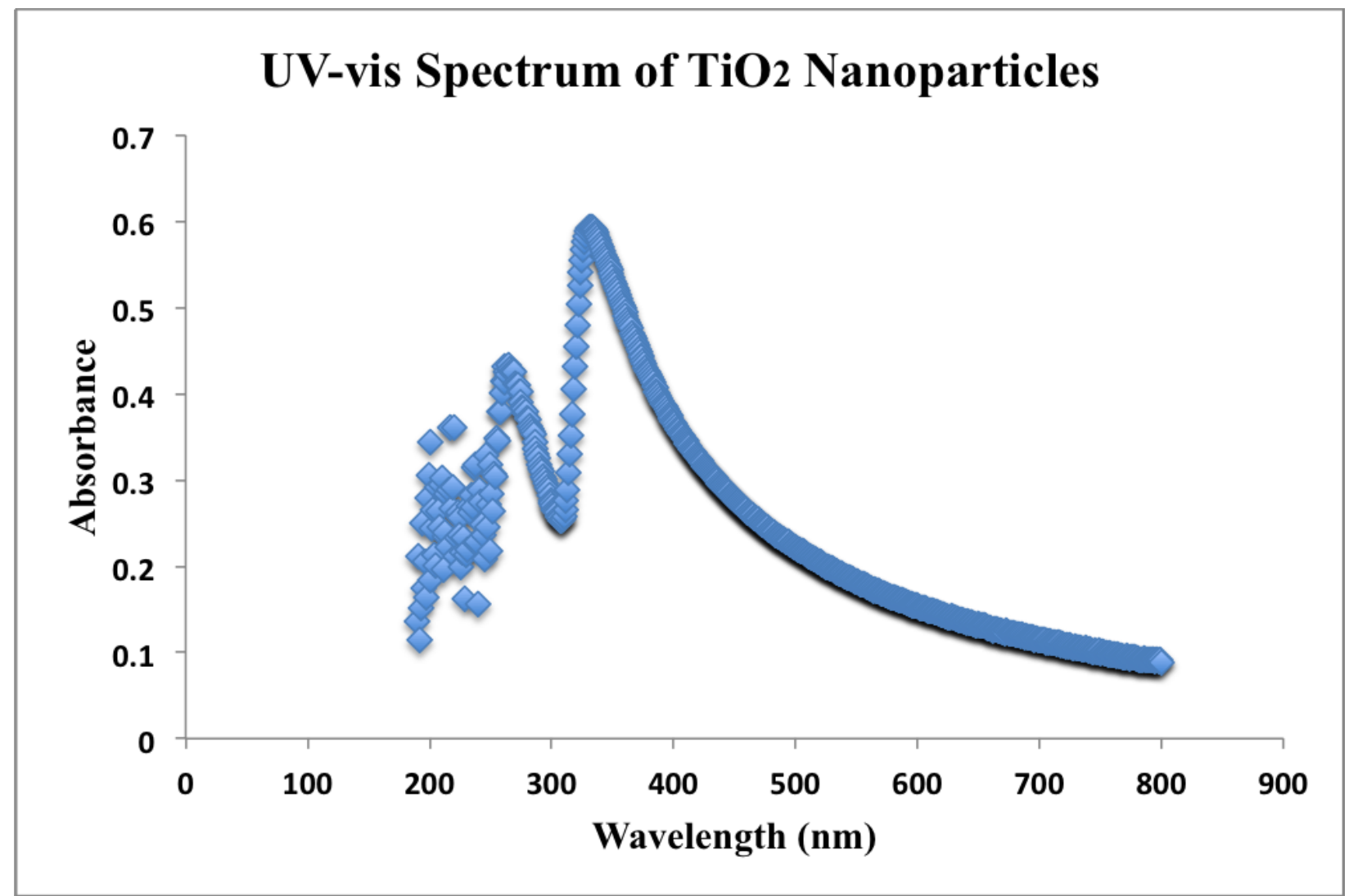

Figure A2: UV-vis spectrum of $\mathrm{TiO}_{2}$. 


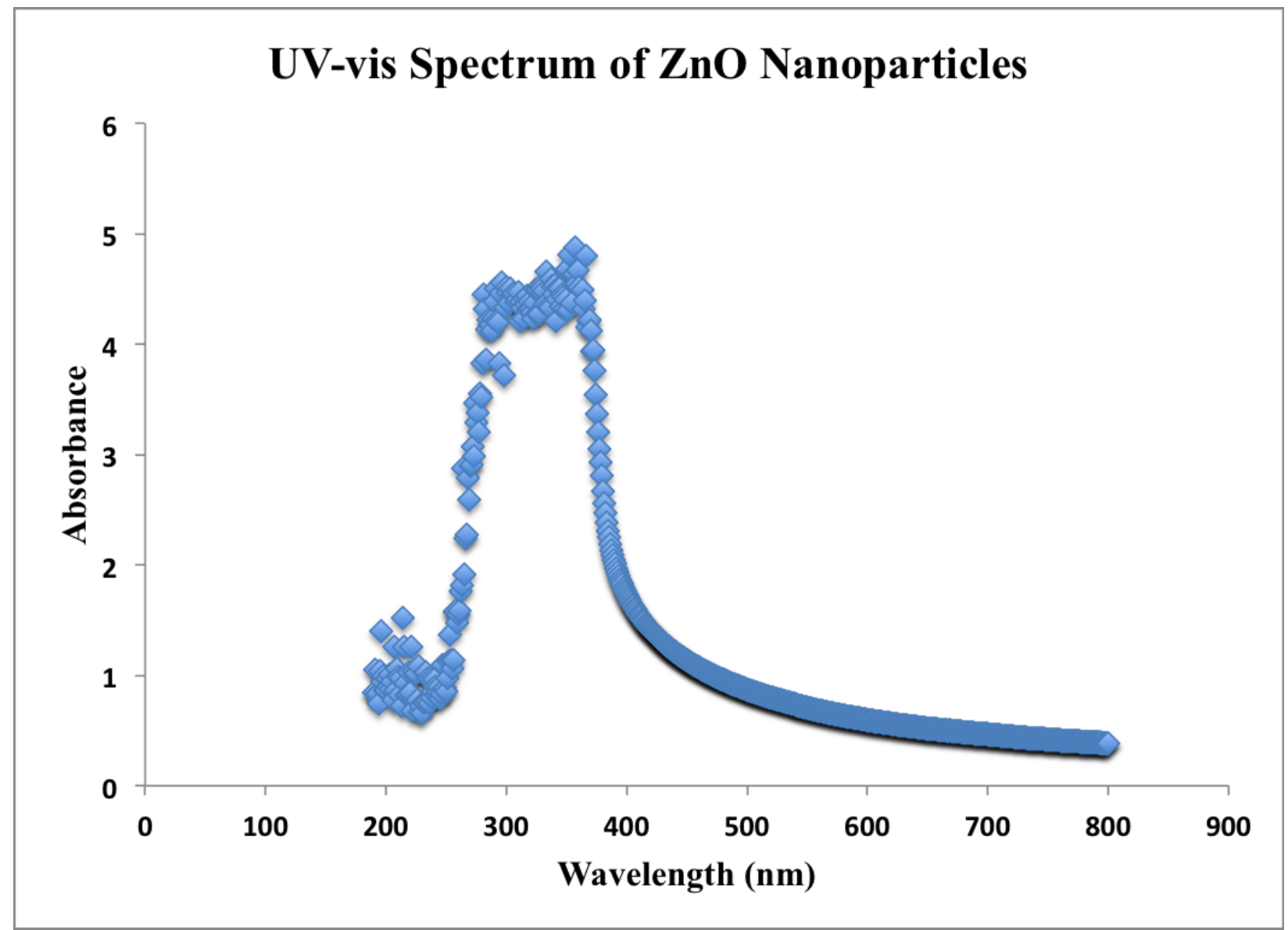

Figure A3: UV-vis spectrum of $\mathrm{ZnO}$. 